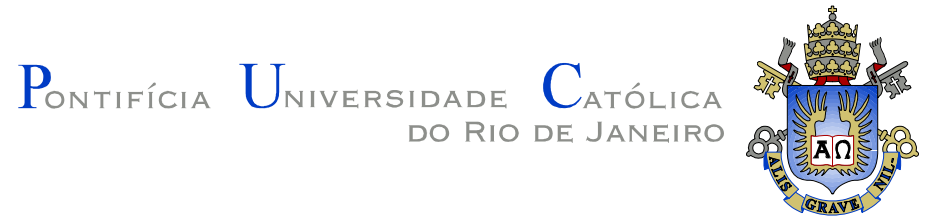

Marcio Alves Amaral Baptista

\title{
Conselhos de Administração e Monitoração da Implementação Estratégica: Um Modelo de Eficácia
}

Tese de Doutorado

Tese apresentada como requisito parcial para obtenção do título de Doutor pelo Programa de PósGraduação em Administração de Empresas da PUCRio.

Orientadora: Prof. Maria Angela Campelo de Melo Co-orientadora: Prof. Teresia Diana Lewe Van Aduard de Macedo-Soares

Rio de Janeiro

Março de 2013 


\section{Marcio Alves Amaral Baptista}

\section{Conselhos de Administração e Monitoração da Implementação Estratégica: Um Modelo de Eficácia}

Tese apresentada como requisito parcial para obtenção do título de Doutor pelo Programa de Pós-Graduação em Administração de Empresas da PUC-Rio. Aprovada pela Comissão Examinadora abaixo assinada.

Prof ${ }^{a}$. Maria Angela Campelo de Melo Orientadora Departamento de Administração - PUC-Rio

Prof ${ }^{\mathrm{a}}$. Teresia Diana Lewe van Aduard de Macedo-Soares Co-orientadora Departamento de Administração - PUC-Rio

Prof. Jorge Ferreira da Silva Departamento de Administração - PUC-Rio

Prof. Paulo Cesar de Mendonca Motta Departamento de Administração - PUC-Rio

Prof. Sérgio Giovanetti Lazzarini Insper Instituto de Ensino e Pesquisa

Prof. José Paulo Afonso Esperança ISCTE

Prof. Walter Fernando Araújo de Moraes UFPE

Prof. Mônica Herz Vice-Decana de Pós-Graduação do CCS - PUC-Rio 
Todos os direitos reservados. É proibida a reprodução total ou parcial do trabalho sem autorização da universidade, do autor e do orientador.

\section{Marcio Alves Amaral Baptista}

Bacharel em Ciências Econômicas pela Universidade do Estado do Rio de Janeiro e Mestre em Administração pelo Instituto Coppead de Administração. Professor, pesquisador e consultor em Estratégia, Governança Corporativa e Internacionalização. Possui experiência profissional nas áreas de Estratégia, Governança Corporativa, Finanças Corporativas, Auditoria, Marketing e Negócios Internacionais. Atuou por 20 anos em cargos de direção geral e gerência na Xerox do Brasil, Xerox/MHW, Booz Allen Hamilton Consultores e Go To Market Consultoria.

Ficha Catalográfica

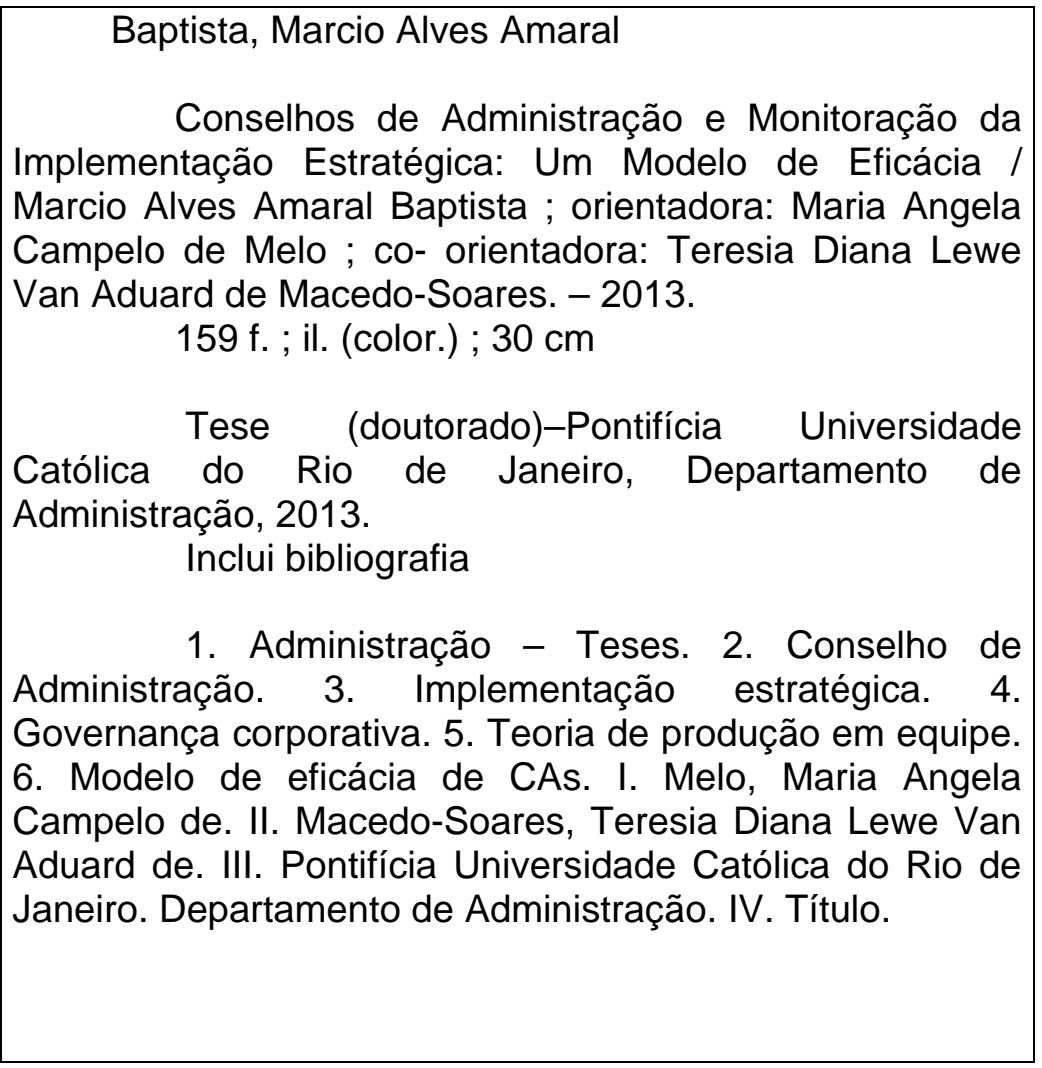


A Mônica, Gabriel e Mariana, minha querida família. 


\section{Agradecimentos}

Não é possível agradecer neste espaço a todos os que, direta ou indiretamente, contribuíram para a realização deste trabalho.

Inicio por agradecer à Prof. Maria Angela Campelo de Melo, minha orientadora, pelo seu exemplo profissional e por sempre me desafiar a ir além.

À Prof. Diana Macedo-Soares, minha co-orientadora, obrigado por me incentivar a ingressar na carreira acadêmica e por sua confiança na minha capacidade de pesquisa.

Aos professores do IAG, muito obrigado pelos seus ensinamentos e dedicação, e por me tornarem um pesquisador em Administração.

Agradeço aos funcionários do IAG, e especialmente à Teresa Campos, por todo o suporte material e pessoal que recebi desde o início do doutorado.

Ao ISCTE - Instituto Universitário de Lisboa, agradeço pelo suporte para o desenvolvimento das etapas finais da tese.

À CAPES, à FAPERJ e à PUC-Rio, agradeço pelos auxílios concedidos, sem os quais este trabalho não poderia ter sido realizado.

Agradeço ao Instituto Brasileiro de Governança Corporativa - IBGC e à Booz \& Company pelo apoio institucional e operacional para a realização da survey com conselheiros de administração.

Aos meus pais, Edmundo e Theresinha, obrigado por terem acreditado em mim e por sempre terem me incentivado a estudar.

Dedico um agradecimento especial à minha esposa Mônica e meus filhos Gabriel e Mariana. O doutorado foi um projeto que, de várias formas, exigiu mais de vocês do que de mim. Muito obrigado por me apoiarem incondicionalmente e pelo seu amor. Espero poder retribuir ao longo da vida.

Acima de tudo, agradeço a Deus por fazer de mim o que sou e serei. 


\section{Resumo}

Baptista, Marcio Alves Amaral; Melo, Maria Angela Campelo de (orientadora); Macedo-Soares, Teresia Diana Lewe Van Aduard de (coorientadora). Conselhos de Administração e Monitoração da Implementação Estratégica: Um Modelo de Eficácia. Rio de Janeiro, 2013. 159p. Tese de Doutorado - Departamento de Administração, Pontifícia Universidade Católica do Rio de Janeiro.

Desenvolveu-se neste estudo um modelo para analisar a eficácia de um Conselho de Administração - CA na monitoração da implementação estratégica IE com base em fatores não estruturais antecedentes. Não obstante o intenso debate em curso sobre como a governança corporativa - GC e os CAs devem assegurar o atingimento dos objetivos estratégicos das empresas, não foram identificados estudos que analisem sistematicamente a tarefa de monitoração da IE nos CAs, propondo modelos de eficácia. Endereçando essa lacuna, partiu-se de modelos gerais de desempenho de CAs para, com base na Teoria de Produção em Equipe (Blair \& Stout, 1999), identificar fatores específicos que podem afetar o desempenho dos conselhos no asseguramento da implementação estratégica. Empregou-se um método de pesquisa integrativo, em duas etapas. A primeira, qualitativa, consistiu de entrevistas com conselheiros de administração experientes, visando obter subsídios para delimitar um modelo conceitual preliminar desenvolvido a partir do referencial teórico. Esse modelo preliminar é, em si mesmo, um produto de pesquisa que poderá embasar estudos futuros. A segunda etapa consistiu de uma survey com 217 conselheiros de administração de empresas brasileiras, com o objetivo de coletar dados sobre a intensidade das relações entre as variáveis selecionadas, confirmando sua validade. Em virtude da existência de relações simultâneas entre os construtos da pesquisa e de erros de mensuração, empregou-se a modelagem de equações estruturais para analisar o desempenho de quatro modelos concorrentes embasados na teoria. O modelo final incluiu cinco construtos explicativos da Eficácia na Monitoração da IE: a Liderança do Presidente do CA, o Acesso a Informações, o Conhecimento do Negócio, a Dinâmica de Trabalho do CA e a Atenção à Monitoração da IE. Esse modelo confirmou todas as hipóteses formuladas sobre relações entre esses construtos e explicou 54\% da variância observada na Eficácia na Monitoração da 
IE. Os resultados indicaram a existência de mediações múltiplas entre os construtos. A Liderança do Presidente do CA mostrou-se positivamente associada ao Acesso a Informações, à Dinâmica de Trabalho do CA e à Atenção à Monitoração da IE. Isso sugere que um presidente do CA com melhores atributos de liderança poderá influenciar simultaneamente diversos fatores que impactam o desempenho do CA na monitoração estratégica. Verificou-se, também, que CAs com melhor acesso às informações e mais conhecimentos específicos do negócio poderão apresentar uma dinâmica de trabalho que favorecerá a monitoração da IE. Também em linha com o esperado, observou-se que o desempenho do CA na monitoração estratégica depende diretamente do grau de atenção dedicado à tarefa. Esse resultado sugere que a adoção tanto de políticas internas como de normas que incluam a monitoração da implementação estratégica na pauta do CA afetará o desempenho do Conselho nessa tarefa. O real funcionamento dos CAs é um tema pouco pesquisado, devido a reconhecidas dificuldades empíricas. Ao identificar a natureza das relações entre os antecedentes de eficácia de CAs na monitoração estratégica em um contexto não anglo-americano, este estudo pretende fazer uma contribuição inovadora para a expansão do conhecimento e para a melhoria das práticas de GC e de gestão estratégica.

\section{Palavras-chave}

Conselho de administração; Implementação estratégica; Governança corporativa; Teoria de produção em equipe; Modelo de eficácia de CAs 


\section{Abstract}

Baptista, Marcio Alves Amaral; Melo, Maria Angela Campelo de (advisor); Macedo-Soares, Teresia Diana Lewe Van Aduard de (co-advisor). Boards of Directors and Monitoring of Strategy Implementation: An Effectiveness Model. Rio de Janeiro, 2013. 159p. Doctoral Dissertation Departamento de Administração, Pontifícia Universidade Católica do Rio de Janeiro.

This study presents a model of non-structural factors that affect the effectiveness of boards of directors in monitoring strategy implementation - SI. Despite the intense debate on the contribution of corporate governance to the strategic success of firms, no studies have analyzed systematically the antecedents of the SI monitoring task that boards are expected to perform. Building on general board performance models, this study used a Team Production Theory perspective (Blair \& Stout, 1999) to identify the factors that may influence a board's performance in ensuring SI. A two-step research method was used. The first step consisted of in-depth interviews with a panel of experienced board directors. The interviews generated insight to delimitate a preliminary analytical framework that was built from literature. This framework is, in itself, a research product that may be used to ground future studies. The second step was a survey with 217 board directors of Brazilian companies. The collected data were analyzed by the method of structural equations - SEM, in order to cope with simultaneous relationships among constructs and measurement errors. Four competing and theoreticallygrounded structural models were analyzed for fit and explanatory power. The final model included five explanatory constructs of Board Effectiveness in SI Monitoring: Board Chairperson Leadership, Access to Information, Business Knowledge, Board Work Dynamics and Attention to SI Monitoring. The model confirmed all the hypothesized relationships among the constructs and explained $54 \%$ of the variance observed in Board Effectiveness in SI Monitoring. The results revealed multiple mediations among the constructs. Board Chairperson Leadership was positively associated with Access to Information, Board Work Dynamics and Attention to SI Monitoring. This suggests that a board chairperson with superior leadership attributes may simultaneously influence several factors that impact the board's strategic monitoring performance. In addition, the results 
showed that boards that have more access to information may display a work dynamics that is conducive to performance in monitoring SI. As expected, a board's effectiveness in the SI monitoring task was found to depend directly on the level of attention devoted to it. This suggests that the adoption of internal policies and norms that include the SI monitoring task in the board's agenda will improve its performance in the task. The actual functioning of boards is a hitherto under-researched phenomenon due to widely acknowledged empirical difficulties. By investigating the nature of the relationships among the antecedents that affect the quality of a board's intervention into the SI process, and by analyzing them in a non anglo-american empirical setting, this study aims to make an innovative contribution to the knowledge and management practices in the fields of corporate governance and strategic management.

\section{Keywords}

Board of directors; Strategy implementation; Corporate governance; Team production theory; Board effectiveness model 


\section{Sumário}

1 Introdução 17

1.1. Objetivos da pesquisa 19

1.2. Delimitações do estudo 20

1.3. Relevância do estudo 20

1.4. Descrição geral do método de pesquisa 21

1.5. Organização da tese $\quad 23$

2 Referencial teórico $\quad 25$

2.1. Revisão da literatura $\quad 25$

2.1.1. Governança corporativa 26

2.1.2. Implementação estratégica 28

2.1.3. Eficácia dos conselhos de administração 30

2.1.3.1. Fatores estruturais de eficácia 31

2.1.3.2. Tarefas do CA 32

2.1.3.3. Fatores não estruturais de eficácia 33

2.1.3.4. Modelos gerais de eficácia de CAs 36

2.1.4. Envolvimento dos CAs na gestão estratégica 40

2.1.5. Envolvimento dos CAs na monitoração da IE 42

2.2. Lacunas constatadas na literatura revista 47

2.3. Modelo conceitual preliminar 48

2.3.1. Eficácia na Monitoração da IE 50

2.3.2. Acesso a informações $\quad 51$

2.3.3. Conhecimento do negócio 53

2.3.4. Dinâmica de trabalho do CA 54

2.3.5. Liderança do PCA 55

2.3.6. Atenção à monitoração da IE 56

2.3.7. Desempenho empresarial passado $\quad 57$

2.3.8. Confiança no CEO 58

2.3.9. Textura causal do ambiente 58

$\begin{array}{ll}\text { 2.3.10. Normas de esforço } & 59\end{array}$ 
3 Pesquisa de campo com conselheiros de administração 61

3.1. Unidade de análise e sujeitos da pesquisa 61

3.2. Procedimentos de coleta de dados 62

3.3. Limitações do método 62

3.4. Análise de resultados 63

3.4.1. Acesso a informações 63

3.4.2. Conhecimento do negócio 65

3.4.3. Dinâmica de trabalho do CA 66

3.4.4. Liderança do presidente do CA 67

3.4.5. Atenção à monitoração da IE 68

4 Modelo conceitual 69

4.1. Construtos 69

4.2. Hipóteses 71

4.2.1. Influência do acesso a informações $\quad 71$

4.2.2. Influência do conhecimento do negócio 72

4.2.3. Influência da dinâmica de trabalho do $C A$

4.2.4. Influência da liderança do presidente do CA 73

4.2.5. Influência da atenção à monitoração da IE

5 Procedimentos metodológicos para teste do modelo conceitual $\quad 77$

5.1. Unidade de análise, população e amostra 77

5.2. Operacionalização das variáveis 78

5.2.1. Definição operacional dos construtos 78

5.2.2. Desenvolvimento de escalas de medição 79

5.2.3. Pré teste das escalas de medição 81

5.3. Coleta de dados 81

5.3.1. Instrumento de coleta de dados 82

5.3.2. Distribuição da pesquisa

5.4. Tratamento de dados $\quad 84$

5.4.1. Substituição de dados faltantes 84

5.4.2. Análise de observações extremas 86

5.4.3. Análise de normalidade multivariada 86 
5.5. Procedimentos de análise de dados

5.6. Limitações do método 89

6 Modelagem estrutural e análise de dados 92

6.1. Contexto da pesquisa 92

6.2. Caracterização da amostra 94

6.3. Análises e resultados 96

6.3.1. Purificação das escalas de medição 96

6.3.2. Desenvolvimento do modelo de medidas teórico 100

6.3.3. Especificação e teste de modelos estruturais concorrentes $\quad 107$

6.3.3.1. Modelo 1

6.3.3.2. Modelo 2

6.3.3.3. Modelo $3 \quad 115$

6.3.3.4. Modelo $4 \quad 121$

6.4. Discussão dos resultados 128

6.4.1. Influência da liderança do presidente do CA 130

6.4.2. Influência do acesso a informações 130

6.4.3. Influência do conhecimento do negócio 131

6.4.4. Influência da dinâmica de trabalho do CA 132

6.4.5. Influência da atenção à monitoração da IE 132

7 Conclusões 134

7.1. Resumo do estudo e resultados 134

7.2. Implicações para a pesquisa acadêmica $\quad 135$

7.2.1. Contribuições teóricas 135

7.2.2. Contribuições metodológicas 136

7.3. Implicações gerenciais $\quad 137$

7.4. Limitações do estudo 140

$\begin{array}{ll}\text { 7.5. Sugestões para estudos futuros } & 141\end{array}$

$\begin{array}{ll}\text { Referências bibliográficas } & 144\end{array}$

$\begin{array}{ll}\text { Apêndice - questionário utilizado na pesquisa } & 156\end{array}$ 


\section{Lista de figuras}

Figura 1 - Modelo geral de eficácia de CAs de Zahra \& Pearce (1989) 37

Figura 2 - Modelo geral de eficácia de CAs de Forbes \& Milliken (1999) 38

Figura 3 - Modelo geral de eficácia de CAs de Huse (2005) 39

Figura 4 - Modelo conceitual preliminar de relações entre fatores

não estruturais de eficácia dos CAs na monitoração da IE

50

Figura 5 - Modelo conceitual simplificado e hipóteses de relações

entre fatores não estruturais de eficácia de CAs na monitoração da IE 70

Figura 6 - Modelo de medidas teórico

101

Figura 7 - Parâmetros estruturais padronizados do Modelo 1

de Eficácia na Monitoração da IE

109

Figura 8 - Parâmetros estruturais padronizados do Modelo 2 de

Eficácia na Monitoração da IE

111

Figura 9 - Parâmetros estruturais padronizados do Modelo 3 de

Eficácia na Monitoração da IE

Figura 10 - Parâmetros estruturais padronizados do Modelo 4 de

Eficácia na Monitoração da IE

122

Figura 11 - Modelo final de relações entre fatores não

estruturais de Eficácia de CAs na Monitoração da IE

129 


\section{Lista de tabelas}

Tabela 1 - Conjuntos alternativos de hipóteses de ligação entre os construtos da pesquisa $\quad 76$

Tabela 2 - Definição operacional dos construtos 79

Tabela 3 - Escalas preliminares de medição dos construtos 80

Tabela 4 - Variáveis demográficas $\quad 81$

Tabela 5 - Incidência de dados faltantes por variável 85

Tabela 6 - Substituição de dados faltantes pelo método hot deck $\quad 86$

Tabela 7 - Características da amostra relativas às empresas $\quad 94$

Tabela 8 - Características da amostra relativas aos CAs 95

Tabela 9 - Medição de Kaiser-Meyer Olkin e teste de esfericidade de Bartlett para correlação entre variáveis 96

Tabela 10 - Medições de adequação de amostragem de Kaiser-Meyer-

Olkin - MSA e correlações parciais entre variáveis

Tabela 11 - Número de fatores a extrair pelo critério de autovalor (eigenvalues) e percentual da variância total explicada pelos fatores 98 Tabela 12 - Matriz de fatores considerando todas as variáveis 99 Tabela 13 - Estrutura reduzida de construtos latentes e variáveis observáveis resultante da análise fatorial exploratória

Tabela 14 - Identificação de parâmetros a serem estimados e graus de liberdade do Modelo de medidas

Tabela 15 - Resultados de qualidade de ajuste do Modelo de medidas 102

Tabela 16 - Cargas fatoriais não-padronizadas e significância do Modelo de medidas

Tabela 17 - Cargas fatoriais padronizadas, variância média extraída e confiabilidade composta dos construtos do Modelo de medidas 104 Tabela 18 - Correlações quadradas entre construtos latentes $\quad 105$ Tabela 19 - Correlações entre construtos do modelo de medidas $\quad 105$ Tabela 20 - Resíduos padronizados do modelo de medidas $\quad 107$ Tabela 21 - Hipóteses do Modelo 1 de Eficácia na Monitoração da IE 108 Tabela 22 - Significância dos parâmetros do Modelo 1 de Eficácia na 
Monitoração da IE

Tabela 23 - Hipóteses do Modelo 2 de Eficácia na Monitoração da IE 111

Tabela 24 - Significância dos parâmetros do Modelo 2 de

Eficácia na Monitoração da IE

112

Tabela 25 - Resultados de qualidade de ajuste dos Modelos 1 e $2 \quad 112$

Tabela 26 - Comparação de cargas fatoriais padronizadas e

confiabilidade composta entre Modelo 2 e Modelo de medidas

Tabela 27 - Comparação de parâmetros padronizados entre

Modelo 2, Modelo 1 e Modelo de medidas

114

Tabela 28 - Hipóteses do Modelo 3 de Eficácia na Monitoração da IE 116

Tabela 29 - Significância dos parâmetros do Modelo 3 de

Eficácia na Monitoração da IE

Tabela 30 - Resultados de qualidade de ajuste dos Modelos 1, 2 e $3 \quad 117$

Tabela 31 - Comparação de cargas fatoriais padronizadas e

confiabilidade composta entre o Modelo 3 e outros modelos

118

Tabela 32 - Comparação de parâmetros padronizados entre o

Modelo 3 e outros modelos

Tabela 33 - Resíduos padronizados do Modelo 3

120

Tabela 34 - Hipóteses do Modelo 4 de Eficácia na Monitoração da IE 122

Tabela 35 - Significância dos parâmetros do Modelo 4 de Eficácia

na Monitoração da IE

Tabela 36 - Resultados de qualidade de ajuste dos Modelos

estruturais 1, 2, 3 e 4

123

Tabela 37 - Comparação de cargas fatoriais padronizadas e confiabilidade composta entre o Modelo 4 e outros modelos

Tabela 38 - Comparação de parâmetros padronizados entre 0

Modelo 4 e outros modelos

125

Tabela 39 - Resíduos padronizados do Modelo 4

Tabela 40 - Resumo dos parâmetros não-padronizados dos

modelos estruturais e significância dos testes de hipóteses

Tabela 41 - Resumo dos resultados dos testes de hipóteses 


\section{Lista de siglas e abreviaturas}

Al - Acesso a Informações

AIC - Critério de Informação de Akaike

AT - Atenção à Monitoração da Implementação Estratégica

AVE - Variância Média Extraída

CA - Conselho de Administração

CEO - Presidente Executivo

CFA - Análise Fatorial Confirmatória

CFI - Índice de Ajuste Comparativo

$\mathrm{CN}$ - Conhecimento do Negócio

DI - Dinâmica de Trabalho do Conselho de Administração

EFA - Análise Fatorial Exploratória

GC - Governança Corporativa

IE - Implementação Estratégica

MO - Eficácia na Monitoração da Implementação Estratégica

MSA - Medição de Adequação de Amostragem de Kaiser-Meyer-Olkin

PC - Liderança do Presidente do Conselho de Administração

PCA - Presidente do Conselho de Administração

RMSEA - Raiz do Erro Quadrático Médio de Aproximação

SEM - Modelagem de Equações Estruturais

TPE - Teoria de Produção em Equipe 


\section{Introdução}

Os principais códigos de governança corporativa - GC do mundo atribuem aos Conselhos de Administração - CAs a responsabilidade pelo sucesso estratégico das empresas. A visão de que os CAs desempenham um papel central no capitalismo moderno é compartilhada por governos, acionistas, reguladores e acadêmicos. No entanto, após a crise sistêmica de 2008, os CAs estão sob pressão e escrutínio severos.

Diversos episódios de má governança têm exemplificado o distanciamento dos CAs em relação ao que acontece de fato na execução das estratégias empresariais. Conforme recentemente demonstrado por empresas internacionais como Lehman Brothers, Citigroup, Sadia e Aracruz Celulose, as práticas de trabalho dos CAs podem não ter sido eficazes em antecipar, avaliar e contornar riscos de execução estratégica. Em um debate sobre as causas da crise de 2008, organizado pelo periódico Financial Times, Larry Fink, CEO da gestora de investimentos Blackrock, declarou: “I actually don't think risk management failed. (...) I think corporate governance failed, because (...) the boards didn't ask the right questions." (Freeland, 2009)

$\mathrm{O}$ caso do HIH Insurance Group, reportado como o maior episódio de falência empresarial da Austrália, é ilustrativo. A exemplo de várias grandes empresas cujo sistema de GC falhou nos últimos anos, o CA do HIH Insurance Group cumpria com as principais recomendações de estrutura. Ainda assim, diversos erros de monitoração estratégica ocorreram. Dentre outros, várias aquisições mal-sucedidas foram realizadas sem que o CA avaliasse os resultados de diligências anteriores ou questionasse as premissas da equipe executiva (Owen, 2003). O colapso da empresa, em 2001, é atribuído à inação do CA perante falhas de IE e decisões estratégicas mal executadas. Conforme relatado por Owen (2003) no relatório da comissão que analisou a falência da empresa, fatores não estruturais, de natureza comportamental e de processos de trabalho, impediram que o CA atuasse eficazmente: 
Generally speaking, it is for management, rather than the board, to propose strategy. (...) Nevertheless, it is the board's responsibility to understand, test and endorse the company's strategy. In monitoring performance, the board needs to measure management proposals by reference to the endorsed strategy, with any deviation in practice being challenged and explained. This is what the HIH board failed to do. (p. xx)

There was blind faith in a leadership that was ill-equipped for the task. There was insufficient ability and independence of mind in and associated with the organisation to see what had to be done and what had to be stopped or avoided. Risks were not properly identified and managed. Unpleasant information was hidden, filtered or sanitised. And there was a lack of sceptical questioning and analysis when and where it mattered. (p. xvii)

Assegurar o sucesso da implementação estratégica - IE é uma questão crucial para as empresas porque, conforme Barney, Wright e Ketchen Jr. (2001) ressaltaram, “(...) the implementation of a strategy to achieve a sustained competitive advantage is unlikely to follow automatically.” (p. 632) Os CAs, porém, encontram-se naturalmente distantes do campo de jogo da IE. Muitas decisões de IE são tomadas a vários níveis organizacionais de distância dos CA, em diferentes subsidiárias e países. Isso é especialmente relevante no contexto de empresas globais, uma vez que os atores envolvidos em decisões de IE são substancialmente influenciados por diferentes fatores cognitivos, comportamentais, políticos, ambientais e sociais. Decisões inconsistentes com a formulação estratégica não necessariamente resultam de má governança, porém há um crescente consenso de que os CAs devem monitorar eficazmente o rumo da IE (Schmidt \& Brauer, 2006). Logo, é importante compreender como os CAs podem trabalhar para que as decisões-chave de IE sejam consistentes com as estratégias planejadas e agreguem valor.

No entanto, a pesquisa acadêmica não tem dedicado atenção suficiente aos modos de operação dos CAs. Na literatura em GC, a maioria dos estudos tem se concentrado em analisar as relações entre as características estruturais de CAs e o desempenho das empresas, em detrimento de fatores comportamentais, sociais e de processos de trabalho (Huse, 2005; Huse, Minichilli \& Schøning, 2005; Macedo-Soares \& Schubsky, 2010). Esses fatores não estruturais são relevantes porque as práticas usualmente aceitas de funcionamento dos CAs têm se mostrado insuficientes para mitigar os riscos de má governança (Judge \& Zeithaml, 1992). 
No caso particular da monitoração da IE pelos CAs, a atenção dos pesquisadores tem sido surpreendentemente esparsa (Schmidt \& Brauer, 2006; Li, Guohui \& Eppler, 2008). Apesar da importância do papel dos CAs, pouco se conhece sobre os fatores que afetam a sua eficácia no asseguramento da IE. Observa-se também que a IE e a GC têm sido examinados de forma predominantemente independente pela pesquisa acadêmica. Apesar de alguns estudos recentes terem fornecido indicações de como os CAs podem trabalhar para o êxito da IE (Drew \& Kaye, 2007; Brauer \& Schmidt, 2008), poucos autores analisaram sistematicamente essas indicações com o objetivo de identificar fatores de influência. Existem poucos modelos integrativos que permitam desenvolver proposições e embasar estudos empíricos sobre o tema. Apesar da ênfase na importância da GC para assegurar o atingimento de objetivos estratégicos, a proposição de ferramentas analíticas que ajudem a compreender como os CAs podem desempenhar essa tarefa não tem sido enfatizada.

Considera-se aqui que essa lacuna na literatura em GC e em estratégia é crítica. Para endereçá-la, levanta-se uma questão central, que se traduz no problema desta pesquisa: De que forma fatores não estruturais antecedentes podem influenciar a eficácia dos Conselhos de Administração na monitoração da Implementação Estratégica?

\section{1.}

\section{Objetivos da pesquisa}

O objetivo final deste estudo é analisar de que forma fatores não estruturais antecedentes podem influenciar a eficácia dos CAs na monitoração da IE. Para tal, buscou-se desenvolver e testar um modelo de relações entre fatores não estruturais de eficácia dos CA na tarefa de monitoração da IE.

Como caminho para atingir o objetivo principal, alguns objetivos intermediários deverão ser alcançados:

- Analisar a contribuição e as limitações dos modelos gerais de eficácia de CAs existentes na literatura;

- Conceituar o papel que os CAs devem desempenhar na monitoração da IE, tomando como base perspectivas teóricas complementares; 
- Com base nesse papel, definir operacionalmente o construto Eficácia na Monitoração da IE;

- Selecionar e operacionalizar os principais fatores não estruturais antecedentes da Eficácia na Monitoração da IE;

- Identificar e modelar os tipos de relações esperadas entre esses fatores e a Eficácia na Monitoração da IE; e

- Testar a validade empírica do modelo conceitual de relações entre esses fatores e a Eficácia na Monitoração da IE.

\section{2. \\ Delimitações do estudo}

Seguindo-se uma linha que difere da pesquisa tradicional em GC (Johnson, Daily \& Ellstrand, 1996), serão estudadas variáveis não estruturais de eficácia de CAs na monitoração da IE. Tais variáveis refletem dimensões comportamentais, contextuais e normativas e podem ampliar o poder explicativo de características estruturais dos CA (tais como o tamanho do CA e outras características demográficas) em relação à sua eficácia.

O nível de análise do estudo é o CA, compreendido como estrutura organizacional semi-autônoma com metas específicas, compartilhadas entre seus membros e alinhadas com os objetivos empresariais.

Quanto à delimitação geográfica do estudo, serão investigadas empresas sob GC, listadas e não listadas em bolsas de valores, que estejam sediadas no Brasil.

\section{3.}

\section{Relevância do estudo}

Considera-se que este estudo é relevante para diversas audiências interessadas na melhoria das práticas de governança estratégica nas empresas. Para os administradores e conselheiros de administração, pretende-se contribuir por meio de um levantamento estruturado dos padrões das práticas de monitoração da IE no âmbito dos CA. Pretende-se propor ferramentas gerencialmente úteis para a análise e melhoria da eficácia dos CAs na monitoração da IE. Essas ferramentas poderão auxiliar nos processos de auto-avaliação de CAs, revelando comportamentos e práticas que requerem maior atenção para melhoria da 
qualidade da sua intervenção na IE. Finalmente, espera-se gerar subsídios para a melhoria dos processos de recrutamento e avaliação de desempenho de conselheiros.

Para a pesquisa acadêmica em GC e estratégia, espera-se que o estudo contribua uma melhor compreensão do fenômeno da eficácia dos CAs e para a expansão do conhecimento no campo da gestão da IE. Pretende-se oferecer um modelo para análise da eficácia de CA na monitoração da IE, o qual até a presente data é inédito. Pretende-se também oferecer um conjunto de construtos que poderão ser inseridos em modelos de gestão estratégica no âmbito dos CAs e testados em pesquisas futuras.

No que tange à relevância deste estudo para acionistas, investidores institucionais, agentes de mercado, reguladores e outros grupos de interesse, espera-se propor recomendações concretas para a melhoria das capacitações de monitoração estratégica dos CAs. Pretende-se gerar novos indicadores de eficácia de CAs que poderão ser empregados em avaliações externas da qualidade das práticas de GC de empresas. Espera-se também fornecer subsídios para o aprimoramento dos códigos de melhores práticas de GC, aproximando-os das dimensões de dinâmica de atuação e de processos de trabalho dos CAs que podem elevar sua eficácia.

Em suma, o problema pesquisado é relevante por: (i) auxiliar na compreensão da IE; (ii) enfocar fatores de eficácia dos CA na monitoração da IE; fenômeno que, até onde se sabe aqui, ainda não foi estudado em pesquisas anteriores; (iii) oferecer um modelo explicativo de monitoração da IE que poderá ser incorporado a outros modelos de gestão no âmbito dos CAs; e (iii) contribuir para a melhoria das práticas de governança eficaz de modo geral e, em particular, em empresas sediadas no Brasil.

\section{4.}

\section{Descrição geral do método de pesquisa}

A questão de interesse do estudo é: de que forma fatores não estruturais antecedentes podem influenciar a eficácia dos CAs na monitoração da IE? Conforme ressaltado por alguns pesquisadores em eficácia de CAs (Huse, 2007; Brauer \& Schmidt, 2008), o método mais apropriado para responder esse tipo de 
pergunta de pesquisa seria a pesquisa ação (Melo, 1985). No entanto, há grande dificuldade prática para o emprego de métodos de coleta de dados baseados em observação participante (ou mesmo não-participante) no contexto dos CAs devido a questões de confidencialidade (Leblanc \& Schwartz, 2007).

Em função dessas restrições, e representando outro extremo, um volume significativo de pesquisas em GC tem sido realizado a uma grande distância dos CAs e dos conselheiros, enfatizando a coleta de dados secundários para mensurar correlações entre variáveis de validade questionável (Stiles, 2001; Dalton \& Dalton, 2010). Em linha com os argumentos de Stiles (2001), considera-se aqui que para compreender a real natureza da operação dos CAs é fundamental capturar as percepções dos próprios conselheiros no fenômeno a ser pesquisado.

Considera-se também, em linha com Jick (1979), que o emprego de métodos isolados não produzirá elementos suficientes para responder às questões da pesquisa. Isto deve-se a que as relações de eficácia dos CAs se caracterizam por uma causalidade complexa, propensa a diversos fatores potencialmente intervenientes e sujeitos a uma avaliação de natureza multidisciplinar. Adicionalmente, o caráter recente das questões da pesquisa requer um método científico que seja capaz de capturar diferentes visões e contemplar vários aspectos de análise e de implicações. Deseja-se um aprofundamento além da superfície (Remenyi, Williams, Money \& Swartz, 1998) nas diversas questões que podem influenciar as práticas dos CAs, buscando compreender sua essência. Isso implica o emprego de uma perspectiva integrativa no estudo das questões da pesquisa.

Dadas essas considerações, decidiu-se aplicar um método de pesquisa em duas etapas, fundamentado na coleta de dados qualitativos e quantitativos. Desejase, assim, aumentar a validade do método de pesquisa por meio de triangulação de fontes de dados (Jick, 1979; Snow \& Hambrick, 1980). Essa abordagem é consistente com a adotada por Judge \& Zeithaml (1992) no estudo do envolvimento de CAs na gestão estratégica.

A primeira etapa do método de pesquisa, qualitativa, compreendeu uma pesquisa de campo que consistiu de entrevistas semi-estruturadas com indivíduos de comprovada experiência nos campos de GC, eficácia de CA e gestão da IE. Seu objetivo foi coletar subsídios para aperfeiçoar e delimitar o modelo conceitual preliminar desenvolvido na seção anterior e, em complemento à revisão da 
literatura, formular as hipóteses do estudo. O capítulo 3 inclui uma descrição detalhada dos procedimentos metodológicos empregados nessa etapa e apresenta os resultados das entrevistas.

A segunda etapa do método de pesquisa, quantitativa, consistiu de uma survey com conselheiros de administração de empresas brasileiras para coletar dados perceptuais em relação aos CAs em que atuam. Seu objetivo foi testar a validade do modelo conceitual final e as hipóteses de pesquisa, desenvolvidos com base no referencial teórico e nos resultados da etapa qualitativa. Os procedimentos metodológicos empregados nessa etapa são descritos em detalhe no capítulo 5. A análise dos resultados, por sua vez, é apresentada no capítulo 6.

\section{5 .}

\section{Organização da tese}

Esta tese está organizada em sete capítulos. Esta introdução é o capítulo 1. No capítulo 2, é desenvolvido o referencial teórico da pesquisa. Nele, analisam-se as contribuições e limitações do estado da arte da literatura sobre a eficácia dos CAs no processo de monitoração da IE. Desenvolve-se também a fundamentação conceitual do estudo, com base na Teoria de Produção em Equipe (Blair \& Stout, 1999). Posteriormente, apresenta-se um modelo conceitual preliminar desenvolvido a partir dos resultados da revisão de literatura. Esse modelo sugere que o desempenho de um CA na monitoração estratégica pode ser influenciado por um conjunto de construtos comportamentais, contextuais e normativos.

O capítulo 3 apresenta os resultados da etapa qualitativa da pesquisa, bem como os procedimentos metodológicos empregados. Trata-se das entrevistas de profundidade com conselheiros de administração experientes, realizadas para refinar o modelo conceitual preliminar.

No capítulo 4, apresenta-se o modelo conceitual final, que incluiu os construtos de maior relevância identificados na etapa qualitativa da pesquisa. São também desenvolvidas as hipóteses da pesquisa.

Os procedimentos adotados para a etapa quantitativa da pesquisa, destinada a testar a validade do modelo conceitual, são descritos no capítulo 5. Nele, são apresentados os passos seguidos para coleta, tratamento e análise de dados. São 
também discutidas as limitações do método de pesquisa e os procedimentos adotados para mitigá-las.

No capítulo 6, são apresentados os resultados da survey com conselheiros de administração de empresas brasileiras. Por meio da modelagem de equações estruturais - SEM, analisam-se nesse capítulo a validade e o desempenho explicativo de quatro modelos estruturais concorrentes. Em seguida, os resultados empíricos são discutidos e interpretados.

Finalmente, no capítulo 7, que conclui o estudo, apresenta-se um resumo dos principais resultados, discutem-se as implicações acadêmicas e gerenciais e sugerem-se linhas de pesquisa futura. 


\section{2 \\ Referencial teórico}

Neste capítulo, é desenvolvido o referencial teórico da pesquisa. Nele, avalia-se criticamente o estado da arte da literatura sobre a eficácia dos CAs no processo de monitoração da IE e apresenta-se um modelo conceitual preliminar, que busca identificar as principais variáveis que podem afetar a eficácia desses conselhos nesse processo.

Inicialmente, na revisão da literatura (seção 2.1), são apresentadas as definições de GC e IE consideradas relevantes para o desenvolvimento teórico do estudo. Em seguida, analisa-se o conceito de eficácia de um CA e os principais modelos explicativos já desenvolvidos. A seguir, analisa-se o envolvimento dos CAs na gestão estratégica e, no caso específico da monitoração da IE, propõe-se uma conceituação do envolvimento dos CAs na tarefa.

Em uma etapa seguinte (seção 2.2), são identificadas as principais lacunas na literatura pesquisada.

O capítulo termina, na seção 2.3, com o desenvolvimento de um modelo conceitual preliminar de Eficácia de CAs na Monitoração da IE. São definidos e caracterizados os construtos comportamentais, contextuais e normativos empregados. O modelo preliminar será delimitado em uma etapa subseqüente do estudo (capítulo 4) para viabilizar a realização de testes por métodos multivariados. No entanto, ele apresenta um quadro explicativo geral para o desempenho de um CA na monitoração estratégica que, por si só, poderá ser útil para os pesquisadores interessados em desenvolver novos estudos sobre o tema.

\section{1.}

\section{Revisão da literatura}

Nesta seção, analisa-se a literatura pertinente ao tema da Eficácia de um CA na Monitoração da IE. 


\subsection{1. \\ Governança corporativa}

A GC tem se convertido em tema de crescente interesse global devido a eventos tais como aumento de privatizações, fusões e aquisições, alianças estratégicas, crescimento dos fundos de pensão, desregulamentação dos mercados de capitais, integração dos fluxos de capital e falências de grandes grupos empresariais decorrentes de escândalos de má governança.

Não existe uma definição consensual para o conceito de GC. A primeira definição formal, formulada por Eells (1960), limitou-se a enfocar aspectos de estrutura e política empresariais. No entanto, a origem das questões relacionadas à GC remonta à formação e ao desenvolvimento da própria organização capitalista moderna. Em função do processo histórico de crescimento e aumento da complexidade das empresas, observou-se no início do século XX a emergência de um padrão de separação entre sua propriedade e controle (Berle \& Means, 1932) de modo a viabilizar o acesso a capital financeiro para investimento e a recursos humanos para gestão. Esse padrão caracterizou-se pela gradativa diluição e despersonalização da propriedade das empresas e pela delegação dos direitos de controle a executivos profissionais.

A formação de estruturas organizacionais nas quais os acionistas (principais) têm pouco controle e os executivos (agentes) têm poucos direitos de propriedade potencializou o problema de conflito de interesses entre esses grupos, assim como os custos de controle decorrentes (Jensen \& Meckling, 1976). Nesse contexto, a GC se desenvolveu como um conjunto de mecanismos destinados a endereçar o problema de agência entre acionistas e executivos.

Os escândalos corporativos ocorridos a partir dos anos 90 suscitaram a proposição de definiç̧ões duras de GC, voltadas para os riscos dos acionistas e a fiscalização dos executivos, como a de Shleifer e Vishny (1997):

Corporate governance deals with the ways in which suppliers of finance to corporations assure themselves of getting a return on their investment. How do the suppliers of finance get managers to return some of the profits to them? How do they make sure that managers do not steal the capital they supply or invest it in bad projects? How do suppliers of finance control managers? (p. 737) 
Ainda que também orientada pela perspectiva de delegação de autoridade e controle do agente pelo principal, Blair (1995) propôs uma definição que considera a influência de aspectos culturais, normativos e contextuais:

I adopt a much broader view of corporate governance, one that refers to the whole set of legal, cultural and institutional arrangements that determine what publicly traded corporations can do, who controls them, how that control is exercised, and how the risks and returns from the activities they undertake are allocated. (p. 3)

Algumas definições mais recentes têm incorporado uma perspectiva de inclusão e alinhamento de outros grupos de interesse (Kakabadse \& Kakabadse, 2001), com base na teoria de stakeholders (Freeman, 1984). Este é o caso da definição oferecida por Adrian Cadbury no prefácio de Claessens (2003):

Corporate Governance is concerned with holding the balance between economic and social goals and between individual and communal goals. The corporate governance framework is there to encourage the efficient use of resources and equally to require accountability for the stewardship of those resources. The aim is to align as nearly as possible the interests of individuals, corporations, and of society. (p. vii)

Observam-se nessas proposições algumas lacunas importantes. Em primeiro lugar, não há uma clara vinculação dos processos de GC ao desempenho empresarial. A definição da Organização para Cooperação e Desenvolvimento Econômico - OECD (Organisation for Economic Cooperation and Development, 2004), amplamente difundida, avançou nesse sentido ao propor que:

Corporate governance involves a set of relationships between a company's management, its board, its shareholders and other stakeholders. Corporate governance also provides the structure through which the objectives of the company are set, and the means of attaining those objectives and monitoring performance are determined. (p. 11)

A segunda lacuna diz respeito à ausência da dimensão estratégica. Entendese aqui que a GC deve assegurar o desempenho estratégico das organizações e a criação de valor a longo prazo. Portanto, como ponto de partida para o posicionamento teórico deste estudo considerou-se a definição de Hitt, Ireland e Hoskisson (2009), assim formulada: 
Corporate Governance is the set of mechanisms used to manage the relationship among stakeholders and to determine and control the strategic direction and performance of organizations. (p. 276)

\subsection{2. \\ Implementação estratégica}

Promover a implementação eficaz das estratégias corporativas é uma questão central para as empresas porque, dentre outras razões, as falhas de IE destroem valor. Um estudo publicado pela consultoria Booz \& Company forneceu evidência nesse sentido, ao mostrar que $60 \%$ do valor destruído nas empresas incluídas na sua amostra resultou de erros estratégicos (Kocourek, Van Lee, Kelly \& Newfrock, 2004).

Isto acontece porque a tarefa de implementar as iniciativas estratégicas é ainda mais complexa que a de formulá-las (Hrebiniak, 2006). Os desvios de gestão estratégica ocorrem mais freqüentemente durante a implementação das estratégias do que em qualquer outra fase (Drew \& Kaye, 2007). A esse respeito, um estudo conduzido pelo periódico The Economist revelou que 57\% das empresas pesquisadas foram mal sucedidas na implementação de iniciativas estratégicas nos três anos anteriores, de acordo com seus executivos de topo (The Economist Intelligence Unit, 2004). Nesse mesmo estudo, as causas de insucesso mencionadas foram a falta de recursos humanos (29\%), de alinhamento e compromisso entre os líderes (22\%), de engajamento dos empregados (18\%), de orçamento $(17 \%)$ e de retorno mensurável sobre o investimento $(8 \%)$, dentre outras $(6 \%)$.

Apesar da importância do processo de IE, pouco se conhece sobre a sua natureza e seus fatores de sucesso ou fracasso (Walker Jr \& Ruekert, 1987). Conforme afirmaram Day e Wensley (1983), uma possível razão para isto é uma visão de parte de alguns pesquisadores que consideram a implementação como uma decorrência estratégica:

Many of the models of strategic management (...) tend to assume too simple a link between the development of strategic direction and its actual implementation via the allocation of resources. In practice, (...) the actual process of resource allocation often incorporates a number of implicit but critical strategic moves. ( $\mathrm{p}$. 86) 
Noble (1999) observa que, em linha com essa visão simplista, as perspectivas de IE mais comumente encontradas na literatura pressupõem tratar-se de uma operacionalização direta de um plano estratégico predefinido. $\mathrm{O}$ autor cita, a título de exemplo, algumas perspectivas de IE como um ato de controle e monitoração:

Implementation is a series of interventions concerning organizational structures, key personnel actions, and control systems designed to control performance with respect to desired ends. (Hrebiniak \& Joyce, 1984) (p. 120)

Implementation is the managerial interventions that align organizational action with strategic intention.(Floyd \& Wooldridge, 1992) (p. 120)

A crítica de Noble (1999), e de vários outros autores, ressalta que essas definições carecem de considerações importantes. A primeira delas refere-se à influência de fatores interpessoais e comportamentais, tais como comportamentos autônomos dos executivos responsáveis pela IE (Guth \& MacMillan, 1986), inércia organizacional (Boeker, 1989), rotinas defensivas (Argyris, 1989) e estilos de liderança (Bourgeois \& Brodwin, 1984).

A segunda carência, relacionada à anterior, advém da premissa simplificadora de que a implementação segue a formulação. Conforme Melo (2002), o planejamento e a execução são tarefas interdependentes, em um processo adaptativo em resposta a contingências ambientais e internas. A autora sugere que a visão atual de planejamento "caracteriza-se por um contínuo monitoramento das ações implementadas e pela permanente avaliação dessas ações, resultando na constante redefinição de objetivos e metas" (p. 11).

A natureza emergente e adaptativa da IE é ilustrada com clareza no clássico estudo de Mintzberg (1978). Segundo Mintzberg, o processo de IE requer uma combinação de perspectivas de controle e de aprendizagem. A estratégia pretendida, produto da formulação estratégica, define o padrão de intenção estratégica da empresa. No entanto, a estratégia realizada, que é o produto da IE, pode diferir da estratégia pretendida como resultado da influência de diversos fatores externos e internos. Tais fatores podem fazer com que (i) alguns elementos da estratégia pretendida não se realizem; e (ii) novas respostas estratégicas emerjam. Em um contexto de implementação, as estratégias emergentes precisam ser avaliadas quanto à sua coerência. Logo, a estratégia realizada resultará do grau 
de disciplina na implementação de planos deliberados e do grau de adaptação desses planos a eventos emergentes que afetam a empresa.

Poucas definições de IE existentes na literatura enfatizam tais perspectivas simultaneamente. Tomando como ponto de partida a definição de Noble (1999), e em linha com os argumentos de Mintzberg (1978), considera-se aqui que a IE é definida como a interpretação, priorização, alinhamento, adaptação e monitoração das estratégias pretendidas e emergentes.

\subsection{3.}

\section{Eficácia dos conselhos de administração}

Há na literatura e na prática gerencial uma crescente percepção de que a melhoria da eficácia dos CA pode criar valor para a empresa (Huse, 2009b). Na qualidade de ativos corporativos importantes (Maassen, 1999), CAs eficazes podem ser um elemento de vantagem competitiva ao influenciar o desempenho organizacional por meio de boa governança (Nicholson \& Kiel, 2004; Charan, 2005). Barton e Wong (2006) sugeriram que a eficácia de um CA pode reduzir o custo de capital das empresas. Uma pesquisa da consultoria McKinsey \& Company, reportada pelos autores, mostrou que investidores institucionais globais estão dispostos a pagar um prêmio de $20 \%$ a $40 \%$ por ações de empresas de mercados emergentes com CAs eficazes.

Pode-se caracterizar a evolução histórica da eficácia dos CA quanto à intensidade e qualidade da sua intervenção na empresa. Os estudos iniciais em GC refletiam uma visão distanciada dos CAs em relação à gestão empresarial. A perspectiva de hegemonia gerencial, subjacente a esses estudos, caracterizava o CA como um órgão cerimonial, dominado pelo CEO, sem capacidade de comunicação com os executivos e sem responsabilidade concreta pela direção e controle das empresas (Mace, 1971; Brown, 1976; Lorsch \& MacIver, 1989). O papel dos CAs cerimoniais se restringia à execução $a d-h o c$ de funções superficiais, mandatórias ou de ratificação dos atos dos executivos. A intervenção dos CAs era, portanto, de baixa intensidade e de baixa qualidade

Os episódios de má governança nos EUA, as demandas por maior ativismo dos acionistas, as reformas institucionais iniciadas nos anos 80 e a precificação da qualidade percebida da GC no preço das ações conduziram os CAs a um segundo 
estágio de eficácia. Esse estágio é caracterizado pela perspectiva ainda dominante na pesquisa em CAs, que é a de supremacia do acionista. A supremacia do acionista sustenta que os CAs têm responsabilidade apenas perante os acionistas e respondem prioritariamente pela maximização do valor econômico das ações (Friedman, 1970). Quanto aos CAs, essa perspectiva é menos pessimista que a de hegemonia gerencial e dá suporte a um papel mais ativo. No entanto, tal papel mais ativo não é necessariamente mais eficaz. Dado que os acionistas passaram a responsabilizar os CAs mais fortemente pelos riscos de observância de controles, observou-se um movimento pendular no sentido de alta intervenção e baixa contribuição dos CA, enfocando tarefas de baixo conteúdo estratégico e pouca agregação de valor (Charan, 2005).

Em um terceiro estágio, a importância do envolvimento estratégico dos CAs tem sido enfatizada, em reconhecimento à necessidade de que os CAs contribuam para a criação de valor e o sucesso a longo prazo das empresas (Andrews, 1981). CAs nesse terceiro estágio de eficácia tendem a operar com mandatos mais abrangentes, orientando-se para tarefas de maior conteúdo estratégico.

\subsubsection{1. \\ Fatores estruturais de eficácia}

A teoria de agência (Jensen \& Meckling, 1976) tem sido a principal fundamentação dos estudos em CAs nas últimas décadas (Daily, Dalton \& Cannella, 2003). O modelo principal-agente pressupõe que os acionistas são os reais proprietários das empresas por serem os únicos clamantes residuais após o cumprimento das obrigações do nexo de contratos com outros agentes e grupos de interesse (Easterbrook \& Fischel, 1991). Nessa visão, o acionista é o único principal e designa o CA como o agente responsável por administrar os ativos empresariais e exercer dever fiduciário no interesse do principal dado que esse carece de conhecimentos, tempo ou pendor para fazê-lo por conta própria.

Os estudos baseados no modelo principal-agente, em sua maioria oriundos da literatura de finanças, buscam estabelecer relações entre características estruturais do CA e o desempenho da empresa. As principais características estruturais estudadas são o tamanho do CA, a ocupação dos cargos de CEO e presidente do CA por pessoas diferentes e a proporção de conselheiros externos. A 
premissa subjacente é de que CAs com tais características estruturais terão mais chance de atuar de forma independente, exercendo uma monitoração mais eficaz sobre os executivos. Nos estudos dessa linha de pesquisa, o desempenho do CA é majoritariamente mensurado pelo próprio desempenho da empresa, na visão de que a função objetiva do CA é maximizar a riqueza dos acionistas (John \& Senbet, 1998).

No entanto, apesar de terem sido extensamente estudadas, as relações entre as características estruturais de um CA e o desempenho empresarial têm se mostrado incertas (Bhagat \& Black, 1999). Daily et al. (2003) demonstraram, em uma meta-análise de pesquisas sobre CAs, que os estudos de relações diretas entre os "suspeitos usuais" e o desempenho da empresa não geraram resultados promissores. A principal razão para os resultados inconclusivos dessa linha de pesquisa é a existência de variáveis intervenientes que podem restringir associações diretas entre estrutura e desempenho empresarial (Finkelstein \& Hambrick, 1996).

Por essa lógica alternativa, existem pelo menos duas dimensões intervenientes que são relevantes para o desenvolvimento deste estudo: (i) a eficácia do CA em si mesma; e (ii) fatores não estruturais antecedentes, relacionados às formas como o $\mathrm{CA}$ desempenha suas tarefas de fato. Para analisálas, é necessário caracterizar as tarefas que o CA deve realizar.

\subsubsection{2.}

\section{Tarefas do CA}

Definir e mensurar a eficácia de um CA não é uma tarefa trivial (Allen, Renner \& English, 2004). Este estudo segue uma linha de pesquisa em GC segundo a qual a eficácia de um CA é definida como o seu desempenho na realização de suas tarefas (Zahra \& Pearce, 1989; Stiles \& Taylor, 1993; Johnson et al., 1996; Forbes \& Milliken, 1999; Kakabadse \& Kakabadse, 2001; Huse, 2005).

As tarefas que o CA deve executar são suportadas na literatura por meio de perspectivas teóricas complementares, e por vezes conflitantes (Daily et al., 2003). Tais tarefas são categorizadas por Zahra \& Pearce (1989) como de controle, de estratégia e de serviço. 
As tarefas de controle seguem predições formuladas com o auxílio da teoria de agência. Segundo essa perspectiva, a principal tarefa do CA é monitorar os executivos e os seus incentivos para que operem no interesse dos acionistas da empresa (Fama \& Jensen, 1983). As duas dimensões de controle relevantes para o CA são (i) de resultados, financeiros e mercadológicos; e (ii) de controles internos, voltada para as operações, os processos e o comportamento individual. Em função da crise sistêmica de 2008 e do decorrente escrutínio sobre o papel dos CAs, o desempenho do CA nas tarefas de monitoração do CA tem sido considerado uma medição importante da sua eficácia (Huse, 2007).

As tarefas de serviço, por sua vez, se fundamentam na teoria de dependência de recursos (Pfeffer \& Salancik, 2003) e visam prover recursos adicionais para a empresa por meio de aconselhamento aos executivos e relacionamento com redes externas.

As tarefas de estratégia englobam simultaneamente as perspectivas de serviço e de controle. Na perspectiva de serviço, em linha com os pressupostos de dependência de recursos, a natureza do trabalho estratégico do CA é de assessoramento aos executivos na avaliação das oportunidades e ameaças ambientais, no desenvolvimento de novas opções estratégicas e na seleção da estratégia pretendida (Zahra \& Pearce, 1990). Na perspectiva de controle estratégico, por sua vez, espera-se que o CA monitore o progresso de implementação da estratégia pretendida. Por serem foco deste estudo, a perspectiva de controle estratégico e a tarefa de monitoração estratégica serão discutidas em maior detalhe nas seção 2.1.5.

\subsubsection{3.}

\section{Fatores não estruturais de eficácia}

As formas pelas quais o CA realiza suas tarefas têm sido pouco estudadas. Conforme Gabrielsson \& Huse (2004b) ressaltaram, as teorias dominantes em GC, fundamentadas no modelo principal-agente, tratam o funcionamento real dos CAs como uma "caixa preta". Huse (2009b) sustentou que isto em boa parte se deveu à tradição de "publicar ou perecer", que conduziu os pesquisadores a buscar dados de fácil disponibilidade e abordagens teóricas de mais fácil aceitação. 
A pesquisa nos campos de estratégia e organizações tem proposto outras abordagens para explicar os determinantes de eficácia dos CAs. Em seu clássico estudo sobre as elites gerenciais, Pettigrew (1992) chamou atenção para a necessidade de analisar os padrões comportamentais dos CAs, conectando-os a diferentes contextos em que os CAs operam e, em última análise, ao desempenho do CA e da empresa. Mais recentemente, Nadler (2004) também observou que a chave para uma melhor GC está nas relações de trabalho entre CAs e executivos, na dinâmica social das interações do $\mathrm{CA}$ e na competência, integridade e envolvimento construtivo dos conselheiros individuais. Tais fatores são de difícil aproximação por meio dos pressupostos da teoria de agência.

Em linha com essa visão, considera-se aqui que: (i) a eficácia do CA nas suas tarefas depende também de fatores não estruturais antecedentes; e (ii) apesar de fornecerem suporte teórico às tarefas que o CA deve realizar, as teorias dominantes em GC não têm poder explicativo suficiente sobre os antecedentes não estruturais de eficácia nessas tarefas. Sendo assim, há a necessidade de analisar perspectivas teóricas complementares para compreender a natureza desses antecedentes não estruturais.

Um caminho promissor é o emprego da Teoria de Produção em Equipe TPE (Alchian \& Demsetz, 1972; Blair \& Stout, 1999; 2001). Em contraste à teoria de agência, a TPE oferece uma resposta alternativa ao papel do CA e aos seus antecedentes de eficácia, ao endereçar um problema diferente. Para Blair \& Stout (1999), existe um problema de produção em equipe quando os grupos de interesse na empresa não conseguem fazer contratos explícitos para distribuir os resultados do seu trabalho conjunto na empresa. Segundo a TPE, as empresas não são compreendidas como um nexo de contratos completos entre principais e agentes, mas como um nexo de ativos, recursos e capacitações que são investidos na empresa por diversos grupos de interesse (acionistas, executivos, empregados, credores, sociedade em geral, dentre outros) que têm a expectativa de obter ganhos por meio da produção em equipe.

Não é possível estabelecer contratos perfeitos que definam ex-ante a magnitude do investimento de recursos a ser feito por todos os membros da equipe de produção. Tampouco é possível estabelecer contratos que definam exante regras perfeitas de divisão dos benefícios gerados pelo empreendimento em equipe, que não são facilmente divisíveis. Uma vez que comportamentos 
oportunistas entre os membros podem diminuir ou eliminar os ganhos obtidos pela equipe de produção, é no melhor interesse coletivo dos membros que tais comportamentos sejam minimizados. Quando o potencial para comportamentos oportunistas entre membros é significativo, eles preferirão abrir mão do controle dos ativos e resultados da produção em equipe em favor de uma hierarquia de mediação. A função principal dessa hierarquia será de maximizar a geração de valor para a equipe como um todo, e não somente para o acionista.

Sendo assim, o modelo preconizado pela TPE atribui ao CA a responsabilidade central de mediação horizontal dos interesses dos membros da equipe de produção, que nesse sentido não são mais compreendidos como principais ou agentes. Nessa visão, a eficácia da GC passa a não depender de mecanismos hierárquicos verticais entre principais e agentes, mas principalmente da coordenação de interações laterais entre os diferentes membros da equipe de produção. Portanto, a TPE fundamenta um modelo de funcionamento dos CAs que é simultaneamente voltado à colaboração e ao controle, complementando a visão tradicional de independência dos agentes, segundo a qual o CA tem a responsabilidade primária de controlar os executivos em nome dos acionistas.

A TPE enfatiza que o papel expandido de mediação atribuído aos CAs requer maior negociação entre os membros da equipe de produção (Blair \& Stout, 1999; 2001). Conforme os pressupostos da TPE, o CA deve coordenar atividades, recursos e capacitações eficazmente para desempenhar suas tarefas e criar valor para a empresa. Dado que provavelmente nenhum conselheiro possui isoladamente as informações e o conhecimento necessários atingir os objetivos desejados, o trabalho como uma equipe permitirá uma maior eficácia do CA nas suas tarefas (Gabrielsson, Huse \& Minichilli, 2007). Ressalta-se, portanto, a importância de perspectivas comportamentais e contingenciais para melhor compreender como os CA podem desempenhar esse papel de mediação eficazmente (Huse, Hoskisson, Zattoni \& Viganò, 2011).

Huse (2009a) desenvolveu uma taxonomia dos estudos em CAs que inclui essas perspectivas. A perspectiva comportamental analisa de que formas as interações entre os atores e os processos de trabalho antecedem e influenciam o desempenho do CA, com o suporte da teoria comportamental da empresa (Cyert \& March, 1992). De modo geral, os estudos dessa linha de pesquisa pressupõem que fatores não estruturais têm maior poder explicativo no desempenho do CA. Os 
principais fatores não estruturais de eficácia de um CA identificados na literatura comportamental compreendem dimensões cognitivas (Forbes \& Milliken, 1999), de processos de trabalho (Dulewicz, MacMillan \& Herbert, 1995; Huse et al., 2005), de informação (Siciliano, 2002) e de conhecimento (McGrath, MacMillan \& Venkataraman, 1995).

Por sua vez, a abordagem contingencial nos estudos em eficácia de CAs analisa de que formas diferentes contextos a afetam. Ela enfatiza que a GC está inserida em um contexto institucional e social maior. Esses estudos enfocam a influência que fatores contextuais como o país, a indústria, a regulação ou o poder relativo dos grupos de interesse podem ter no desempenho do CA (Zajac \& Westphal, 1994; Pettigrew \& McNulty, 1995; Buck, Filatotchev \& Wright, 1998; Grundei \& Talaulicar, 2002). Essa linha de pesquisa analisa os problemas decorrentes da generalização de teorias sem a devida consideração de impactos contextuais específicos.

\subsubsection{4. \\ Modelos gerais de eficácia de CAs}

Os principais modelos gerais de eficácia de CAs encontrados na literatura privilegiam o estudo da influência de fatores não estruturais, sob a premissa de que o poder explicativo das variáveis estruturais é limitado. Os modelos gerais mais influentes são os de Zahra \& Pearce (1989), Forbes \& Milliken (1999) e Huse (2005). O nível de análise dos três modelos é o CA como grupo de trabalho, e não o conselheiro individual. Eles serão analisados a seguir.

O modelo desenvolvido no influente artigo de Zahra \& Pearce (1989), ilustrado na Figura 1, prevê que a eficácia do CA nas tarefas de serviço, estratégia e controle (representada pelos autores como "papéis do CA"): (i) é influenciada por fatores não estruturais relacionados à dinâmica de trabalho do CA e à experiência dos conselheiros (representados como "características", "estrutura" e "processo"); e (ii) influencia o desempenho financeiro da empresa.

Quanto aos fatores estruturais (representados como "composição"), as ligações sólidas e pontilhadas sugerem que o seu efeito no desempenho financeiro é predominantemente indireto, por meio dos fatores não estruturais e da eficácia do CA nas suas tarefas. 


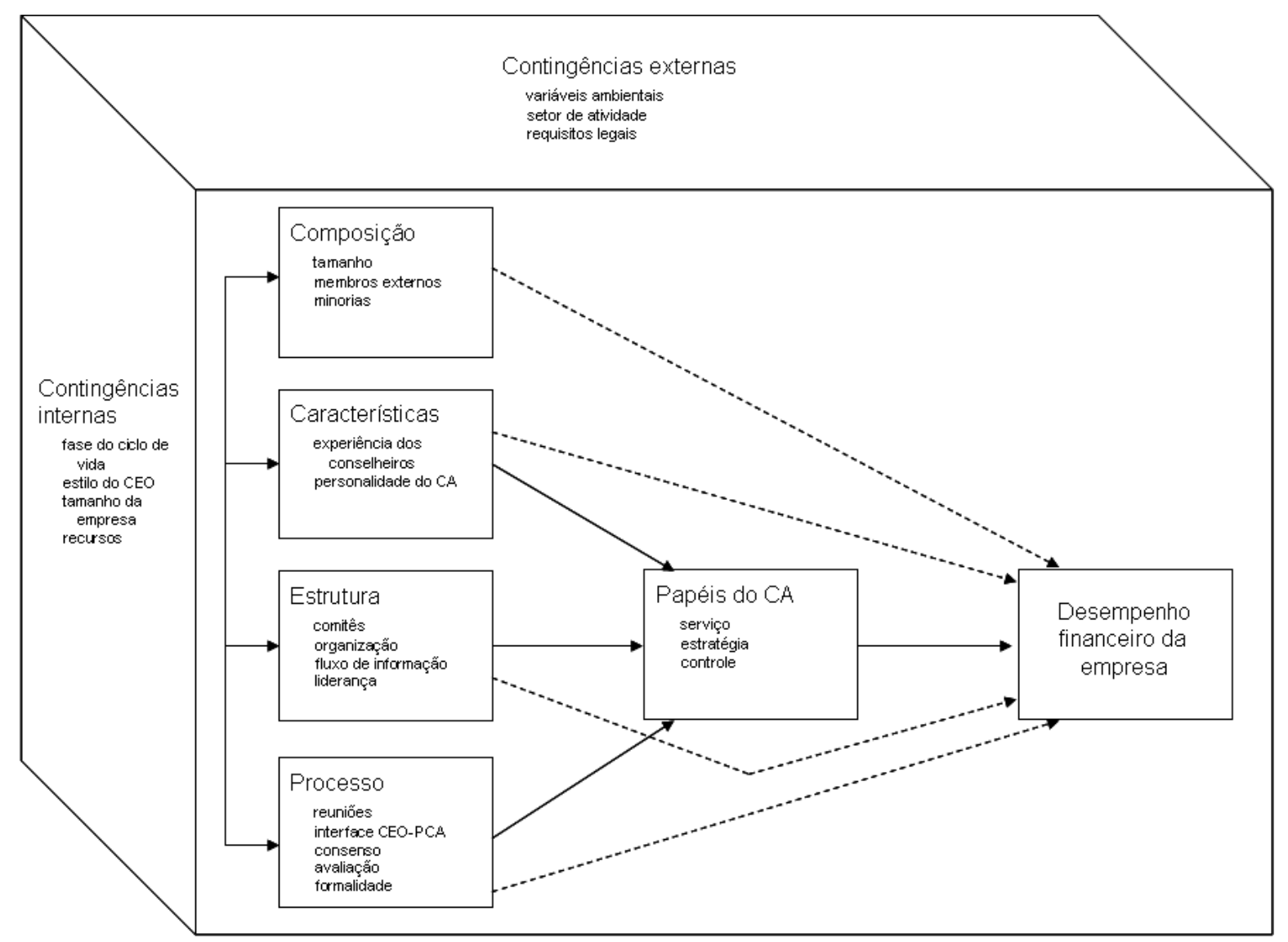

Figura 1 - Modelo geral de eficácia de CAs de Zahra \& Pearce (1989)

Ao prever que as contingências externas e internas podem afetar as relações do modelo, Zahra \& Pearce reconheceram a importância do contexto como um fator a ser considerado na pesquisa em eficácia dos CAs.

O modelo de Forbes \& Milliken (1999), ilustrado na Figura 2, caracteriza a eficácia do CA como o seu desempenho nas tarefas de controle e serviço. O modelo é fundamentado na abordagem comportamental mas também inclui considerações normativas de expectativas de papéis do CA. Não foram feitas considerações contextuais.

Os autores propõem uma lógica de mediação, na qual as características estruturais e demográficas do CA (tamanho do CA, proporção de conselheiros externos e tempo do conselheiro na função) influenciarão a dinâmica de interação entre os conselheiros antes que se possam observar resultados. 


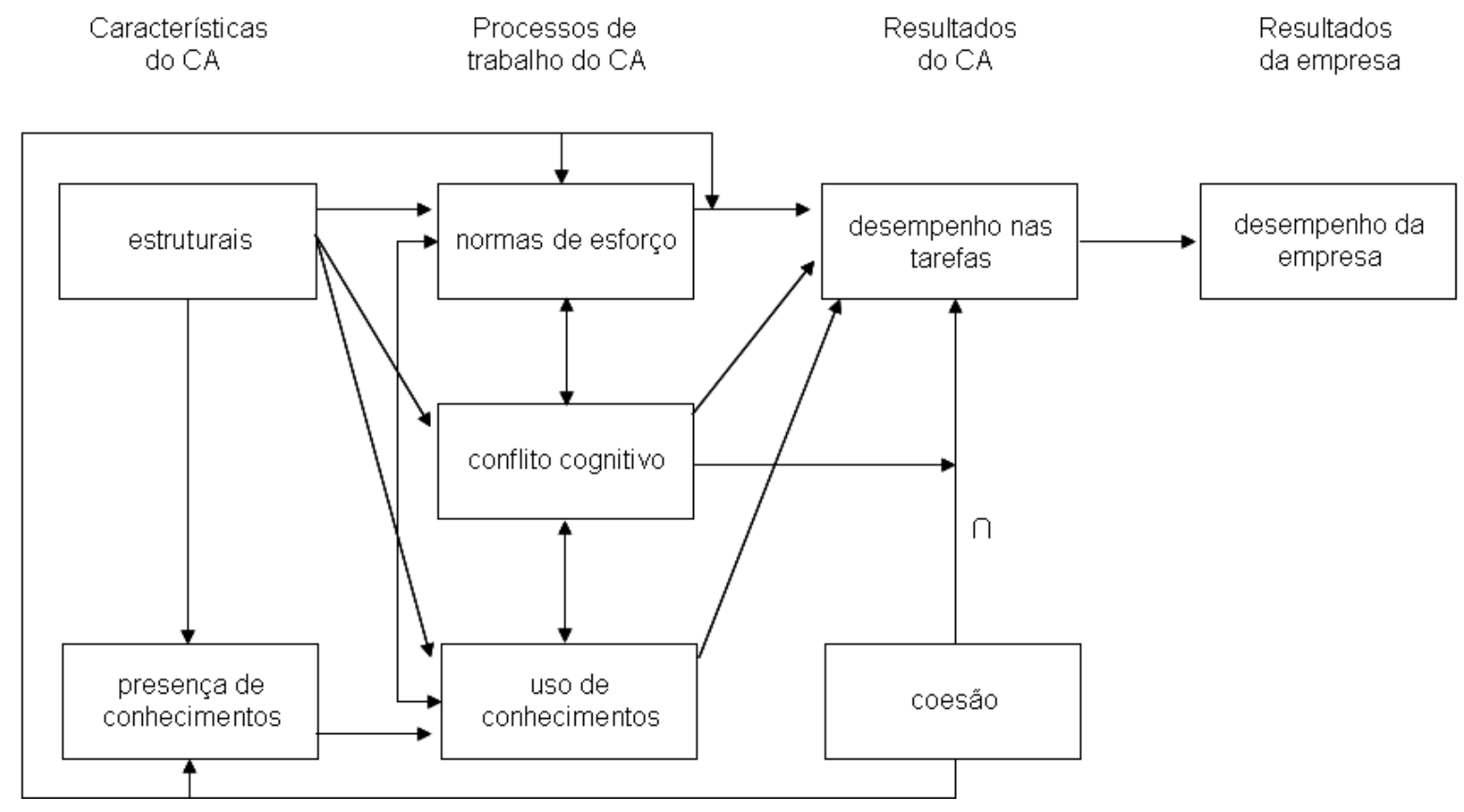

Figura 2 - Modelo geral de eficácia de CAs de Forbes \& Milliken (1999)

Sua principal contribuição é a definição dos construtos não estruturais intervenientes. Nesse sentido, o modelo prevê a influência das normas de esforço, dos conflitos cognitivos, dos conhecimentos e da coesão. As normas de esforço refletem o nível de esforço que o CA deve dedicar às suas tarefas, influenciando sua eficácia. Os conflitos cognitivos são definidos como discordâncias entre os conselheiros que podem elevar a capacidade de crítica e questionamento do CA. Os autores sugerem que a presença e o efetivo uso dos conhecimentos existentes no CA auxiliarão os conselheiros a tomar decisões mais embasadas e com maior potencial de agregação de valor. Finalmente, sugerem que a coesão entre os conselheiros facilitará o desempenho nas tarefas ao melhorar o processo decisório.

Em uma consideração importante, Forbes e Milliken (1999) previram que pode haver relações adicionais de mediação entre construtos que não foram antecipadas no seu modelo original:

In addition to the effects captured in these propositions, we note that the processes discussed above have the potential to influence one another. For example, to the extent that high-effort norms result in more intense participation among members, they may stimulate cognitive conflict and lead to an increased use of members' knowledge and skills. Similarly, cognitive conflict may surface task-relevant information, and, conversely, the elicitation of members' knowledge may give rise to further conflict. However, the exact nature and strength of these relationships are likely to vary. (p. 497) 
O modelo geral de Huse (2005), ilustrado na Figura 3, embasou uma recente linha de pesquisa com CAs de empresas norueguesas, denominada The Value Creating Board. O modelo identifica os fatores que, na visão do autor, podem elevar o desempenho de tarefas do CA.

Ele representa uma evolução em relação a Forbes \& Milliken (1999) na medida em que prevê explicitamente a influência de atores internos e externos à empresa e do contexto onde a empresa opera, em uma lógica dinâmica de aprendizado.

Em linha com a teoria contingencial, o modelo prevê que o contexto influencia o poder relativo dos membros do CA e do CA em relação a outros atores, bem como a composição estrutural do CA. A estrutura, por sua vez, influencia e é influenciada pelas interações entre conselheiros e pela cultura decisória no CA, em linha com a perspectiva comportamental e à semelhança do proposto por Forbes \& Milliken (1999). As normas e expectativas de papéis também influenciam a cultura decisória do CA. A cultura decisória é definida como uma consolidação dos construtos de processos de trabalho do CA de Forbes \& Milliken. Ela, por sua vez, influenciará o desempenho do CA nas suas tarefas e, finalmente, o desempenho empresarial.

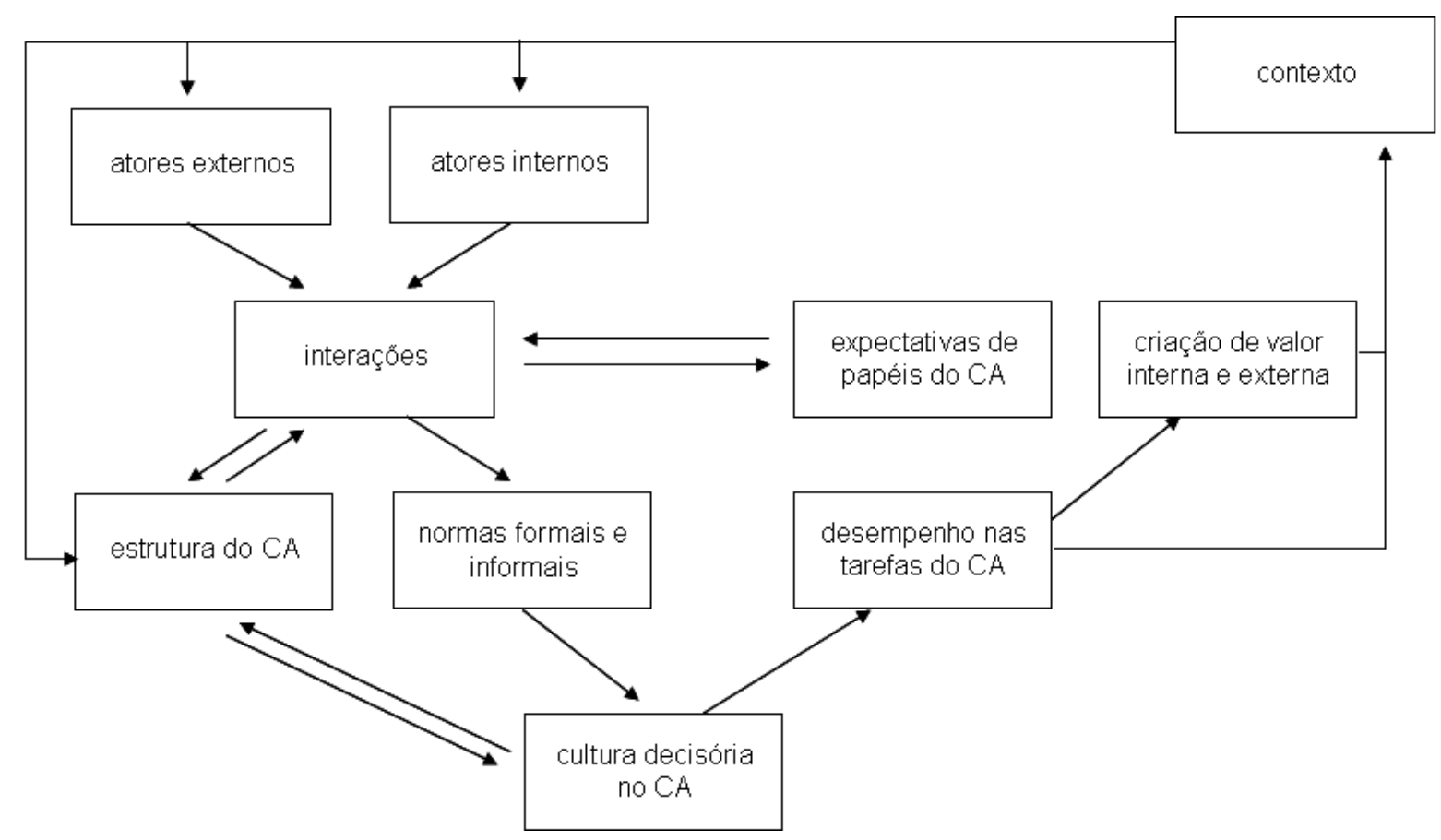

Figura 3 - Modelo geral de eficácia de CAs de Huse (2005) 
Em suma, os principais modelos gerais de eficácia de CAs enfatizam a importância dos fatores não estruturais antecedentes e sugerem que pode haver relações mediadas entre eles. No entanto, tais fatores são genéricos e podem não ter poder explicativo suficiente sobre tarefas específicas, como é o caso da monitoração da IE.

A atuação específica dos CAs na dimensão estratégica consolida duas áreas temáticas de interesse neste estudo: GC e estratégia. Ela será discutida na próxima seção.

\subsection{4.}

\section{Envolvimento dos CAs na gestão estratégica}

Diversos códigos de melhores práticas em GC recomendam que os CAs enfatizem as tarefas estratégicas. Citam-se aqui alguns exemplos. Os Princípios de GC da OECD (2004) mencionam que uma das principais responsabilidades dos CA é a de guiar e revisar a estratégia corporativa. O Código Combinado de GC do Reino Unido (Financial Reporting Council, 2008), por sua vez, ressalta que as empresas devem ser lideradas por um CA eficaz, coletivamente responsável pelo sucesso da empresa e responsável por prover liderança corporativa, definir objetivos estratégicos e revisar o desempenho empresarial.

A prática empresarial parece estar se orientando a esses direcionamentos normativos. Segundo um estudo da consultoria McKinsey \& Company (2006) com 1.468 executivos, 64\% deles consideraram que os CAs estavam mais ativamente envolvidos em atividades de criação de valor do que nos cinco anos anteriores. Segundo os entrevistados, $84 \%$ dos conselheiros de suas empresas tinham um nível de entendimento das estratégias corporativas que podia ser considerado bom ou completo. Em outra pesquisa com 71 conselheiros de empresas européias, Demb \& Neubauer (1992) mostraram que os CA se envolviam ativamente em atividades de formulação estratégica. Stiles \& Taylor (1993) publicaram resultados semelhantes em um estudo com empresas do Reino Unido.

A literatura acadêmica mais recente também tem apresentado algum suporte ao papel dos CAs na gestão estratégica (Demb \& Neubauer, 1990; Zahra, 1990; 
Judge \& Zeithaml, 1992; Sadtler, 1993; Hoskisson, Hitt, Wan \& Yiu, 1999; Pugliese, Bezemer, Zattoni, Huse, Van den Bosch \& Volberda, 2009). Esse suporte se fundamenta no entendimento de que os CAs são responsáveis em última instância pelo funcionamento eficaz das organizações (Jensen, 1993; Johnson et al., 1996; Blair \& Stout, 2001).

Em termos de evidência empírica, alguns estudos demonstraram a existência de relações significantes entre o envolvimento estratégico dos CAs e o desempenho empresarial. Pearce (1983) identificou que as atitudes dos conselheiros no processo de gestão estratégica influenciaram a rentabilidade de bancos norte-americanos. Judge \& Zeithaml (1992) estudaram quatro amostras de empresas norte-americanas de capital aberto e fechado e identificaram que o seu desempenho financeiro foi significativamente influenciado pelo grau de envolvimento do CA na formulação e na avaliação das estratégias. Golden \& Zajac (2001) encontraram relação positiva e significante entre o envolvimento estratégico dos CA e a mudança estratégica em uma amostra de cerca de três mil hospitais. Zahra \& Pearce (1990) demonstraram de forma pioneira que variáveis comportamentais e contextuais afetam o envolvimento de um CA na gestão estratégica.

No entanto, a visão de que os CAs têm um papel ativo na gestão estratégica não é consensual na literatura. Os trabalhos mais influentes que contestam o envolvimento estratégico dos CAs são os de Mace (1971) e Lorsch \& MacIver (1989). Ainda que tenham sido desenvolvidos em uma fase de baixa participação dos CAs nas decisões empresariais, esses trabalhos refletem uma visão de hegemonia gerencial e de passividade dos CAs que ainda pode ser observada em empresas e países com sistemas de GC menos desenvolvidos. Os autores argumentaram que os CAs não são capazes de participar da gestão estratégica por não terem os recursos nem a autoridade para tal ou, como mencionou Mace, por serem "criaturas do CEO". Mace observou que a tentativa de ingerência do CA nas tarefas de gestão estratégica, que cabem por prerrogativa à equipe executiva e ao $\mathrm{CEO}$, deflagra conflitos de autoridade prejudiciais ao processo decisório da empresa. Segundo essa ótica passiva, cabe ao CA revisar as análises estratégicas do CEO e sugerir ajustes. Logo, segundo essa linha de pensamento os CAs não deveriam intervir na formulação ou na implementação das estratégias a não ser que haja desvios significativos. 
Apesar de os CAs geralmente terem, do ponto de vista fiduciário, a obrigação legal de revisar e monitorar a estratégia empresarial (Stiles, 2001), essas visões alternativas revelam que ainda não se tem um entendimento aprofundado de como os CA devem atuar na gestão estratégica (Hendry, Kiel \& Nicholson, 2009). Em um extremo, a visão de hegemonia gerencial sustenta que a estratégia é um domínio do CEO. Outros estudos que suportam o envolvimento estratégico dos CAs advogam uma intervenção mais ampla, em uma combinação de suas tarefas de controle e serviço, compreendendo aspectos como a definição do negócio, o desenvolvimento da missão e da visão, a avaliação do ambiente, a formulação e a implementação dos planos estratégicos (Zahra, 1990). Conforme Hendry \& Kiel (2004) observaram, as principais pesquisas na área sugerem: (i) uma distinção entre as etapas de formulação e implementação estratégica; e (ii) que o envolvimento do CA nessas etapas pode ser representado por um contínuo.

Em suma, apesar de a literatura normativa prescrever o envolvimento dos CAs na gestão estratégica, e de alguma evidência empírica sugerindo a influência do envolvimento estratégico do CA no desempenho empresarial, ainda há lacunas na pesquisa acadêmica quanto à intensidade e as formas como os CAs devem intervir. Em linha com os argumentos de Hendry, Kiel \& Nicholson (2009), considera-se aqui que não há na literatura uma distinção suficientemente clara entre os papéis do CA e do CEO na formulação e na implementação estratégica. Conclui-se também que a relação entre fatores comportamentais, contextuais e normativos antecedentes e a eficácia do CA nas tarefas de desenvolvimento e monitoração estratégica ainda não está suficientemente estabelecida na literatura.

Esses temas serão elaborados na próxima seção deste estudo, no contexto específico da tarefa de monitoração da IE.

\subsection{5. \\ Envolvimento dos CAs na monitoração da IE}

Na seção anterior, discorreu-se sobre a crescente importância da intervenção dos CAs na gestão estratégica. A ênfase da literatura normativa recente nas responsabilidades dos CAs em assegurar o sucesso estratégico das empresas sugere que o seu envolvimento na tarefa específica de monitoração da IE é importante para assegurar que as estratégias planejadas criam o valor esperado. 
$\mathrm{Na}$ literatura acadêmica, um argumento relevante nesse sentido foi formulado por Barney et al. (2001) ao apontarem questões para pesquisa futura no campo da visão baseada em recursos:

While governance, per se, may not be a source of competitive advantage, failure to implement the correct governance in a situation can lead firms to not fully realize the benefits of the resources they control. Although the necessary resources may be present, a sustained competitive advantage may not be created where the corporate governance system fails to incentivize and/or monitor management to undertake the relevant actions. (p. 632)

Apesar desses chamados, verifica-se que o papel do CA na monitoração da IE tem sido, surpreendentemente, muito pouco discutido pelos pesquisadores em GC e estratégia. Até a data, há pouco conhecimento teórico ou empírico sobre a natureza, o alcance e a eficácia da atuação dos CA em IE (Brauer \& Schmidt, 2008). A esparsa contribuição da pesquisa atual é fundamentalmente prescritiva. O corpo de pesquisa sobre o tema se divide em duas vertentes. A primeira delas é conceitual, baseada em ensaios teóricos. A segunda enfoca a proposição de instrumentos para auxiliar os CAs na tarefa de monitoração da IE.

Do ponto de vista conceitual, destacam-se as contribuições de Hendry \& Kiel (2004), Schmidt \& Brauer (2006) e Brauer \& Schmidt (2008).

Hendry \& Kiel caracterizaram as funções de controle estratégico que o CA deve desempenhar, em um desenvolvimento das proposições de Stiles \& Taylor (1996). Conforme desenvolvido na seção 2.1.4 deste estudo, as tarefas de estratégia do CA envolvem perspectivas simultâneas de serviço e de controle. Os autores, com base nessas perspectivas, sugeriram que o CA deve ter um papel de controle comportamental sobre a estratégia, moldando: (i) as condições para o desenvolvimento do processo estratégico na empresa; (ii) o conteúdo da estratégia, requerendo que a equipe executiva justifique suas propostas e avaliando alternativas, à semelhança do proposto por Stiles (2001); e (iii) a implementação da estratégia, monitorando continuamente a IE e fazendo mudanças quando necessário. Observa-se que os autores sugerem um envolvimento moderado do CA na gestão estratégica que, no entanto, envolve explicitamente a dimensão da IE. Segundo Hendry \& Kiel, o CA deve concentrar seu papel estratégico na avaliação das propostas estratégicas preparadas pela equipe executiva e na monitoração da IE. Há na proposição dos autores a premissa 
implícita de que a intervenção do CA na aprovação ou rejeição dos planos estratégicos formulados e emergentes contribui para a sua eficácia na tarefa de monitoração da IE.

Schmidt \& Brauer (2006) e Brauer \& Schmidt (2008) endereçaram especificamente a tarefa de monitoração da IE. No entanto, diferentemente de Hendry \& Kiel (2004), sugeriram um envolvimento menos ativo, concentrado na avaliação do grau de consistência estratégica da empresa. A consistência estratégica foi definida como o grau de alinhamento entre as decisões de alocação de recursos tomadas pela equipe executiva e a estratégia pretendida. A intervenção do CA, por sua vez, deve ser disciplinada e restrita à correção de desvios não gerenciados pelos executivos. Segundo os autores:

Boards should intervene if intended and realized strategy diverges significantly or the realization of the intended strategy goes off track and corrective actions are not taken by corporate management (Jensen \& Meckling, 1976; Jensen, 1986). (p. 651-652)

Quanto à proposição de ferramentas para auxiliar o CA na monitoração da IE, foram identificados na literatura três estudos principais.

Donaldson (1995) desenvolveu uma ferramenta de auditoria estratégica para uso pelos CA. O principal objetivo é inserir um mecanismo formal de monitoração estratégica no sistema de governança da empresa.

Siciliano (2002) apresentou uma ferramenta semelhante, empregando uma metodologia baseada em indicadores balanceados (Kaplan \& Norton, 1992).

Drew \& Kaye (2007) também propuseram uma ferramenta de avaliação estratégica para uso pelos CAs. Duas dimensões de gestão foram empregadas: IE e riscos estratégicos. Os autores também formularam prescrições sobre o papel do CA. Segundo eles, a monitoração da IE deve enfocar poucos eventos e iniciativas vitais definidos previamente nas etapas de formulação estratégica. O CA deve avaliar o estágio de implementação dessas iniciativas em comparação aos objetivos e prazos planejados. A dimensão de riscos estratégicos, por sua vez, compreende o grau de exposição a fatores externos que podem impactar a capacidade de atingimento dos objetivos estratégicas. Nessa dimensão, os CAs devem: (i) identificar os principais riscos estratégicos; (ii) avaliar sua importância regularmente; (iii) produzir respostas estratégicas para mitigar, eliminar ou aceitar 
os riscos estratégicos; e (iv) avaliar o progresso da implementação das respostas estratégicas.

Dada a carência de estudos sobre o tema, considera-se aqui que é necessário formular uma definição do papel dos CAs nessa tarefa. A seguir, serão analisadas diferentes perspectivas teóricas para melhor embasar a natureza da atuação dos CA no asseguramento dos objetivos estratégicos das empresas.

Com base no argumento de Hendry \& Kiel (2004), considera-se que a teoria de agência tem uma clara implicação para as tarefas de controle estratégico do CA. A autoridade delegada ao CA no modelo principal-agente atende ao interesse dos acionistas porque permite um melhor processamento de informações, coordenação de atividades e tomada de decisões. Nessa posição estrutural teoricamente vantajosa, o CA é responsável por monitorar os atos dos executivos na implementação da vontade estratégica dos acionistas. A lógica de agência reforça a importância do papel de monitoração estratégica dos CA porque os executivos podem tomar decisões de IE sub-ótimas, ou não tomar tais decisões oportunamente, em função de abuso de juízo gerencial, interesses divergentes ou inação (Mahoney, 2001). Esses comportamentos, em última análise, podem expropriar valor dos acionistas. Conforme os pressupostos da teoria de agência, é importante que o CA seja independente dos executivos para que possa exercer uma monitoração eficaz do desenvolvimento estratégico da empresa.

As perspectivas de processo estratégico também contribuem para clarificar o papel do CA na tarefa. Brauer \& Schmidt (2008) argumentaram que o CA deve assegurar que a estratégia pretendida se converta na realizada. No entanto, a definição de IE desenvolvida na seção 2.1.2 deste estudo ressalta que é necessário considerar também as estratégias emergentes e seu efeito adaptativo no padrão de intenção estratégica da empresa (Mintzberg, 1978). Conforme Stiles (2001), a natureza emergente da estratégia tem sido ignorada pela pesquisa acadêmica em CAs. Portanto, em linha com o conceito de capacitações dinâmicas proposto por Teece (2007) e Schreyogg \& Kliesch Eberl (2007), considera-se aqui que os CA podem exercer uma tarefa de monitoração de segunda ordem eficaz para diagnosticar e endereçar desvios de IE de forma sistêmica, contribuindo para o alinhamento estratégico dinâmico das empresas. Para isso, a tarefa de monitoração da IE no CA deve compreender instâncias proativas de análise do progresso das estratégias pretendidas e emergentes. 
Estudos recentes em eficácia de CAs (Gabrielsson et al., 2007; Huse et al., 2011) empregaram a Teoria de Produção em Equipe (Blair \& Stout, 1999) como fundamento teórico paro embasar a eficácia do CA em termos gerais. Tomando como base os argumentos desses autores, e estendendo-os, propõe-se aqui que a eficácia do CA na tarefa de monitoração da IE é um problema de produção em equipe.

Segundo a lógica da TPE, o CA deve assegurar a conversão das estratégias pretendidas e emergentes em realizadas de modo a maximizar valor para todos os grupos de interesse na empresa, e não só dos acionistas. Conforme desenvolvido na seção 2.1.3.3, a natureza dos conflitos de interesse nesse contexto não é necessariamente vertical entre principal e agente, mas horizontal, entre principais. Conflitos principal-principal influenciam o processo de GC e a eficácia do CA (Young, Peng, Ahlstrom, Bruton \& Jiang, 2008). Por exemplo, em empresas de controle definido o grupo de controle pode decidir as nomeações de conselheiros. Nesse contexto, o CA pode não ser capaz de impedir decisões que expropriem valor dos acionistas minoritários (Young et al., 2008) e de outros grupos de interesse. Em relação à estratégia, acionistas controladores ou outros grupos de interesse podem pressionar o CA a apoiar escolhas estratégicas sub-ótimas por razões políticas em detrimento do desempenho (Filatotchev, Wright, Uhlenbruck, Tihanyi \& Hoskisson, 2003). Logo, para assegurar uma gestão bem sucedida da IE, o CA precisará exercer de forma eficaz o papel de mediação e negociação preconizado pela TPE. Conforme discutido na seção 2.1.3.3, a TPE sugere que o desempenho eficaz do CA neste papel mediador requer comportamentos coletivos e processos de trabalho que favoreçam a produção em equipe.

Conclui-se, portanto, que os pressupostos da teoria de agência suportam parcialmente o papel de monitoração estratégica do CA. As perspectivas teóricas de processo estratégico são um complemento necessário para caracterizar a natureza dinâmica da IE e, em decorrência disso, suportar a visão de que a monitoração da IE pelo CA deve incluir proativamente as estratégias pretendidas e emergentes. Principalmente, verifica-se que o modelo principal-agente não é capaz de explicar as formas pelas quais o CA deve desempenhar a tarefa de monitoração estratégica.

A TPE endereça essa lacuna teórica, ao sugerir que o CA deve ter comportamentos coletivos e processos de trabalho que o permitam assegurar que a 
IE maximizará valor para os grupos de interesse na empresa. Dado que os membros do CA possuem diferentes objetivos, valores e normas, sua contribuição individual e dinâmica de interação deve ser gerenciada de modo a que o CA possa dedicar a atenção necessária ao questionamento e avaliação de decisões de IE que possam ser prejudiciais ao interesse de alguns dos membros da equipe de produção.

Com base nesses argumentos, propõe-se aqui que para desempenhar a tarefa de monitoração da IE o CA deve: (i) representar os grupos de interesse que geram valor para a empresa; (ii) aglutinar informações relevantes sobre a operação da empresa e o ambiente para avaliar o impacto das decisões estratégicas; (iii) coordenar as contribuições dos seus membros de modo a utilizar eficazmente os recursos, conhecimentos e habilidades existentes; (iv) promover regularmente e mediar as discussões sobre potenciais desvios de IE que possam destruir valor para alguns dos membros da equipe de produção, considerando o progresso da implementação das estratégias pretendidas e a coerência das estratégias emergentes; e (v) definir linhas de ação corretiva para realinhamento do rumo estratégico da empresa.

\section{2. \\ Lacunas constatadas na literatura revista}

Nesta seção sumariam-se as lacunas identificadas na revisão da literatura.

Primeiramente, apesar da importância da execução das estratégias para a criação de valor e o sucesso a longo prazo das empresas, verificou-se que a pesquisa acadêmica não se dedicou suficientemente a unir as áreas temáticas de GC e de estratégia, particularmente no domínio da IE.

Em segundo lugar, na literatura normativa e acadêmica, e na prática gerencial, reconhece-se que o CA deve ser "o ápice do sistema de controle decisório das organizações" (Fama \& Jensen, 1983, p. 311). No entanto, a revisão da literatura mostrou que ainda não se tem um entendimento claro das formas pelas quais o CA deve exercer suas tarefas de controle estratégico. No contexto específico deste estudo, verificou-se que não há pesquisas que tenham analisado sistematicamente os possíveis antecedentes de eficácia dos CAs na monitoração da IE com o objetivo de identificar fatores de influência. Os principais modelos 
gerais de eficácia de CAs já desenvolvidos se baseiam em construtos genéricos, que podem não ser representar adequadamente os fatores não estruturais específicos que afetam o desempenho do CA na monitoração estratégica. Por sua abrangência, considera-se também que esses modelos podem ser demasiadamente complexos para fornecer uma explicação parcimoniosa do fenômeno específico em estudo.

Constatou-se que a teoria de agência fundamenta o papel do CA na monitoração da IE de forma útil, porém incompleta, dado que pouco contribui para a compreensão dos possíveis fatores não estruturais antecedentes. Verificouse que a Teoria de Produção em Equipe (Blair \& Stout, 1999; 2001) fornece subsídios para um melhor entendimento desses possíveis fatores. Estudos recentes em eficácia de CAs (Gabrielsson et al., 2007; Huse et al., 2011) empregaram a TPE. Porém, não foram identificados estudos que empreguem a TPE no contexto específico de eficácia dos CAs na monitoração da IE.

\section{3. \\ Modelo conceitual preliminar}

Os poucos estudos sobre eficácia dos CA na monitoração da IE concentramse em propor prescrições e ferramentas para avaliar o desempenho do CA nessa tarefa. Neste estudo propõe-se uma abordagem diferente que, no entanto, não exclui o uso de ferramentas de avaliação. Seu objetivo é analisar a influência de fatores não estruturais comportamentais, contextuais e normativos para a eficácia dos CA na monitoração da IE. O estudo enfoca, portanto, o que pode afetar a eficácia do CA nessa tarefa e não a tarefa em si.

Nesta seção será desenvolvido um modelo conceitual preliminar de relações entre fatores não estruturais que podem afetar a eficácia dos CAs na monitoração da IE, fundamentado na TPE (Blair \& Stout, 1999; 2001). Tomando como base os modelos gerais de Zahra \& Pearce (1989), Forbes \& Milliken (1999) e Huse (2005), este modelo preliminar enfocará perspectivas teóricas comportamentais, contingenciais e normativas.

O modelo compreende algumas delimitações adicionais. A primeira delas diz respeito à natureza dos construtos. Conforme indicado anteriormente, o poder explicativo dos fatores estruturais não é claramente evidenciado pela pesquisa em 
GC. A TPE sugere que a qualidade da produção em equipe no CA é influenciada por fatores não estruturais de natureza comportamental e de processos de trabalho. Os modelos gerais de eficácia de CAs também sugerem que esses fatores podem ser mais relevantes que os estruturais. Logo, apesar de reconhecer-se que a estrutura do CA pode ter algum efeito na sua eficácia na monitoração da IE, o modelo aqui desenvolvido se concentrará na influência de fatores não estruturais.

A segunda delimitação diz respeito à busca de uma explicação parcimoniosa para os antecedentes da eficácia dos CAs na monitoração estratégica. Nesse sentido, não se pretende que o modelo capture de forma exaustiva todos os possíveis fatores não estruturais intervenientes. Reconhece-se que há na literatura outros fatores que poderiam ser incluídos. De modo a gerar um modelo testável e potencialmente útil para a prática gerencial, dois passos serão seguidos. Em primeiro lugar, o modelo conceitual preliminar incluirá somente os construtos que a literatura indique como de maior relevância potencial. Posteriormente, o modelo será aperfeiçoado e delimitado por meio de subsídios coletados em uma pesquisa de campo com conselheiros de administração com experiência em eficácia de CAs. Os resultados dessa pesquisa e o modelo conceitual final serão apresentados nos capítulos 3 e 4 , respectivamente.

A terceira delimitação é de escopo. A variável dependente de interesse é a eficácia do CA na monitoração da IE. Portanto, a influência dessa variável na IE não será analisada.

O modelo conceitual preliminar é representado graficamente na Figura 4. O sentido esperado da influência dos construtos está indicado ao lado de cada um.

A perspectiva comportamental suporta a visão de que o Acesso a Informações, o Conhecimento do Negócio, a Dinâmica de Trabalho do CA e a Liderança do Presidente do Conselho de Administração - PCA podem influenciar a Eficácia do CA na Monitoração da IE. Essa também pode ser influenciada pela Atenção à Monitoração da IE.

Conforme a perspectiva contingencial, a atenção do CA à monitoração da IE é afetada por construtos contextuais que podem aproximar ou distanciar o CA da monitoração estratégica: (i) o Desempenho Empresarial Passado; (ii) a Confiança no CEO; e (iii) a Textura Causal do Ambiente. 


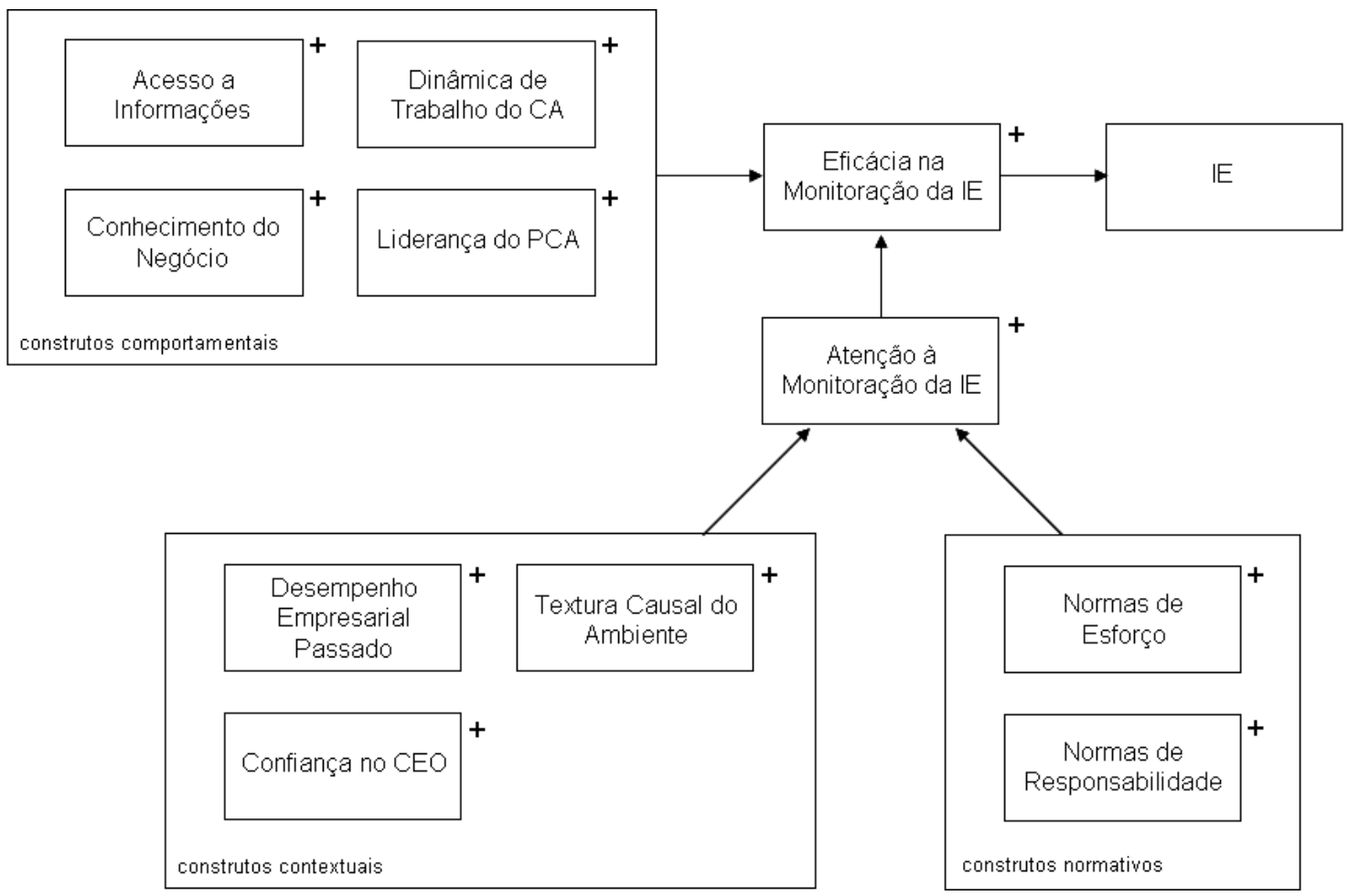

Figura 4 - Modelo conceitual preliminar de relações entre fatores não estruturais de eficácia dos CAs na monitoração da IE

Conforme a perspectiva normativa, espera-se que a Atenção à Monitoração da IE também seja influenciada pelas Normas de Esforço e pelas Normas de Responsabilidade do CA.

A seguir, serão definidos e caracterizados os construtos do modelo conceitual preliminar.

\subsection{1.}

\section{Eficácia na Monitoração da IE}

Com base em Zahra \& Pearce (1989), Forbes \& Milliken (1999) e Huse (2005), define-se operacionalmente o construto como o grau em que o CA desempenha suas tarefas de monitoração da IE eficazmente.

Ao estudar a eficácia de CAs Noruegueses, Sellevoll et al. (2007) desenvolveram medições de desempenho nas tarefas de monitoração, estratégia e serviço. Algumas delas se aplicam ao contexto específico da tarefa de monitoração da IE. Por exemplo, de modo a monitorar a IE eficazmente, o CA deve acompanhar sistematicamente o progresso das iniciativas estratégicas e as 
decisões chave de alocação de recursos. O CA deve questionar ativamente o progresso da IE, bem como compreender as razões pelas quais as estratégias realizadas e emergentes se desviaram da pretendida (Charan, 2005; Schmidt \& Brauer, 2006). Ao atuarem dessa forma, os CAs estimularão uma dinâmica positiva de interações estratégicas com o CEO e a equipe executiva, impedindo a inação estratégica e estabelecendo uma agenda voltada para a implementação dos planos estratégicos (Schmidt \& Brauer, 2006). Conforme discutido na seção 2.1.3, o CA não deve participar diretamente nas atividades de IE mas sim na sua monitoração, sob pena de provocar conflitos de autoridade com os executivos e de limitar a sua própria capacidade de crítica, prejudicando sua eficácia no processo de IE (Mace, 1971; Brauer \& Schmidt, 2008; McDonald \& Westphal, 2010).

Conforme Sellevoll et al. (2007), CAs que apresentem alto grau de envolvimento e autoridade em orientar a IE poderão ter melhor desempenho na monitoração da IE. Especificamente nesse contexto, espera-se que o CA tenha um papel ativo na definição das prioridades de IE da empresa (Siciliano, 2002; Li et al., 2008). O envolvimento do CA no processo de IE deve ser contínuo, ao invés de esporádico (Zahra, 1990). De modo a assegurar a coerência das propostas estratégicas geradas pelos executivos, espera-se que o CA atue como órgão avaliador e decisor dessas propostas, solicitando mudanças quando necessário (Stiles, 2001; Stiles \& Taylor, 2001).

Tomando-se como base os indicadores de consistência estratégica de Brauer \& Schmidt (2008) e as perspectivas de processo estratégico discutidas na revisão de literatura, sugere-se também que a qualidade da monitoração da IE pelo CA pode ser medida: (i) pela identificação oportuna dos desvios de IE; (ii) pela capacidade de vetar propostas estratégicas emergentes que careçam de coerência e afastem a empresa da estratégia pretendida; e (iii) pela capacidade de promover as decisões necessárias para restabelecer o rumo estratégico desejado.

\subsection{2.}

\section{Acesso a informações}

Define-se operacionalmente o Acesso a Informações como o grau em que o CA tem acesso às informações relevantes necessárias para monitorar a IE. Em 
linha com o sugerido por Zahra (1990) e Barney et al. (2001), propõe-se que a participação eficaz dos conselheiros nas questões estratégicas depende da qualidade do acesso às informações necessárias.

Estudos anteriores demonstraram que melhores níveis de acesso a informações podem permitir que o CA desempenhe tarefas de controle mais eficazmente (Gnan \& Zattoni, 2009). No que tange à monitoração estratégica, o CA tem necessidades específicas de acesso a informações para compreender os principais problemas de IE. Em termos de escopo, o CA deve definir proativamente suas necessidades de informação em linha com os objetivos estratégicos da empresa (Drew \& Kaye, 2007), sob pena de se confundir com relatórios e apresentações da diretoria executiva. Esse tipo de informação pode enfocar minúcias ou dimensões não-estratégicas, refletindo uma visão viesada da empresa que pode desviar ou estreitar a amplitude de análise e intervenção do CA. Ao definir suas necessidades, o CA deve considerar diversas dimensões de informação em adição à financeira (Drew \& Kaye, 2007). Apesar de os demonstrativos financeiros fornecerem algumas indicações sobre por que determinadas decisões estratégicas falharam, aquelas podem não ser suficientes para compreender o que está causando os desvios de IE. Uma vez que o escopo e os métodos para acessar informações podem influenciar o envolvimento do CA na monitoração estratégica, é desejável que o CA tenha acesso às informações relevantes de forma oportuna e completa (Siciliano, 2002).

Quanto aos métodos, as revisões de IE do CA devem ser suportadas por ferramentas e indicadores específicos (Donaldson \& Davis, 1991; Park, 1995; Steinberg \& Bromilow, 2000; Siciliano, 2002; Schmidt \& Brauer, 2006; Drew \& Kaye, 2007). O formato das informações disponibilizadas ao CA deve facilitar a discussão das questões prioritárias de IE. Para ter uma perspectiva de 'vida real' das barreiras ao sucesso da IE, os conselheiros devem ter acesso direto aos executivos e aos empregados chave (Park, 1995; Drew \& Kaye, 2007). Uma vez que o acesso a informações é importante para os processos de tomada de decisão do CA (Forbes \& Milliken, 1999), os conselheiros devem ser proativos em requerer as informações que julguem necessárias (Petrovic, 2008). 


\subsection{3.}

\section{Conhecimento do negócio}

Com base em Forbes \& Milliken (1999), o Conhecimento do Negócio é definido operacionalmente como o grau em que os conhecimentos específicos do negócio, requeridos para que o CA desempenhe sua tarefa de monitoração da IE, estão coletivamente presentes no CA.

A importância do capital humano é largamente reconhecida como uma fonte interna de vantagem competitiva. Na literatura em estratégia, a visão baseada em recursos fundamenta a noção de que as capacitações, competências e práticas de trabalho influenciam o desempenho empresarial (Penrose, 1959; Barney, 1991). Para desempenhar suas tarefas, o CA deve reunir competências e conhecimentos em diversas áreas (Forbes \& Milliken, 1999). Alguns deles, genéricos, são de natureza funcional (finanças, contabilidade, direito, dentre outros) ou relacional (relacionamentos com redes externas). Outros são específicos à empresa e ao ambiente em que ela atua e, portanto, podem contribuir para o desempenho do CA na monitoração estratégica.

O Conhecimento do Negócio pode ser interno ou externo. No contexto das tarefas de estratégia, Zahra \& Pearce (1990) evidenciaram que a experiência na indústria e nas operações da empresa elevou o envolvimento estratégico dos CAs analisados. De modo a desempenhar suas tarefas em estratégia, o CA deve conhecer a indústria, o cenário competitivo e as forças ambientais que podem interferir na estratégia da empresa (Coulson-Thomas, 1991). Para compreender as implicações mais importantes para o sucesso da IE, o CA deve possuir suficientes conhecimentos de aspectos tais como mudanças nas necessidades dos clientes, dinâmica competitiva e fontes de riscos de negócio (McGrath et al., 1995). Tão importante quanto o conhecimento externo é o entendimento da estratégia da empresa (Coulson-Thomas, 1991), das operações e das questões gerenciais internas (Forbes \& Milliken, 1999). Finalmente, os conselheiros devem possuir conhecimentos explícitos e tácitos das operações internas de modo a tomar decisões estratégicas coerentes (Nonaka, 1994; Nicholson \& Kiel, 2004; Huse, 2005; Drew \& Kaye, 2007). 


\subsection{4.}

\section{Dinâmica de trabalho do CA}

Forbes \& Milliken (1999) ressaltaram que o estoque de conhecimento existente no CA não necessariamente é ativado e utilizado. Para que isto aconteça, é necessário que exista no CA uma cultura orientada à produção em equipe, à tomada de decisão e ao desempenho dos seus processos de trabalho (Huse, 2007). Huse (2007) argumentou que as interações entre os conselheiros, e desses com a equipe executiva, podem influenciar a o desempenho do CA nas suas tarefas. No contexto da tarefa de monitoração da IE, define-se a Dinâmica de Trabalho do CA como o grau em que o CA apresenta práticas de trabalho orientadas à produção em equipe e à qualidade dos processos de análise e tomada de decisão.

Para que o CA atue decisivamente nas questões que podem causar desvios de IE, deve haver processos de trabalho robustos que assegurem que essas questões sejam identificadas, analisadas e endereçadas de forma oportuna e abrangente. O CA deve ter discussões aprofundadas para formar um entendimento suficiente das implicações de linhas de ação alternativas (Sellevoll et al., 2007). Dada a alta complexidade das questões de IE, o CA deve evitar a tomada de decisão com base em análises superficiais.

Apoiando-se em Jehn (1995), Forbes \& Milliken (1999) argumentaram que as discordâncias de opiniões no CA, ou conflitos cognitivos, favorecem a qualidade da sua dinâmica de trabalho. Discordâncias no CA podem conduzir a um enriquecimento das discussões de questões estratégicas (Forbes \& Milliken, 1999), levando a um aumento da capacidade de investigação crítica do CA. Um CA eficaz deve estimular a capacidade de cada conselheiro dizer o que pensa em um ambiente de abertura à diversidade de pontos de vista (Kakabadse \& Kakabadse, 2001; Huse et al., 2005). A disposição dos conselheiros em expressar suas preocupações estratégicas nas reuniões do CA foi considerada crítica para evitar a persistência estratégica em resposta ao baixo desempenho (Westphal \& Bednar, 2005).

Espera-se também que o CA questione ativamente o rumo estratégico da empresa e as causas para os desvios de IE. Conforme Davies (1999): 
Non-executive directors have a duty to be independent, challenging and watchful of personal agendas of their executive colleagues - they need to generate creative tension, not harmony, in board deliberations. (p. 73)

Questionar e desafiar as premissas e crenças dos demais conselheiros e dos executivos ajudará a combater o problema de groupthink (Coulson-Thomas, 1991; Forbes \& Milliken, 1999). Uma postura questionadora induzirá os conselheiros e os executivos à necessidade de justificar, refletir e possivelmente modificar suas posições em relação às questões estratégicas relevantes. Ao desafiar o status quo e discutir linhas de ação alternativas, o CA pode se beneficiar de múltiplos pontos de vista que poderão enriquecer o processo analítico e a tomada de decisão (Nadler, 2004; Huse, 2005).

\subsection{5. \\ Liderança do PCA}

O construto é definido operacionalmente como o grau em que o presidente do CA (PCA) possui atributos que favorecem a produção em equipe e a qualidade dos processos de análise e tomada de decisão do CA. Conforme Gabrielsson et al. (2007) argumentaram, o CA é o órgão decisor máximo da maioria das organizações, mas o PCA não está no topo de hierarquias decisórias como é o caso do CEO. Segundo os autores:

(...) the board chairperson is part of a team with equal colleagues. Board tasks are not performed only by the chairperson but shared with the entire group. This means that the board person, in many ways, has a greater challenge than the CEO in making things happen. (p. 24-25)

Sob a perspectiva de agência, a qualidade da liderança do PCA tenderia a depender principalmente deste não ser também o presidente executivo da empresa, uma característica estrutural (Jensen, 1993). Os pressupostos da TPE, por sua vez, reforçam a potencial influência de características comportamentais do PCA e da sua interação com o CA. Em linha com os argumentos de Leblanc (2005) e Gabrielsson et al. (2007), espera-se que o PCA influencie o desempenho do CA por meio da condução dos seus processos de trabalho e da indução de comportamentos colaborativos entre os conselheiros. 
Em termos da monitoração da IE, quatro dimensões desse papel do PCA parecem relevantes. A primeira delas é capacidade de otimizar a interação entre os membros do CA. Dado que o CA se reúne episodicamente, há uma tendência natural a que haja dificuldades de interação e cooperação entre os conselheiros (Forbes \& Milliken, 1999). Nessas circunstâncias, cabe ao PCA viabilizar a dinâmica de trabalho e a cultura de produção em equipe do CA. Ao atuar como facilitador da dinâmica de trabalho do CA, espera-se que o PCA motive os outros conselheiros a trabalhar em conjunto e a fazer contribuições relevantes em suas áreas de especialização (Sellevoll et al., 2007).

Uma segunda dimensão se refere ao efetivo uso do estoque de conhecimentos existente no CA. A análise do rumo da IE é uma tarefa analítica que requer um entendimento profundo da estratégia formulada e das barreiras internas e externas à sua execução. Para suplantar a inércia no uso dos conhecimentos complementares dos membros do CA, o PCA eficaz deve ser capaz de garantir a contribuição de cada um dos conselheiros para a análise dos desvios de IE (Sellevoll et al., 2007).

A terceira dimensão é relativa ao estabelecimento de uma cultura questionadora no CA (Gabrielsson et al., 2007), de modo a que os conselheiros possam tomar decisões que divirjam da opinião do CEO quando necessário. Sendo a monitoração da IE, em boa parte, uma tarefa de controle de decisões de alocações de recursos tomadas pela equipe executiva, cabe ao PCA incentivar os conselheiros a obter informações de várias fontes e a questionar construtivamente as informações prestadas pela diretoria ou por outros conselheiros.

Finalmente, espera-se que o PCA seja capaz de organizar os trabalhos do CA para que a monitoração da IE seja eficaz. Dois aspectos se destacam nesse sentido: o direcionamento da pauta do CA para as questões de alta importância estratégica da empresa e a facilitação ao acesso às informações relevantes (MacAvoy \& Millstein, 2003; Gabrielsson et al., 2007).

\subsection{6.}

\section{Atenção à monitoração da IE}

Define-se operacionalmente este construto como o grau em que o CA dedica atenção à tarefa de monitoração da IE. O envolvimento do CA na nessa tarefa 
pode não ser uniforme, uma vez que diversas outras tarefas e papéis disputam sua atenção (Huse \& Rindova, 2001) apesar das significativas limitações de tempo e de informações. A visão da empresa baseada em atenção, proposta por Ocasio (1997), sugere o CA deve dedicar atenção seletiva a algumas questões em detrimento de outras. Conforme observado por Tuggle et al. (2010),

The ABV suggests that board members' attention to monitoring represents an important antecedent to actual monitoring, yet the allocation of attention to monitoring is expected to vary based on contextual and structural factors. (p. 947)

Em uma extensão do argumento de Tuggle et al. (2010), postula-se que a Atenção à Monitoração da IE pode influenciar a Eficácia na Monitoração da IE. O tempo alocado pelo CA à tarefa de monitoração da IE é um potencial indicador do grau de atenção dedicado a ela. Além do tempo alocado durante as reuniões do CA, os conselheiros devem dedicar tempo substancial e suficiente para obter as informações relevantes e se preparar com antecedência para contribuir de forma efetiva na tarefa de monitoração da IE. Outros possíveis indicadores são a inclusão das questões de IE na pauta de trabalho do CA e a regularidade com que o CA avalia o rumo da IE (Sellevoll et al., 2007).

\subsection{7. \\ Desempenho empresarial passado}

O construto é definido como o grau em que o desempenho recente da empresa variou, positiva ou negativamente, em relação às expectativas. Supõe-se que o desempenho empresarial passado seja um preditor da atenção do CA à monitoração da IE com base na lógica de que um desempenho passado inferior às expectativas motivará o CA a exercer maior escrutínio sobre possíveis desvios em relação ao plano estratégico com o objetivo de acelerar ações corretivas.

Com base em considerações da teoria de prospecto (Kahneman \& Tversky, 1979), Tuggle et al. (2010) demonstraram que desvios negativos em relação ao desempenho passado aumentaram a alocação de atenção do CA às tarefas de monitoração. Vafeas (1999) encontrou resultados empíricos semelhantes. Por outro lado, Zahra \& Pearce (1990) não encontraram evidência de associação entre o desempenho passado da empresa e o envolvimento do CA em tarefas estratégicas. Os conselheiros podem se motivar a alocar mais atenção à 
monitoração da IE em um contexto de baixo desempenho para evitar possíveis riscos à sua reputação. Dado que o $\mathrm{CA}$ tem a responsabilidade fiduciária de monitorar e avaliar o desempenho dos executivos, os desvios em relação ao desempenho passado podem ser uma contingência relevante.

\subsection{8. Confiança no CEO}

A Confiança no CEO é definida como o grau de confiança que o CA detém na capacidade de o CEO tomar decisões seguras e independentes (Tacheva \& Huse, 2006). Um CEO confiável tenderá a ser percebido pelo CA como um agente diligente a serviço dos interesses do principal.

Estudos passados demonstraram que a confiança no CEO é importante para o desempenho do CA em suas tarefas de controle (Huse, 1993; Zhang, 2011). Supõe-se aqui que essa relação não se dê de forma direta. Uma vez que um envolvimento excessivo do CA na monitoração da IE pode criar conflitos de autoridade com o CEO (Mace, 1971; Lorsch \& MacIver, 1989), espera-se que os conselheiros dediquem menos atenção a essa tarefa quando o CEO for confiável. De modo inverso, se o relacionamento entre o CA e o CEO for de desconfiança, espera-se que o CA seja mais diligente na avaliação das decisões estratégicas e de alocação de recursos, dedicando mais atenção à monitoração da IE.

\subsection{9. \\ Textura causal do ambiente}

Tomando-se como base a contribuição teórica de Emery \& Trist (1965) sobre como as empresas e seus ambientes externos co-evoluem por meio de conexões mútuas, a Textura Causal do Ambiente é definida como o grau de turbulência ambiental e de incerteza que afeta o desenvolvimento estratégico da empresa.

Em um contexto de maior turbulência, espera-se que as respostas estratégicas da empresa tenham alta repercussão em seu campo social, contribuindo para co-produzir mais turbulência (Selsky, Goes \& Babüroglu, 2007). De modo a lidar com níveis mais altos de turbulência, espera-se que o grau de atenção do CA às decisões de IE aumente. Uma vez que as respostas 
estratégicas à turbulência podem ter conseqüências disfuncionais na empresa no campo social, espera-se que o CA revise as decisões estratégicas com maior ênfase e detalhe. Em linha com os argumentos de Emery \& Trist (1965), também se espera que o CA assuma um papel ativo em identificar e negociar bases comuns para respostas estratégicas coletivas no nível ambiental, visando estabilizar as regras de competição e reduzir a incerteza.

\subsubsection{0.}

\section{Normas de esforço}

Conforme desenvolvido na seções 2.1.1 e 2.1.3, as expectativas dos diferentes grupos de interesse quanto aos papéis que o CA deve desempenhar têm mudado ao longo do tempo. Essas expectativas podem ou não estar refletidas na literatura normativa, porém influenciam o trabalho do CA. Com base nos argumentos teóricos de Wageman (1995) e Forbes \& Milliken (1999), define-se Normas de Esforço como as crenças compartilhadas sobre o grau de esforço que o CA deve dedicar à tarefa de monitoração da IE. No âmbito deste estudo, tais normas podem ser formais ou informais e incluem expectativas (internas e externas ao CA) quanto à: (i) importância relativa da tarefa de monitoração da IE em relação a outras; (ii) disponibilidade e uso do tempo do CA; e (iii) qualidade da sua contribuição à IE.

Forbes \& Milliken (1999) sugeriram que as Normas de Esforço podem influenciar diretamente a eficácia do CA, sob o argumento de que uma maior intensidade dessas normas conduzem a uma maior participação e contribuição. Em linha com Huse (2005) e Huse et al. (2005), supõe-se aqui que essa influência não seja direta. Com base na lógica da visão baseada em atenção desenvolvida por Tuggle et al. (2010), é esperado que o efeito das Normas de Esforço sobre a Eficácia na Monitoração da IE seja mediada pela Atenção à Monitoração da IE. Conforme esse argumento, normas de esforço mais intensas para a tarefa de asseguramento da IE farão com que o CA dedique mais atenção à tarefa, o que por sua vez influenciará a eficácia do CA. 


\subsubsection{1.}

\section{Normas de responsabilidade}

Ao passo que as Normas de Esforço refletem a importância relativa atribuída à tarefa de gestão da IE, propõe-se aqui uma distinção conceitual. Normas de Responsabilidade são definidas como o grau em que se entende que o CA deva intervir na monitoração da IE.

Conforme discutido anteriormente, as expectativas quanto ao papel do CA na monitoração da IE não são consensuais na literatura - e possivelmente também não o são na prática gerencial. Assim, é possível que alguns CAs não percebam a tarefa de monitoração da IE como uma atribuição pertinente, na visão de que esse papel cabe aos executivos.

Com base nos argumentos de Huse et al. (2005), sugere-se que as Normas de Responsabilidade podem incluir expectativas quanto à aplicabilidade, autoridade e responsabilidade do CA para avaliar e tomar decisões de IE. Em um raciocínio análogo às Normas de Esforço, e em linha com os argumentos de Tuggle et al. (2010), supõe-se que as Normas de Responsabilidade influenciarão positivamente a Atenção à Monitoração da IE.

Em suma, a análise do referencial teórico indicou que a natureza e o alcance da atuação dos CAs na monitoração estratégica ainda não estão claramente estabelecidos na literatura, devido à carência de estudos sobre o tema e a uma insuficiente fundamentação teórica. Nesse sentido, propôs-se aqui uma reconceituação do papel do CA nessa tarefa, com base na TPE e em perspectivas de processo estratégico.

Verificou-se também que os principais modelos gerais de eficácia de CAs não são capazes de fornecer uma explicação específica e parcimoniosa para os antecedentes de eficácia na tarefa de monitoração da IE. Adicionalmente, constatou-se que não há na literatura modelos que tenham sido desenvolvidos para esse fim em particular. Logo, tomando como ponto de partida os modelos gerais de eficácia de CAs aqui analisados, desenvolveu-se um modelo conceitual preliminar de eficácia de CAs na monitoração da IE que incluiu construtos nas dimensões comportamental, contextual e normativa. Esse modelo preliminar será delimitado e testado nos capítulos a seguir. 


\section{3 Pesquisa de campo com conselheiros de administração}

Conforme já discutido, deseja-se aqui desenvolver uma explicação válida e ao mesmo tempo parcimoniosa para a eficácia dos CAs na monitoração da IE. No entanto, identificou-se que ainda não há na literatura uma base de conhecimento suficientemente coesa sobre esse fenômeno em particular. Além disso, é necessário reduzir a quantidade de construtos do modelo conceitual preliminar desenvolvido no capítulo anterior para que se atinja uma delimitação testável por métodos multivariados.

Logo, visando enriquecer os achados da revisão de literatura e, ao mesmo tempo, obter subsídios para priorizar os construtos de maior relevância, conduziuse uma pesquisa de campo qualitativa com conselheiros de administração. Tratase da primeira etapa do método de pesquisa adotado neste estudo.

Essa etapa consistiu de entrevistas semi-estruturadas com conselheiros de administração com grande experiência em eficácia de CAs. O objetivo das entrevistas foi de coletar percepções sobre quais fatores influenciam mais intensamente a eficácia de um CA na tarefa de monitoração estratégica, e de que formas essa influência pode se manifestar.

Com base nos resultados dessa etapa, proceder-se-á ao desenvolvimento do modelo conceitual final e à formulação das hipóteses de pesquisa a serem testadas posteriormente (capítulo 4).

\section{1.}

\section{Unidade de análise e sujeitos da pesquisa}

A unidade de análise é o CA. Os sujeitos da pesquisa foram selecionados por conveniência dentre indivíduos com mais de quinze anos de experiência como conselheiros de administração de empresas listadas em bolsas de valores. Foram entrevistados dez sujeitos, dos quais oito são homens e duas são mulheres. Sete dos dez entrevistados atuam majoritariamente em CAs de empresas brasileiras; dois, em empresas portuguesas; e um, em empresas inglesas. 


\section{2. \\ Procedimentos de coleta de dados}

As entrevistas foram realizadas entre Agosto de 2011 e Março de 2012, quando foram concluídas pelo critério de saturação teórica. As entrevistas tiveram uma duração média de 70 minutos e foram conduzidas por este pesquisador. As entrevistas foram gravadas e transcritas.

Quanto ao roteiro, as entrevistas foram iniciadas com um breve relato do pesquisador acerca do problema geral da pesquisa e da motivação para o estudo. Para assegurar a confidencialidade, os entrevistados foram informados de que nem eles nem as empresas mencionadas seriam identificados nos resultados da pesquisa. Em seguida, foi formulada uma única pergunta aberta aos entrevistados: "Com base na sua experiência, quais são os principais fatores que influenciam a eficácia de um CA na monitoração da IE, e por quê são importantes?” De modo a não influenciar as respostas, permitiu-se que os entrevistados respondessem livremente à pergunta formulada. Quando necessário, foi solicitado aos entrevistados que elaborassem mais sobre alguns dos fatores espontaneamente mencionados em resposta à pergunta inicial.

Os sujeitos da pesquisa serão identificados por uma notação numérica (isto é, de Entrevistado 1 a Entrevistado 10).

\section{3. \\ Limitações do método}

Reconhece-se aqui que as informações coletadas por meio de questões abertas e entrevistas estão sujeitas à subjetividade, devido a fatores como compreensão pelo respondente do que foi perguntado, sua capacidade ou grau de interesse em contribuir, suas perspectivas pessoais, possíveis incorreções na captura e transcrição das respostas e interpretação que o pesquisador fará do que foi respondido. Adicionalmente, o alto grau de sensibilidade e sigilo das questões de funcionamento dos CAs poderia acarretar desinteresse dos entrevistados em responder ou incidência de respostas falsas.

Para reduzir as limitações de captura e interpretação das respostas, procedeu-se à gravação de todas as entrevistas. Este pesquisador conduziu 
pessoalmente todas as entrevistas para assegurar consistência com o roteiro planejado, a correta comunicação do que foi perguntado, o aprofundamento em questões-chave e desdobramentos que surgissem no decorrer das entrevistas e a posterior interpretação das respostas. Quanto às perspectivas pessoais dos respondentes, pode-se considerar que são válidas no contexto do objetivo desta pesquisa, uma vez que tais perspectivas cumprem um papel importante na tomada de decisão estratégica.

A escolha por conveniência de dez sujeitos com grande experiência nas questões da pesquisa não permite que os resultados desta etapa sejam generalizados. No entanto, a natureza desta etapa da pesquisa é exploratória. Uma vez que o seu objetivo é gerar subsídios para refinamento do modelo conceitual preliminar, e não a validade externa dos resultados, considera-se que essa impossibilidade de generalização dos achados não é uma questão crucial.

Finalmente, espera-se que o emprego de um método de pesquisa baseado em duas etapas contribua para reduzir as limitações inerentes ao uso de métodos isolados e para a validade dos resultados.

\section{4 .}

\section{Análise de resultados}

A seguir apresentam-se os construtos mais consistentemente mencionados pelos entrevistados como relevantes para a eficácia dos CAs na tarefa de monitoração da IE. Não houve menções relevantes de outros construtos.

\subsection{1.}

\section{Acesso a informações}

A importância do Acesso a Informações pelo CA foi ressaltada por oito dos dez entrevistados, em função do pouco tempo que o conselheiro tipicamente dedica ao $\mathrm{CA}$ e do seu distanciamento em relação à operação da empresa. $\mathrm{O}$ aspecto mais saliente é a necessidade de que o CA defina as informações relevantes de acompanhamento da IE que deverá monitorar. O ponto fundamental neste sentido é contrariar a tendência natural de ser da diretoria executiva a responsabilidade por configurar as informações que o CA utiliza. Conforme o Entrevistado 9, "deve haver um fluxo informativo, definido pelo CA, para que a 
diretoria discuta a evolução da estratégia da empresa com o CA”. Segundo o Entrevistado 8,

Uma vez aprovada a estratégia no CA, não se discute como o CA acompanhará sua execução. (...) O CA deve definir, dados os pilares da estratégia e suas frentes de desdobramento, quais os eventos-chave e indicadores que deverão ser monitorados para verificar que a execução esteja acontecendo conforme planejado. (...) A partir deste ponto, deve construir uma agenda para acompanhar a IE.

Alguns dos entrevistados ressaltaram a importância do direito à informação, que se traduz no livre acesso a todos os níveis da organização para obter as informações necessárias. Conforme mencionado pelo Entrevistado 9,

\begin{abstract}
Desafiar as decisões estratégicas da diretoria executiva é difícil porque a informação é esmagadoramente manipulada (pela diretoria executiva). Devido à premência das decisões estratégicas, é lógico que a diretoria executiva resista a partilhar informações com o CA. Logo, o CA anda à procura de informação.
\end{abstract}

Conforme o Entrevistado 7,

Tenho a sorte de participar de CAs onde o CEO não me impede de falar diretamente com quem quer que seja se eu preciso de uma informação. A regra é perguntar, ouvir as respostas e não dar opiniões exceto nas reuniões do CA. Se não fosse assim, eu não participaria deste CA.

A existência de comitês do CA que atuem como mecanismos de facilitação do acesso a informações também foi mencionada. Seu papel foi assim descrito pelo Entrevistado 9:

De modo geral as empresas ou dão informação demasiada ao CA, ou quase nenhuma. Os comitês, ao interagirem diretamente com os executivos, conseguem acessar as informações de que o CA necessita. Um comitê eficiente ajuda o CA a fazer a seleção das informações relevantes. (...) A estrutura intermediária tem que ser responsabilizada por explicar aos comitês por que as decisões estão sendo tomadas. Isto permite que os comitês detectem possíveis inconsistências, e que se criem pontos de controle entre o CA e a diretoria executiva.

Outros pontos ressaltados pelos entrevistados foram o recebimento de informações com antecedência suficiente, a existência de interações com a empresa além das reuniões do CA e o acesso a informações não financeiras. 


\subsection{2.}

\section{Conhecimento do negócio}

A importância do Conhecimento do Negócio como um fator de eficácia de um CA na monitoração da IE foi corroborada por sete dos dez entrevistados. Conforme ressaltado pelo Entrevistado 7, não é imperativo que o conselheiro tenha experiência prévia no setor em que a empresa atua, pois isto pode enviesar seu processo analítico em favor de soluções que funcionaram no passado mas que não necessariamente funcionarão em outro contexto. Parece ser mais importante, segundo os entrevistados, que o CA primeiramente conheça a agenda estratégica da empresa. Não necessariamente o CA liderará a formulação estratégica, e em algumas circunstâncias é possível que alguns conselheiros sequer a tenham aprovado. No entanto, espera-se que os conselheiros saibam articular a racional estratégica e de criação de valor da empresa. A esse respeito, o Entrevistado 6 mencionou:

\footnotetext{
Um nível de atuação do CA é atuar em decisões estratégicas. Outro é dialogar entre si e com a diretoria executiva sobre uma agenda estratégica: articulação das partes, priorização das ações. Isto é fundamental para que o CA possa navegar na altitude em que navega. Ë muito difícil para o conselheiro exercer um papel crítico se ele não enxerga o todo. Uma parte pode ser excelente, mas pode carecer de vínculo ou coerência com as restantes, bem como de senso de prioridade e urgência. Logo, o CA tem que conhecer e compreender a articulação da agenda estratégica da empresa.
}

Alguns dos entrevistados ressaltaram a importância de que os conselheiros participem de atividades de treinamento e educação no negócio da empresa. A discussão do rumo estratégico pressupõe a compreensão das fontes externas e internas de vantagem competitiva. Os conselheiros, principalmente aqueles que não participaram do desenvolvimento histórico do negócio, precisam ser capacitados para que possam compreender profundamente o modelo de negócio. A capacidade de argumentação e contribuição de um conselheiro pode ser reduzida se não houver um alto grau de conhecimento do negócio, particularmente em empresas de maior complexidade. Conforme os Entrevistados 6, 7 e 8 ressaltaram, algumas empresas têm adotado programas de preparação do conselheiro nos conteúdos específicos da empresa e dos setores em que atua (alguns exemplos citados incluem programas de imersão de novos conselheiros, 
seminários de tendências setoriais, sessões dedicadas ao desenvolvimento estratégico e ao conhecimento da diretoria executiva e de capacitações internas).

\subsection{3.}

\section{Dinâmica de trabalho do CA}

Segundo sete dos dez entrevistados, o engajamento do CA na monitoração da IE requer uma dinâmica interna de trabalho que o favoreça. $\mathrm{O}$ ponto mais freqüentemente mencionado pelos entrevistados foi a capacidade de discutir os problemas com a diretoria executiva de forma aberta. A diretoria executiva é a responsável primária pela IE. No âmbito da tarefa de monitoração da IE, cabe ao CA implantar formas de interação com a diretoria executiva que por um lado viabilizem a cobrança dos objetivos de IE estabelecidos, e por outro propiciem uma discussão aberta e objetiva dos desvios. Este tipo de interação pressupõe que haja uma relação de confiança entre o CA e a diretoria executiva, para evitar que essa retenha informações sobre o real rumo da IE.

Outro ponto freqüentemente mencionado foi a existência de uma atitude questionadora no CA quanto ao rumo da IE. O Entrevistado 3 ressaltou que o CA deve ter a "capacidade de desafiar, questionar e testar a diretoria" com o objetivo de, conforme o Entrevistado 4, "entender se há algum viés, o que está por trás dos desvios, se as explicações são legítimas." É importante, segundo o Entrevistado 1, “(...) que o CA se imponha, que não se sinta intimidado pelo $\mathrm{CEO}$ ou pelos representantes do acionista controlador, que assuma seu dever para com o sucesso da empresa".

Uma boa dinâmica de trabalho no CA também pressupõe que haja liberdade para fazer perguntas, questionar-se o que não se entende e manifestar opiniões livremente. Segundo o Entrevistado 2, "é importante que os conselheiros estejam à vontade para perguntar o que quiserem, para pedir mais informação; porém, isto nem sempre acontece." Um exemplo citado pelo Entrevistado 4 foi o recente episódio, noticiado publicamente, de destruição de valor da Sadia S/A, provocado por uma exposição excessiva a derivativos financeiros de alta complexidade sem que o CA fosse capaz de solicitar informações suficientes para compreender os riscos envolvidos. 
$\mathrm{O}$ aspecto de conflito cognitivo também foi mencionado, ainda que com menor freqüência. Uma contribuição neste sentido foi dada pelo Entrevistado 6:

O equilíbrio de vozes e o dissenso no CA geram uma discussão estratégica mais rica. O processo de seleção de conselheiros deve buscar pessoas que facilitem a dinâmica interpessoal nesse sentido. Pessoas excelentes em discussões um a um podem ser péssimas em discussões em grupo. Ë um ponto sutil mas poderoso para o bom desempenho do CA. Também é importante para a qualidade do diálogo com os executivos. À falta disso, os executivos acabam dominando ante o silêncio e a inconclusão do CA.

\subsection{4.}

\section{Liderança do presidente do CA}

O papel do PCA na condução da dinâmica de trabalho do CA foi ressaltado por cinco entrevistados. A característica do PCA mais freqüentemente citada como desejável para o seu bom desempenho foi o estímulo à participação e à contribuição dos conselheiros. Segundo o Entrevistado 6, um bom PCA "reúne e estimula o uso do talento existente no CA." O Entrevistado 9, de forma semelhante, qualificou o PCA como um "catalisador das contribuições dos conselheiros", sendo esta a sua tarefa mais importante. Conforme o Entrevistado 8 ,

O PCA é uma liderança importante no sentido de fazer com que a dinâmica seja adequada do ponto de vista dos questionamentos e contribuições dos vários conselheiros. O PCA tem um papel semelhante ao de um maestro ao fazer com que as contribuições dos participantes venham na forma, momento e intensidade adequados. No entanto, freqüentemente o PCA atua mais como um mantenedor da agenda do CA do que como um provocador dessas intervenções.

Espera-se também que o PCA estimule a postura questionadora do CA. Segundo o Entrevistado 4, "trata-se do elemento mais forte no CA, com capacidade de puxar a discussão, (...) contrapor a diretoria, (...) quebrar o ambiente de ação entre amigos." Conforme o Entrevistado 2,

O PCA pode fomentar o questionamento à diretoria ou pode tentar matá-lo. Os conselheiros sentirão mais ou menos graus de liberdade para intervir em função do papel que o PCA os deixe ter.

A tarefa de conduzir a pauta do CA também foi enfatizada, em três vertentes: (i) direcioná-la para as questões importantes de IE; (ii) promover 
discussões profundas e conclusivas sobre o rumo da IE; e (iii) facilitar o acesso do CA às informações relevantes.

\subsection{5.}

\section{Atenção à monitoração da IE}

Apesar dos vários depoimentos coletados em favor da intervenção do CA no processo de monitoração da IE, alguns entrevistados corroboraram a visão de que a atenção ao tema não é uniforme. Há pouco tempo disponível no CA, e nem sempre o debate das questões estratégicas da empresa é aprofundado. Segundo o Entrevistado 8, CAs ineficazes tendem a dedicar tempo demais no desempenho financeiro de curto prazo, em conflitos horizontais de governança e em controles internos, em detrimento de questões de médio e longo prazo que impactam a criação de valor. Conforme o Entrevistado 3, nem sempre há uma monitoração sistemática dos pilares das estratégias de negócio.

Dois dos entrevistados especificamente relataram que a tarefa não é de alta importância para um CA: (i) por ser de atribuição primária da diretoria executiva (Entrevistado 3); (ii) por ser um tema fragmentado e de difícil acompanhamento pelo CA (Entrevistados 2 e 3).

Em suma, os resultados da pesquisa de campo com conselheiros de administração sugeriram a importância da dimensão comportamental dos antecedentes de eficácia de um CA na monitoração da IE. As observações dos entrevistados se concentraram nos construtos comportamentais antecipados na revisão da literatura. No que tange aos construtos das dimensões contingencial e normativa, não foram observadas menções relevantes. Alguma sugestão a eles foi observada indiretamente nos comentários sobre os diferentes graus de atenção que os CAs dedicam à tarefa de monitoração da IE. 


\section{4 Modelo conceitual}

Neste capítulo, delimita-se o modelo conceitual da pesquisa com base nos resultados da revisão da literatura e da pesquisa qualitativa com conselheiros de administração.

O objetivo da formulação deste modelo é produzir uma possível explicação mais parcimoniosa para a eficácia dos CAs na monitoração da IE. Ao reduzir-se a quantidade de construtos do modelo preliminar desenvolvido na seção 2.3, desejase obter uma ferramenta de análise que seja: (i) mais facilmente testável por meio de métodos multivariados; e (ii) mais útil para a prática gerencial.

São apresentados a seguir os construtos incluídos no modelo conceitual final, bem como as hipóteses de ligação entre eles.

\section{1. \\ Construtos}

Os resultados da pesquisa de campo com conselheiros de administração corroboraram a suposição, desenvolvida no modelo conceitual preliminar com o suporte da Teoria de Produção em Equipe, de que a dimensão comportamental de atuação do CA influencia sua eficácia na monitoração da IE.

$\mathrm{Na}$ percepção dos entrevistados, cinco construtos podem exercer maior influência na eficácia de um CA na monitoração estratégica: o Acesso a Informações, o Conhecimento do Negócio, a Dinâmica de Trabalho do CA, a Liderança do Presidente do CA e a Atenção à Monitoração da IE. Pouco ou nenhum suporte empírico foi obtido para as dimensões contextuais e normativas previstas no modelo conceitual preliminar. Os resultados sugerem que esses cinco construtos podem fornecer uma explicação mais simples e parcimoniosa para a eficácia de um CA na tarefa de monitoração da IE.

Com base na análise do referencial teórico e nos resultados das entrevistas, desenvolveu-se um modelo conceitual simplificado, ilustrado na Figura 5. 


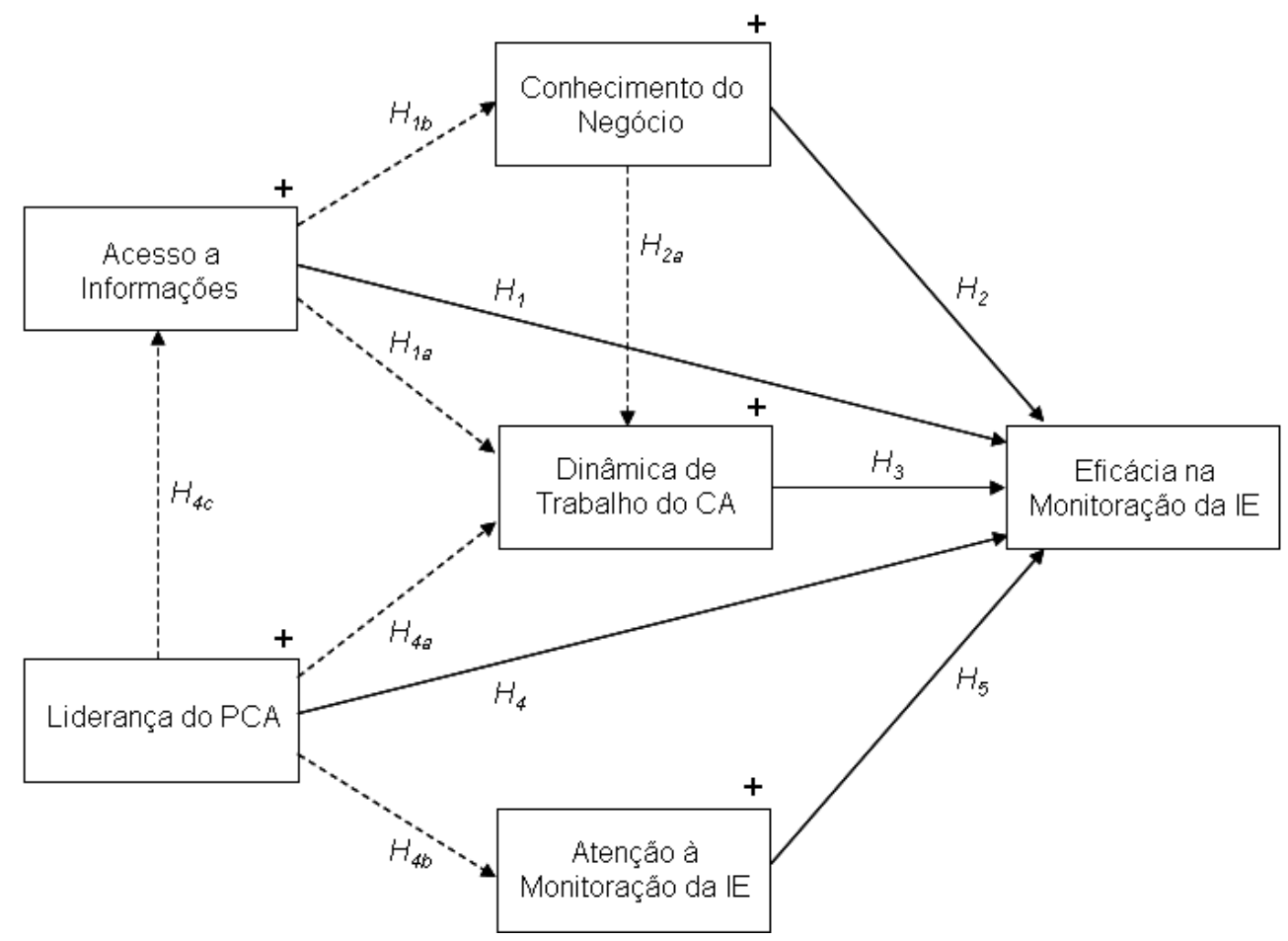

Figura 5 - Modelo conceitual simplificado e hipóteses de relações entre fatores não estruturais de eficácia de CAs na monitoração da IE

Propõe-se aqui que os construtos do modelo conceitual podem estar relacionados de diferentes formas. A primeira delas, mais simples, prevê relações diretas entre os cinco construtos explicativos e a Eficácia na Monitoração da IE (representadas na Figura 5 por conectores sólidos). O sentido esperado da influência dos construtos está indicado ao lado de cada um.

Alternativamente, supõe-se que possa haver relações mediadas entre eles. Essas ligações estão representadas na Figura 5 por conectores pontilhados. Conforme os pressupostos da visão da empresa baseada em conhecimento (Nonaka, 1994; Grant, 1996), pode-se conceituar o desenvolvimento da capacitação de monitoração estratégica no CA como um processo de acumulação e aplicação de conhecimentos relevantes. Segundo essa lógica de aprendizagem (Kale \& Singh, 2007), o processo de monitoração estratégica no CA pode envolver uma seqüência de atividades relacionadas: (i) o acesso às fontes de informação relevantes; (ii) a articulação do conhecimento disponível no CA e ao redor do CA; (iii) o compartilhamento do conhecimento, por meio de interações interpessoais e processos de análise e tomada de decisão no CA; e (iv) a 
internalização do conhecimento, por meio de ações para facilitar a absorção das decisões estratégicas tomadas no CA pelos executivos responsáveis pela IE.

Com base nesses argumentos, foram formuladas hipóteses prevendo relações diretas e mediadas entre os construtos. Elas estão indicadas graficamente na Figura 5 e serão descritas na próxima seção.

\section{2.}

\section{Hipóteses}

Nesta seção são apresentadas as hipóteses de relações entre os construtos do modelo conceitual.

\subsection{1. \\ Influência do acesso a informações}

Conforme desenvolvido no referencial teórico (seção 2.3.2) e na análise das entrevistas (seção 3.4.1), o Acesso a Informações pode ter influência direta e positiva sobre a Eficácia na Monitoração da IE. Logo, formula-se a seguinte hipótese:

\section{$H_{1}$ : $\quad$ O Acesso a Informações está positivamente relacionado à Eficácia na Monitoração da IE.}

Alternativamente, a análise do referencial teórico indicou que a influência do Acesso a Informações pode não ser direta, mas mediada pela Dinâmica de Trabalho do CA. Zahra (1990) sugeriu que um bom nível de acesso a informações pode elevar a qualidade da participação dos conselheiros nas discussões -- um elemento de dinâmica coletiva de trabalho que antecede a eficácia na tarefa de monitoração estratégica. Assim, formula-se a seguinte hipótese concorrente:

$H_{1 a}: \quad O$ Acesso a Informações está positivamente relacionado à Dinâmica de Trabalho do CA.

As perspectivas de conhecimento e aprendizagem sugerem que o Acesso a Informações pode influenciar o Conhecimento do Negócio. Conforme sugerido 
nas entrevistas de profundidade, o conselheiro atua a grande distância das fontes de informação da empresa e tem o seu desempenho potencialmente restringido pela falta de informações. Há poucas instâncias de interação com a empresa além das reuniões do CA. Logo, as informações obtidas fora das reuniões do CA, e mesmo nelas, podem contribuir para que o conselheiro conheça melhor a evolução de indicadores de desempenho e o andamento das iniciativas estratégicas da empresa. São necessários canais eficazes de acesso à informação para que o CA adquira os conhecimentos explícitos e tácitos do real funcionamento da empresa (Nonaka, 1994). Portanto, com base nesses argumentos, propõe-se alternativamente que:

\section{$H_{1 b}$ : $\quad O$ Acesso a Informações está positivamente relacionado ao Conhecimento do Negócio.}

\subsection{2. \\ Influência do conhecimento do negócio}

O modelo geral de Zahra e Pearce (1989), ilustrado na Figura 1, sugere que CAs com maiores níveis de conhecimentos podem ser mais eficazes no desempenho de suas tarefas. A revisão da literatura (seção 2.3.3) e os resultados das entrevistas com conselheiros (seção 3.4.2) sugerem a existência de uma ligação direta e positiva entre o Conhecimento do Negócio e a Eficácia na Monitoração da IE. Logo, desenvolveu-se a seguinte hipótese:

\section{$\mathrm{H}_{2}$ : $\quad \mathrm{O}$ Conhecimento do Negócio está positivamente relacionado à Eficácia na Monitoração da IE.}

Há indicações na literatura de que a relação entre o Conhecimento do Negócio e a Eficácia na Monitoração da IE pode ser mediada pela Dinâmica de Trabalho do CA. A perspectiva de aprendizagem sugere que as interações no CA envolvem a articulação e o compartilhamento do conhecimento coletivo do CA. Forbes \& Milliken (1999) observaram que a simples presença de conhecimentos no CA não significa que eles serão efetivamente usados em benefício da dinâmica de trabalho do CA. Huse (2005) propôs que as competências dos conselheiros 
podem estar relacionadas com a cultura interna de tomada de decisão do CA. Conforme Brauer \& Schmidt (2008), CAs com um alto nível de conhecimentos estão mais bem preparados para oferecer uma visão complementar à do CEO na discussão de falhas de IE. Owen (2003) argumentou que os CAs que não entendem a estratégia da empresa não são capazes de fazer as perguntas certas para assegurar que a estratégia está sendo adequadamente executada, nem de avaliar as respostas recebidas. Logo, sua contribuição para a dinâmica de trabalho do CA é limitada. Com base nesses argumentos, formula-se a seguinte hipótese concorrente:

$H_{2 a}: \quad O$ Conhecimento do Negócio está positivamente relacionado à Dinâmica de Trabalho do CA.

\subsection{3. Influência da dinâmica de trabalho do CA}

A importância da Dinâmica de Trabalho do CA para a Eficácia na Monitoração da IE emerge da análise da literatura (seção 2.3.4). Os principais modelos gerais de eficácia de CAs previram ligações diretas e positivas entre a qualidade das interações e processos de trabalho do CA e o seu desempenho de tarefas (Zahra \& Pearce, 1989; Forbes \& Milliken, 1999; Huse, 2005). As percepções dos conselheiros entrevistados, sumariadas na seção 3.4.3, reforçam a visão de que uma dinâmica de questionamento e abertura nas interações no CA e com os executivos favorece o asseguramento do rumo da IE. Portanto, com o suporte da TPE propõe-se que:

\section{$H_{3}$ : $\quad$ A Dinâmica de Trabalho do CA está positivamente relacionada à Eficácia na Monitoração da IE.}

\subsection{4.}

\section{Influência da liderança do presidente do CA}

Os achados da revisão da literatura (seção 2.3.5) e da pesquisa de campo com conselheiros (seção 3.4.4) sugerem que a Liderança do PCA pode influenciar 
a Eficácia na Monitoração da IE de diferentes formas. A primeira delas é direta, conforme a seguinte hipótese de pesquisa:

H4: $\quad$ A Liderança do Presidente do CA está positivamente relacionada à Eficácia na Monitoração da IE.

No entanto, há várias indicações da existência de possíveis efeitos indiretos. Conforme alguns dos conselheiros entrevistados, o PCA desempenha um papel importante de coordenação dos trabalhos do CA e da interação entre os conselheiros. Outros aspectos destacados por eles foram o estímulo ao efetivo uso dos conhecimentos e à postura questionadora no $\mathrm{CA}$, em linha com o sugerido por Gabrielsson et al. (2007) e Sellevoll et al. (2007). Espera-se que o PCA estimule a produção em equipe no CA preconizada pela TPE. Logo, formula-se a seguinte hipótese concorrente:

$H_{4 a}$ : $\quad$ A Liderança do Presidente do CA está positivamente relacionada à Dinâmica de Trabalho do CA.

Outro importante papel atribuído ao PCA é de direcionamento e priorização dos trabalhos do CA. Dado que diversos temas competem pela atenção do CA (Tuggle et al., 2010), espera-se que o PCA assegure a inclusão regular da monitoração da IE na sua pauta de trabalho (Gabrielsson et al., 2007). Assim, propõe-se que:

\section{$H_{4 b}: \quad$ A Liderança do Presidente do CA está positivamente relacionada à Atenção à Monitoração da IE.}

Finalmente, espera-se também que o PCA facilite o acesso às informações relevantes para que o CA monitore a IE (Sison \& Kleiner, 2001; MacAvoy \& Millstein, 2003). A importância deste papel complementar foi especificamente 
reconhecida por alguns dos conselheiros entrevistados. Logo, formula-se a seguinte hipótese:

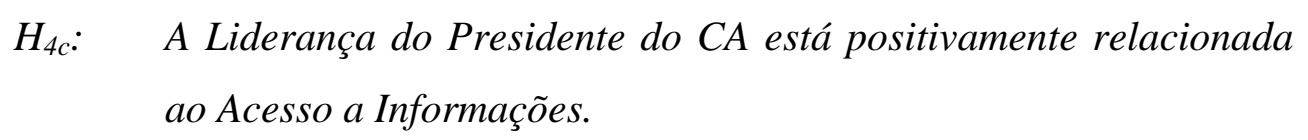

\subsection{5.}

\section{Influência da atenção à monitoração da IE}

Alguns dos conselheiros de administração entrevistados (seção 3.4.5) indicaram que alguns CAs não desempenham eficazmente a tarefa de monitoração da IE porque não dedicam atenção suficiente a ela. Esse achado é consistente com o referencial teórico desenvolvido na seção 2.3.6, segundo o qual o grau de Atenção à Monitoração da IE pode influenciar a Eficácia na Monitoração da IE (Tuggle et al., 2010). Assim, com base nos resultados da revisão de literatura e das entrevistas com conselheiros propõe-se que:

$H_{5}$ : $\quad$ A Atenção à Monitoração da IE está positivamente relacionada à Eficácia na Monitoração da IE.

Em suma, têm-se quatro conjuntos alternativos de hipóteses de ligação entre os construtos. Eles estão sumariados na Tabela 1. Esses conjuntos representam diferentes especificações do modelo conceitual final que serão testadas empiricamente. O capítulo 5 descreverá os procedimentos metodológicos adotados para tal. 
Tabela 1 - Conjuntos alternativos de hipóteses de ligação entre os construtos da pesquisa

\begin{tabular}{|c|c|c|c|c|c|}
\hline & \multirow{2}{*}{ Hipóteses } & \multicolumn{4}{|c|}{ Conjuntos alternativos } \\
\hline & & 1 & 2 & 3 & 4 \\
\hline$H_{1}:$ & $\begin{array}{l}\text { O Acesso a Informações está positivamente } \\
\text { relacionado à Eficácia na Monitoração da IE. }\end{array}$ & 0 & & & \\
\hline$H_{1 \mathrm{a}}:$ & $\begin{array}{l}\text { O Acesso a Informações está positivamente } \\
\text { relacionado à Dinâmica de Trabalho do CA. }\end{array}$ & & 0 & J & \\
\hline$H_{1 \mathrm{~b}}:$ & $\begin{array}{l}\text { O Acesso a Informações está positivamente } \\
\text { relacionado ao Conhecimento do Negócio. }\end{array}$ & & & & 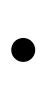 \\
\hline$H_{2}:$ & $\begin{array}{l}\text { O Conhecimento do Negócio está positivamente } \\
\text { relacionado à Eficácia na Monitoração da IE. }\end{array}$ & 0 & & & \\
\hline$H_{2 \mathrm{a}}:$ & $\begin{array}{l}\text { O Conhecimento do Negócio está positivamente } \\
\text { relacionado à Dinâmica de Trabalho do CA. }\end{array}$ & & 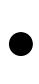 & & 0 \\
\hline$H_{3}:$ & $\begin{array}{l}\text { A Dinâmica de Trabalho do CA está } \\
\text { positivamente relacionada à Eficácia na } \\
\text { Monitoração da IE. }\end{array}$ & 0 & ) & & 0 \\
\hline$H_{4}:$ & $\begin{array}{l}\text { A Liderança do Presidente do CA está } \\
\text { positivamente relacionada à Eficácia na } \\
\text { Monitoração da IE. }\end{array}$ & 0 & & & \\
\hline$H_{4 a}:$ & $\begin{array}{l}\text { A Liderança do Presidente do CA está } \\
\text { positivamente relacionada à Dinâmica de } \\
\text { Trabalho do CA. }\end{array}$ & & D & D & 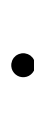 \\
\hline$H_{4 \mathrm{~b}}:$ & $\begin{array}{l}\text { A Liderança do Presidente do CA está } \\
\text { positivamente relacionada à Atenção à } \\
\text { Monitoração da IE. }\end{array}$ & & & & \\
\hline$H_{4 c}:$ & $\begin{array}{l}\text { A Liderança do Presidente do CA está } \\
\text { positivamente relacionada ao Acesso a } \\
\text { Informações. }\end{array}$ & & & & \\
\hline$H_{5}:$ & $\begin{array}{l}\text { A Atenção à Monitoração da IE está } \\
\text { positivamente relacionada à Eficácia na } \\
\text { Monitoração da IE. }\end{array}$ & & & & \\
\hline
\end{tabular}




\section{5 Procedimentos metodológicos para teste do modelo conceitual}

Este capítulo descreve os procedimentos adotados para testar a validade do modelo conceitual e as hipóteses desenvolvidas no capítulo 4 .

Trata-se da segunda etapa do método de pesquisa definido para este estudo. A primeira, qualitativa, consistiu de uma pesquisa de campo exploratória com conselheiros de administração, descrita no capítulo 3 .

Nessa segunda etapa, cujos procedimentos são aqui detalhados, foi realizada uma survey com conselheiros de administração de empresas brasileiras para coletar dados perceptuais sobre a incidência e intensidade das variáveis observáveis selecionadas. Os dados coletados foram analisados pelo método multivariado de equações estruturais.

A seguir, serão descritos: (i) a unidade de análise, população e amostra da pesquisa; (ii) os procedimentos para operacionalização das variáveis; (iii) os procedimentos para coleta, tratamento e análise dos dados; e (iii) as limitações do método empregado nessa etapa.

\section{1. Unidade de análise, população e amostra}

Este projeto de pesquisa foi desenvolvido para compreender e explorar a natureza das relações entre fatores não estruturais antecedentes e a eficácia de um CA na tarefa de monitoração da IE. Logo, a sua unidade de análise é o CA.

Conforme desenvolvido no capítulo 1, existem poucos estudos que capturem percepções dos próprios conselheiros de administração. Há reconhecidas dificuldades práticas de acesso a respondentes com essa qualificação, que dificultam a obtenção de amostras representativas. Por outro lado, considera-se fundamental coletar as percepções dos próprios conselheiros sobre o real funcionamento do CA (Stiles, 2001). 
Portanto, decidiu-se ampliar ao máximo possível a população desta etapa do estudo, sujeito às seguintes restrições: (i) os respondentes devem ocupar, ou ter ocupado, o cargo de conselheiro de administração titular, excluindo-se os ocupantes de cargos suplentes ou de conselheiro fiscal; e (ii) as empresas devem ser sediadas no Brasil. Quanto à primeira restrição, quis-se assegurar que os respondentes tivessem vivência nas questões da pesquisa. A segunda restrição, relativa ao país, visou delimitar as observações a um contexto único de modo a minimizar a ocorrência de efeitos indesejados relacionados a diferenças nos sistemas nacionais de GC e nos níveis de proteção legal (Shleifer \& Vishny, 1997; Klapper \& Love, 2004).

Foi realizada uma amostragem não-probabilística por conveniência, uma vez que não é possível acessar todos os conselheiros de administração de empresas brasileiras. A amostra inicialmente obtida foi de 252 observações, das quais 8 foram excluídas por serem de empresas sediadas em outros países, 26 foram excluídas por conterem mais de $20 \%$ de dados faltantes (Hair, Black, Babin \& Anderson, 2010) e uma foi excluída por conter dados faltantes em mais de duas variáveis do construto endógeno (Hair et al., 2010). Assim, a amostra final foi de 217 observações válidas.

\section{2.}

\section{Operacionalização das variáveis}

Descrevem-se a seguir os procedimentos adotados para operacionalização dos construtos e variáveis observáveis da pesquisa.

\subsection{1.}

\section{Definição operacional dos construtos}

Com base no referencial teórico, produziram-se definições operacionais dos seis construtos do modelo conceitual ilustrado na Figura 5. No desenvolvimento dos construtos, buscou-se evitar caracterizações genéricas que pudessem ter pouco significado prático ou baixo poder explicativo no fenômeno específico da monitoração da IE no CA. Logo, foram desenvolvidos construtos específicos. Suas definições estão descritas na Tabela 2. 
Tabela 2 - Definição operacional dos construtos

\begin{tabular}{|l|c|l|}
\hline \multicolumn{1}{|c|}{ Construto } & Abreviação & \multicolumn{1}{|c|}{ Definição operacional } \\
\hline Acesso a Informações & Al & $\begin{array}{l}\text { Grau em que o CA tem acesso às informações } \\
\text { relevantes necessárias para monitorar a IE. }\end{array}$ \\
\hline Conhecimento do Negócio & CN & $\begin{array}{l}\text { Grau em que os conhecimentos específicos do } \\
\text { negócio, requeridos para que o CA desempenhe sua } \\
\text { tarefa de monitoração da IE, estão coletivamente } \\
\text { presentes no CA. }\end{array}$ \\
\hline $\begin{array}{l}\text { Dinâmica de Trabalho do } \\
\text { CA }\end{array}$ & DI & $\begin{array}{l}\text { Grau em que o CA apresenta práticas de trabalho } \\
\text { orientadas à produção em equipe e à qualidade dos } \\
\text { processos de análise e tomada de decisão. }\end{array}$ \\
\hline $\begin{array}{l}\text { Liderança do Presidente do } \\
\text { CA }\end{array}$ & PC & $\begin{array}{l}\text { Grau em que o PCA possui atributos que favorecem } \\
\text { a produção em equipe e a qualidade dos processos } \\
\text { de análise e tomada de decisão do CA. }\end{array}$ \\
\hline $\begin{array}{l}\text { Atenção à Monitoração da } \\
\text { IE }\end{array}$ & AT & $\begin{array}{l}\text { Grau em que o CA dedica atenção à tarefa de } \\
\text { monitoração da IE. }\end{array}$ \\
\hline $\begin{array}{l}\text { Eficácia na Monitoração da } \\
\text { IE }\end{array}$ & MO & $\begin{array}{l}\text { Grau em que o CA desempenha suas tarefas de } \\
\text { monitoração da IE eficazmente. }\end{array}$ \\
\hline
\end{tabular}

\subsection{2. \\ Desenvolvimento de escalas de medição}

Dada a ausência de estudos empíricos sobre os antecedentes da monitoração da IE no CA, não foram encontradas na revisão da literatura escalas de medição pré-testadas para os construtos de interesse. Assim, procedeu-se ao desenvolvimento de escalas de medição para operacionalização desta etapa do estudo, conforme os procedimentos indicados por Converse \& Presser (1986) e Spector (1992).

Para mensurar cada um dos construtos, desenvolveu-se um conjunto inicial de escalas reflexivas de múltiplos itens. Com base nos resultados da revisão de literatura e das entrevistas com conselheiros de administração, foram identificadas as variáveis observáveis possivelmente associadas aos construtos (Tabela 3). As variáveis observáveis foram mensuradas por meio de uma escala de Likert variando de 1 (discordo muito) a 7 (concordo muito).

Com o objetivo de caracterizar a amostra desta etapa da pesquisa, foram também definidas as variáveis demográficas constantes da Tabela 4. 
Tabela 3 - Escalas preliminares de medição dos construtos

\begin{tabular}{|c|c|c|c|c|}
\hline \multirow[b]{2}{*}{ código } & \multirow[b]{2}{*}{ variável observável } & \multirow[b]{2}{*}{ afirmação } & \multicolumn{2}{|l|}{ referências } \\
\hline & & & bibliográficas & $\begin{array}{c}\text { entrevistado } \\
\text { (número) }\end{array}$ \\
\hline \multicolumn{5}{|c|}{ Acesso a Informações (Al) } \\
\hline Al1 & Antecedência & $\begin{array}{l}\text { Nossos conselheiros obtêm as informaçôes para as discussôes do Conselho de } \\
\text { Administração com suficiente antecedência. }\end{array}$ & Siciliano (2002) & $1,2,7$ \\
\hline $\mathrm{Al} 2$ & Suficiência & $\begin{array}{l}\text { Nossos conselheiros têm acesso a informações suficientes para monitorar a } \\
\text { execução estratégica da empresa. }\end{array}$ & $\begin{array}{l}\text { Drew \& Kaye (2007), Siciliano } \\
(2002)\end{array}$ & 2,9 \\
\hline Al3 & Interação além das reuniões & $\begin{array}{l}\text { Nossos conselheiros interagem com a empresa além das reuniōes do Conselho de } \\
\text { Administração para obter informaçôes. }\end{array}$ & & $1,6,7$ \\
\hline Al4 & Informações não-financeiras & $\begin{array}{l}\text { Nossos conselheiros têm acesso a informaçốes nâo-financeiras relevantes para a } \\
\text { tomada de decisão. }\end{array}$ & $\begin{array}{l}\text { Drew \& Kaye (2007), Siciliano } \\
\text { (2002) }\end{array}$ & \\
\hline Al5 & Acesso a outras fontes & $\begin{array}{l}\text { Nossos conselheiros obtêm informações de diversas fontes, não se restringindo aos } \\
\text { relatórios fornecidos pela diretoria executiva. }\end{array}$ & Selevoll et al. (2007) & \\
\hline Al6 & Comitês do CA & $\begin{array}{l}\text { Nossos conselheiros são apoiados por comitês ou comissões do Conselho para } \\
\text { obterem as informaçôes de que precisam (se não houver comitês, deixe em branco). }\end{array}$ & & \\
\hline Al7 & Acesso aos funcionários & $\begin{array}{l}\text { Nossos conselheiros têm acesso aos funcionários da empresa para obter as } \\
\text { informaçôes de que precisam. }\end{array}$ & Park (1995), Drew \& Kaye (2007) & 4,7 \\
\hline \multicolumn{5}{|c|}{ Conhecimento do Negócio (CN) } \\
\hline CN1 & Conhecimento da operação & Coletivamente, o Conselho conhece muito bem as operaçōes da empresa. & $\begin{array}{l}\text { Forbes \& Milliken (1999); Drew \& } \\
\text { Kaye (2007), Selevoll et al. (2007) }\end{array}$ & 7 \\
\hline CN2 & $\begin{array}{l}\text { Conhecimento de } \\
\text { competências e capacitações }\end{array}$ & $\begin{array}{l}\text { Coletivamente, o Conselho conhece muito bem as competências e capacitações } \\
\text { internas da empresa. }\end{array}$ & Selevoll et al. (2007) & \\
\hline CN3 & Conhecimento do setor & $\begin{array}{l}\text { Coletivamente, o Conselho conhece muito bem os principais setores em que a } \\
\text { empresa opera. }\end{array}$ & $\begin{array}{l}\text { McGrath et al. (1995), Selevoll et } \\
\text { al. (2007) }\end{array}$ & \\
\hline CN4 & $\begin{array}{l}\text { Conhecimento do ambiente } \\
\text { competitivo }\end{array}$ & $\begin{array}{l}\text { Coletivamente, o Conselho conhece muito bem o ambiente competitivo onde a } \\
\text { empresa opera (concorrentes, fornecedores, clientes, regulação). }\end{array}$ & $\begin{array}{l}\text { McGrath et al. (1995), Selevoll et } \\
\text { al. (2007) }\end{array}$ & \\
\hline CN5 & $\begin{array}{l}\text { Conhecimento das } \\
\text { prioridades estratégicas }\end{array}$ & $\begin{array}{l}\text { Coletivamente, o Conselho conhece muito bem as prioridades estratégicas da } \\
\text { empresa. }\end{array}$ & Forbes \& Milliken (1999) & 6,7 \\
\hline CN6 & Treinamento nos negócios & $\begin{array}{l}\text { Coletivamente, o Conselho participa de atividades de treinamento e aprendizagem } \\
\text { sobre os negócios da empresa. }\end{array}$ & Selevoll et al. (2007) & $5,6,7,8$ \\
\hline CN7 & $\begin{array}{l}\text { Participação na formulação } \\
\text { estratégica }\end{array}$ & Coletivamente, o Conselho tem um papel ativo na definição da estratégia da empresa. & & $1,2,9$ \\
\hline \multicolumn{5}{|c|}{ Dinâmica de Trabalho do CA (DI) } \\
\hline Dl1 & Postura questionadora & $\begin{array}{l}\text { Nossos conselheiros têm uma postura questionadora quanto às questões } \\
\text { importantes da empresa. }\end{array}$ & Davies (1999) & $1,2,3,4$ \\
\hline $\mathrm{D} 12$ & Liberdade de perguntar & Nossos conselheiros têm a liberdade de perguntar o que for necessário. & & $2,4,7$ \\
\hline DI3 & $\begin{array}{l}\text { Liberdade de dizer o que } \\
\text { pensa }\end{array}$ & Nossos conselheiros dizem o que pensam de forma aberta. & $\begin{array}{l}\text { Forbes \& Milliken (1999), Huse et } \\
\text { al. (2005), O'Reilly et al. (1989) }\end{array}$ & 4,7 \\
\hline DI4 & Discordâncias & $\begin{array}{l}\text { Nossos conselheiros frequentemente discordam quanto a questões importantes da } \\
\text { empresa. }\end{array}$ & $\begin{array}{l}\text { Forbes \& Milliken (1999), Huse et } \\
\text { al. (2005), O'Reilly et al. (1989) }\end{array}$ & \\
\hline DI5 & Profundidada das discussões & $\begin{array}{l}\text { Nossos conselheiros discutem as questões importantes da empresa com a } \\
\text { necessária profundidade. }\end{array}$ & Sellevoll et al. (2007) & \\
\hline D16 & $\begin{array}{l}\text { Contribuiç̃oes dos } \\
\text { conselheiros }\end{array}$ & $\begin{array}{l}\text { Nossos conselheiros contribuem decisivamente na discussão das questões } \\
\text { importantes da empresa. }\end{array}$ & Owen (2003) & \\
\hline D17 & $\begin{array}{l}\text { Abertura com a diretoria } \\
\text { executiva }\end{array}$ & $\begin{array}{l}\text { Nossos conselheiros discutem os problemas da empresa com a diretoria executiva } \\
\text { de forma aberta. }\end{array}$ & & $3,4,8$ \\
\hline \multicolumn{5}{|c|}{ Liderança do PCA (PC) } \\
\hline PC1 & Direcionamento da pauta & $\begin{array}{l}\text { O presidente do Conselho é excelente em direcionar a pauta do Conselho para as } \\
\text { questôes de alta importância estratégica da empresa. }\end{array}$ & $\begin{array}{l}\text { Gabrielsson et al. (2007), } \\
\text { MacAvoy \& Millstein (2003) }\end{array}$ & $4,6,10$ \\
\hline PC2 & Acesso a informações & $\begin{array}{l}\text { O presidente do Conselho é excelente em viabilizar um fluxo de informações } \\
\text { relevantes para o Conselho. }\end{array}$ & $\begin{array}{l}\text { Gabrielsson et al. (2007), } \\
\text { MacAvoy \& Millstein (2003) }\end{array}$ & 2 \\
\hline PC3 & Estimulo ao questionamento & $\begin{array}{l}0 \text { presidente do Conselho é excelente em estimular a atitude questionadora do } \\
\text { Conselho. }\end{array}$ & Gabrielsson et al. (2007) & 2,4 \\
\hline $\mathrm{PC} 4$ & Estimulo a contribuições & $\begin{array}{l}\text { O presidente do Conselho é excelente em garantir a contribuição de cada um dos } \\
\text { conselheiros. }\end{array}$ & $\begin{array}{l}\text { Gabrielsson et al. (2007), Selevoll } \\
\text { et al. (2007) }\end{array}$ & $6,8,9$ \\
\hline PC5 & Profundidada das discussões & $\begin{array}{l}\text { O presidente do Conselho é excelente em assegurar que as questões estratégicas } \\
\text { são discutidas no Conselho com a profundidade necessária. }\end{array}$ & & 6 \\
\hline $\mathrm{PC6}$ & $\begin{array}{l}\text { Estimulo a discussões } \\
\text { conclusivas }\end{array}$ & $\begin{array}{l}\text { O presidente do Conselho é excelente em promover discussões conclusivas no } \\
\text { Conselho. }\end{array}$ & $\begin{array}{l}\text { Gabrielsson et al. (2007), Selevoll } \\
\text { et al. (2007) }\end{array}$ & 3,6 \\
\hline PC7 & $\begin{array}{l}\text { Priorização de iniciativas a } \\
\text { monitorar }\end{array}$ & $\begin{array}{l}\text { O presidente do Conselho é excelente em priorizar as iniciativas estratégicas que } \\
\text { devem ser monitoradas pelo Conselho. }\end{array}$ & & 6,7 \\
\hline \multicolumn{5}{|c|}{ Atençäo à Monitoração da IE (AT) } \\
\hline AT1 & $\begin{array}{l}\text { Importância da monitoração } \\
\text { da IE }\end{array}$ & $\begin{array}{l}\text { O Conselho considera que a monitoração da execução estratégica da empresa é } \\
\text { uma de suas tarefas importantes. }\end{array}$ & & 2 \\
\hline AT2 & $\begin{array}{l}\text { Dedicação de tempo à } \\
\text { monitoração da IE }\end{array}$ & $\begin{array}{l}\text { O Conselho dedica uma parte significativa do seu tempo a discussões relacionadas à } \\
\text { monitoração da execução estratégica. }\end{array}$ & Tug & 3,8 \\
\hline АТЗ & Inclusão da IE na pauta do CA & O Conselho segue uma pauta que contempla as questões de execução estratégica. & & 6 \\
\hline AT4 & $\begin{array}{l}\text { Regularidade na monitoração } \\
\text { da IE }\end{array}$ & O Conselho monitora a execução estratégica com regularidade. & Selevoll et al. (2007) & 2 \\
\hline AT5 & $\begin{array}{l}\text { Responsabilidade pela } \\
\text { monitoração da IE }\end{array}$ & O Conselho tem o papel de monitorar a execução estratégica da empresa. & & 2,3 \\
\hline AT6 & $\begin{array}{l}\text { Autoridade para monitorar a } \\
\mathbb{E}\end{array}$ & O Conselho tem autoridade para monitorar a execução estratégica da empresa. & Park (1995), Selevoll et al. (2007) & \\
\hline \multicolumn{5}{|c|}{ Eficácia na Monitoração da IE (MO) } \\
\hline M01 & Definição de prioridades de $\mathrm{IE}$ & $\begin{array}{l}\text { O Conselho tem um papel ativo na definição das prioridades de execução estratégic } \\
\text { da empresa. }\end{array}$ & Siciliano, 2002, Li et al., 2008 & \\
\hline MO2 & $\begin{array}{l}\text { Monitoração de decisões e } \\
\text { projetos }\end{array}$ & $\begin{array}{l}\text { O Conselho monitora ativamente a evolução dos projetos estratégicos e as decisões } \\
\text { estratégicas de médio-longo prazo. }\end{array}$ & Selevoll et al. (2007) & \\
\hline MO3 & $\begin{array}{l}\text { Implementação de decisões } \\
\text { estratégicas }\end{array}$ & $\begin{array}{l}\text { O Conselho envolve-se em assegurar que as decisões estratégicas são postas em } \\
\text { prática. }\end{array}$ & Selevoll et al. (2007) & \\
\hline MO4 & $\begin{array}{l}\text { Avaliação de propostas } \\
\text { estratégicas }\end{array}$ & $\begin{array}{l}\text { O Conselho avalia ativamente as novas propostas estratégicas da empresa } \\
\text { (exemplos: aquisiçốes, reestruturaçôes, desenvolvimento de novas tecnologias). }\end{array}$ & $\begin{array}{l}\text { Stiles (2001), Brauer \& Schmidt } \\
(2008) \text {, Selevoll et al. (2007) }\end{array}$ & \\
\hline MO5 & Participação em decisões & $\begin{array}{l}\text { O Conselho participa ativamente nas decisôes-chave de investimento e alocaçẫo de } \\
\text { recursos da empresa. }\end{array}$ & $\begin{array}{l}\text { Brauer \& Schmidt (2008), Sellevoll } \\
\text { et al. (2007) }\end{array}$ & \\
\hline MO6 & Veto a inconsistências de $\mathbb{E}$ & $\begin{array}{l}\text { O Conselho veta novas propostas estratégicas que não sejam coerentes com a } \\
\text { estratégia definida para a empresa. }\end{array}$ & Braver \& Schmidt (2008) & \\
\hline M07 & Dete & $\begin{array}{l}\text { O Conselho identifica oportunamente quando a empresa está se desviando do rumo } \\
\text { estratégico desejado. }\end{array}$ & ers 5 & \\
\hline MO8 & $\begin{array}{l}\text { Correçôes de rumo } \\
\text { estratégico }\end{array}$ & $\begin{array}{l}\text { O Conselho promove oportunamente as correçôes necessárias para que a empresa } \\
\text { retome o rumo estratégico desejado. }\end{array}$ & Brauer \& Schmidt (2008) & \\
\hline
\end{tabular}


Tabela 4 - Variáveis demográficas

\begin{tabular}{|c|c|c|c|c|}
\hline código & variável observável & afirmação & escala de medição & referências bibliográficas \\
\hline \multicolumn{5}{|c|}{ Relativas à empresa } \\
\hline PAIS & Pais onde está registrada & Pais onde a empresa está registrada: & lista de paises & Klapper \& Love (2004) \\
\hline SETOR & Setor & Principal ramo de atividade da empresa: & $\begin{array}{l}\text { indústria }=1 \text {; comércio }=2 ; \text { bancos- } \\
\text { seguros }=3 \text {; serviços }=4 \text {; outros }=5\end{array}$ & Selevoll et al. (2007) \\
\hline TECNOLOGIA & Alta tecnologia & A empresa é considerada de alta tecnologia? & sim=1; não=0 & $\begin{array}{l}\text { Forbes \& Milliken (1999), } \\
\text { Selevoll et al. (2007) }\end{array}$ \\
\hline IDADE & Idade & Há quantos anos a empresa foi fundada? & $\begin{array}{l}0 \text { a } 10=1 ; 10 \text { a } 20=2 ; 20 \text { a } 30=3 ; 30 \text { a } \\
40=4 ;>40=5\end{array}$ & Selevoll et al. (2007) \\
\hline RECETA & Receita & Qual a receita anual da empresa? (RS milhões/ano) & $\begin{array}{l}0 \text { a } 100=1 ; 100 \text { a } 1 \text { bi }=2 ; 1 \text { a } 10 \mathrm{bi}=3 ; \\
>10 \text { bi=4 }\end{array}$ & Klapper \& Love (2004) \\
\hline DNERSIFICACAO & Grau de diversificação & $\begin{array}{l}\text { Qual o grau de diversificação dos negócios da } \\
\text { empresa? }\end{array}$ & baixo $=1 ;$ médio $=2 ;$ alto=3 & Selevoll et al. (2007) \\
\hline INTERNACIONALIZACAO & Grau de internacionalização & $\begin{array}{l}\text { Qual o grau de atuação da empresa em mercados } \\
\text { internacionais? }\end{array}$ & baixo $=1 ;$ médio $=2 ;$ alto $=3$ & Sellevoll et al. (2007) \\
\hline CONTROLE & Tipo de controle acionário & O controle do capital votante da empresa é: & $\begin{array}{l}\text { familiar }=1 ; \text { governamental=2; investidor } \\
\text { profissional=3; não de finido }=4\end{array}$ & Selevoll et al. (2007) \\
\hline LISTADA & Listagem em bolsa de valores & A empresa é listada em alguma bolsa de valores? & sim=1; não=0 & Silveira et al. (2009) \\
\hline CAPTALDERISCO & Presença de capital de risco & $\begin{array}{l}\text { Há participação de fundo de private equity/capital de risco } \\
\text { no capital da empresa? }\end{array}$ & sim=1; não=0 & $\begin{array}{l}\text { Acharya, Kehoe \& Reyner } \\
(2009)\end{array}$ \\
\hline MAIORACIONISTA & Concentração de propriedade & $\begin{array}{l}\text { Qual o percentual aproximado de açôes com direito a } \\
\text { voto em poder do maior acionista/quotista da empresa? }\end{array}$ & percentual & Selevoll et al. (2007) \\
\hline \multicolumn{5}{|c|}{ Relativas ao CA } \\
\hline DUALIDADE & Dualidade do CEO & $\begin{array}{l}\text { Os cargos de Presidente do Conselho e Presidente } \\
\text { executivo da empresa são ocupados pela mesma }\end{array}$ & $\operatorname{sim}=1 ;$ não=0 & Fama \& Jensen (1983) \\
\hline TAMANHODOCA & Tamanho do CA & $\begin{array}{l}\text { O Conselho é formado por quantos membros? (não } \\
\text { incluir suplentes e Conselho Fiscal) }\end{array}$ & número de conselheiros & Selevoll et al. (2007) \\
\hline MULHERES & $\begin{array}{l}\text { Conselheiros que são } \\
\text { mulheres }\end{array}$ & Quantos conselheiros são mulheres? & número de mulheres & Selevoll et al. (2007) \\
\hline REUNIOES & Frequência de reuniões do $\mathrm{CA}$ & $\begin{array}{l}\text { Quantas reuniões o Conselho de Administração realiza } \\
\text { anualmente? }\end{array}$ & número de reuniões por ano & Vafeas (1999) \\
\hline COMTEESTRAT & $\begin{array}{l}\text { Existência de comitê de } \\
\text { estratégia }\end{array}$ & $\begin{array}{l}\text { Existe um Comitê de Estratégia, ou órgão similar, no } \\
\text { Conselho? }\end{array}$ & $\operatorname{sim}=1 ;$ não=0 & Zahra (1990) \\
\hline \multicolumn{5}{|c|}{ Relativas ao respondente } \\
\hline EXPERIENCIAANOS & $\begin{array}{l}\text { Experiência como conselheiro } \\
\text { em anos }\end{array}$ & $\begin{array}{l}\text { Qual a sua experiência global como Conselheiro/a de } \\
\text { Administração? (em anos) }\end{array}$ & número de anos & Selevoll et al. (2007) \\
\hline EXPERIENCIACA & $\begin{array}{l}\text { Experiência como conselheiro } \\
\text { em número de CAs }\end{array}$ & $\begin{array}{l}\text { Qual a sua experiência global como Conselheiro/a de } \\
\text { Administração? (em número de Conselhos) }\end{array}$ & número de CAs & Selevoll et al. (2007) \\
\hline
\end{tabular}

\subsection{3. \\ Pré teste das escalas de medição}

Uma versão preliminar do questionário da pesquisa foi preparada com base nas escalas de medição desenvolvidas e foi pré-testada durante o mês de Maio de 2012. Como primeiro procedimento, o questionário preliminar foi enviado a 20 respondentes, não incluídos na amostra final do estudo, com o objetivo testar a validade de face das escalas. Foram sugeridas e efetuadas mudanças na redação de 18 afirmações, para maior clareza do seu significado. Como segundo procedimento, o questionário preliminar foi analisado por três outros respondentes, que foram capazes de relacionar sem erros as variáveis observáveis aos construtos.

\section{3.}

\section{Coleta de dados}

São descritos a seguir os procedimentos empregados para coleta de dados. 


\subsection{1. Instrumento de coleta de dados}

Os dados foram coletados por meio do questionário final constante do Apêndice. Duas versões do questionário foram utilizadas: uma eletrônica, por meio da ferramenta de pesquisa online Qualtrics ${ }^{\mathrm{TM}}$, e outra em papel. O questionário foi composto de 42 itens divididos entre os seis construtos de interesse do estudo. Além desses itens, há mais 18 itens para medir as variáveis demográficas dos respondentes, do CA e da empresa (Converse \& Presser, 1986).

Quanto à estrutura do questionário, inicia-se com um parágrafo explicando a motivação para o estudo. Nesse parágrafo foi mencionado que a pesquisa era conduzida pela PUC-Rio com o apoio institucional do Instituto Brasileiro de Governança Corporativa - IBGC e da empresa de consultoria Booz \& Company, os quais concordaram em apoiar a divulgação da pesquisa. Em seguida, são fornecidas instruções para que o respondente escolha o CA mais atuante em que já trabalhou, e para que baseie todas as suas respostas nesse CA. Seguem-se os itens relativos às variáveis demográficas da empresa e do CA escolhidos. Em seguida, são apresentadas as perguntas relativas aos cinco construtos exógenos da pesquisa, agrupadas por construto. Posteriormente, são apresentadas as perguntas relativas ao construto endógeno. Finalmente, seguem-se os itens relativos às variáveis demográficas do respondente e uma opção para registro de e-mail caso o respondente queira receber uma cópia do relatório da pesquisa.

\subsection{2. \\ Distribuição da pesquisa}

Dadas as dificuldades para a obtenção de respostas de conselheiros de administração, adotou-se uma estratégia de distribuição do questionário por múltiplos passos. O primeiro foi a montagem de um banco de dados com nomes e e-mails de 379 conselheiros de administração de empresas brasileiras. Para a preparação desse banco de dados, obtiveram-se junto à empresa de consultoria Booz \& Company os nomes e e-mails de 241 conselheiros de administração. Posteriormente, foram acrescidos nomes e e-mails de 138 conselheiros de administração constantes dos arquivos do pesquisador. 
O questionário eletrônico foi enviado a esses conselheiros durante os meses de Setembro e Outubro de 2012, em e-mail personalizado explicando a natureza, objetivos e benefícios da pesquisa. Um e-mail de seguimento foi enviado ao fim de 30 dias, solicitando novamente a resposta ao questionário. Para aumentar o alcance da distribuição do questionário, solicitou-se nesses e-mails que os respondentes repassassem o link da pesquisa aos demais membros dos CAs de que participavam. Adicionalmente, vários dos conselheiros cadastrados no banco de dados foram contatados pessoalmente pelo pesquisador por telefone para que respondessem à pesquisa. Admitiu-se que os conselheiros que participassem de mais de um CA respondessem a mais de um questionário se o desejassem, de modo a capturar suas percepções acerca desses diferentes CAs. Também se admitiu que mais de um representante de um mesmo CA respondesse à pesquisa.

O segundo passo, entre os meses de Setembro e Novembro de 2012, foi o envio do questionário eletrônico para conselheiros de administração de empresas brasileiras identificados como tal na rede social LinkedIn ${ }^{\mathrm{TM}}$. Adicionalmente, um convite para responder ao questionário, assim como o link da pesquisa, foi inserido nas comunidades "Boards and Advisors", "Corporate Governance", “Corporate Governance Research”, "Governança Corporativa - Brasil” e "IBGC - SP" da rede LinkedIn ${ }^{\mathrm{TM}}$.

Também entre Setembro e Novembro de 2012, o questionário eletrônico foi enviado para: (i) os associados do IBGC; (ii) os membros do banco de conselheiros certificados do IBGC; (iii) os membros da Associação de Investidores no Mercado de Capitais - AMEC; e (iv) os membros da Associação Nacional dos Executivos de Finanças, Administração e Contabilidade ANEFAC. Essas associações também divulgaram o link da pesquisa nos seus websites.

Finalmente, foram coletados 46 questionários em papel, dos quais 31 foram respondidos durante a conferência anual da International Corporate Governance Network - ICGN, realizada em Junho de 2012 no Rio de Janeiro, e 15 foram respondidos durante o congresso anual do IBGC, realizado em Outubro de 2012 em São Paulo. Na conferência da ICGN foram distribuídas versões do questionário em português e inglês, uma vez que havia participantes estrangeiros. Oito questionários em inglês foram coletados, dos quais cinco foram considerados 
válidos para inclusão na amostra por serem referentes a empresas sediadas no Brasil.

\section{4.}

\section{Tratamento de dados}

Os dados coletados foram tratados com auxílio do pacote estatístico PASW $^{\mathrm{TM}}$ versão 18 . Os procedimentos adotados para tratamento dos dados estão descritos a seguir.

\subsection{1. Substituição de dados faltantes}

A amostra da pesquisa foi de 217 observações válidas, conforme descrito na seção 5.1. Desse total, o número de observações completas (ou seja, sem dados faltantes) foi de 142, equivalente a 65,4\%. Para aumentar o número de observações completas, empregou-se o procedimento de substituição de dados faltantes indicado em Hair et al. (2010). Das 60 variáveis da pesquisa, 25 tiveram incidência de dados faltantes, conforme a Tabela 5. A variável AI6 (Comitês do CA) foi excluída por apresentar incidência de dados faltantes superior a $20 \%$ (Hair et al., 2010). Com base no mesmo critério, as demais variáveis foram mantidas.

Testou-se a aleatoriedade dos dados faltantes por meio do Teste MCAR de Little, não sendo possível rejeitar a hipótese nula de que os dados faltantes são completamente aleatórios (Qui-quadrado = 1135,5; GL = 1084; Sig. =0,135). Logo, pôde-se proceder à substituição de dados faltantes.

Os dados faltantes das variáveis categóricas PAIS (dois valores faltantes, conforme a Tabela 6), SETOR (um valor faltante) e CONTROLE (um valor faltante) foram substituídos pelo método hot deck, no qual os valores faltantes são substituídos por valores válidos de observações semelhantes. Os dados faltantes das variáveis dicotômicas LISTADA (dois valores faltantes), TECNOLOGIA (dois valores faltantes) e CAPITALDERISCO (um valor faltante) também foram substituídos pelo método hot deck. Os critérios empregados para essas substituições são descritos na Tabela 6. As demais variáveis apresentaram 6\% ou 
menos de incidência de dados faltantes. Logo, procedeu-se sua à substituição pelas respectivas médias ${ }^{1}$.

Tabela 5 - Incidência de dados faltantes por variável

\begin{tabular}{|c|c|c|c|}
\hline \multirow{2}{*}{ Variável } & \multicolumn{2}{|c|}{ Observações com dados faltantes } & \multirow{2}{*}{ Observações completas } \\
\hline & $\mathrm{N}$ & $\%$ & \\
\hline Al6 & 50 & $23,0 \%$ & 167 \\
\hline MULHERES & 13 & $6,0 \%$ & 204 \\
\hline MAIORACIONISTA & 10 & $4,6 \%$ & 207 \\
\hline MO6 & 2 & $0,9 \%$ & 215 \\
\hline MO4 & 2 & $0,9 \%$ & 215 \\
\hline PC3 & 2 & $0,9 \%$ & 215 \\
\hline LISTADA & 2 & $0,9 \%$ & 215 \\
\hline INTERNACIONALIZACAO & 2 & $0,9 \%$ & 215 \\
\hline RECEITA & 2 & $0,9 \%$ & 215 \\
\hline TECNOLOGIA & 2 & $0,9 \%$ & 215 \\
\hline PAIS & 2 & $0,9 \%$ & 215 \\
\hline $\mathrm{MO3}$ & 1 & $0,5 \%$ & 216 \\
\hline AT5 & 1 & $0,5 \%$ & 216 \\
\hline $\mathrm{PC1}$ & 1 & $0,5 \%$ & 216 \\
\hline DI6 & 1 & $0,5 \%$ & 216 \\
\hline DI5 & 1 & $0,5 \%$ & 216 \\
\hline CN6 & 1 & $0,5 \%$ & 216 \\
\hline CN5 & 1 & $0,5 \%$ & 216 \\
\hline $\mathrm{Al3}$ & 1 & $0,5 \%$ & 216 \\
\hline TAMANHODOCA & 1 & $0,5 \%$ & 216 \\
\hline CAPITALDERISCO & 1 & $0,5 \%$ & 216 \\
\hline CONTROLE & 1 & $0,5 \%$ & 216 \\
\hline DIVERSIFICACAO & 1 & $0,5 \%$ & 216 \\
\hline IDADE & 1 & $0,5 \%$ & 216 \\
\hline SETOR & 1 & $0,5 \%$ & 216 \\
\hline
\end{tabular}

${ }^{1}$ Analisou-se a possibilidade de substituição dos dados faltantes das variáveis MULHERES e MAIORACIONISTA, cuja incidência foi superior a 3\%, por modelos de regressão linear por mínimos quadrados. No entanto, não foram identificadas variáveis explicativas com relação suficiente para gerar predições válidas. 
Tabela 6 - Substituição de dados faltantes pelo método hot deck

\begin{tabular}{|l|c|c|c|}
\hline \multicolumn{1}{|c|}{ Variável } & Observação & Critério de substituição & $\begin{array}{c}\text { Valor } \\
\text { substituído }\end{array}$ \\
\hline \multirow{2}{*}{ PAIS } & 109 & Similaridade com observação 53 & 1 \\
\cline { 2 - 4 } & 125 & Similaridade com observação 117 & 1 \\
\hline \multirow{2}{*}{ SETOR } & 125 & Similaridade com observação 117 & 1 \\
\hline CONTROLE & 125 & Similaridade com observação 117 & 1 \\
\hline \multirow{2}{*}{ LISTADA } & 125 & Similaridade com observação 117 & 0 \\
\cline { 2 - 5 } & 183 & Similaridade com caso 173 & 1 \\
\hline \multirow{2}{*}{ TECNOLOGIA } & 125 & Similaridade com observação 117 & 0 \\
\cline { 2 - 5 } & 191 & Similaridade com observação 180 & 0 \\
\hline CAPITALDERISCO & 125 & Similaridade com observação 117 & 0 \\
\hline
\end{tabular}

Como resultado desses procedimentos, eliminou-se a incidência de dados faltantes e preservou-se o tamanho da amostra final em 217 observações.

\subsection{2.}

\section{Análise de observações extremas}

Procedeu-se a uma análise univariada de observações extremas por meio da inspeção de box plots de todas as variáveis. Verificou-se que as observações extremas: (i) não se deveram a erros de procedimentos; (ii) não se deveram a eventos extraordinários; (iii) não são aberrantes; e (iv) são representativas das observações da população. Logo, conforme o preconizado por Hair et al. (2010), todas as observações foram mantidas.

\subsection{3.}

\section{Análise de normalidade multivariada}

Para determinar se os dados apresentam normalidade multivariada, procedeu-se primeiramente a uma análise visual dos histogramas e gráficos do tipo Q-Q da distribuição dos dados de todas as variáveis (eles não serão exibidos neste estudo para conservar espaço). A princípio, as distribuições pareceram ser não-normais. Em seguida, analisaram-se os indicadores de assimetria e curtose dessas distribuições, os quais também indicaram ausência de normalidade dos dados. Finalmente, realizou-se o teste de normalidade univariada de KolgomorovSmirnov, cuja hipótese nula é de a distribuição dos dados ser normal. Rejeitou-se 
a hipótese nula para todas as variáveis analisadas (Sig. $=0,000)$, confirmando que a distribuição dos dados é não normal.

A análise de dados empregará a modelagem de equações estruturais pelo método de máxima verossimilhança. Apesar da não normalidade dos dados, Hair et al. (2010) observaram que o impacto da não normalidade dos dados em equações estruturais é reduzido em amostras superiores a 200 observações. Além disso, Olsson, Foss, Troye \& Howell (2000) demonstraram que as estimações pelo método de máxima verossimilhança são robustas contra violações da premissa de normalidade, gerando resultados estáveis e similares aos de outras técnicas. Logo, com base nesses argumentos considerou-se que a violação da premissa de normalidade multivariada dos dados não invalida a estimação por máxima verossimilhança empregada neste estudo. Em conseqüência disso, não foram realizadas transformações de dados, que foram analisados em nível.

\section{5. Procedimentos de análise de dados}

A análise dos dados é desenvolvida no capítulo 6. São descritos nesta seção os principais procedimentos de análise adotados.

Os dados foram analisados com auxílio do pacote estatístico Amos Graphics $^{\mathrm{TM}}$ versão 18.0. O teste do modelo conceitual e das hipóteses concorrentes do estudo foi realizado com o emprego da modelagem de equações estruturais - SEM com estimação pelo método de máxima verossimilhança. A modelagem SEM é adequada para as questões de pesquisa deste estudo por duas razões. Em primeiro lugar, trata-se de um método particularmente útil para o estudo de modelos com construtos latentes e erros de medida (Hair et al., 2010). Em segundo lugar, a modelagem SEM permite a estimação de ligações simultâneas entre diversas variáveis independentes e dependentes e a mensuração de efeitos intervenientes (Bagozzi \& Phillips, 1982). Essa característica torna possível avaliar conjuntamente todas as relações entre construtos previstas no modelo conceitual, eliminando possíveis distorções resultantes do emprego de análises separadas (Hair et al., 2010).

Foram seguidos os procedimentos preconizados por Hair et al. (2010). Primeiramente, fez-se uma sucinta descrição do contexto brasileiro de GC. Em 
seguida, procedeu-se a uma análise descritiva para caracterização das variáveis observáveis do estudo.

Dado que não foram identificadas na literatura escalas de medição prétestadas para os construtos específicos deste estudo, realizou-se uma purificação das escalas de medição aqui desenvolvidas, constantes da Tabela 3. Nesse passo, realizou-se uma análise fatorial exploratória - EFA com o objetivo de: (i) verificar se existe uma estrutura de fatores subjacente às 41 variáveis observáveis empregadas no estudo; (ii) verificar se essa estrutura reflete o agrupamento de variáveis por construto que foi desenvolvido com base no referencial teórico; e (ii) reduzir a quantidade de variáveis observáveis, formando escalas de medição mais parcimoniosas.

O passo seguinte foi a realização de uma análise fatorial confirmatória CFA para definir um modelo de medidas teórico valido que assegure a confiabilidade dos construtos a serem medidos (Anderson \& Gerbing, 1988; Hair et al., 2010).

Posteriormente foram testados os modelos estruturais propriamente ditos (Anderson \& Gerbing, 1988; Hair et al., 2010). Quatro modelos concorrentes foram especificados e estimados para testar as hipóteses da pesquisa, em linha com as indicações do referencial teórico. Comparou-se o desempenho desses modelos por meio dos seus respectivos índices de ajuste aos dados. Quatro índices de ajuste foram empregados, uma vez que não existe um consenso na literatura sobre a existência de um índice único que reflita de maneira completa a qualidade do ajuste de um modelo estrutural (Hu \& Bentler, 1999). Conforme as indicações de Hair et al. (2010), utilizou-se um índice de ajuste geral (estatística quiquadrada do modelo e respectivos graus de liberdade), um de ajuste absoluto (raiz do erro quadrático médio de aproximação - RMSEA, e seu respectivo intervalo de confiança), um de ajuste incremental (índice de ajuste comparativo - CFI) e um de ajuste parcimonioso (critério de informação de Akaike - AIC). O modelo estrutural que apresentou melhor desempenho em termos de ajuste aos dados foi então selecionado para embasar a interpretação dos resultados empíricos. 


\section{6.}

\section{Limitações do método}

Quanto à coleta de dados, constitui limitação o fato de o mesmo respondente ter fornecido respostas para as variáveis dos construtos exógenos e endógenos. Reconhece-se aqui que um potencial viés de método comum poderia ter sido mais bem controlado se as observações viessem de amostras separadas ou de fontes de dados diferentes. Porém, não foi possível identificar fontes alternativas de dados que pudessem representar validamente os construtos de interesse. A alternativa de obtenção de amostras separadas para coleta de dados dos construtos exógenos e endógenos mostrou-se inviável por duas razões. Em primeiro lugar, não se pôde determinar a priori quais construtos serão endógenos, à exceção da Eficácia na Monitoração da IE, dado que as hipóteses formuladas prevêem diferentes possibilidades de mediação entre eles. Em segundo lugar, a obtenção de duas amostras reduzidas causaria uma significativa perda de informação e possíveis resultados espúrios.

Nessas circunstâncias, Podsakoff, Mackenzie, Lee \& Podsakoff (2003) observaram que um remédio para contornar parcialmente o viés de método comum é tomar medidas para proteger o anonimato do respondente. Segundo os autores, esse procedimento contribui para reduzir a apreensão do respondente em avaliar as questões, tornando-os menos propensos a fornecer respostas aquiescentes ou socialmente desejáveis. Em linha com essa observação, tomou-se nesta etapa da pesquisa o cuidado de não identificar o respondente nem a empresa cujo CA foi avaliado. Solicitou-se aos respondentes que desejassem receber uma cópia do relatório da pesquisa que informassem um e-mail ao final do questionário. No entanto, essa informação era voluntária e o e-mail não era necessariamente do próprio respondente, ou facilmente identificável. Assim, espera-se ter controlado, ao menos parcialmente, um possível viés de método único.

Quanto à organização das perguntas no questionário, o fato de não terem sido dispostas aleatoriamente pode ter introduzido viés de método. Ainda assim, optou-se por agrupá-las por construto para minimizar o esforço dos respondentes e um eventual abandono do questionário. 
$\mathrm{O}$ fato de ter sido admitido mais de um respondente por CA poderia ser encarado como uma potencial fonte de viés. A este respeito, este estudo se alinha com a opinião de Huse (2005), segundo a qual análises do real comportamento de CAs se beneficiam das percepções complementares dos diferentes grupos de membros do conselho (como, por exemplo, PCAs, CEOs, mulheres e representantes dos empregados).

Uma potencial limitação diz respeito à inclusão de CAs de empresas que não estão listadas em bolsas de valores, uma vez que a sua experiência com as práticas de GC pode ser menor que a de empresas listadas. Em princípio, tinha-se a intenção de delimitar o estudo aos CAs de empresas listadas. Porém, o tamanho reduzido da população de conselheiros de empresas brasileiras nessa condição e a dificuldade em obter respostas desses conselheiros tornariam o tamanho da amostra inferior aos requisitos mínimos para análise de dados pelo método multivariado de equações estruturais, indicado para este estudo.

Reconhece-se que, mesmo com os cuidados seguidos para especificação e validação dos modelos conceituais da pesquisa, pode haver problemas de estimação oriundos da não normalidade dos dados e do tamanho da amostra. Dada a complexidade dos modelos conceituais testados e o número de variáveis, seria recomendável um número de observações maior que as 217 obtidas para amenizar a ausência de normalidade multivariada dos dados. No entanto, Olsson et al. (2000) ressaltaram que o método de estimação por máxima verossimilhança, empregado neste estudo, fornece estimadores confiáveis na presença de dados não normais. Além disso, ressalta-se que a amostra empregada é superior ao tamanho mínimo de 150 observações preconizado por Hair et al. (2010) para o emprego do método de equações estruturais em modelos com sete ou menos construtos, comunalidades inferiores a 0,5 e inexistência de construtos sub-identificados (p. 660), tais como os aqui testados. Logo, espera-se que o risco de problemas de estimação tenha sido minimizado.

O fato de haver sido empregado um único conjunto de dados para as análises fatoriais exploratória - EFA e confirmatória - CFA também constitui limitação. Reconhece-se aqui que o uso de amostras separadas para a identificação e o teste da estrutura de fatores subjacente aos dados poderia gerar uma maior evidência da estabilidade do modelo de medidas. No entanto, a obtenção de uma segunda amostra não seria viável em função das limitações para obtenção de 
respostas discutidas nesta seção. Alem disso, a adoção de um procedimento de divisão da amostra obtida geraria sub-amostras pequenas que potencialmente invalidariam o uso da modelagem de equações estruturais ou gerariam resultados espúrios.

O emprego de uma amostra por conveniência prejudica a sua representatividade em relação à população de conselheiros de administração de empresas brasileiras e a generalizabilidade dos resultados. No entanto, o propósito do estudo é estudar a estrutura de relações entre as variáveis e não a validade externa dos resultados. Logo, considerou-se que a representatividade da amostra não constitui uma questão crucial.

Finalmente, no que tange ao referencial teórico, o estágio atual da pesquisa acadêmica no objeto da pesquisa, que ainda é recente e fragmentado, constitui limitação. Considera-se que a etapa inicial de pesquisa qualitativa com conselheiros de administração contribuiu para contornar parcialmente essa limitação. 


\section{6 \\ Modelagem estrutural e análise de dados}

Neste capítulo, apresenta-se a análise dos dados obtidos por meio da survey com conselheiros de administração de empresas brasileiras.

O objetivo da análise de dados foi de especificar e testar a validade dos modelos de medidas e estruturais propostos, e testar as hipóteses de pesquisa formuladas com suporte do referencial teórico.

Inicia-se o capítulo com uma breve descrição do contexto em que os CAs analisados operam (seção 6.1). Uma vez que foram incluídos na amostra CAs de empresas brasileiras, analisam-se as características mais importantes do ambiente institucional de governança corporativa no Brasil.

Em seguida, procede-se a uma caracterização da amostra da pesquisa (seção $6.2)$.

Os resultados da análise dos dados são apresentados na seção 6.3. Empregou-se a modelagem de equações estruturais - SEM para analisar o desempenho de quatro modelos estruturais concorrentes embasados na teoria.

Encerra-se o capítulo com a discussão dos resultados empíricos (seção 6.4).

\section{1. Contexto da pesquisa}

$\mathrm{O}$ ambiente institucional de $\mathrm{GC}$ no Brasil apresenta diferenças marcantes em relação ao da maioria dos países desenvolvidos. Diversas empresas brasileiras de capital aberto apresentam estruturas de propriedade concentradas e assimetria de direitos de controle em favor do acionista controlador, decorrentes da prática de emissão de ações preferenciais sem direito a voto (Silveira, Leal, Barros \& Carvalhal da Silva, 2009). O ambiente empresarial se caracteriza pela presença de grupos familiares pouco diversificados (Aldrighi \& Postali, 2010). A participação do estado no capital das empresas, tanto na condição de controlador como na de minoritário, é elevada - cerca de $34 \%$ do seu valor de mercado (Musacchio \& Lazzarini, 2012). 
A adoção de práticas avançadas de GC é um fenômeno relativamente recente no Brasil. Seu impulso inicial se deu nos anos 90 com a abertura da economia, as privatizações, o Plano Real e o desenvolvimento do mercado de controle corporativo (Carvalhal da Silva, 2006). Desde então, várias iniciativas foram implantadas para melhorar a base legal e normativa de GC no país. Destacam-se dentre elas: (i) a Nova Lei das S/A; (ii) as recomendações da CVM sobre GC (Comissão de Valores Mobiliários, 2002); (iii) o código de melhores práticas do IBGC (Instituto Brasileiro de Governança Corporativa, 2009), hoje em sua quarta edição; e (iv) as regras de listagem nos segmentos de empresas com padrões diferenciados de GC na Bolsa de Valores de São Paulo - BMF/Bovespa. A literatura normativa brasileira sugere práticas de GC comparáveis às dos principais códigos internacionais, tais como a separação entre os cargos de PCA e CEO, o número mínimo de conselheiros de administração superior ao previsto em lei, a nomeação de conselheiros independentes e a supressão de ações sem direito a voto. A ênfase na adoção de melhores práticas de GC tem aumentado, inclusive por parte de empresas não listadas que desejam ingressar no mercado de capitais, assim como a abrangência dos modelos de GC adotados.

Os CAs brasileiros têm passado por um período de profissionalização, em função do aumento da atividade econômica, do número de empresas que abriram e que aspiram a abrir capital, da crescente exigência de melhores práticas de GC e da demanda por certificação de conselheiros. Uma recente pesquisa do IBGC (Instituto Brasileiro de Governança Corporativa, 2010), que comparou dados coletados em 2003 e 2010, mostrou que: (i) tem-se observado um aumento na participação de conselheiros independentes; (ii) a atenção dos conselheiros aos riscos estratégicos tem aumentado; (iii) a eficácia do funcionamento CAs ainda é, de forma geral, percebida por conselheiros e executivos como insuficiente. Os principais fatores de ineficácia apontados foram a dinâmica das interações dos conselheiros, a existência de conselheiros pouco engajados e o acompanhamento insuficiente das decisões tomadas no CA. 


\section{2.}

\section{Caracterização da amostra}

As Tabelas 7 e 8 ilustram estatísticas descritivas que caracterizam a amostra final de 217 observações.

Tabela 7 - Características da amostra relativas às empresas

\begin{tabular}{|c|c|c|c|c|c|c|}
\hline Característica & $\mathrm{n}$ & $\begin{array}{c}\text { percentual da } \\
\text { amostra }\end{array}$ & mínimo & máximo & média & $\begin{array}{l}\text { desvio- } \\
\text { padrão }\end{array}$ \\
\hline \multicolumn{7}{|l|}{ Ramo de atividade } \\
\hline indústria & 83 & $38,2 \%$ & & & & \\
\hline comércio & 20 & $9,2 \%$ & & & & \\
\hline bancos/seguros & 11 & $5,1 \%$ & & & & \\
\hline serviços & 78 & $35,9 \%$ & & & & \\
\hline outros & 25 & $11,5 \%$ & & & & \\
\hline \multicolumn{7}{|c|}{ É considerada de alta tecnologia? } \\
\hline $\operatorname{sim}$ & 60 & $27,6 \%$ & & & & \\
\hline não & 157 & $72,4 \%$ & & & & \\
\hline \multicolumn{7}{|l|}{ Há quantos anos foi fundada } \\
\hline 0 a 10 anos & 29 & $13,4 \%$ & & & & \\
\hline 10 a 20 anos & 38 & $17,5 \%$ & & & & \\
\hline 20 a 30 anos & 23 & $10,6 \%$ & & & & \\
\hline 30 a 40 anos & 26 & $12,0 \%$ & & & & \\
\hline$>40$ anos & 101 & $46,5 \%$ & & & & \\
\hline \multicolumn{7}{|l|}{ Receita anual (R\$) } \\
\hline 0 a 100 milhões & 44 & $20,3 \%$ & & & & \\
\hline 100 milhões a 1 bilhão & 85 & $39,2 \%$ & & & & \\
\hline 1 a 10 bilhões & 71 & $32,7 \%$ & & & & \\
\hline$>10$ bilhões & 17 & $7,8 \%$ & & & & \\
\hline \multicolumn{7}{|c|}{ Grau de diversificação dos negócios } \\
\hline baixo & 115 & $53,0 \%$ & & & & \\
\hline médio & 87 & $40,1 \%$ & & & & \\
\hline alto & 15 & $6,9 \%$ & & & & \\
\hline \multicolumn{7}{|c|}{ Grau de atuação em mercados internacionais } \\
\hline baixo & 153 & $70,5 \%$ & & & & \\
\hline médio & 30 & $13,8 \%$ & & & & \\
\hline alto & 34 & $15,7 \%$ & & & & \\
\hline \multicolumn{7}{|l|}{ Controle do capital votante } \\
\hline familiar & 117 & $53,9 \%$ & & & & \\
\hline governamental & 8 & $3,7 \%$ & & & & \\
\hline investidor profissional & 55 & $25,3 \%$ & & & & \\
\hline não definido & 37 & $17,1 \%$ & & & & \\
\hline \multicolumn{7}{|c|}{ É listada em alguma bolsa de valores? } \\
\hline $\operatorname{sim}$ & 92 & $42,4 \%$ & & & & \\
\hline não & 125 & $57,6 \%$ & & & & \\
\hline \multicolumn{7}{|c|}{ Presença de private equity/capital de risco no capital } \\
\hline $\operatorname{sim}$ & 64 & $29,5 \%$ & & & & \\
\hline não & 153 & $70,5 \%$ & & & & \\
\hline $\begin{array}{l}\text { Percentual de ações com di } \\
\text { acionista/quotista }\end{array}$ & & & $0,0 \%$ & $100,0 \%$ & $49,2 \%$ & $26,5 \%$ \\
\hline
\end{tabular}

Nota: N=217. 
Tabela 8 - Características da amostra relativas aos CAs

\begin{tabular}{|c|c|c|c|c|c|c|}
\hline Característica & $\mathrm{n}$ & $\begin{array}{l}\text { percentual } \\
\text { da amostra }\end{array}$ & mínimo & máximo & média & $\begin{array}{l}\text { desvio- } \\
\text { padrão }\end{array}$ \\
\hline \multicolumn{7}{|c|}{$\begin{array}{l}\text { Cargos de PCA e presidente executivo da empresa } \\
\text { ocupados pela mesma pessoa }\end{array}$} \\
\hline $\operatorname{sim}$ & 45 & $20,7 \%$ & & & & \\
\hline não & 172 & $79,3 \%$ & & & & \\
\hline \multicolumn{7}{|l|}{ Existência de comitê de estratégia } \\
\hline $\operatorname{sim}$ & 86 & $39,6 \%$ & & & & \\
\hline não & 131 & $60,4 \%$ & & & & \\
\hline Número total de conselheiros & & & 2 & 19 & 7,27 & 2,71 \\
\hline Número de conselheiras mulheres & & & 0 & 5 & 0,70 & 0,90 \\
\hline Número de reuniões por ano & & & 0 & 25 & 9,63 & 4,45 \\
\hline
\end{tabular}

Nota: $\mathrm{N}=217$.

Quanto às empresas, a Tabela 7 indica que os principais ramos de atividade representados na amostra foram a indústria $(38,2 \%$ do total) e os serviços $(35,9 \%)$. A maioria delas $(72,4 \%)$ não foi considerada de alta tecnologia. Quanto à idade, um pouco menos da metade delas $(46,5 \%)$ foi fundada há mais de 40 anos, ao passo que 13,4\% são empresas novas, com menos de 10 anos. Quanto à sua receita anual, houve poucas empresas muito grandes $(7,8 \%$ com receita superior a $\mathrm{R}$ \$ 10 bilhões/ano) ou muito pequenas $(20,3 \%$ com receita inferior a $\mathrm{R} \$ 100$ milhões/ano). Cerca de metade das empresas apresenta um baixo grau de diversificação de negócios (53\%), ao passo que mais de 70\% tem um baixo grau de atuação internacional. Quanto ao controle do capital votante, observou-se um predomínio de empresas familiares $(53,9 \%)$ e muito poucas empresas de controle governamental (3,7\%). Quanto à concentração de propriedade, medida pelo percentual de ações com direito a voto em poder do maior acionista/quotista da empresa, o percentual médio de 49,2\% indica elevada concentração. Um pouco menos da metade $(42,7 \%)$ das empresas é listada em bolsa de valores, e cerca de $30 \%$ das empresas representadas na amostra tem presença de fundos de private equity ou capital de risco no seu capital.

Quanto aos CAs (Tabela 8), observou-se uma baixa incidência de dualidade do CEO (20,7\%), definida como a ocupação pela mesma pessoa dos cargos de PCA e CEO. Os CAs representados na amostra têm em média 7,27 conselheiros, dos quais menos de uma é do sexo feminino $(0,70)$. A freqüência de reuniões é um pouco inferior a uma por mês (9,63 reuniões por ano). Cerca de $40 \%$ dos CAs representados na amostra têm um comitê de estratégia.

Os respondentes têm em média 8,9 anos de experiência no cargo de conselheiro de administração e trabalharam em 4,55 CAs em média. 


\section{3. \\ Análises e resultados}

Analisam-se a seguir os resultados empíricos desta etapa do estudo.

\subsection{1.}

\section{Purificação das escalas de medição}

Com o objetivo de purificar as escalas de medição dos construtos da pesquisa, ilustradas na Tabela 3, procedeu-se a uma análise fatorial exploratória (EFA) das 41 variáveis observáveis relacionadas aos construtos. A amostra de 217 observações cumpre com o requisito mínimo de cinco observações por variável, indicado por Hair et al. (2010) para o emprego da modelagem SEM. Dado que o objetivo deste passo é de redução de variáveis para identificação do máximo grau de variância total explicado pelo mínimo número de fatores e variáveis, adotou-se o método de componentes principais. Para melhorar a interpretação dos resultados e obter uma separação mais evidente dos fatores, adotou-se o procedimento de rotação ortogonal de fatores VARIMAX.

Para verificar a existência de multicolinearidade entre as variáveis e a adequação da análise fatorial, procedeu-se ao teste de esfericidade de Bartlett, cuja hipótese nula é a existência de correlação entre variáveis. Calculou-se também a medição de adequação de amostragem de Kaiser-Meyer-Olkin - MSA (Tabela 9).

Tabela 9 - Medição de Kaiser-Meyer Olkin e teste de esfericidade de Bartlett para correlação entre variáveis

( $H_{0}$ : há correlação)

\begin{tabular}{|c|c|c|}
\hline \multicolumn{2}{|c|}{$\begin{array}{l}\text { Medição geral Kaiser-Meyer-Olkin de adequação de } \\
\text { amostragem - MSA }\end{array}$} & 0,936 \\
\hline \multirow{3}{*}{$\begin{array}{l}\text { Teste de esfericidade de } \\
\text { Bartlett }\end{array}$} & Qui-quadrado aproximado & 7690,632 \\
\hline & Graus de liberdade & 820 \\
\hline & Significância & 0,000 \\
\hline
\end{tabular}

Espera-se que o MSA, geral e individual para cada variável, seja superior a 0,5. Caso haja variáveis com MSA menor que 0,5, deve-se proceder à exclusão da variável com menor MSA e repetir-se o teste até que o MSA de todas as variáveis seja maior que 0,5. Os resultados apresentados na Tabela 9 confirmam que: (i) as 
variáveis são fatoráveis, conforme demonstrado pelo MSA geral de 0,936 ; e (ii) as correlações entre as variáveis são significantes a $1 \%$, conforme o teste de esfericidade de Bartlett.

Todas as variáveis apresentaram MSA individual consideravelmente acima do limite inferior de 0,5, conforme indicado na diagonal da Tabela 10. Logo, nenhuma delas foi excluída.

Tabela 10 - Medições de adequação de amostragem de Kaiser-Meyer-Olkin - MSA e correlações parciais entre variáveis

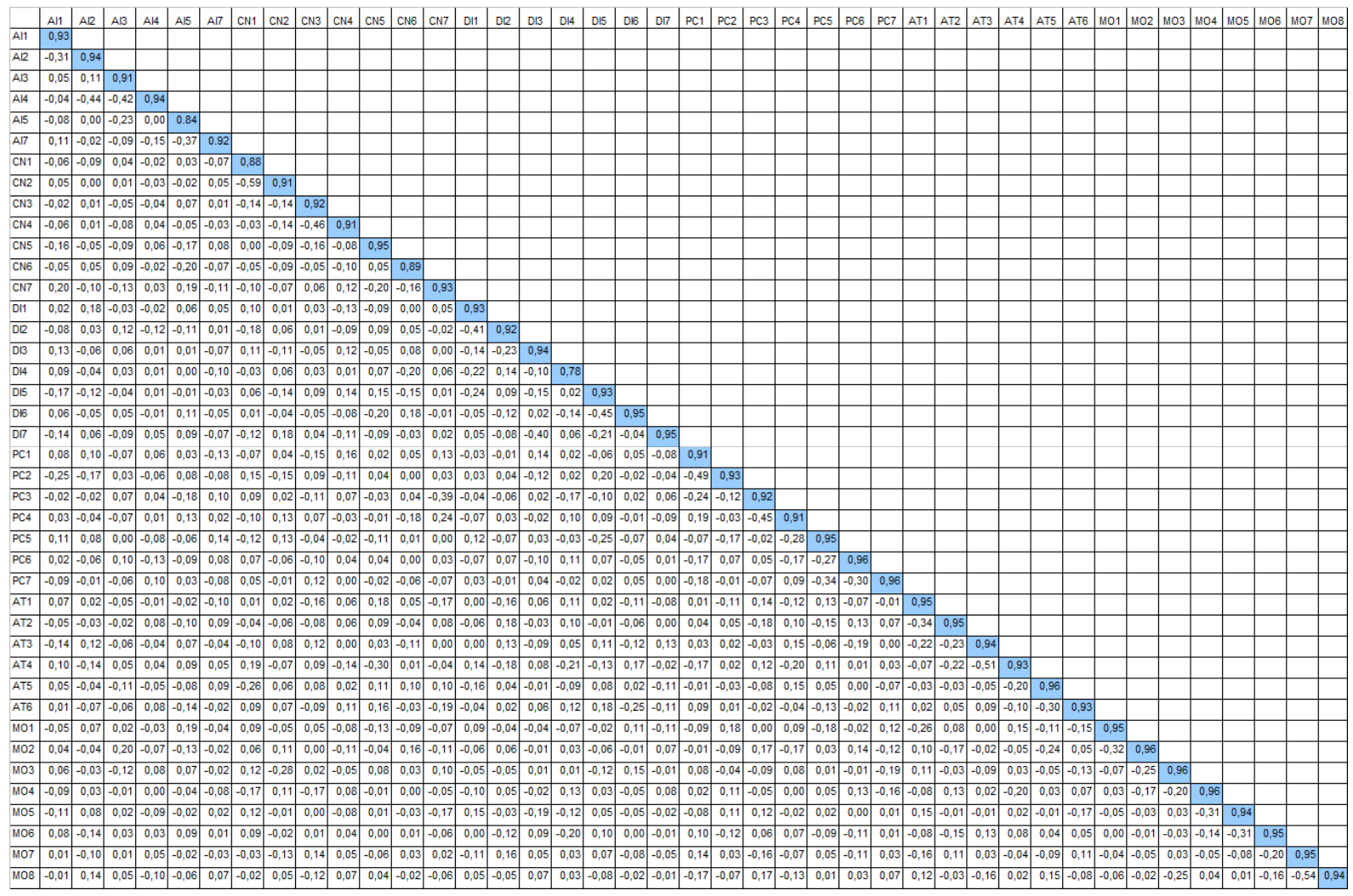

Nota: as medições de adequação de amostragem (MSA) estão grifadas na diagonal. As demais células ilustram correlações parciais.

Procedeu-se à extração e avaliação do ajuste dos fatores. Há razões para predeterminar que seis fatores, correspondentes aos seis construtos identificados na revisão da literatura, deveriam ser extraídos. No entanto, Hair et al. (2010) observaram que a decisão quanto ao número de fatores requer outras considerações. Assim, para selecionar o número de componentes a reter na análise, empregaram-se os seguintes critérios: (i) identificar os fatores com raízes latentes, ou autovalores (eigenvalues) maiores que um; (ii) identificar os fatores que cumulativamente expliquem mais de $60 \%$ da variância total; e (iii) considerar 
soluções alternativas (um fator a mais ou a menos que a solução inicial) para assegurar a identificação da melhor estrutura de dados.

A Tabela 11 demonstra que sete fatores apresentaram autovalor maior que um e, portanto, podem ser considerados significantes. Dentre esses, também se observa que qualquer solução entre quatro e sete fatores gera um percentual acumulado de variância total explicada superior a $60 \%$.

Tabela 11 - Número de fatores a extrair pelo critério de autovalor (eigenvalues) e percentual da variância total explicada pelos fatores

\begin{tabular}{|c|c|c|c|c|c|c|c|c|c|}
\hline \multirow{2}{*}{ Componentes } & \multicolumn{3}{|c|}{ Autovalores iniciais } & \multicolumn{3}{|c|}{$\begin{array}{c}\text { Somas das cargas quadradas } \\
\text { extraídas }\end{array}$} & \multicolumn{3}{|c|}{$\begin{array}{c}\text { Somas das cargas quadradas } \\
\text { rotacionadas }\end{array}$} \\
\hline & total & $\begin{array}{c}\% \text { da } \\
\text { variância }\end{array}$ & $\begin{array}{c}\% \\
\text { acumulado }\end{array}$ & total & $\begin{array}{c}\% \text { da } \\
\text { variância }\end{array}$ & $\begin{array}{c}\% \\
\text { acumulado }\end{array}$ & total & $\begin{array}{c}\% \text { da } \\
\text { variância }\end{array}$ & $\begin{array}{c}\% \\
\text { acumulado }\end{array}$ \\
\hline 1 & 18,413 & 44,909 & 44,909 & 18,413 & 44,909 & 44,909 & 6,130 & 14,950 & 14,950 \\
\hline 2 & 2,908 & 7,093 & 52,002 & 2,908 & 7,093 & 52,002 & 6,073 & 14,812 & 29,762 \\
\hline 3 & 2,239 & 5,460 & 57,462 & 2,239 & 5,460 & 57,462 & 4,511 & 11,002 & 40,764 \\
\hline 4 & 1,988 & 4,849 & 62,311 & 1,988 & 4,849 & 62,311 & 4,385 & 10,694 & 51,458 \\
\hline 5 & 1,473 & 3,592 & 65,903 & 1,473 & 3,592 & 65,903 & 4,243 & 10,349 & 61,807 \\
\hline 6 & 1,218 & 2,972 & 68,875 & 1,218 & 2,972 & 68,875 & 2,741 & 6,684 & 68,491 \\
\hline 7 & 1,100 & 2,683 & 71,558 & 1,100 & 2,683 & 71,558 & 1,257 & 3,066 & 71,558 \\
\hline 8 & ,895 & 2,184 & 73,741 & & & & & & \\
\hline 9 & ,819 & 1,998 & 75,739 & & & & & & \\
\hline 10 &, 752 & 1,834 & 77,573 & & & & & & \\
\hline 11 & ,674 & 1,643 & 79,216 & & & & & & \\
\hline 12 &, 644 & 1,571 & 80,788 & & & & & & \\
\hline 13 &, 604 & 1,473 & 82,261 & & & & & & \\
\hline 14 &, 573 & 1,399 & 83,659 & & & & & & \\
\hline 15 &, 553 & 1,348 & 85,007 & & & & & & \\
\hline 16 & ,482 & 1,174 & 86,181 & & & & & & \\
\hline 17 & ,459 & 1,119 & 87,300 & & & & & & \\
\hline 18 &, 434 & 1,059 & 88,359 & & & & & & \\
\hline 19 & ,412 & 1,005 & 89,364 & & & & & & \\
\hline 20 & ,388 & ,947 & 90,312 & & & & & & \\
\hline 21 & ,355 & ,865 & 91,177 & & & & & & \\
\hline 22 & ,342 & ,835 & 92,012 & & & & & & \\
\hline 23 & ,301 & ,733 & 92,745 & & & & & & \\
\hline 24 & ,278 & ,677 & 93,422 & & & & & & \\
\hline 25 & ,268 &, 655 & 94,077 & & & & & & \\
\hline 26 & ,249 & ,606 & 94,683 & & & & & & \\
\hline 27 & ,239 &, 584 & 95,267 & & & & & & \\
\hline 28 & ,210 &, 512 & 95,779 & & & & & & \\
\hline 29 & ,201 & ,490 & 96,269 & & & & & & \\
\hline 30 &, 180 & ,440 & 96,708 & & & & & & \\
\hline 31 &, 170 & ,414 & 97,122 & & & & & & \\
\hline 32 & ,162 & ,396 & 97,518 & & & & & & \\
\hline 33 & ,153 & ,372 & 97,890 & & & & & & \\
\hline 34 &, 140 & ,341 & 98,231 & & & & & & \\
\hline 35 & ,132 & ,322 & 98,554 & & & & & & \\
\hline 36 & ,121 & ,296 & 98,850 & & & & & & \\
\hline 37 &, 113 & ,276 & 99,125 & & & & & & \\
\hline 38 & , 107 & ,260 & 99,386 & & & & & & \\
\hline 39 & ,098 & ,239 & 99,625 & & & & & & \\
\hline 40 &, 085 & ,207 & 99,831 & & & & & & \\
\hline 41 &, 069 & ,169 & 100,000 & & & & & & \\
\hline
\end{tabular}

Nota: método de extração - análise de componentes principais. 
A matriz de cargas fatoriais constante da Tabela 12 sugere uma solução com seis a sete fatores. As células grifadas indicam cargas fatoriais maiores que 0,7, consideradas significantes para interpretação.

Tabela 12 - Matriz de fatores considerando todas as variáveis

\begin{tabular}{|c|c|c|c|c|c|c|c|c|}
\hline & \multicolumn{7}{|c|}{ Fatores } & \multirow{2}{*}{ Comunalidade } \\
\hline & 1 & 2 & 3 & 4 & 5 & 6 & 7 & \\
\hline Al1 & 0,445 & 0,124 & 0,218 & 0,472 & $-0,006$ & 0,196 & $-0,204$ & 0,564 \\
\hline $\mathrm{Al} 2$ & 0,421 & 0,386 & 0,237 & 0,382 & 0,079 & 0,330 & $-0,128$ & 0,659 \\
\hline $\mathrm{Al} 3$ & 0,140 & 0,076 & 0,101 & 0,231 & 0,203 & 0,711 & $-0,081$ & 0,643 \\
\hline Al4 & 0,324 & 0,315 & 0,253 & 0,360 & 0,076 & 0,549 & $-0,145$ & 0,726 \\
\hline $\mathrm{Al} 5$ & 0,171 & 0,002 & 0,016 & 0,203 & 0,057 & 0,730 & 0,185 & 0,642 \\
\hline Al7 & 0,054 & 0,173 & 0,159 & 0,148 & 0,079 & 0,751 & 0,138 & 0,669 \\
\hline CN1 & 0,080 & 0,091 & 0,126 & 0,795 & 0,164 & 0,192 & 0,043 & 0,728 \\
\hline CN2 & 0,130 & 0,197 & 0,122 & 0,793 & 0,192 & 0,128 & 0,098 & 0,763 \\
\hline CN3 & 0,149 & 0,120 & 0,147 & 0,781 & 0,120 & 0,154 & 0,002 & 0,707 \\
\hline CN4 & 0,049 & 0,053 & 0,220 & 0,766 & 0,146 & 0,146 & 0,024 & 0,683 \\
\hline CN5 & 0,318 & 0,327 & 0,234 & 0,531 & 0,169 & 0,110 & 0,052 & 0,588 \\
\hline CN6 & 0,222 & 0,073 & $-0,081$ & 0,377 & 0,042 & 0,224 & 0,640 & 0,665 \\
\hline CN7 & 0,151 & 0,616 & 0,152 & 0,171 & 0,287 & 0,201 & 0,180 & 0,610 \\
\hline $\mathrm{Dl1}$ & 0,163 & 0,145 & 0,759 & 0,155 & 0,226 & 0,007 & 0,192 & 0,736 \\
\hline DI2 & 0,136 & 0,156 & 0,733 & 0,308 & 0,075 & 0,122 & $-0,018$ & 0,696 \\
\hline DI3 & 0,156 & 0,227 & 0,796 & 0,105 & 0,088 & 0,103 & 0,052 & 0,741 \\
\hline $\mathrm{DI} 4$ & 0,018 & 0,220 & 0,322 & $-0,144$ & 0,034 & 0,031 & 0,677 & 0,633 \\
\hline DI5 & 0,403 & 0,219 & 0,639 & 0,200 & 0,204 & 0,100 & 0,144 & 0,730 \\
\hline DI6 & 0,312 & 0,373 & 0,604 & 0,277 & 0,228 & 0,089 & 0,053 & 0,741 \\
\hline DI7 & 0,283 & 0,231 & 0,706 & 0,173 & 0,140 & 0,184 & $-0,051$ & 0,718 \\
\hline $\mathrm{PC} 1$ & 0,772 & 0,033 & 0,085 & 0,068 & 0,265 & 0,175 & 0,012 & 0,710 \\
\hline PC2 & 0,774 & 0,121 & 0,127 & 0,188 & 0,144 & 0,191 & $-0,090$ & 0,731 \\
\hline PC3 & 0,697 & 0,218 & 0,245 & 0,093 & 0,200 & 0,093 & 0,251 & 0,714 \\
\hline PC4 & 0,685 & 0,264 & 0,235 & 0,109 & 0,131 & $-0,034$ & 0,108 & 0,636 \\
\hline PC5 & 0,774 & 0,278 & 0,275 & 0,143 & 0,202 & 0,088 & 0,076 & 0,827 \\
\hline PC6 & 0,755 & 0,279 & 0,177 & 0,143 & 0,220 & 0,091 & 0,018 & 0,757 \\
\hline PC7 & 0,742 & 0,276 & 0,128 & 0,074 & 0,248 & 0,147 & 0,090 & 0,740 \\
\hline AT1 & 0,234 & 0,344 & 0,221 & 0,240 & 0,665 & 0,172 & $-0,040$ & 0,754 \\
\hline AT2 & 0,302 & 0,267 & 0,134 & 0,241 & 0,746 & 0,068 & 0,054 & 0,802 \\
\hline AT3 & 0,360 & 0,317 & 0,088 & 0,193 & 0,755 & 0,100 & 0,050 & 0,858 \\
\hline AT4 & 0,334 & 0,359 & 0,166 & 0,204 & 0,711 & 0,084 & 0,076 & 0,827 \\
\hline AT5 & 0,218 & 0,354 & 0,353 & 0,114 & 0,614 & 0,271 & $-0,004$ & 0,761 \\
\hline AT6 & 0,169 & 0,490 & 0,335 & $-0,081$ & 0,311 & 0,303 & $-0,035$ & 0,578 \\
\hline MO1 & 0,202 & 0,587 & 0,340 & 0,127 & 0,397 & 0,097 & 0,019 & 0,685 \\
\hline MO2 & 0,300 & 0,581 & 0,279 & 0,143 & 0,508 & 0,113 & 0,002 & 0,797 \\
\hline MO3 & 0,361 & 0,534 & 0,243 & 0,209 & 0,439 & 0,107 & 0,057 & 0,726 \\
\hline MO4 & 0,173 & 0,659 & 0,197 & 0,283 & 0,350 & 0,159 & 0,056 & 0,734 \\
\hline MO5 & 0,070 & 0,810 & 0,240 & 0,076 & 0,085 & 0,138 & 0,078 & 0,758 \\
\hline MO6 & 0,246 & 0,817 & 0,135 & 0,082 & 0,109 & $-0,015$ & 0,084 & 0,772 \\
\hline MO7 & 0,334 & 0,718 & 0,145 & 0,190 & 0,301 & 0,021 & 0,073 & 0,781 \\
\hline MO8 & 0,406 & 0,664 & 0,112 & 0,176 & 0,319 & 0,012 & 0,040 & 0,753 \\
\hline
\end{tabular}

Notas: a) método de extração - análise de componentes principais; b) método de rotação VARIMAX com normalização de Kaiser; c) a rotação convergiu em 7 iterações. 
Todas as variáveis com carga fatorial acima do limite mínimo de 0,7 apresentaram cargas fatoriais altas em um só fator. Todas as variáveis apresentaram comunalidade maior que 0,5. Verificou-se um padrão de agrupamento das variáveis significantes nos fatores de 1 a 6 . Desconsiderou-se o fator 7 por não apresentar nenhuma variável com carga fatorial maior que 0,7. Logo, a estrutura que emergiu da análise fatorial exploratória permitiu a identificação dos seis fatores, ou construtos latentes, e 22 variáveis que serão utilizados nos passos seguintes da análise do modelo estrutural (Tabela 13).

Tabela 13 - Estrutura reduzida de construtos latentes e variáveis observáveis resultante da análise fatorial exploratória

\begin{tabular}{|c|c|c|}
\hline \multicolumn{2}{|c|}{ Fatores (construtos latentes) } & \multirow{2}{*}{ Variáveis observáveis } \\
\hline número & Nome & PC1, PC2, PC5, PC6, PC7 \\
\hline 1 & Liderança do Presidente do CA (PC) & MO5, MO6, MO7 \\
\hline 2 & Eficácia na Monitoração da IE (MO) & DI1, DI2, DI3, DI7 \\
\hline 3 & Dinâmica de Trabalho do CA (DI) & CN1, CN2, CN3, CN4 \\
\hline 4 & Conhecimento do Negócio (CN) & AT2, AT3, AT4 \\
\hline 5 & Atenção à Monitoração da IE (AT) & Al3, Al5, Al7 \\
\hline 6 & Acesso a Informações (AI) & \\
\hline
\end{tabular}

\subsection{2. \\ Desenvolvimento do modelo de medidas teórico}

Desenvolveu-se o modelo de medidas teórico, ilustrado na Figura 6, a partir dos construtos latentes e variáveis observáveis listados na Tabela 13. Todas as medidas são, por hipótese, reflexivas; ou seja, com direção de causalidade do construto latente para as variáveis observáveis. Como ainda não se sabe se os construtos são independentes, todos são correlacionados uns aos outros. Por hipótese, o modelo é congenérico, uma vez que não se admitiram cargas cruzadas entre variáveis observáveis e construtos ou entre erros.

Conforme a Tabela 14, o modelo de medidas teórico tem 253 graus de liberdade e 59 parâmetros a serem estimados. Logo, é sobreidentificado, o que significa que contém informação suficiente para identificar uma solução para o conjunto de equações estruturais. Espera-se, portanto, que o modelo gere resultados confiáveis. 


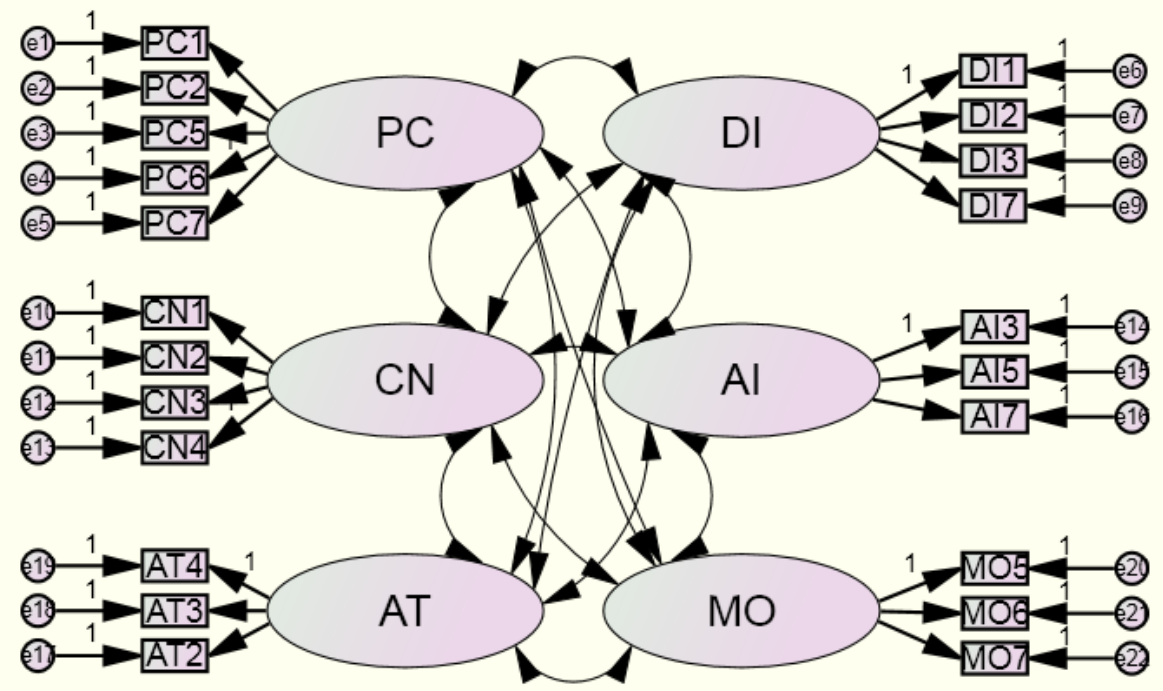

Figura 6 - Modelo de medidas teórico

Tabela 14 - Identificação de parâmetros a serem estimados e graus de liberdade do Modelo de medidas

\begin{tabular}{|c|c|c|}
\hline Parâmetros a serem estimados & & 59 \\
\hline Cargas fatoriais das variáveis observáveis & 22 & \\
\hline (-) Cargas fatoriais dos construtos & (6) & \\
\hline (+) Variâncias dos construtos & 6 & \\
\hline (+) Covariâncias entre construtos & 15 & \\
\hline (+) Termos de erro das variáveis observáveis & 22 & \\
\hline Graus de liberdade & & 253 \\
\hline
\end{tabular}

O modelo de medidas teórico foi testado quanto à sua validade por meio de análise fatorial confirmatória (CFA). Os resultados de ajuste do modelo constam da Tabela 15. O qui-quadrado de 405,038 é significante a $1 \%(p=0,000)$. O índice qui-quadrado dividido pelo número de graus de liberdade, no valor de 2,088, está contido no intervalo entre 2 e 5 e é considerado aceitável. Adicionalmente, deve-se analisar pelo menos um índice de ajuste absoluto e um índice de ajuste incremental (Hair et al., 2010). A raiz do erro quadrático médio de aproximação $(\mathrm{RMSEA}=0,071)$ é menor que o valor de referência máximo de 0,08 para um modelo com 22 variáveis e 217 observações. O índice de ajuste comparativo $(\mathrm{CFI}=0,937)$ é superior ao valor de referência mínimo de 0,9. Analisados em conjunto, os resultados permitem inferir que o modelo de medidas 
teórico fornece um ajuste aceitável e que, portanto, pode-se proceder às etapas seguintes de análise do modelo estrutural.

Tabela 15 - Resultados de qualidade de ajuste do Modelo de medidas

\begin{tabular}{|lr|}
\hline Qui-quadrado & 405,038 \\
\hline Graus de liberdade & 194 \\
Qui-quadrado/graus de liberdade & 2,088 \\
$P$ & 0 \\
\hline Medidas de ajuste absoluto & 0,071 \\
\hline Raiz do erro quadrático médio de aproximação (RMSEA) & 0,061 \\
Intervalo de confiança & 0,081 \\
\hline Medidas de ajuste incremental & 0,937 \\
\hline \multicolumn{2}{|l}{ Índice de ajuste comparativo (CFI) } \\
\hline Medidas de ajuste parcimonioso & 523,038 \\
\hline Critério de informação de Akaike (AIC)
\end{tabular}

O passo seguinte foi uma análise da validade convergente, discriminante e nomológica dos construtos. Conforme discutido na seção 5.2.3, sua validade de face foi estabelecida com base no conteúdo dos itens componentes das escalas. Quanto à validade convergente, examinou-se a matriz de cargas fatoriais não padronizadas constante da Tabela 16. Todas as cargas não padronizadas do modelo de medidas foram significantes a $1 \%$, conforme requerido para indicação de validade convergente. Todas as correlações entre construtos latentes previstas no modelo de medidas foram significantes a $1 \%^{2}$.

Investigou-se a confiabilidade do modelo de medidas por meio de análise das cargas fatoriais padronizadas (Tabela 17). Todas as cargas fatoriais padronizadas individuais foram maiores que o valor de referência mínimo de 0,7, à exceção de uma variável, AI5, que apresentou carga fatorial de 0,692. No entanto, esse valor é suficientemente próximo de 0,7 , e como tal não foi considerado fonte de problemas. As estimativas de variância média extraída dos construtos latentes variaram entre 49,0\% para Acesso a Informações (AI) e 82,8\% para Atenção à Monitoração da IE (AT). Todas excederam o valor de referência mínimo de 50\%, à exceção da estimativa para o construto AI que, entretanto, pode

\footnotetext{
${ }^{2}$ Tabela não incluída por razões de espaço.
} 
ser considerado suficientemente próximo de 50\%. Os índices de confiabilidade composta de todos os construtos latentes foram maiores que o valor de referência mínimo de 0,7 (Nunnally \& Bernstein, 1994; Hair et al., 2010), sugerindo um adequado grau de confiabilidade.

Tabela 16 - Cargas fatoriais não-padronizadas e significância do Modelo de medidas

\begin{tabular}{|c|c|c|c|c|c|c|}
\hline $\begin{array}{l}\text { Variáveis } \\
\text { observáveis }\end{array}$ & & Construtos & Carga estimada & Erro padrão & $t$-value & $P$ \\
\hline PC6 & $\leftarrow$ & PC & 1,000 & & & \\
\hline PC5 & $\leftarrow$ & PC & 1,017 & 0,053 & 19,172 & $* * *$ \\
\hline PC2 & $\leftarrow$ & PC & 0,880 & 0,063 & 13,933 & *** \\
\hline PC1 & $\leftarrow$ & PC & 0,844 & 0,059 & 14,343 & $* * *$ \\
\hline CN4 & $\leftarrow$ & $\mathrm{CN}$ & 1,000 & & & \\
\hline CN3 & $\leftarrow$ & $\mathrm{CN}$ & 1,116 & 0,099 & 11,317 & $* * *$ \\
\hline CN2 & $\leftarrow$ & $\mathrm{CN}$ & 1,284 & 0,102 & 12,549 & $* * *$ \\
\hline CN1 & $\leftarrow$ & $\mathrm{CN}$ & 1,179 & 0,096 & 12,237 & $* * *$ \\
\hline AT4 & $\leftarrow$ & AT & 1,000 & & & \\
\hline АT3 & $\leftarrow$ & AT & 0,972 & 0,040 & 24,500 & $* * *$ \\
\hline AT2 & $\leftarrow$ & AT & 0,929 & 0,048 & 19,308 & $* * *$ \\
\hline DI1 & $\leftarrow$ & $\mathrm{DI}$ & 1,000 & & & \\
\hline DI2 & $\leftarrow$ & DI & 0,772 & 0,066 & 11,695 & $* * *$ \\
\hline DI3 & $\leftarrow$ & DI & 1,018 & 0,083 & 12,227 & $* * *$ \\
\hline DI7 & $\leftarrow$ & DI & 1,076 & 0,090 & 12,022 & $* * *$ \\
\hline PC7 & $\leftarrow$ & PC & 1,028 & 0,058 & 17,629 & $* * *$ \\
\hline MO5 & $\leftarrow$ & MO & 1,000 & & & \\
\hline MO6 & $\leftarrow$ & $\mathrm{MO}$ & 1,442 & 0,119 & 12,099 & $* * *$ \\
\hline MO7 & $\leftarrow$ & MO & 1,267 & 0,101 & 12,503 & $* * *$ \\
\hline $\mathrm{Al} 3$ & $\leftarrow$ & $\mathrm{Al}$ & 1,000 & & & \\
\hline Al5 & $\leftarrow$ & $\mathrm{Al}$ & 1,206 & 0,153 & 7,870 & $* * *$ \\
\hline $\mathrm{Al} 7$ & $\leftarrow$ & $\mathrm{Al}$ & 1,155 & 0,145 & 7,941 & $* * *$ \\
\hline
\end{tabular}

Nota: ${ }^{* *}$ significante a $0,1 \%$

Analisados como um todo, conclui-se que os resultados suportaram a validade convergente do modelo de medidas. 
Tabela 17 - Cargas fatoriais padronizadas, variância média extraída e confiabilidade composta dos construtos do Modelo de medidas

\begin{tabular}{|c|c|c|c|c|c|c|}
\hline \multirow{2}{*}{ Variáveis observáveis } & \multicolumn{6}{|c|}{ Construtos } \\
\hline & $\mathrm{Al}$ & AT & $\mathrm{CN}$ & $\mathrm{DI}$ & MO & $\mathrm{PC}$ \\
\hline $\mathrm{Al} 3$ & 0,702 & & & & & \\
\hline Al5 & 0,692 & & & & & \\
\hline Al7 & 0,705 & & & & & \\
\hline AT2 & & 0,858 & & & & \\
\hline AT3 & & 0,944 & & & & \\
\hline AT4 & & 0,926 & & & & \\
\hline CN1 & & & 0,852 & & & \\
\hline CN2 & & & 0,876 & & & \\
\hline CN3 & & & 0,788 & & & \\
\hline CN4 & & & 0,735 & & & \\
\hline DI1 & & & & 0,765 & & \\
\hline DI2 & & & & 0,790 & & \\
\hline DI3 & & & & 0,825 & & \\
\hline DI7 & & & & 0,811 & & \\
\hline MO5 & & & & & 0,747 & \\
\hline MO6 & & & & & 0,838 & \\
\hline $\mathrm{MO} 7$ & & & & & 0,875 & \\
\hline PC1 & & & & & & 0,776 \\
\hline PC2 & & & & & & 0,762 \\
\hline PC5 & & & & & & 0,906 \\
\hline PC6 & & & & & & 0,877 \\
\hline $\mathrm{PC7}$ & & & & & & 0,869 \\
\hline Variância média extraída (AVE) & $49,0 \%$ & $82,8 \%$ & $66,4 \%$ & $63,7 \%$ & $67,5 \%$ & $70,6 \%$ \\
\hline Confiabilidade composta & 0,742 & 0,935 & 0,887 & 0,875 & 0,861 & 0,923 \\
\hline
\end{tabular}

Como passo seguinte, analisou-se a validade discriminante do modelo de medidas. A Tabela 18 ilustra as correlações quadradas entre os construtos latentes, que devem ser menores que as respectivas variâncias médias extraídas (AVE). Verifica-se que todas as estimativas de AVE constantes da Tabela 17 são maiores que as respectivas correlações quadradas indicadas na Tabela 18. Logo, o teste indicou que o modelo de medidas não apresenta problemas de validade discriminante. 
Tabela 18 - Correlações quadradas entre construtos latentes

\begin{tabular}{|cccc|}
\hline \multicolumn{2}{|c|}{$\begin{array}{c}\text { Construtos } \\
\text { latentes }\end{array}$} & $\begin{array}{c}\text { Correlações } \\
\text { quadradas }\end{array}$ \\
\hline $\mathrm{AT}$ & $\leftrightarrow$ & $\mathrm{DI}$ & 0,247 \\
$\mathrm{AT}$ & $\leftrightarrow$ & $\mathrm{Al}$ & 0,173 \\
$\mathrm{AT}$ & $\leftrightarrow$ & $\mathrm{MO}$ & 0,483 \\
$\mathrm{CN}$ & $\leftrightarrow$ & $\mathrm{DI}$ & 0,250 \\
$\mathrm{CN}$ & $\leftrightarrow$ & $\mathrm{Al}$ & 0,316 \\
$\mathrm{CN}$ & $\leftrightarrow$ & $\mathrm{MO}$ & 0,177 \\
$\mathrm{CN}$ & $\leftrightarrow$ & $\mathrm{AT}$ & 0,231 \\
$\mathrm{DI}$ & $\leftrightarrow$ & $\mathrm{Al}$ & 0,193 \\
$\mathrm{DI}$ & $\leftrightarrow$ & $\mathrm{MO}$ & 0,328 \\
$\mathrm{MO}$ & $\leftrightarrow$ & $\mathrm{Al}$ & 0,125 \\
$\mathrm{PC}$ & $\leftrightarrow$ & $\mathrm{DI}$ & 0,321 \\
$\mathrm{PC}$ & $\leftrightarrow$ & $\mathrm{Al}$ & 0,205 \\
$\mathrm{PC}$ & $\leftrightarrow$ & $\mathrm{MO}$ & 0,404 \\
$\mathrm{PC}$ & $\leftrightarrow$ & $\mathrm{CN}$ & 0,188 \\
$\mathrm{PC}$ & $\leftrightarrow$ & $\mathrm{AT}$ & 0,465 \\
\hline
\end{tabular}

A Tabela 19 contém as correlações entre as cargas fatoriais de cada construto latente, necessárias para que se avalie a validade nomológica do modelo de medidas.

Tabela 19 - Correlações entre construtos do modelo de medidas

\begin{tabular}{|cccc|}
\hline \multicolumn{2}{|c|}{$\begin{array}{c}\text { Construtos } \\
\text { latentes }\end{array}$} & Correlações \\
\hline $\mathrm{AT}$ & $\leftrightarrow$ & $\mathrm{DI}$ & 0,497 \\
$\mathrm{AT}$ & $\leftrightarrow$ & $\mathrm{Al}$ & 0,416 \\
$\mathrm{AT}$ & $\leftrightarrow$ & $\mathrm{MO}$ & 0,695 \\
$\mathrm{CN}$ & $\leftrightarrow$ & $\mathrm{DI}$ & 0,500 \\
$\mathrm{CN}$ & $\leftrightarrow$ & $\mathrm{Al}$ & 0,562 \\
$\mathrm{CN}$ & $\leftrightarrow$ & $\mathrm{MO}$ & 0,421 \\
$\mathrm{CN}$ & $\leftrightarrow$ & $\mathrm{AT}$ & 0,481 \\
$\mathrm{DI}$ & $\leftrightarrow$ & $\mathrm{Al}$ & 0,439 \\
$\mathrm{DI}$ & $\leftrightarrow$ & $\mathrm{MO}$ & 0,573 \\
$\mathrm{MO}$ & $\leftrightarrow$ & $\mathrm{Al}$ & 0,353 \\
$\mathrm{PC}$ & $\leftrightarrow$ & $\mathrm{DI}$ & 0,567 \\
$\mathrm{PC}$ & $\leftrightarrow$ & $\mathrm{Al}$ & 0,453 \\
$\mathrm{PC}$ & $\leftrightarrow$ & $\mathrm{MO}$ & 0,636 \\
$\mathrm{PC}$ & $\leftrightarrow$ & $\mathrm{CN}$ & 0,434 \\
$\mathrm{PC}$ & $\leftrightarrow$ & $\mathrm{AT}$ & 0,682 \\
\hline
\end{tabular}


A análise de validade nomológica visa verificar se as correlações entre os construtos latentes se comportam conforme as indicações fornecidas pela teoria. Com base na pesquisa em eficácia de CAs, espera-se que avaliações mais favoráveis dos construtos produzam resultados positivos na eficácia de um CA na tarefa de monitoração da IE. Todos os construtos latentes são positivamente correlacionados uns aos outros, conforme as predições da teoria (Tabela 19). Mais especificamente, verifica-se correlação positiva entre a Eficácia na Monitoração da IE (MO) e a Atenção à Monitoração da IE (AT), o Conhecimento do Negócio $(\mathrm{CN})$, a Dinâmica de Trabalho do CA (DI), o Acesso a informações (AI) e a Liderança do presidente do CA (PC). Logo, as correlações entre os construtos latentes da pesquisa suportam a validade nomológica do modelo de medidas.

Apesar dos resultados positivos até este ponto, aplicaram-se outras medidas de diagnóstico para identificar possíveis melhorias no modelo de medidas. Foram analisados os resíduos padronizados constantes da Tabela 20. Resíduos padronizados maiores que $|4|$ denotam possíveis problemas de medição, e resíduos padronizados entre $|2,5|$ e $|4|$ devem ser avaliados se outros testes de diagnóstico indicarem possíveis problemas. Observa-se que nenhum dos resíduos padronizados é maior que esses valores de referência. Logo, as medidas de diagnóstico adicionais não indicaram a necessidade de exclusão de variáveis para reespecificação do modelo de medidas.

Em suma, os resultados da análise fatorial confirmatória suportaram o modelo de medidas teórico. As estatísticas de ajuste sugeriram que o modelo de medidas reproduz suficientemente bem a matriz de covariância da amostra. Há evidência suficiente de validade de face, convergente, discriminante e nomológica dos construtos latentes. Assim, validam-se as escalas desenvolvidas para mensurar os antecedentes da Eficácia na Monitoração da IE e considera-se que o questionário da pesquisa mede adequadamente os construtos latentes.

Pode-se, portanto, proceder à análise dos modelos estruturais de relações entre os construtos da pesquisa com o objetivo de examinar empiricamente a natureza das ligações entre eles. 
Tabela 20 - Resíduos padronizados do modelo de medidas

\begin{tabular}{|c|c|c|c|c|c|c|c|c|c|c|c|c|c|c|c|c|c|c|c|c|c|c|}
\hline & Al7 & Al5 & $\mathrm{Al} 3$ & MO7 & MO6 & MO5 & $\mathrm{PC7}$ & D17 & DI3 & $\mathrm{DI} 2$ & DI1 & AT2 & AT3 & AT4 & CN1 & $\mathrm{CN} 2$ & $\mathrm{CN} 3$ & $\mathrm{CN} 4$ & PC1 & $\mathrm{PC} 2$ & $\mathrm{PC5}$ & PC6 \\
\hline A17 & 0,0 & & & & & & & & & & & & & & & & & & & & & \\
\hline Al5 & 0,4 & 0,0 & & & & & & & & & & & & & & & & & & & & \\
\hline $\mathrm{Al} 3$ & $-0,3$ & $-0,1$ & 0,0 & & & & & & & & & & & & & & & & & & & \\
\hline MO7 & 0,7 & $-0,3$ & 0,5 & 0,0 & & & & & & & & & & & & & & & & & & \\
\hline MO6 & 0,1 & $-1,6$ & $-0,8$ & $-0,1$ & 0,0 & & & & & & & & & & & & & & & & & \\
\hline MO5 & 1,4 & \begin{tabular}{|l} 
\\
\end{tabular} & 0,5 & $-0,5$ & 0,8 & 0,0 & & & & & & & & & & & & & & & & \\
\hline $\mathrm{PC7}$ & 0,1 & \begin{tabular}{|l}
$-0,1$ \\
\end{tabular} & 0,4 & 0,4 & $-0,1$ & $-0,4$ & 0,0 & & & & & & & & & & & & & & & \\
\hline DI7 & 1,3 & \begin{tabular}{|l|} 
\\
\end{tabular} & 1,2 & 0,7 & $-0,2$ & 1,2 & 0,3 & 0,0 & & & & & & & & & & & & & & \\
\hline DI3 & 0,6 & \begin{tabular}{|l} 
\\
\end{tabular} & $-0,6$ & $-0,5$ & $-0,7$ & 1,3 & $-0,9$ & 0,6 & \begin{tabular}{|l} 
\\
\end{tabular} & & & & & & & & & & & & & \\
\hline DI2 & 0,8 & $-0,2$ & 0,0 & $-0,8$ & $-0,6$ & 0,3 & $-1,0$ & $-0,4$ & $-0,2$ & 0,0 & & & & & & & & & & & & \\
\hline DI1 & $-0,2$ & \begin{tabular}{|l}
$-0,9$ \\
\end{tabular} & $-0,2$ & 0,6 & $-0,3$ & 0,1 & $-0,2$ & $-0,7$ & \begin{tabular}{|l}
$-0,1$ \\
\end{tabular} & 0,9 & 0,0 & & & & & & & & & & & \\
\hline AT2 & $-0,3$ & \begin{tabular}{|l}
$-0,1$ \\
\end{tabular} & 0,8 & 0,7 & $-0,3$ & $-0,7$ & $-0,2$ & 0,8 & $-0,1$ & $-0,5$ & 0,8 & 0,0 & & & & & & & & & & \\
\hline AT3 & $-0,1$ & $-0,8$ & 0,9 & 0,7 & $-1,1$ & $-0,7$ & 0,1 & 0,1 & $-0,7$ & $-1,1$ & \begin{tabular}{|l} 
\\
\end{tabular} & 0,0 & 0,0 & & & & & & & & & \\
\hline AT4 & $-0,1$ & \begin{tabular}{|l}
$-0,8$ \\
\end{tabular} & 0,6 & 1,0 & $-0,6$ & 0,0 & 0,0 & 1,0 & $-0,1$ & 0,0 & \begin{tabular}{|l|}
0,8 \\
\end{tabular} & $-0,1$ & 0,0 & 0,0 & & & & & & & & \\
\hline CN1 & 0,0 & \begin{tabular}{|l} 
\\
\end{tabular} & 0,3 & 0,4 & $-1,5$ & $-1,2$ & $-1,0$ & 0,0 & \begin{tabular}{|l} 
\\
\end{tabular} & 1,0 & \begin{tabular}{|l|} 
\\
\end{tabular} & 0,3 & $-0,5$ & $-0,7$ & 0,0 & & & & & & & \\
\hline $\mathrm{CN} 2$ & $-0,4$ & \begin{tabular}{|l|} 
\\
\end{tabular} & 0,1 & 1,7 & $-0,1$ & 0,0 & $-0,1$ & $-0,4$ & $-0,6$ & 0,6 & $-0,1$ & 1,1 & 0,2 & 0,3 & 0,6 & 0,0 & & & & & & \\
\hline $\mathrm{CN} 3$ & $-0,1$ & $-0,1$ & 1,0 & 0,1 & $-0,5$ & 0,2 & $-0,3$ & 0,4 & $-0,7$ & 1,3 & \begin{tabular}{|l|} 
\\
\end{tabular} & \begin{tabular}{|l|}
0,8 \\
\end{tabular} & $-0,5$ & $-0,2$ & \begin{tabular}{|c|} 
\\
\end{tabular} & $-0,5$ & 0,0 & & & & & \\
\hline $\mathrm{CN} 4$ & 0,0 & \begin{tabular}{|l}
0,3 \\
\end{tabular} & 0,9 & $-0,3$ & $-1,2$ & 0,2 & $-0,7$ & 0,9 & $-0,5$ & 2,0 & 1,0 & 0,3 & $-0,3$ & 0,5 & $-0,7$ & $-0,5$ & 1,8 & 0,0 & & & & \\
\hline PC1 & 0,5 & $\mid-0,1$ & 0,6 & $-0,9$ & $-1,7$ & $-2,1$ & 0,2 & 0,3 & 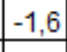 & $\mid-1,1$ & $-0,8$ & $-0,3$ & $\mid-0,1$ & 0,0 & \begin{tabular}{|c|} 
\\
\end{tabular} & $-0,3$ & 0,7 & $-0,8$ & 0,0 & & & \\
\hline $\mathrm{PC} 2$ & 0,8 & 0,2 & 0,8 & 0,1 & $-0,4$ & \begin{tabular}{|l} 
\\
\end{tabular} & $-0,2$ & 1,1 & $-0,5$ & $-0,3$ & $|-0,6|$ & \begin{tabular}{|l|} 
\\
\end{tabular} & $-0,2$ & 0,0 & 0,0 & 1,0 & 1,1 & 0,8 & 2,1 & 0,0 & & \\
\hline PC5 & $-0,9$ & $-0,2$ & 0,4 & 0,7 & 0,1 & $-0,5$ & 0,0 & 1,5 & \begin{tabular}{|l|}
0,1 \\
\end{tabular} & 0,2 & \begin{tabular}{|l|} 
\\
\end{tabular} & 0,2 & $-0,1$ & $-0,3$ & $-0,3$ & 0,2 & 0,8 & 0,0 & $-0,4$ & \begin{tabular}{|l|} 
\\
\end{tabular} & 0,0 & \\
\hline $\mathrm{PC} 6$ & $-0,7$ & $\mid-0,3$ & 0,2 & 1,2 & 0,2 & $-0,6$ & 0,0 & 0,8 & \begin{tabular}{|l}
$-0,2$ \\
\end{tabular} & $-0,5$ & \begin{tabular}{|l|l|}
0,1 \\
\end{tabular} & $-0,1$ & 0,5 & 0,0 & $|-0,5|$ & 0,4 & 0,7 & $-0,4$ & $-0,4$ & $-0,5 \mid$ & 0,2 & 0,0 \\
\hline
\end{tabular}

\subsection{3.}

\section{Especificação e teste de modelos estruturais concorrentes}

O objetivo desta etapa da análise de dados é testar as relações estruturais entre os construtos e as hipóteses de pesquisa. Serão testados quatro modelos concorrentes, desenvolvidos com base na teoria e nas entrevistas com conselheiros de administração.

\subsubsection{1. Modelo 1}

Especificou-se um modelo estrutural que serviu de ponto de partida para a análise das possíveis relações entre os construtos. O Modelo 1 pressupõe que o Acesso a Informações (AI), o Conhecimento do Negócio (CN), a Dinâmica de Trabalho do CA (DI), a Liderança do PCA (PC) e a Atenção à Monitoração da IE 
(AT) estão direta e positivamente relacionados à Eficácia na Monitoração da IE (MO), que é representada como construto endógeno. As hipóteses do Modelo 1 são descritas na Tabela 21. Não há razão para pressupor que os construtos exógenos AI, CN, DI, PC e AT são independentes. Assim, foram incluídas relações de covariância entre eles, as quais serão estimadas no modelo estrutural.

Tabela 21 - Hipóteses do Modelo 1 de Eficácia na Monitoração da IE

\begin{tabular}{|l|l|}
\hline$H_{1}: \mathrm{Al}+\rightarrow \mathrm{MO}$ & $\begin{array}{l}\text { O Acesso a Informações está positivamente relacionado à Eficácia na } \\
\text { Monitoração da IE. }\end{array}$ \\
\hline$H_{2}: \mathrm{CN}+\rightarrow \mathrm{MO}$ & $\begin{array}{l}\text { O Conhecimento do Negócio está positivamente relacionado à Eficácia na } \\
\text { Monitoração da IE. }\end{array}$ \\
\hline$H_{3}: \mathrm{DI}+\rightarrow \mathrm{MO}$ & $\begin{array}{l}\text { A Dinâmica de Trabalho do CA está positivamente relacionada à Eficácia na } \\
\text { Monitoração da IE. }\end{array}$ \\
\hline$H_{4}: \mathrm{PC}+\rightarrow \mathrm{MO}$ & $\begin{array}{l}\text { A Liderança do Presidente do CA está positivamente relacionada à Eficácia } \\
\text { na Monitoração da IE. }\end{array}$ \\
\hline$H_{5}: \mathrm{AT}+\rightarrow \mathrm{MO}$ & $\begin{array}{l}\text { A Atenção à Monitoração da IE está positivamente relacionada à Eficácia na } \\
\text { Monitoração da IE. }\end{array}$ \\
\hline
\end{tabular}

Analisaram-se os resultados do Modelo 1. Os índices de ajuste são os mesmos do modelo de medidas (Tabela 15), uma vez que ambos têm o mesmo número de graus de liberdade (253) e de parâmetros estimados (59). Pela mesma razão, as estimativas de variância média extraída e confiabilidade composta dos construtos latentes também são iguais. A exemplo do modelo de medidas, todos os índices são melhores que os respectivos valores de referência e sugerem que o Modelo 1 fornece um bom ajuste geral.

A Figura 7 ilustra visualmente os parâmetros estruturais padronizados resultantes da aplicação do Modelo 1 aos dados. A significância dos parâmetros encontra-se na Tabela 22. Três dos cinco parâmetros estruturais estimados são significantes e no sentido esperado, indicando que a Dinâmica de Trabalho do CA (DI), a Liderança do PCA (PC) e a Atenção à Monitoração da IE (AT) estão diretamente relacionados à Eficácia na Monitoração da IE (MO). As exceções são as estimativas entre: (i) o Acesso a Informações (AI) e a Eficácia na Monitoração da IE (MO); e (ii) o Conhecimento do Negócio (CN) e a Eficácia na Monitoração da IE (MO). Nenhuma delas apresentou significância estatística. Além disso, a estimativa entre AI e MO apresentou sinal negativo, contrariamente ao esperado. Logo, o Modelo 1 suportou as hipóteses $H_{3}, H_{4}$ e $H_{5}$, mas não as hipóteses $H_{1}$ e 
$\mathrm{H}_{2}$. Conclui-se, portanto, que os resultados validam apenas parcialmente o Modelo 1.

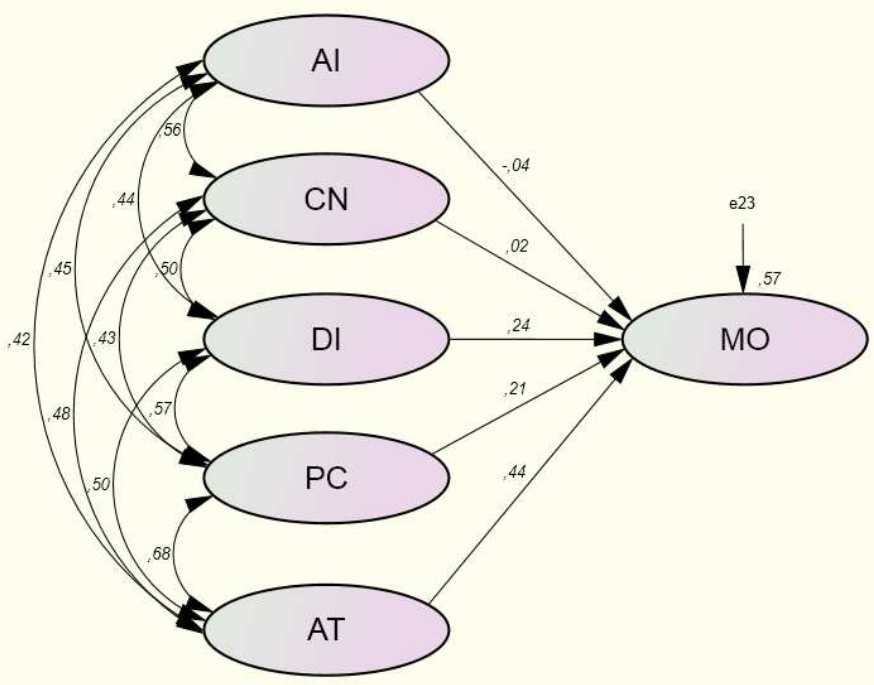

Figura 7 - Parâmetros estruturais padronizados do Modelo 1 de Eficácia na Monitoração da IE

Tabela 22 - Significância dos parâmetros do Modelo 1 de Eficácia na Monitoração da IE

\begin{tabular}{|lccccc|}
\hline \multicolumn{1}{|c}{ Relação estrutural } & $\begin{array}{c}\text { Parâmetros não- } \\
\text { padronizados } \\
\text { estimados }\end{array}$ & $\begin{array}{c}\text { Erro } \\
\text { padrão }\end{array}$ & $t$-value & Significância & $\begin{array}{c}\text { Parâmetros } \\
\text { padronizados } \\
\text { estimados }\end{array}$ \\
\hline$H_{1}:$ Al $+\rightarrow$ MO & $-0,04$ & 0,084 & $-0,511$ & 0,609 & $-0,04$ \\
$H_{2}:$ CN $+\rightarrow$ MO & 0,03 & 0,093 & 0,266 & 0,790 & 0,02 \\
$H_{3}:$ DI $+\rightarrow$ MO & 0,24 & 0,079 & 3,057 & 0,002 & 0,25 \\
$H_{4}:$ PC $+\rightarrow$ MO & 0,15 & 0,063 & 2,374 & 0,018 & 0,21 \\
$H_{5}:$ AT $+\rightarrow$ MO & 0,30 & 0,060 & 5,069 & $* * *$ & 0,43 \\
PC correlacionado a AT & 1,08 & 0,143 & 7,515 & $* * *$ & 0,68 \\
PC correlacionado a DI & 0,63 & 0,103 & 6,132 & $* * *$ & 0,57 \\
CN correlacionado a DI & 0,34 & 0,064 & 5,324 & $* * *$ & 0,50 \\
CN correlacionado a Al & 0,38 & 0,072 & 5,283 & $* * *$ & 0,56 \\
AT correlacionado a DI & 0,57 & 0,100 & 5,673 & $* * *$ & 0,50 \\
PC correlacionado a CN & 0,41 & 0,080 & 5,058 & $* * *$ & 0,43 \\
DI correlacionado a Al & 0,35 & 0,079 & 4,477 & $* * *$ & 0,44 \\
CN correlacionado a AT & 0,46 & 0,084 & 5,523 & $* * *$ & 0,48 \\
PC correlacionado a Al & 0,50 & 0,105 & 4,791 & $* * *$ & 0,45 \\
AT correlacionado a Al & 0,47 & 0,104 & 4,530 & $* \star *$ & 0,42 \\
\hline
\end{tabular}

Nota: ${ }^{* *}$ significante a $0,1 \%$ 
Quanto à possibilidade de adição de novas relações estruturais entre os construtos, analisaram-se: (i) as correlações entre eles; e (ii) os resíduos padronizados do Modelo 1. As elevadas correlações entre os construtos exógenos, indicadas na Figura 3, sugerem que pode haver relações estruturais significantes entre eles. Por outro lado, a análise dos resíduos padronizados do modelo não sugeriu que o modelo possa ser significativamente melhorado com a inclusão de novas relações estruturais, uma vez que nenhum dos resíduos superou o valor de referência de |2,5|. Esses resultados podem ser considerados inconclusivos e, portanto, a possibilidade de inclusão de novas relações estruturais não deve ser descartada.

Conforme discutido no capítulo 4, o referencial teórico e as entrevistas com conselheiros indicaram que as relações entre os construtos exógenos e a Eficácia na monitoração da IE podem não ser diretas. Logo, foram formuladas hipóteses concorrentes que envolvem uma possível mediação entre os construtos exógenos. Para testar essas hipóteses, foram introduzidas reespecificações ao Modelo 1. Esses modelos estruturais concorrentes serão analisados a seguir.

\subsubsection{2. Modelo 2}

É possível que o Acesso a Informações, o Conhecimento do Negócio e a Liderança do PCA não influenciem a Eficácia na Monitoração da IE de forma direta. Conforme desenvolvido no capítulo 4, é possível que CAs que tenham um bom acesso a informações, que conheçam coletivamente o negócio e que contem com um PCA ativo trabalhem de forma mais produtiva. Logo, a Dinâmica de Trabalho do CA pode ser influenciada por esses fatores e pode influenciar o desempenho do CA na tarefa de monitorar a IE. Em termos estruturais, DI pode mediar a influência de AI, CN e PC sobre MO. Essa teoria estrutural concorrente, denominada Modelo 2, está representada sob a forma de hipóteses na Tabela 23. As hipóteses $H_{1 a}, H_{2 a}$ e $H_{4 a}$ contemplam as relações alternativas esperadas. As hipóteses $H_{3}$ e $H_{5}$ não foram modificadas. 
Tabela 23 - Hipóteses do Modelo 2 de Eficácia na Monitoração da IE

\begin{tabular}{|l|l|}
\hline$H_{1 a}:$ Al $+\rightarrow$ DI & $\begin{array}{l}\text { O Acesso a Informações está positivamente relacionado à Dinâmica de } \\
\text { Trabalho do CA. }\end{array}$ \\
\hline$H_{2 a}: \mathrm{CN}+\rightarrow \mathrm{DI}$ & $\begin{array}{l}\text { O Conhecimento do Negócio está positivamente relacionado à Dinâmica de } \\
\text { Trabalho do CA. }\end{array}$ \\
\hline$H_{4 a}: \mathrm{PC}+\rightarrow \mathrm{DI}$ & $\begin{array}{l}\text { A Liderança do Presidente do CA está positivamente relacionada à } \\
\text { Dinâmica de Trabalho do CA. }\end{array}$ \\
\hline$H_{3}: \mathrm{DI}+\rightarrow \mathrm{MO}$ & $\begin{array}{l}\text { A Dinâmica de Trabalho do CA está positivamente relacionada à Eficácia na } \\
\text { Monitoração da IE. }\end{array}$ \\
\hline$H_{5}: \mathrm{AT}+\rightarrow \mathrm{MO}$ & $\begin{array}{l}\text { A Atenção à Monitoração da IE está positivamente relacionada à Eficácia na } \\
\text { Monitoração da IE. }\end{array}$ \\
\hline
\end{tabular}

Os resultados da estimação do Modelo 2 constam da Figura 8 e da Tabela 24. O Modelo 2 também atende ao requisito de sobre-identificação, dado que tem os mesmos 253 graus de liberdade do Modelo 1 mas estima quatro parâmetros a menos (55). Os parâmetros de todas as relações estruturais estimadas foram significantes a $1 \%$, à exceção de $\mathrm{AI} \rightarrow \mathrm{DI}$. Com isso, não se podem rejeitar as hipóteses do Modelo 2, à exceção de $H_{l a}$. Em adição ao Modelo 1, os resultados do Modelo 2 indicaram que a Dinâmica de Trabalho do CA (DI) media o efeito do Conhecimento do Negócio (CN) e da Liderança do PCA (PC) na Monitoração da IE (MO) (hipóteses $H_{2 a}, H_{3}$ e $H_{4 a}$ ). Corroborando resultados observados no Modelo 1, validou-se o efeito direto da Atenção à Monitoração da IE (AT) na Eficácia na Monitoração da IE (MO). Não foram observados efeitos do Acesso a Informações (AI), diretos ou indiretos, em outros construtos endógenos.

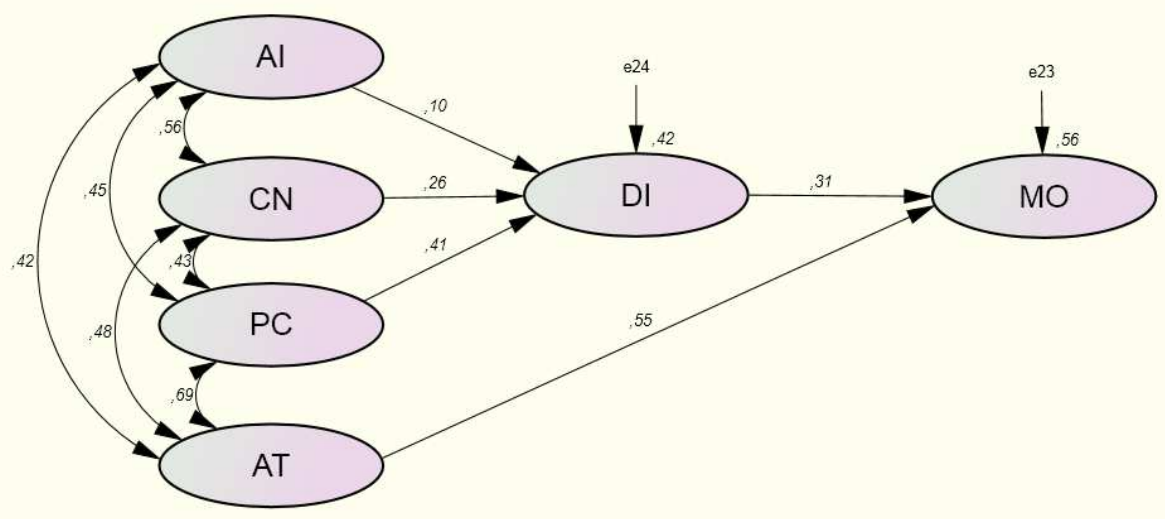

Figura 8 - Parâmetros estruturais padronizados do Modelo 2 de Eficácia na Monitoração da IE 
Tabela 24 - Significância dos parâmetros do Modelo 2 de Eficácia na Monitoração da IE

\begin{tabular}{|c|c|c|c|c|c|}
\hline Relação estrutural & $\begin{array}{l}\text { Parâmetros } \\
\text { não- } \\
\text { padronizados } \\
\text { estimados }\end{array}$ & $\begin{array}{c}\text { Erro } \\
\text { padrão }\end{array}$ & t-value & Significância & $\begin{array}{c}\text { Parâmetros } \\
\text { padronizados } \\
\text { estimados }\end{array}$ \\
\hline$H_{1 a}: \mathrm{Al}+\rightarrow \mathrm{DI}$ & 0,11 & 0,095 & 1,110 & 0,267 & 0,10 \\
\hline $\mathrm{H}_{2 a}: \mathrm{CN}+\rightarrow \mathrm{DI}$ & 0,31 & 0,102 & 3,058 & 0,002 & 0,26 \\
\hline$H_{4 a}: \mathrm{PC}+\rightarrow \mathrm{DI}$ & 0,30 & 0,056 & 5,323 & *** & 0,41 \\
\hline$H_{3}: \mathrm{DI}+\rightarrow \mathrm{MO}$ & 0,31 & 0,070 & 4,438 & *** & 0,31 \\
\hline$H_{5}: \mathrm{AT}+\rightarrow \mathrm{MO}$ & 0,38 & 0,051 & 7,551 & $* * *$ & 0,55 \\
\hline PC correlacionado a AT & 1,09 & 0,144 & 7,555 & $* * *$ & 0,69 \\
\hline $\mathrm{CN}$ correlacionado a $\mathrm{Al}$ & 0,38 & 0,072 & 5,279 & *** & 0,56 \\
\hline PC correlacionado a $\mathrm{CN}$ & 0,41 & 0,080 & 5,057 & $* * *$ & 0,43 \\
\hline CN correlacionado a AT & 0,47 & 0,084 & 5,541 & *** & 0,48 \\
\hline PC correlacionado a Al & 0,50 & 0,104 & 4,786 & *** & 0,45 \\
\hline AT correlacionado a Al & 0,47 & 0,104 & 4,543 & $* \star *$ & 0,42 \\
\hline
\end{tabular}

Nota: ${ }^{* *}$ significante a $0,1 \%$

Os índices de ajuste do Modelo 2 foram comparáveis aos do Modelo 1, com poucas mudanças (Tabela 25). Todos os índices foram melhores que os respectivos valores de referência e indicam que o Modelo 2 fornece um bom grau de ajuste geral.

Tabela 25 - Resultados de qualidade de ajuste dos Modelos 1 e 2

\begin{tabular}{|lrr|}
\hline & Modelo 1 & Modelo 2 \\
\hline Qui-quadrado & 405,038 & 411,593 \\
\hline Graus de liberdade & 194 & 198 \\
Qui-quadrado/graus de liberdade & 2,088 & 2,079 \\
$P$ & 0,000 & 0,000 \\
\hline Medidas de ajuste absoluto & & \\
\hline Raiz do erro quadrático médio de aproximação (RMSEA) & 0,071 & 0,071 \\
\hline Intervalo de confiança & 0,061 & 0,061 \\
\hline Medidas de ajuste incremental & 0,081 & 0,080 \\
\hline Índice de ajuste comparativo (CFI) & 0,937 & 0,936 \\
\hline Medidas de ajuste parcimonioso & 523,038 & 521,593 \\
\hline Critério de informação de Akaike (AIC) & & \\
\hline
\end{tabular}


Não houve mudança substancial entre as cargas fatoriais padronizadas do Modelo 2 e as do Modelo de medidas (Tabela 26). O mesmo é observado quanto às confiabilidades compostas dos construtos. Isto indica que há estabilidade entre as variáveis observáveis mensuradas e reforça a validade do modelo de medidas.

Tabela 26 - Comparação de cargas fatoriais padronizadas e confiabilidade composta entre Modelo 2 e Modelo de medidas

\begin{tabular}{|c|c|c|c|}
\hline Variáveis observáveis & Construtos & $\begin{array}{l}\text { Modelo de } \\
\text { medidas }\left(^{*}\right)\end{array}$ & Modelo 2 \\
\hline & & \multicolumn{2}{|c|}{ Cargas fatoriais padronizadas } \\
\hline $\mathrm{Al} 3$ & $\mathrm{Al}$ & 0,702 & 0,701 \\
\hline Al5 & $\mathrm{Al}$ & 0,692 & 0,691 \\
\hline Al7 & $\mathrm{Al}$ & 0,705 & 0,707 \\
\hline AT2 & AT & 0,858 & 0,858 \\
\hline AT3 & AT & 0,944 & 0,944 \\
\hline AT4 & AT & 0,926 & 0,924 \\
\hline CN1 & $\mathrm{CN}$ & 0,852 & 0,851 \\
\hline CN2 & $\mathrm{CN}$ & 0,876 & 0,876 \\
\hline CN3 & $\mathrm{CN}$ & 0,788 & 0,788 \\
\hline CN4 & $\mathrm{CN}$ & 0,735 & 0,735 \\
\hline DI1 & $\mathrm{DI}$ & 0,765 & 0,763 \\
\hline DI2 & DI & 0,790 & 0,790 \\
\hline DI3 & DI & 0,825 & 0,823 \\
\hline DI7 & $\mathrm{DI}$ & 0,811 & 0,812 \\
\hline MO5 & $\mathrm{MO}$ & 0,747 & 0,752 \\
\hline MO6 & MO & 0,838 & 0,836 \\
\hline MO7 & MO & 0,875 & 0,871 \\
\hline PC1 & PC & 0,776 & 0,779 \\
\hline PC2 & PC & 0,762 & 0,764 \\
\hline PC5 & PC & 0,906 & 0,906 \\
\hline PC6 & PC & 0,877 & 0,876 \\
\hline \multirow[t]{8}{*}{$\mathrm{PC} 7$} & PC & 0,869 & 0,868 \\
\hline & & \multicolumn{2}{|c|}{ Confiabilidades compostas } \\
\hline & $\mathrm{Al}$ & 0,742 & 0,742 \\
\hline & AT & 0,935 & 0,935 \\
\hline & $\mathrm{CN}$ & 0,887 & 0,887 \\
\hline & DI & 0,875 & 0,875 \\
\hline & MO & 0,861 & 0,861 \\
\hline & PC & 0,923 & 0,923 \\
\hline
\end{tabular}

Nota: (*) os valores do Modelo 1 são iguais aos do Modelo de medidas. 
Procedeu-se a uma comparação entre os parâmetros padronizados do Modelo 2, Modelo 1 e Modelo de medidas (Tabela 27). Se por um lado os parâmetros das covariâncias entre os construtos exógenos do Modelo 2 são comparáveis às do Modelo de medidas, os parâmetros correspondentes às hipóteses de pesquisa são consistentemente menores no Modelo 2. Observa-se que as quatro relações correlacionais excluídas do Modelo 2 são significativas no modelo de medidas (por exemplo, $\mathrm{PC} \leftrightarrow \mathrm{MO}=0,64$ ). Adicionalmente, observase que no Modelo 2 há relações correlacionais fortes e significativas. Chama atenção nesse sentido a relação entre a Liderança do PCA (PC) e a Atenção à Monitoração da IE (AT) (PC $\leftrightarrow \mathrm{AT}=0,69)$. Isto sugere que a adição de dessas relações possivelmente melhoraria o ajuste do modelo estrutural.

Tabela 27 - Comparação de parâmetros padronizados entre Modelo 2, Modelo $1 \mathrm{e}$ Modelo de medidas

\begin{tabular}{|c|c|c|c|c|c|}
\hline \multicolumn{2}{|c|}{ Modelo de medidas } & \multicolumn{2}{|c|}{ Modelo 1} & \multicolumn{2}{|c|}{ Modelo 2} \\
\hline $\begin{array}{l}\text { Relação } \\
\text { correlacional }\end{array}$ & $\begin{array}{l}\text { Parâmetros } \\
\text { padroni- } \\
\text { zados } \\
\text { estimados }\end{array}$ & $\begin{array}{l}\text { Relação } \\
\text { estrutural }\end{array}$ & $\begin{array}{l}\text { Parâmetros } \\
\text { padroni- } \\
\text { zados } \\
\text { estimados }\end{array}$ & $\begin{array}{l}\text { Relação } \\
\text { estrutural }\end{array}$ & $\begin{array}{l}\text { Parâmetros } \\
\text { padroni- } \\
\text { zados } \\
\text { estimados }\end{array}$ \\
\hline Al corr. a DI & 0,44 & Al corr. a DI & 0,44 & $\mathrm{H}_{1 a}: \mathrm{Al}+\rightarrow \mathrm{DI}$ & 0,10 \\
\hline CN corr. a DI & 0,50 & $\mathrm{CN}$ corr. a DI & 0,50 & $\mathrm{H}_{2 a}: \mathrm{CN}+\rightarrow \mathrm{DI}$ & 0,26 \\
\hline PC corr. a DI & 0,57 & PC corr. a DI & 0,57 & $\mathrm{H}_{4 a}: \mathrm{PC}+\rightarrow \mathrm{DI}$ & 0,41 \\
\hline DI corr. a MO & 0,57 & $\mathrm{H}_{3}: \mathrm{DI}+\rightarrow \mathrm{MO}$ & 0,25 & $\mathrm{H}_{3}: \mathrm{DI}+\rightarrow \mathrm{MO}$ & 0,31 \\
\hline AT corr. a MO & 0,70 & $\mathrm{H}_{5}: \mathrm{AT}+\rightarrow \mathrm{MO}$ & 0,43 & $\mathrm{H}_{5}: \mathrm{AT}+\rightarrow \mathrm{MO}$ & 0,55 \\
\hline PC corr. a AT & 0,68 & PC corr. a AT & 0,68 & PC corr. a AT & 0,69 \\
\hline $\mathrm{CN}$ corr. a Al & 0,56 & $\mathrm{CN}$ corr. a $\mathrm{Al}$ & 0,56 & $\mathrm{CN}$ corr. a Al & 0,56 \\
\hline PC corr. a CN & 0,43 & PC corr. a CN & 0,43 & PC corr. a CN & 0,43 \\
\hline CN corr. a AT & 0,48 & CN corr. a AT & 0,48 & CN corr. a AT & 0,48 \\
\hline PC corr. a Al & 0,45 & PC corr. a Al & 0,45 & PC corr. a Al & 0,45 \\
\hline AT corr. a Al & 0,42 & AT corr. a Al & 0,42 & AT corr. a Al & 0,42 \\
\hline Al corr. a MO & 0,35 & $\mathrm{H}_{1}: \mathrm{Al}+\rightarrow \mathrm{MO}$ & $-0,04$ & não estimado & \\
\hline AT corr. a DI & 0,50 & AT corr. a DI & 0,50 & não estimado & \\
\hline PC corr. a MO & 0,64 & $\mathrm{H}_{4}: \mathrm{PC}+\rightarrow \mathrm{MO}$ & 0,21 & não estimado & \\
\hline $\mathrm{CN}$ corr. a $\mathrm{MO}$ & 0,42 & $\mathrm{H}_{2}: \mathrm{CN}+\rightarrow \mathrm{MO}$ & 0,02 & não estimado & \\
\hline
\end{tabular}


Como diagnóstico adicional, foram analisados os resíduos padronizados do Modelo 2. Nenhum dos resíduos superou o valor de referência de |2,5|. Além disso, foram analisados os índices de modificação das relações estruturais não calculadas no Modelo 2. Relações não calculadas com índice de modificação maiores que 4,0 sugerem que o ajuste do modelo poderia ser melhorado por meio da sua adição ao modelo estrutural. Nenhuma dessas relações apresentou índice de modificação superior ao valor de referência. Logo, esses procedimentos adicionais não indicaram que a inclusão de novas relações adicionais possa melhorar significativamente o ajuste do modelo.

Em suma, os resultados suportaram a validade do Modelo 2. Seu grau de ajuste foi bom e ligeiramente superior ao do Modelo 1. Em especial, o Modelo 2 forneceu suporte significante a todas as hipóteses exceto $H_{l a}(\mathrm{AI} \rightarrow \mathrm{DI})$. Verificou-se que a Dinâmica de Trabalho do CA mediou o efeito entre o Conhecimento do Negócio e da Liderança do PCA na Eficácia na Monitoração da IE. Confirmou-se também o efeito da Atenção à Monitoração da IE na Eficácia na Monitoração da IE, a exemplo do Modelo 1. Nada se pôde inferir quanto à influência do Acesso a Informações, à semelhança do Modelo 1.

No entanto, os testes de diagnóstico para melhoria no ajuste do Modelo 2 também foram inconclusivos. Logo, não se deve descartar a possibilidade de que o modelo possa ser melhorado pela inclusão de novas relações entre construtos. Em particular, a alta correlação entre PC e AT, ilustrada na Figura 8, sinalizou uma possível nova ligação estrutural suportada pela teoria. A inclusão dessa relação será analisada a seguir.

\subsubsection{3.}

\section{Modelo 3}

Os resultados de diagnóstico do Modelo 2 sugeriram uma possível relação estrutural entre os construtos PC e AT. A teoria e os resultados das entrevistas embasaram a formulação de uma hipótese de ligação entre eles $\left(H_{4 b}\right.$ : a Liderança do Presidente do CA está positivamente relacionada à Atenção à Monitoração da IE). Para testar $H_{4 b}$, especificou-se um modelo estrutural concorrente - Modelo 3 - no qual essa relação foi acrescentada. As hipóteses do Modelo 3 encontram-se na Tabela 28. 
Os resultados da estimação do Modelo 3 constam da Figura 9 e da Tabela 29. Os parâmetros apresentaram significâncias comparáveis aos do Modelo 2 (Tabela 24) e superiores aos do Modelo 1 (Tabela 22). Todas as hipóteses testadas no Modelo 3 foram suportadas a $1 \%$ de significância, à exceção, novamente, de $H_{1 a}$. Como contribuição incremental em relação ao Modelo 2, o Modelo 3 evidenciou o efeito positivo da Liderança do Presidente do CA (PC) na Atenção à Monitoração da IE (MO), conforme previa $H_{4 b}$. A exemplo dos modelos anteriores, não se verificou o efeito do Acesso a Informações (AI) em outros construtos da pesquisa - neste caso, na Dinâmica de Trabalho do CA (DI).

Tabela 28 - Hipóteses do Modelo 3 de Eficácia na Monitoração da IE

\begin{tabular}{|l|l|}
\hline$H_{1 a}: \mathrm{Al}+\rightarrow \mathrm{DI}$ & $\begin{array}{l}\text { O Acesso a Informações está positivamente relacionado à Dinâmica de } \\
\text { Trabalho do CA. }\end{array}$ \\
\hline$H_{2 a}: \mathrm{CN}+\rightarrow \mathrm{DI}$ & $\begin{array}{l}\text { O Conhecimento do Negócio está positivamente relacionado à Dinâmica de } \\
\text { Trabalho do CA. }\end{array}$ \\
\hline$H_{4 a}: \mathrm{PC}+\rightarrow \mathrm{DI}$ & $\begin{array}{l}\text { A Liderança do Presidente do CA está positivamente relacionada à } \\
\text { Dinâmica de Trabalho do CA. }\end{array}$ \\
\hline$H_{4 b}: \mathrm{PC}+\rightarrow \mathrm{AT}$ & $\begin{array}{l}\text { A Liderança do Presidente do CA está positivamente relacionada à Atenção } \\
\text { à Monitoração da IE. }\end{array}$ \\
\hline$H_{3}: \mathrm{DI}+\rightarrow \mathrm{MO}$ & $\begin{array}{l}\text { A Dinâmica de Trabalho do CA está positivamente relacionada à Eficácia na } \\
\text { Monitoração da IE. }\end{array}$ \\
\hline$H_{5}: \mathrm{AT}+\rightarrow \mathrm{MO}$ & $\begin{array}{l}\text { A Atenção à Monitoração da IE está positivamente relacionada à Eficácia na } \\
\text { Monitoração da IE. }\end{array}$ \\
\hline
\end{tabular}

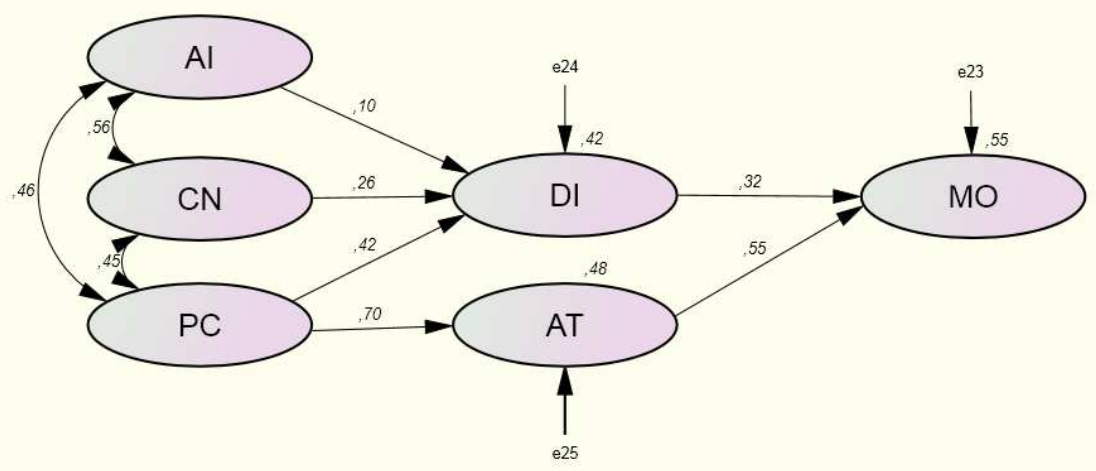

Figura 9 - Parâmetros estruturais padronizados do Modelo 3 de Eficácia na Monitoração da IE 
Tabela 29 - Significância dos parâmetros do Modelo 3 de Eficácia na Monitoração da IE

\begin{tabular}{|c|c|c|c|c|c|}
\hline Relação estrutural & $\begin{array}{l}\text { Parâmetros } \\
\text { não- } \\
\text { padronizados } \\
\text { estimados }\end{array}$ & $\begin{array}{c}\text { Erro } \\
\text { padrão }\end{array}$ & $t$-value & Significância & $\begin{array}{c}\text { Parâmetros } \\
\text { padronizados } \\
\text { estimados }\end{array}$ \\
\hline$H_{1 a}: \mathrm{Al}+\rightarrow \mathrm{DI}$ & 0,10 & 0,095 & 1,084 & 0,278 & 0,10 \\
\hline$H_{2 a}: \mathrm{CN}+\rightarrow \mathrm{DI}$ & 0,30 & 0,102 & 2,959 & 0,003 & 0,26 \\
\hline$H_{4 a}: \mathrm{PC}+\rightarrow \mathrm{DI}$ & 0,30 & 0,057 & 5,334 & *** & 0,42 \\
\hline$H_{4 b}: \mathrm{PC}+\rightarrow \mathrm{AT}$ & 0,32 & 0,068 & 4,627 & $* * *$ & 0,32 \\
\hline $\mathrm{H}_{3}: \mathrm{DI}+\rightarrow \mathrm{MO}$ & 0,38 & 0,049 & 7,709 & *** & 0,55 \\
\hline$H_{5}: \mathrm{AT}+\rightarrow \mathrm{MO}$ & 0,72 & 0,064 & 11,113 & *** & 0,70 \\
\hline $\mathrm{CN}$ correlacionado a $\mathrm{Al}$ & 0,38 & 0,072 & 5,277 & *** & 0,56 \\
\hline PC correlacionado a CN & 0,42 & 0,081 & 5,197 & $* * *$ & 0,45 \\
\hline PC correlacionado a Al & 0,51 & 0,104 & 4,855 & $* * *$ & 0,46 \\
\hline
\end{tabular}

Nota: ${ }^{* \star *}$ significante a $0,1 \%$

O Modelo 3 apresentou boa qualidade de ajuste, em níveis superiores aos dos modelos anteriores (Tabela 30).

Tabela 30 - Resultados de qualidade de ajuste dos Modelos 1, 2 e 3

\begin{tabular}{|lrrr|}
\hline & Modelo & Modelo & Modelo \\
& 1 & 2 & 3 \\
\hline Qui-quadrado & 405,038 & 411,593 & 425,021 \\
\hline Graus de liberdade & 194 & 198 & 201 \\
Qui-quadrado/graus de liberdade & 2,088 & 2,079 & 2,125 \\
$p$ & 0,000 & 0,000 & 0,000 \\
\hline Medidas de ajuste absoluto & & & \\
\hline Raiz do erro quadrático médio de aproximação (RMSEA) & 0,071 & 0,071 & 0,072 \\
Intervalo de confiança & 0,061 & 0,061 & 0,063 \\
\hline Medidas de ajuste incremental & 0,081 & 0,080 & 0,082 \\
\hline Índice de ajuste comparativo (CFI) & & & \\
\hline Medidas de ajuste parcimonioso & 0,937 & 0,936 & 0,933 \\
\hline Critério de informação de Akaike (AIC) & & & \\
\hline
\end{tabular}


As cargas fatoriais padronizadas e confiabilidades compostas mantiveram-se estáveis em relação aos modelos anteriores, conforme a Tabela 31.

Tabela 31 - Comparação de cargas fatoriais padronizadas e confiabilidade composta entre o Modelo 3 e outros modelos

\begin{tabular}{|c|c|c|c|c|}
\hline Variáveis observáveis & Construtos & $\begin{array}{l}\text { Modelo de } \\
\text { medidas }\left({ }^{*}\right)\end{array}$ & Modelo 2 & Modelo 3 \\
\hline & & \multicolumn{3}{|c|}{ Cargas fatoriais padronizadas } \\
\hline Al3 & $\mathrm{Al}$ & 0,702 & 0,701 & 0,699 \\
\hline Al5 & Al & 0,692 & 0,691 & 0,693 \\
\hline Al7 & Al & 0,705 & 0,707 & 0,707 \\
\hline AT2 & AT & 0,858 & 0,858 & 0,855 \\
\hline AT3 & AT & 0,944 & 0,944 & 0,946 \\
\hline AT4 & AT & 0,926 & 0,924 & 0,924 \\
\hline CN1 & $\mathrm{CN}$ & 0,852 & 0,851 & 0,851 \\
\hline CN2 & $\mathrm{CN}$ & 0,876 & 0,876 & 0,873 \\
\hline CN3 & $\mathrm{CN}$ & 0,788 & 0,788 & 0,792 \\
\hline CN4 & $\mathrm{CN}$ & 0,735 & 0,735 & 0,736 \\
\hline DI1 & DI & 0,765 & 0,763 & 0,763 \\
\hline $\mathrm{DI} 2$ & DI & 0,790 & 0,790 & 0,790 \\
\hline DI3 & DI & 0,825 & 0,823 & 0,823 \\
\hline DI7 & DI & 0,811 & 0,812 & 0,812 \\
\hline MO5 & MO & 0,747 & 0,752 & 0,750 \\
\hline MO6 & MO & 0,838 & 0,836 & 0,834 \\
\hline MO7 & MO & 0,875 & 0,871 & 0,869 \\
\hline PC1 & PC & 0,776 & 0,779 & 0,778 \\
\hline PC2 & PC & 0,762 & 0,764 & 0,765 \\
\hline PC5 & PC & 0,906 & 0,906 & 0,905 \\
\hline PC6 & PC & 0,877 & 0,876 & 0,876 \\
\hline \multirow[t]{8}{*}{ PC7 } & PC & 0,869 & 0,868 & 0,867 \\
\hline & & \multicolumn{3}{|c|}{ Confiabilidades compostas } \\
\hline & $\mathrm{Al}$ & 0,742 & 0,742 & 0,742 \\
\hline & AT & 0,935 & 0,935 & 0,935 \\
\hline & $\mathrm{CN}$ & 0,887 & 0,887 & 0,887 \\
\hline & DI & 0,875 & 0,875 & 0,875 \\
\hline & MO & 0,861 & 0,861 & 0,859 \\
\hline & PC & 0,923 & 0,923 & 0,923 \\
\hline
\end{tabular}

Nota: (*) os valores do Modelo 1 são iguais aos do Modelo de medidas.

Os parâmetros padronizados do Modelo 3 correspondentes às hipóteses de pesquisa são semelhantes aos do Modelo 2 (Tabela 32). Os parâmetros das 
covariâncias entre os construtos exógenos do Modelo 3 são comparáveis aos do Modelo de medidas. Observa-se elevada correlação entre: (i) o Acesso a Informações e o Conhecimento do Negócio $(\mathrm{CN} \leftrightarrow \mathrm{AI}=0,56)$, (ii) a Liderança do Presidente do CA e o Acesso a Informações ( $\mathrm{PC} \leftrightarrow \mathrm{AI}=0,46)$; e (iii) a Liderança do Presidente do CA e o Conhecimento do Negócio ( $\mathrm{PC} \leftrightarrow \mathrm{CN}=0,45$ ). Esses dados sugerem que pode haver relações estruturais significantes entre esses construtos.

Tabela 32 - Comparação de parâmetros padronizados entre o Modelo 3 e outros modelos

\begin{tabular}{|c|c|c|c|c|c|c|c|}
\hline \multicolumn{2}{|c|}{ Modelo de medidas } & \multicolumn{2}{|c|}{ Modelo 1} & \multicolumn{2}{|c|}{ Modelo 2} & \multicolumn{2}{|c|}{ Modelo 3} \\
\hline $\begin{array}{c}\text { Relação } \\
\text { correlacional }\end{array}$ & $\begin{array}{c}\text { Parâmetros } \\
\text { padroni- } \\
\text { zados } \\
\text { estimados }\end{array}$ & $\begin{array}{l}\text { Relação } \\
\text { estrutural }\end{array}$ & $\begin{array}{l}\text { Parâmetros } \\
\text { padroni- } \\
\text { zados } \\
\text { estimados }\end{array}$ & $\begin{array}{l}\text { Relação } \\
\text { estrutural }\end{array}$ & $\begin{array}{l}\text { Parâmetros } \\
\text { padroni- } \\
\text { zados } \\
\text { estimados }\end{array}$ & $\begin{array}{l}\text { Relação } \\
\text { estrutural }\end{array}$ & $\begin{array}{l}\text { Parâmetros } \\
\text { padroni- } \\
\text { zados } \\
\text { estimados }\end{array}$ \\
\hline Al corr. a DI & 0,44 & Al corr. a DI & 0,44 & $\mathrm{H}_{1 a}: \mathrm{Al}+\rightarrow \mathrm{DI}$ & 0,10 & $\mathrm{H}_{1 a}: \mathrm{Al}+\rightarrow \mathrm{DI}$ & 0,10 \\
\hline CN corr. a DI & 0,50 & CN corr. a DI & 0,50 & $\mathrm{H}_{2 \mathrm{a}}: \mathrm{CN}+\rightarrow \mathrm{DI}$ & 0,26 & $\mathrm{H}_{2 a}: \mathrm{CN}+\rightarrow \mathrm{DI}$ & 0,26 \\
\hline PC corr. a DI & 0,57 & PC corr. a DI & 0,57 & $\mathrm{H}_{4 a}: \mathrm{PC}+\rightarrow \mathrm{DI}$ & 0,41 & $\mathrm{H}_{4 a}: \mathrm{PC}+\rightarrow \mathrm{DI}$ & 0,42 \\
\hline PC corr. a AT & 0,68 & PC corr. a AT & 0,68 & PC corr. a AT & 0,69 & $\mathrm{H}_{4 b}: \mathrm{PC}+\rightarrow \mathrm{AT}$ & 0,70 \\
\hline DI corr. a MO & 0,57 & $\mathrm{H}_{3}: \mathrm{DI}+\rightarrow \mathrm{MO}$ & 0,25 & $\mathrm{H}_{3}: \mathrm{DI}+\rightarrow \mathrm{MO}$ & 0,31 & $\mathrm{H}_{3}: \mathrm{DI}+\rightarrow \mathrm{MO}$ & 0,32 \\
\hline AT corr. a MO & 0,70 & $\mathrm{H}_{5}: \mathrm{AT}+\rightarrow \mathrm{MO}$ & 0,43 & $\mathrm{H}_{5}: \mathrm{AT}+\rightarrow \mathrm{MO}$ & 0,55 & $\mathrm{H}_{5}: \mathrm{AT}+\rightarrow \mathrm{MO}$ & 0,55 \\
\hline CN corr. a Al & 0,56 & $\mathrm{CN}$ corr. a Al & 0,56 & CN corr. a Al & 0,56 & $\mathrm{CN}$ corr. a Al & 0,56 \\
\hline PC corr. a CN & 0,43 & PC corr. a CN & 0,43 & PC corr. a CN & 0,43 & PC corr. a CN & 0,45 \\
\hline PC corr. a Al & 0,45 & PC corr. a Al & 0,45 & PC corr. a Al & 0,45 & PC corr. a Al & 0,46 \\
\hline CN corr. a AT & 0,48 & CN corr. a AT & 0,48 & CN corr. a AT & 0,48 & não estimado & \\
\hline AT corr. a Al & 0,42 & AT corr. a Al & 0,42 & AT corr. a Al & 0,42 & não estimado & \\
\hline Al corr. a MO & 0,35 & $\mathrm{H}_{1}: \mathrm{Al}+\rightarrow \mathrm{MO}$ & $-0,04$ & não estimado & & não estimado & \\
\hline AT corr. a DI & 0,50 & AT corr. a DI & 0,50 & não estimado & & não estimado & \\
\hline PC corr. a MO & 0,64 & $\mathrm{H}_{4}: \mathrm{PC}+\rightarrow \mathrm{MO}$ & 0,21 & não estimado & & não estimado & \\
\hline $\mathrm{CN}$ corr. a $\mathrm{MO}$ & 0,42 & $\mathrm{H}_{2}: \mathrm{CN}+\rightarrow \mathrm{MO}$ & 0,02 & não estimado & & não estimado & \\
\hline
\end{tabular}

Quanto aos resíduos padronizados (Tabela 33), dois deles (grifados), envolvendo as variáveis $\mathrm{CN} 2$, AT2 e MO7, foram superiores ao valor inferior de referência de $|2,5|$. Nenhum deles superou o valor superior de $|4|$. Quanto às 
relações estruturais excluídas do modelo, uma delas, $\mathrm{CN} \rightarrow \mathrm{AT}$, apresentou índice de modificação de 9,8 - superior, portanto, ao valor de referência de 4,0. Analisados em conjunto, esses testes adicionais de diagnóstico sugerem que poderia haver uma relação estrutural significante entre o Conhecimento do Negócio (CN) e a Atenção à Monitoração da IE (AT).

Tabela 33 - Resíduos padronizados do Modelo 3

\begin{tabular}{|c|c|c|c|c|c|c|c|c|c|c|c|c|c|c|c|c|c|c|c|c|c|c|}
\hline & Al7 & Al5 & $\mathrm{Al} 3$ & MO7 & MO6 & MO5 & PC7 & DI7 & $\mathrm{D} 13$ & $\mathrm{DI} 2$ & DI1 & AT2 & AT3 & AT4 & $\mathrm{CN} 1$ & $\mathrm{CN} 2$ & $\mathrm{CN} 3$ & $\mathrm{CN} 4$ & $\mathrm{PC} 1$ & $\mathrm{PC} 2$ & PC5 & PC6 \\
\hline Al7 & 0,0 & & & & & & & & & & & & & & & & & & & & & \\
\hline Al5 & 0,4 & 0,0 & & & & & & & & & & & & & & & & & & & & \\
\hline Al3 & $-0,3 \mid$ & 0,0 & 0,0 & & & & & & & & & & & & & & & & & & & \\
\hline MO7 & 1,1 & 0,0 & 0,9 & 0,2 & & & & & & & & & & & & & & & & & & \\
\hline MO6 & 0,4 & $-1,3$ & $-0,5$ & 0,2 & 0,2 & & & & & & & & & & & & & & & & & \\
\hline MO5 & 1,7 & 0,0 & 0,8 & $-0,3$ & 1,0 & 0,2 & & & & & & & & & & & & & & & & \\
\hline $\mathrm{PC7}$ & 0,0 & $-0,1$ & 0,4 & 1,3 & 0,6 & 0,2 & 0,0 & & & & & & & & & & & & & & & \\
\hline DI7 & 1,3 & $-0,7$ & 1,2 & 1,0 & 0,1 & 1,5 & 0,1 & 0,0 & & & & & & & & & & & & & & \\
\hline DI3 & 0,6 & $-1,4$ & $-0,6$ & $-0,1$ & $-0,3$ & 1,6 & $-1,0$ & 0,6 & 0,0 & & & & & & & & & & & & & \\
\hline $\mathrm{DI} 2$ & 0,8 & $-0,2$ & 0,0 & $-0,4$ & $-0,3$ & 0,6 & $-1,1$ & $-0,4$ & $-0,2$ & 0,0 & & & & & & & & & & & & \\
\hline DI1 & $-0,2$ & $-0,9$ & $-0,1$ & 1,0 & 0,1 & 0,4 & $-0,3$ & $-0,7$ & 0,0 & 0,9 & 0,0 & & & & & & & & & & & \\
\hline AT2 & 0,5 & 0,7 & 1,7 & 1,0 & $-0,1$ & $-0,5$ & $-0,3$ & 1,7 & 0,8 & 0,4 & 1,7 & 0,0 & & & & & & & & & & \\
\hline AT3 & 0,8 & 0,1 & 1,8 & 1,0 & $-0,9$ & $-0,6$ & 0,0 & 1,1 & 0,3 & $-0,1$ & 1,0 & 0,0 & 0,0 & & & & & & & & & \\
\hline AT4 & 0,8 & 0,1 & 1,6 & 1,3 & $-0,4$ & 0,2 & $-0,1$ & 2,0 & 0,9 & 1,0 & \begin{tabular}{|l|}
1,7 \\
\end{tabular} & 0,0 & 0,0 & 0,0 & & & & & & & & \\
\hline $\mathrm{CN} 1$ & 0,0 & $-0,4$ & 0,3 & 1,4 & $-0,6$ & $-0,4$ & \begin{tabular}{|l|} 
\\
\end{tabular} & 0,0 & $-1,4$ & 1,0 & $-0,9$ & 2,1 & 1,4 & 1,2 & 0,0 & & & & & & & \\
\hline $\mathrm{CN} 2$ & $-0,4$ & $-0,7$ & 0,2 & 2,8 & 0,9 & 0,8 & $-0,2$ & $-0,4$ & $-0,6$ & 0,6 & $-0,1$ & 3,0 & 2,2 & 2,3 & 0,6 & 0,0 & & & & & & \\
\hline $\mathrm{CN} 3$ & $-0,2$ & $-0,1$ & 1,0 & 1,0 & 0,3 & 1,0 & $-0,5$ & 0,4 & $-0,7$ & 1,3 & \begin{tabular}{|l}
0,0 \\
\end{tabular} & 2,4 & 1,3 & 1,5 & $-0,4$ & $-0,5$ & 0,0 & & & & & \\
\hline $\mathrm{CN} 4$ & $-0,1$ & 0,3 & 0,9 & 0,6 & $-0,4$ & 0,9 & \begin{tabular}{|l|} 
\\
\end{tabular} & 0,9 & $-0,5$ & 1,9 & 1,0 & 1,9 & 1,4 & 2,2 & $-0,7$ & $-0,5$ & 1,8 & 0,0 & & & & \\
\hline PC1 & 0,5 & $-0,1$ & 0,6 & $-0,3$ & $-1,1$ & $-1,6$ & 0,2 & 0,2 & $-1,7$ & $-1,3$ & \begin{tabular}{|l}
$-0,9$ \\
\end{tabular} & $-0,4$ & $-0,3$ & $-0,2$ & $-0,9$ & $-0,4$ & 0,5 & $-1,0$ & 0,0 & & & \\
\hline $\mathrm{PC} 2$ & 0,7 & 0,1 & 0,7 & 0,8 & 0,2 & $-1,2$ & \begin{tabular}{|l} 
\\
$-0,2$ \\
\end{tabular} & 0,9 & $-0,6$ & $-0,4$ & \begin{tabular}{|l|} 
\\
\end{tabular} & $-0,1$ & $-0,3$ & $-0,1$ & $-0,2$ & 0,9 & 0,9 & 0,7 & 2,1 & 0,0 & & \\
\hline PC5 & $-1,0$ & $-0,3$ & 0,3 & 1,5 & 0,9 & 0,2 & 0,1 & 1,4 & \begin{tabular}{|l|l} 
\\
\end{tabular} & 0,1 & 0,4 & 0,1 & $-0,3$ & $-0,4$ & $-0,4$ & 0,0 & 0,7 & $-0,2$ & $-0,4$ & $-0,2$ & 0,0 & \\
\hline $\mathrm{PC} 6$ & $\mid-0,8$ & $|-0,4|$ & 0,2 & 2,1 & 1,0 & 0,0 & 0,0 & \begin{tabular}{|l|}
0,6 \\
\end{tabular} & $-0,4$ & $|-0,6|$ & \begin{tabular}{|l|} 
\\
\end{tabular} & $-0,2$ & 0,4 & $|-0,1|$ & $-0,6$ & 0,3 & 0,6 & $-0,5$ & $-0,4$ & $|-0,5|$ & 0,3 & 0,0 \\
\hline
\end{tabular}

Conclui-se que os resultados suportam a validade do Modelo 3, que apresentou índices de ajuste superiores aos modelos anteriores. Verificou-se suporte significante a todas as hipóteses exceto, novamente, $H_{l a}(\mathrm{AI} \rightarrow \mathrm{DI})$. A contribuição incremental do Modelo 3 foi a observação de que a influência da 
Liderança do Presidente do CA sobre a Eficácia da Monitoração da IE se dá por via indireta, por meio da Atenção à Monitoração da IE (hipóteses $H_{4 b}$ e $H_{5}$ ). A exemplo dos resultados dos modelos anteriores, nada se pôde inferir quanto à influência do Acesso a Informações.

Os testes de diagnóstico sugeriram que a inclusão das relações estruturais $\mathrm{PC} \rightarrow \mathrm{AI}, \mathrm{AI} \rightarrow \mathrm{CN}, \mathrm{PC} \rightarrow \mathrm{CN}$ e $\mathrm{CN} \rightarrow$ AT poderia melhorar o grau de ajuste obtido no Modelo 3. As duas primeiras estão embasadas no referencial teórico. Por meio delas, supõe-se que o PCA seja capaz de facilitar o acesso às informações de que o CA necessita, e que CAs que tenham mais acesso às informações da empresa tenham um maior conhecimento do negócio. Essas hipóteses serão testadas por meio de uma nova especificação estrutural (Modelo 4), que será desenvolvida a seguir. As relações $\mathrm{PC} \rightarrow \mathrm{CN}$ e $\mathrm{CN} \rightarrow \mathrm{AT}$, apesar de serem de certa forma intuitivas, não serão incluídas no Modelo 4 por carecerem de fundamentação teórica.

\subsubsection{4. Modelo 4}

A análise do Modelo 3 sugeriu a adição de duas relações estruturais, PC $\rightarrow$ AI e AI $\rightarrow$ CN. Para verificá-las, conduziu-se uma análise baseada na especificação e estimação de um novo modelo estrutural concorrente. Tomando como ponto de partida o Modelo 3, foram acrescidas as relações PC $\rightarrow$ AI e AI $\rightarrow$ $\mathrm{CN}$. A relação não-mediada $\mathrm{AI} \rightarrow \mathrm{DI}$, não validada empiricamente nos modelos anteriores, foi substituída pelo caminho indireto AI $\rightarrow \mathrm{CN} \rightarrow$ DI. A Tabela 34 ilustra as hipóteses formuladas com base nos resultados do referencial teórico e das entrevistas. 
Tabela 34 - Hipóteses do Modelo 4 de Eficácia na Monitoração da IE

\begin{tabular}{|l|l|}
\hline$H_{1 b}:$ Al $+\rightarrow \mathrm{CN}$ & $\begin{array}{l}\text { O Acesso a Informações está positivamente relacionado ao } \\
\text { Conhecimento do Negócio. }\end{array}$ \\
\hline$H_{2 a}: \mathrm{CN}+\rightarrow \mathrm{DI}$ & $\begin{array}{l}\text { O Conhecimento do Negócio está positivamente relacionado à Dinâmica } \\
\text { de Trabalho do CA. }\end{array}$ \\
\hline$H_{4 a}: \mathrm{PC}+\rightarrow \mathrm{DI}$ & $\begin{array}{l}\text { A Liderança do Presidente do CA está positivamente relacionada à } \\
\text { Dinâmica de Trabalho do CA. }\end{array}$ \\
\hline$H_{4 b}: \mathrm{PC}+\rightarrow \mathrm{AT}$ & $\begin{array}{l}\text { A Liderança do Presidente do CA está positivamente relacionada à } \\
\text { Atenção à Monitoração da IE. }\end{array}$ \\
\hline$H_{4 c}: \mathrm{PC}+\rightarrow \mathrm{Al}$ & $\begin{array}{l}\text { A Liderança do Presidente do CA está positivamente relacionada ao } \\
\text { Acesso a Informações. }\end{array}$ \\
\hline$H_{3}: \mathrm{DI}+\rightarrow \mathrm{MO}$ & $\begin{array}{l}\text { A Dinâmica de Trabalho do CA está positivamente relacionada à Eficácia } \\
\text { na Monitoração da IE. }\end{array}$ \\
\hline$H_{5}: \mathrm{AT}+\rightarrow \mathrm{MO}$ & $\begin{array}{l}\text { A Atenção à Monitoração da IE está positivamente relacionada à Eficácia } \\
\text { na Monitoração da IE. }\end{array}$ \\
\hline
\end{tabular}

Os resultados da estimação do Modelo 4 constam da Figura 10 e da Tabela 35. Todas as hipóteses foram suportadas no Modelo 4 e todos os parâmetros foram significantes a $0,1 \%$. O caminho direto $\mathrm{AI} \rightarrow \mathrm{DI}$, que não era significante nos modelos anteriores, foi substituído pelos caminhos indiretos $\mathrm{AI} \rightarrow \mathrm{CN}$ e $\mathrm{CN}$ $\rightarrow$ DI, ambos significantes a $0,1 \%$. O caminho PC $\rightarrow$ AI, incluído no Modelo 4, também apresentou significância a $0,1 \%$.

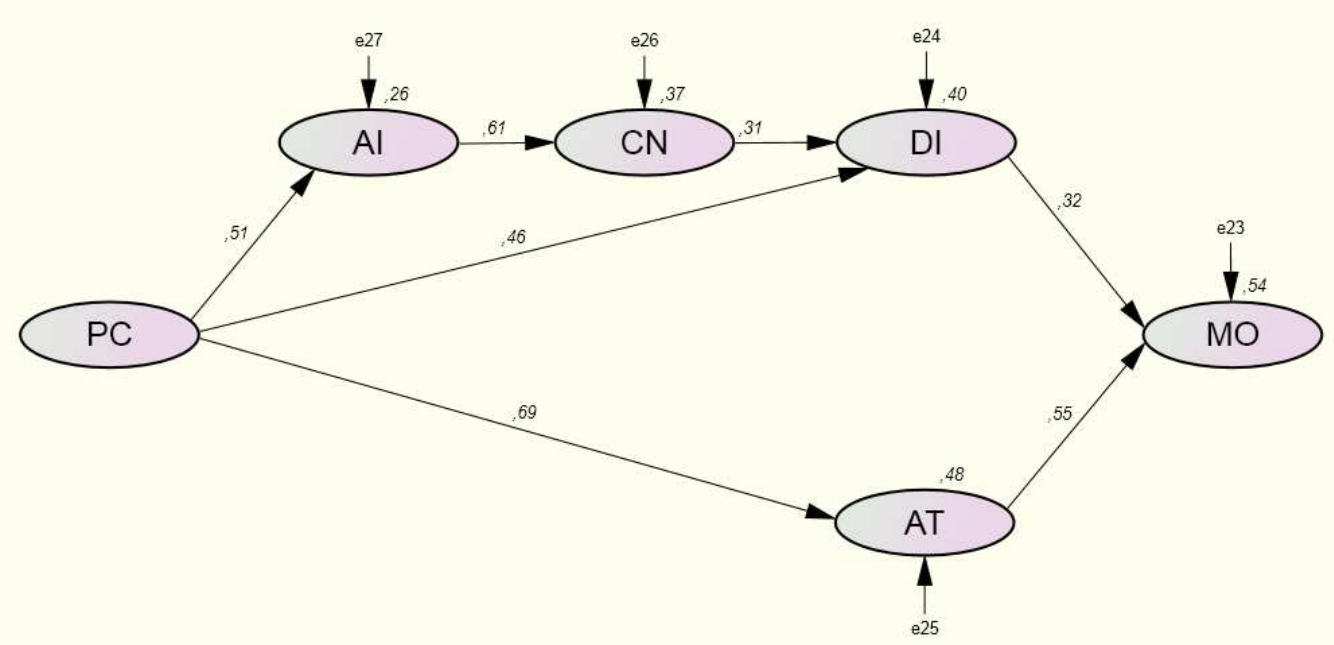

Figura 10 - Parâmetros estruturais padronizados do Modelo 4 de Eficácia na Monitoração da IE 
Tabela 35 - Significância dos parâmetros do Modelo 4 de Eficácia na Monitoração da IE

\begin{tabular}{|lccccc|}
\hline Relação estrutural & $\begin{array}{c}\text { Parâmetros } \\
\text { não- } \\
\text { padronizados } \\
\text { estimados }\end{array}$ & $\begin{array}{c}\text { Erro } \\
\text { padrão }\end{array}$ & $t$-value & Significância & $\begin{array}{c}\text { Parâmetros } \\
\text { padronizados } \\
\text { estimados }\end{array}$ \\
\hline$H_{1 b}: \mathrm{Al}+\rightarrow \mathrm{CN}$ & 0,52 & 0,081 & 6,386 & $* * *$ & 0,61 \\
$H_{22}: \mathrm{CN}+\rightarrow \mathrm{DI}$ & 0,37 & 0,084 & 4,350 & $* * *$ & 0,31 \\
$H_{4 a}: \mathrm{PC}+\rightarrow \mathrm{DI}$ & 0,33 & 0,052 & 6,304 & ${ }^{* * *}$ & 0,46 \\
$H_{4 b}: \mathrm{PC}+\rightarrow \mathrm{AT}$ & 0,72 & 0,065 & 11,057 & $* * *$ & 0,69 \\
$H_{4 c}: \mathrm{PC}+\rightarrow \mathrm{Al}$ & 0,37 & 0,060 & 6,146 & $* * *$ & 0,51 \\
$H_{3}: \mathrm{DI}+\rightarrow \mathrm{MO}$ & 0,32 & 0,069 & 4,603 & $* *$ & 0,32 \\
$H_{5}: \mathrm{AT}+\rightarrow \mathrm{MO}$ & 0,38 & 0,049 & 7,756 & $* *$ & 0,55 \\
\hline
\end{tabular}

Nota: ${ }^{* *}$ significante a $0,1 \%$

Conforme a Tabela 36, o Modelo 4 produziu um grau de ajuste que pode ser considerado superior ao dos demais modelos concorrentes. Todos os índices de ajuste foram superiores aos respectivos valores de referência. $O$ índice quiquadrado do Modelo $4(=435,205)$ é maior que o dos Modelos 1,2 e 3 e é significante a $1 \%$. As medidas de ajuste absoluto e incremental, apesar de ligeiramente inferiores, são comparáveis às dos outros modelos. O aumento do critério de informação de Akaike $(\mathrm{AIC}=581,025)$ também indica um ajuste superior do Modelo 4 em relação aos demais.

Tabela 36 - Resultados de qualidade de ajuste dos Modelos estruturais 1, 2, 3 e 4

\begin{tabular}{|lrrrr|}
\hline & Modelo & Modelo & Modelo & Modelo \\
& 1 & 2 & 4 & 4 \\
\hline Qui-quadrado & 405,038 & 411,593 & 425,021 & 435,205 \\
\hline Graus de liberdade & 194 & 198 & 200 & 202 \\
Qui-quadrado/graus de liberdade & 2,088 & 2,079 & 2,125 & 2,154 \\
$P$ & 0,000 & 0,000 & 0,000 & 0,000 \\
\hline Medidas de ajuste absoluto & & & & \\
\hline Raiz do erro quadrático médio de aproximação & 0,071 & 0,071 & 0,072 & 0,073 \\
(RMSEA) & 0,061 & 0,061 & 0,063 & 0,064 \\
Intervalo de confiança & 0,081 & 0,080 & 0,082 & 0,083 \\
\hline Medidas de ajuste incremental & & & & \\
\hline Índice de ajuste comparativo (CFI) & 0,937 & 0,936 & 0,933 & 0,930 \\
\hline Medidas de ajuste parcimonioso & & & & \\
\hline Critério de informação de Akaike (AIC) & 523,038 & 521,593 & 575,021 & 581,205 \\
\hline
\end{tabular}


Não houve mudança importante nas cargas fatoriais padronizadas das variáveis observáveis nem nas confiabilidades compostas dos construtos (Tabela $37)$.

Tabela 37 - Comparação de cargas fatoriais padronizadas e confiabilidade composta entre o Modelo 4 e outros modelos

\begin{tabular}{|c|c|c|c|c|c|}
\hline $\begin{array}{c}\text { Variáveis } \\
\text { observáveis }\end{array}$ & Construtos & $\begin{array}{l}\text { Modelo de } \\
\text { medidas }\left({ }^{*}\right)\end{array}$ & Modelo 2 & Modelo 3 & Modelo 4 \\
\hline & & \multicolumn{4}{|c|}{ Cargas fatoriais padronizadas } \\
\hline $\mathrm{Al} 3$ & $\mathrm{Al}$ & 0,702 & 0,701 & 0,699 & 0,703 \\
\hline Al5 & $\mathrm{Al}$ & 0,692 & 0,691 & 0,693 & 0,679 \\
\hline Al7 & $\mathrm{Al}$ & 0,705 & 0,707 & 0,707 & 0,686 \\
\hline AT2 & AT & 0,858 & 0,858 & 0,855 & 0,855 \\
\hline AT3 & AT & 0,944 & 0,944 & 0,946 & 0,946 \\
\hline AT4 & AT & 0,926 & 0,924 & 0,924 & 0,924 \\
\hline CN1 & $\mathrm{CN}$ & 0,852 & 0,851 & 0,851 & 0,853 \\
\hline CN2 & $\mathrm{CN}$ & 0,876 & 0,876 & 0,873 & 0,870 \\
\hline CN3 & CN & 0,788 & 0,788 & 0,792 & 0,791 \\
\hline CN4 & $\mathrm{CN}$ & 0,735 & 0,735 & 0,736 & 0,738 \\
\hline DI1 & DI & 0,765 & 0,763 & 0,763 & 0,759 \\
\hline DI2 & DI & 0,790 & 0,790 & 0,790 & 0,787 \\
\hline DI3 & DI & 0,825 & 0,823 & 0,823 & 0,819 \\
\hline DI7 & DI & 0,811 & 0,812 & 0,812 & 0,807 \\
\hline MO5 & MO & 0,747 & 0,752 & 0,750 & 0,748 \\
\hline MO6 & MO & 0,838 & 0,836 & 0,834 & 0,833 \\
\hline MO7 & MO & 0,875 & 0,871 & 0,869 & 0,868 \\
\hline PC1 & PC & 0,776 & 0,779 & 0,778 & 0,779 \\
\hline PC2 & PC & 0,762 & 0,764 & 0,765 & 0,764 \\
\hline PC5 & PC & 0,906 & 0,906 & 0,905 & 0,904 \\
\hline PC6 & PC & 0,877 & 0,876 & 0,876 & 0,875 \\
\hline \multirow[t]{8}{*}{$\mathrm{PC7}$} & PC & 0,869 & 0,868 & 0,867 & 0,868 \\
\hline & & \multicolumn{4}{|c|}{ Confiabilidades compostas } \\
\hline & $\mathrm{Al}$ & 0,742 & 0,742 & 0,742 & 0,731 \\
\hline & AT & 0,935 & 0,935 & 0,935 & 0,935 \\
\hline & $\mathrm{CN}$ & 0,887 & 0,887 & 0,887 & 0,887 \\
\hline & DI & 0,875 & 0,875 & 0,875 & 0,872 \\
\hline & MO & 0,861 & 0,861 & 0,859 & 0,858 \\
\hline & PC & 0,923 & 0,923 & 0,923 & 0,923 \\
\hline
\end{tabular}

Nota: $\left({ }^{*}\right)$ os valores do Modelo 1 são iguais aos do Modelo de medidas. 
A Tabela 38 demonstra que o Modelo 4 gerou parâmetros padronizados um pouco maiores que os do Modelo 3, à exceção de $\mathrm{PC} \rightarrow \mathrm{AT}$ e DI $\rightarrow \mathrm{MO}$, ainda que comparáveis.

Tabela 38 - Comparação de parâmetros padronizados entre o Modelo 4 e outros modelos

\begin{tabular}{|c|c|c|c|c|c|c|c|c|c|}
\hline \multicolumn{2}{|c|}{ Modelo de medidas } & \multicolumn{2}{|c|}{ Modelo 1} & \multicolumn{2}{|c|}{ Modelo 2} & \multicolumn{2}{|c|}{ Modelo 3} & \multicolumn{2}{|c|}{ Modelo 4} \\
\hline $\begin{array}{c}\text { Relação } \\
\text { correlacional }\end{array}$ & $\begin{array}{l}\text { Parâ- } \\
\text { metros } \\
\text { padroni- } \\
\text { zados } \\
\text { estimados }\end{array}$ & $\begin{array}{l}\text { Relação } \\
\text { estrutural }\end{array}$ & $\begin{array}{c}\text { Parâ- } \\
\text { metros } \\
\text { padroni- } \\
\text { zados } \\
\text { estimados }\end{array}$ & $\begin{array}{l}\text { Relação } \\
\text { estrutural }\end{array}$ & $\begin{array}{l}\text { Parâ- } \\
\text { metros } \\
\text { padroni- } \\
\text { zados } \\
\text { estimados }\end{array}$ & $\begin{array}{l}\text { Relação } \\
\text { estrutural }\end{array}$ & $\begin{array}{l}\text { Parâ- } \\
\text { metros } \\
\text { padroni- } \\
\text { zados } \\
\text { estimados }\end{array}$ & $\begin{array}{l}\text { Relação } \\
\text { estrutural }\end{array}$ & $\begin{array}{l}\text { Parâ- } \\
\text { metros } \\
\text { padroni- } \\
\text { zados } \\
\text { estimados }\end{array}$ \\
\hline $\mathrm{CN}$ corr. a Al & 0,56 & $\mathrm{CN}$ corr. a $\mathrm{Al}$ & 0,56 & $\mathrm{CN}$ corr. a $\mathrm{Al}$ & 0,56 & $\mathrm{CN}$ corr. a $\mathrm{Al}$ & 0,56 & $\mathrm{H}_{1 b}: \mathrm{Al}+\rightarrow \mathrm{CN}$ & 0,61 \\
\hline CN corr. a DI & 0,50 & $\mathrm{CN}$ corr. a DI & 0,50 & $\mathrm{H}_{2 a}: \mathrm{CN}+\rightarrow \mathrm{DI}$ & 0,26 & $\mathrm{H}_{2 a}: \mathrm{CN}+\rightarrow \mathrm{DI}$ & 0,26 & $\mathrm{H}_{2 a}: \mathrm{CN}+\rightarrow \mathrm{DI}$ & 0,31 \\
\hline PC corr. a DI & 0,57 & PC corr. a DI & 0,57 & $\mathrm{H}_{4 a}: \mathrm{PC}+\rightarrow \mathrm{DI}$ & 0,41 & $\mathrm{H}_{4 a}: \mathrm{PC}+\rightarrow \mathrm{DI}$ & 0,42 & $\mathrm{H}_{4 a}: \mathrm{PC}+\rightarrow \mathrm{DI}$ & 0,46 \\
\hline PC corr. a AT & 0,68 & PC corr. a AT & 0,68 & PC corr. a AT & 0,69 & $\mathrm{H}_{4 b}: \mathrm{PC}+\rightarrow \mathrm{AT}$ & 0,70 & $\mathrm{H}_{4 b}: \mathrm{PC}+\rightarrow \mathrm{AT}$ & 0,69 \\
\hline PC corr. a Al & 0,45 & PC corr. a Al & 0,45 & PC corr. a Al & 0,45 & PC corr. a Al & 0,46 & $\mathrm{H}_{4 c}: \mathrm{PC}+\rightarrow \mathrm{Al}$ & 0,51 \\
\hline DI corr. A MO & 0,57 & $\mathrm{H}_{3}: \mathrm{DI}+\rightarrow \mathrm{MO}$ & 0,25 & $\mathrm{H}_{3}: \mathrm{DI}+\rightarrow \mathrm{MO}$ & 0,31 & $\mathrm{H}_{3}: \mathrm{DI}+\rightarrow \mathrm{MO}$ & 0,32 & $\mathrm{H}_{3}: \mathrm{DI}+\rightarrow \mathrm{MO}$ & 0,32 \\
\hline AT corr. A MO & 0,70 & $\mathrm{H}_{5}: \mathrm{AT}+\rightarrow \mathrm{MO}$ & 0,43 & $\mathrm{H}_{5}: \mathrm{AT}+\rightarrow \mathrm{MO}$ & 0,55 & $\mathrm{H}_{5}: \mathrm{AT}+\rightarrow \mathrm{MO}$ & 0,55 & $\mathrm{H}_{5}: \mathrm{AT}+\rightarrow \mathrm{MO}$ & 0,55 \\
\hline Al corr. A DI & 0,44 & Al corr. a DI & 0,44 & $\mathrm{H}_{1 a}: \mathrm{Al}+\rightarrow \mathrm{DI}$ & 0,10 & $\mathrm{H}_{1 a}: \mathrm{Al}+\rightarrow \mathrm{DI}$ & 0,10 & não estimado & \\
\hline CN corr. a AT & 0,48 & CN corr. a AT & 0,48 & CN corr. a AT & 0,48 & não estimado & & não estimado & \\
\hline PC corr. a CN & 0,43 & PC corr. a CN & 0,43 & PC corr. a CN & 0,43 & PC corr. a CN & 0,45 & não estimado & \\
\hline AT corr. A Al & 0,42 & AT corr. a Al & 0,42 & AT corr. a Al & 0,42 & não estimado & & não estimado & \\
\hline Al corr. A MO & 0,35 & $\mathrm{H}_{1}: \mathrm{Al}+\rightarrow \mathrm{MO}$ & $-0,04$ & não estimado & & não estimado & & não estimado & \\
\hline AT corr. A DI & 0,50 & AT corr. a DI & 0,50 & não estimado & & não estimado & & não estimado & \\
\hline PC corr. a MO & 0,64 & $\mathrm{H}_{4}: \mathrm{PC}+\rightarrow \mathrm{MO}$ & 0,21 & não estimado & & não estimado & & não estimado & \\
\hline $\mathrm{CN}$ corr. a $\mathrm{MO}$ & 0,42 & $\mathrm{H}_{2}: \mathrm{CN}+\rightarrow \mathrm{MO}$ & 0,02 & não estimado & & não estimado & & não estimado & \\
\hline
\end{tabular}

A análise de resíduos padronizados do Modelo 4 (Tabela 39) sugere uma possível ligação estrutural significante entre o Conhecimento do Negócio (CN) e a Atenção à Monitoração da IE (AT). Essa possibilidade é evidenciada pelos diversos resíduos maiores que o valor inferior de referência de $|2,5|$ observados entre as variáveis que compõem os construtos CN e AT (grifados). Observa-se que um deles, entre as variáveis CN2 e AT2, é maior que o valor de referência máximo de $|4|$. O índice de modificação associado à ligação $\mathrm{CN} \rightarrow \mathrm{AT}$, no valor 
de 11,123 (logo, superior ao valor de referência de 4,0), também reforça a possibilidade de sua existência. Observa-se o mesmo em relação à ligação PC $\rightarrow$ CN, também excluída do Modelo 4, cujo índice de modificação é de 5,409. A análise do Modelo 3 já tinha fornecido indicações da existência dessas duas relações estruturais. A exemplo do que foi discutido anteriormente, considera-se que essas duas ligações não têm um embasamento teórico claramente estabelecido e, portanto, não devem ser estimadas em um novo modelo estrutural.

Tabela 39 - Resíduos padronizados do Modelo 4

\begin{tabular}{|c|c|c|c|c|c|c|c|c|c|c|c|c|c|c|c|c|c|c|c|c|c|c|}
\hline & Al7 & Al5 & $\mathrm{Al} 3$ & MO7 & MO6 & MO5 & PC7 & D17 & DI3 & $\mathrm{Dl} 2$ & DI1 & AT2 & AT3 & AT4 & $\mathrm{CN} 1$ & $\mathrm{CN}_{2}$ & $\mathrm{CN} 3$ & $\mathrm{CN} 4$ & PC1 & $\mathrm{PC} 2$ & $\mathrm{PC} 5$ & PC6 \\
\hline Al7 & 0,0 & & & & & & & & & & & & & & & & & & & & & \\
\hline Al5 & 0,7 & 0,0 & & & & & & & & & & & & & & & & & & & & \\
\hline Al3 & $-0,2$ & 0,0 & 0,0 & & & & & & & & & & & & & & & & & & & \\
\hline MO7 & 1,1 & 0,0 & 0,8 & 0,3 & & & & & & & & & & & & & & & & & & \\
\hline MO6 & 0,4 & $-1,4$ & $-0,6$ & 0,3 & 0,3 & & & & & & & & & & & & & & & & & \\
\hline MO5 & 1,6 & 0,0 & 0,7 & $-0,3$ & 1,1 & 0,2 & & & & & & & & & & & & & & & & \\
\hline $\mathrm{PC} 7$ & $-0,3$ & $-0,5$ & $-0,1$ & 1,4 & 0,7 & 0,3 & 0,0 & & & & & & & & & & & & & & & \\
\hline DI7 & 1,6 & $-0,4$ & 1,4 & 1,3 & 0,3 & 1,7 & 0,5 & 0,2 & & & & & & & & & & & & & & \\
\hline DI3 & 0,9 & $-1,2$ & $-0,4$ & 0,1 & $-0,1$ & 1,9 & $-0,7$ & 0,8 & 0,2 & & & & & & & & & & & & & \\
\hline $\mathrm{DI} 2$ & 1,1 & 0,0 & 0,1 & $-0,2$ & 0,0 & 0,8 & $-0,8$ & $-0,2$ & 0,0 & 0,2 & & & & & & & & & & & & \\
\hline DI1 & 0,0 & $-0,7$ & 0,0 & 1,2 & 0,3 & 0,6 & 0,0 & $-0,5$ & 0,2 & 1,2 & 0,2 & & & & & & & & & & & \\
\hline AT2 & 0,3 & 0,5 & 1,4 & 1,1 & 0,0 & $-0,4$ & $-0,3$ & 2,0 & 1,1 & 0,6 & 1,9 & 0,0 & & & & & & & & & & \\
\hline AT3 & 0,6 & $-0,2$ & 1,4 & 1,1 & $-0,9$ & $-0,5$ & 0,0 & 1,4 & 0,6 & 0,1 & 1,3 & 0,0 & 0,0 & & & & & & & & & \\
\hline AT4 & 0,5 & $-0,2$ & 1,2 & 1,4 & $-0,3$ & 0,3 & $-0,1$ & 2,3 & 1,2 & 1,2 & 2,0 & 0,0 & 0,0 & 0,0 & & & & & & & & \\
\hline $\mathrm{CN} 1$ & $-0,2$ & $-0,7$ & $-0,1$ & 2,1 & 0,1 & 0,3 & 0,3 & 0,5 & $-0,9$ & 1,5 & $-0,4$ & 3,1 & 2,6 & 2,3 & 0,0 & & & & & & & \\
\hline $\mathrm{CN} 2$ & $-0,6$ & $-0,9$ & $-0,2$ & 3,6 & 1,7 & 1,5 & 1,3 & 0,2 & $-0,1$ & 1,1 & 0,4 & 4,1 & 3,4 & 3,5 & 0,6 & 0,0 & & & & & & \\
\hline $\mathrm{CN} 3$ & $-0,4$ & $-0,4$ & 0,6 & 1,7 & 1,0 & 1,6 & 0,9 & 0,9 & $-0,2$ & 1,8 & 0,4 & 3,4 & 2,3 & 2,6 & $-0,4$ & $-0,4$ & 0,0 & & & & & \\
\hline $\mathrm{CN} 4$ & $-0,3$ & 0,0 & 0,6 & 1,2 & 0,2 & 1,4 & 0,4 & 1,4 & 0,0 & 2,4 & 1,4 & 2,8 & 2,3 & 3,2 & $-0,8$ & $-0,5$ & 1,8 & 0,0 & & & & \\
\hline $\mathrm{PC} 1$ & 0,2 & $-0,5$ & 0,1 & $-0,1$ & $-1,0$ & $-1,5$ & 0,2 & 0,5 & $-1,5$ & $-1,0$ & $-0,7$ & $-0,4$ & $-0,3$ & $-0,2$ & 0,4 & 0,9 & 1,7 & 0,1 & 0,0 & & & \\
\hline $\mathrm{PC} 2$ & 0,4 & $-0,2$ & 0,3 & 0,9 & 0,3 & $-1,1$ & $-0,2$ & 1,2 & $-0,3$ & $-0,2$ & $-0,4$ & $-0,1$ & $-0,3$ & $-0,1$ & 1,1 & 2,3 & 2,1 & 1,8 & 2,1 & 0,0 & & \\
\hline PC5 & $-1,3$ & $-0,7$ & $-0,1$ & 1,7 & 1,0 & 0,3 & 0,1 & 1,8 & 0,4 & 0,4 & 0,8 & 0,1 & $-0,3$ & $-0,4$ & 1,1 & 1,6 & 2,1 & 1,1 & $-0,4$ & $-0,2$ & 0,0 & \\
\hline PC6 & $-1,1$ & $-0,7$ & $-0,3$ & 2,2 & 1,1 & 0,2 & 0,0 & 1,0 & 0,0 & $-0,3$ & 0,3 & $-0,2$ & 0,4 & 0,0 & 0,8 & 1,8 & 1,9 & 0,7 & $-0,4$ & $-0,5$ & 0,3 & 0,0 \\
\hline
\end{tabular}

Em suma, as modificações introduzidas no Modelo 4 melhoraram o modelo estrutural. Em uma comparação mais ampla entre os modelos concorrentes, ilustrada na Tabela 40, verifica-se que os resultados suportam uma lógica de mediação entre os construtos: 
- O Modelo 1, que previu ligações não mediadas entre os construtos exógenos e a Eficácia na Monitoração da IE, obteve os menores índices de ajuste e teve rejeitadas as hipóteses que prediziam efeitos diretos do Acesso a Informações e do Conhecimento do Negócio na Eficácia na Monitoração da IE (hipóteses $H_{1}$ e $H_{2}$ ).

- O Modelo 2 apresentou um ajuste comparativamente melhor que o Modelo 1. Além disso, suportou o efeito mediador da Dinâmica de Trabalho do CA na Eficácia na Monitoração da IE, mas não pela influência do Acesso a Informações (hipótese $H_{1 a}$, rejeitada), e sim do Conhecimento do Negócio (hipótese $H_{2 a}$, não rejeitada).

- O Modelo 3 permitiu conclusão semelhante, e teve a vantagem de suportar o efeito da Liderança do Presidente do CA na Atenção à Monitoração da IE (hipótese $H_{4 b}$, não rejeitada). Adicionalmente, ajustou-se melhor aos dados em comparação ao Modelo 2.

- Finalmente, o Modelo 4 apresentou o melhor nível de ajuste aos dados e teve todas as suas hipóteses suportadas. Conforme a Figura 6, o Modelo 4 foi capaz de explicar 54\% da variância da Eficácia na Monitoração da IE (MO), acima do valor de referência de 50\% indicado por Hair et al. (2010). Além disso, o Modelo 4 agregou evidências importantes à explicação fornecida pelo Modelo 3. Em primeiro lugar, observou-se a influência do Acesso a Informações (AI) sobre a Eficácia na Monitoração da IE (MO) -- não de forma direta, mas por meio do Conhecimento do Negócio (CN) (hipótese $H_{l b}$, não rejeitada) e da Dinâmica de Trabalho do CA (DI) (hipótese $H_{2 a}$, não rejeitada). Em segundo lugar, evidenciou-se que a Liderança do Presidente do CA (PC) exerce influência, direta ou indireta, sobre todos os demais construtos do modelo estrutural.

Neste ponto, portanto, conclui-se que: (i) as relações estruturais entre fatores de Eficácia na Monitoração da IE foram testadas e validadas; (ii) todas as relações de mediação entre construtos representadas pelo Modelo 4 foram confirmadas empiricamente; (iii) o Modelo 4 ajustou-se de forma válida aos dados; e (iv) o Modelo 4 apresentou a melhor qualidade de ajuste dentre os modelos estruturais 
concorrentes. Pode-se, portanto, proceder à interpretação da natureza das relações entre os construtos da pesquisa com base nos resultados empíricos do Modelo 4.

Tabela 40 - Resumo dos parâmetros não-padronizados dos modelos estruturais e significância dos testes de hipóteses

\begin{tabular}{|c|c|c|c|c|c|c|c|c|}
\hline \multirow{2}{*}{$\begin{array}{l}\text { Relação } \\
\text { estrutural }\end{array}$} & \multicolumn{2}{|c|}{ Modelo 1} & \multicolumn{2}{|c|}{ Modelo 2} & \multicolumn{2}{|c|}{ Modelo 3} & \multicolumn{2}{|c|}{ Modelo 4} \\
\hline & parâmetro & Sig. & parâmetro & Sig. & parâmetro & Sig. & parâmetro & Sig. \\
\hline$H_{1}: \mathrm{Al}+\rightarrow \mathrm{MO}$ & $-0,04$ & 0,609 & & & & & & \\
\hline$H_{1 \mathrm{a}}: \mathrm{Al}+\rightarrow \mathrm{DI}$ & & & 0,11 & 0,267 & 0,10 & 0,278 & & \\
\hline$H_{1 \mathrm{~b}}: \mathrm{Al}+\rightarrow \mathrm{CN}$ & & & & & & & 0,52 & $\star * *$ \\
\hline $\mathrm{H}_{2}: \mathrm{CN}+\rightarrow \mathrm{MO}$ & 0,03 & 0,790 & & & & & & \\
\hline$H_{2 \mathrm{a}}: \mathrm{CN}+\rightarrow \mathrm{DI}$ & & & 0,31 & 0,002 & 0,30 & 0,003 & 0,37 & $\star \star *$ \\
\hline $\mathrm{H}_{3}: \mathrm{DI}+\rightarrow \mathrm{MO}$ & 0,24 & 0,002 & 0,31 & $* * *$ & 0,32 & *** & 0,32 & $* * *$ \\
\hline$H_{4}: \mathrm{PC}+\rightarrow \mathrm{MO}$ & 0,15 & 0,018 & & & & & & \\
\hline$H_{4 a}: P C+\rightarrow D I$ & & & 0,30 & *** & 0,30 & *** & 0,33 & $* \star *$ \\
\hline$H_{4 \mathrm{~b}}: \mathrm{PC}+\rightarrow \mathrm{AT}$ & & & & & 0,72 & $* * *$ & 0,72 & $* * *$ \\
\hline$H_{4 \mathrm{c}}: \mathrm{PC}+\rightarrow \mathrm{Al}$ & & & & & & & 0,37 & $* * *$ \\
\hline$H_{5}: \mathrm{AT}+\rightarrow \mathrm{MO}$ & 0,30 & $* * *$ & 0,38 & $* * *$ & 0,38 & $* * *$ & 0,38 & $* * *$ \\
\hline
\end{tabular}

Nota: ${ }^{* * *}$ significante a $0,1 \%$

\section{4 . \\ Discussão dos resultados}

Os resultados empíricos confirmaram a influência de fatores não estruturais na eficácia de um CA na tarefa de monitoração da IE. Diferentes hipóteses de ligação entre fatores antecedentes foram investigadas, com base na análise de modelos estruturais concorrentes. Dentre eles, o modelo que melhor se ajustou aos dados foi o Modelo 4, em que os fatores pesquisados se relacionam à Eficácia na Monitoração da IE segundo uma lógica de mediação, tendo como principal fator antecedente a Liderança do Presidente do CA. Tal modelo foi capaz de explicar melhor a Eficácia na Monitoração da IE do que os modelos concorrentes que não previram um encadeamento entre os fatores. O Modelo final de relações entre os fatores, resultante deste estudo e correspondente ao Modelo 4, é ilustrado na Figura 11. 


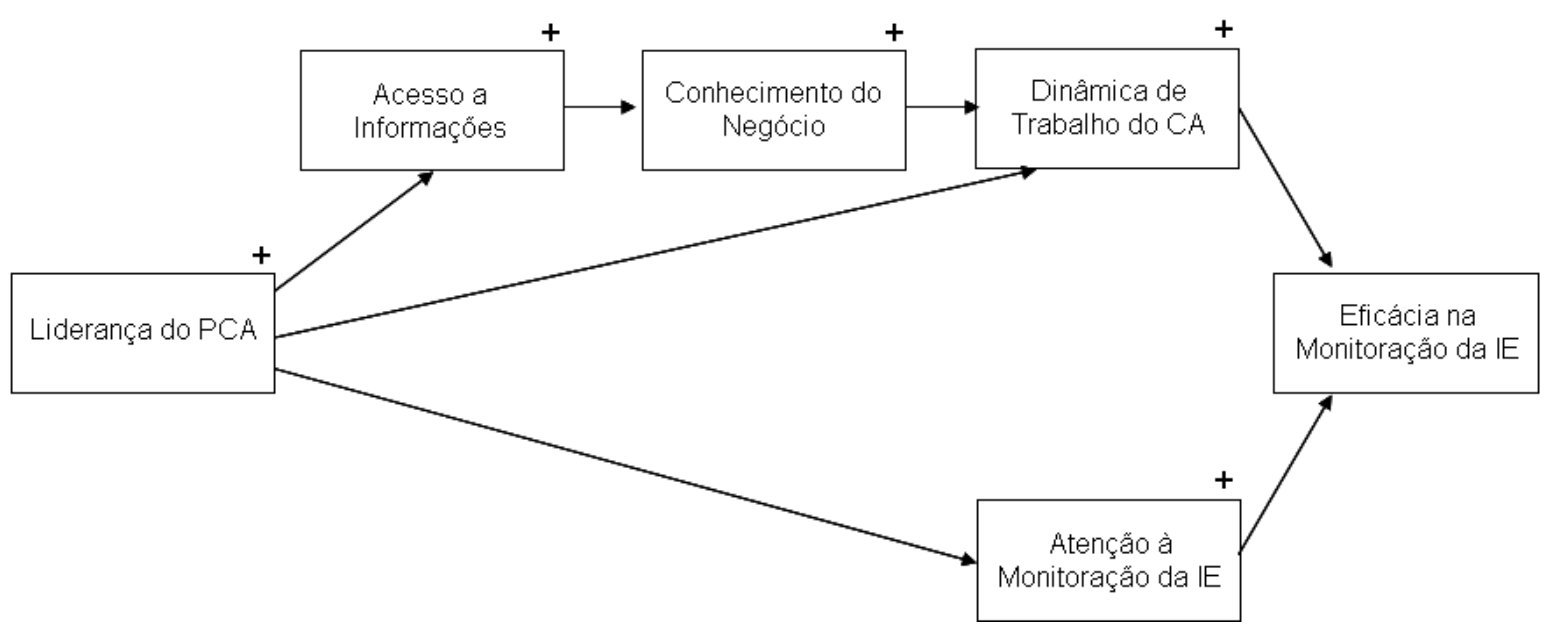

Figura 11 - Modelo final de relações entre fatores não estruturais de Eficácia de CAs na Monitoração da IE

Todas as hipóteses do Modelo final foram validadas empiricamente. A

Tabela 41 contém um resumo das hipóteses analisadas.

Tabela 41 - Resumo dos resultados dos testes de hipóteses

\begin{tabular}{|ll|c|}
\hline \multicolumn{1}{|c|}{ Hipótese de pesquisa } & $\begin{array}{c}\text { Hipótese } \\
\text { verificada }\end{array}$ \\
\hline$H_{1 b}: \quad \begin{array}{l}\text { O Acesso a Informações está positivamente relacionado ao Conhecimento } \\
\text { do Negócio. }\end{array}$ & sim \\
\hline$H_{2 a}: \quad \begin{array}{l}\text { O Conhecimento do Negócio está positivamente relacionado à Dinâmica de } \\
\text { Trabalho do CA. }\end{array}$ & sim \\
\hline$H_{3}: \quad \begin{array}{l}\text { A Dinâmica de Trabalho do CA está positivamente relacionada à Eficácia na } \\
\text { Monitoração da IE. }\end{array}$ & sim \\
\hline$H_{4 a}: \quad \begin{array}{l}\text { A Liderança do Presidente do CA está positivamente relacionada à Dinâmica } \\
\text { de Trabalho do CA. }\end{array}$ & sim \\
\hline$H_{4 b}:$ & $\begin{array}{l}\text { A Liderança do Presidente do CA está positivamente relacionada à Atenção } \\
\text { à Monitoração da IE. }\end{array}$ & sim \\
\hline$H_{4 c}:$ & $\begin{array}{l}\text { A Liderança do Presidente do CA está positivamente relacionada ao Acesso } \\
\text { a Informaçes. }\end{array}$ & sim \\
\hline$H_{5}:$ & $\begin{array}{l}\text { A Atenção à Monitoração da IE está positivamente relacionada à Eficácia na } \\
\text { Monitoração da IE. }\end{array}$ & \\
\hline
\end{tabular}




\subsection{1. Influência da liderança do presidente do CA}

Os resultados confirmaram que a Liderança do Presidente do CA é um antecedente importante da Eficácia na Monitoração da IE. Em linha com as hipóteses formuladas, verificou-se que a sua influência se dá de múltiplas formas: é direta, positiva e significante sobre o Acesso a Informações, a Dinâmica de Trabalho do CA e a Atenção à Monitoração da IE.

A magnitude desses efeitos foi sempre superior a 0,4, conforme a Figura 10. $\mathrm{O}$ mais forte deles, sobre a Atenção à Monitoração da $\operatorname{IE}(=0,69)$, confirma que o PCA tem um papel importante em assegurar que o CA enfoque e priorize as questões de execução estratégica. A magnitude do efeito sobre o Acesso a Informações $(=0,51)$, por sua vez, valida a noção de que o PCA influencia a forma como o CA obtém as informações de que precisa para intervir no rumo estratégico das empresas. A atuação do PCA como catalisador das contribuições do CA também é confirmada pelo efeito que ele exerce sobre a Dinâmica de Trabalho do $\mathrm{CA}(=0,45)$.

Logo, infere-se que CAs cujos presidentes sejam capazes de integrar tais elementos terão um melhor desempenho na monitoração das estratégias. Confirma-se, portanto, o papel crítico do PCA como viabilizador do potencial de criação de valor do CA por meio da monitoração estratégica. Nesse sentido, preconiza-se para o PCA um triplo papel: (i) o de direcionador do CA para a monitoração da IE; (ii) o de dinamizador das interações e contribuições dos conselheiros; e, finalmente, (iii) o de facilitador do acesso as informações relevantes para o CA.

\subsection{2.}

\section{Influência do acesso a informações}

Verificou-se que o Acesso a Informações influencia a Eficácia de um CA na Monitoração da IE. Seu efeito é indireto, por meio do Conhecimento do Negócio. Em linha com as predições teóricas, CAs que dispõem de melhores condições de acesso às informações relevantes terão melhores conhecimentos dos aspectos específicos das operações da empresa. 
Trata-se de um aspecto importante de desenvolvimento de capacitações dos conselheiros, pois conforme Siciliano (2002) ressaltou, há poucas oportunidades disponíveis para que os conselheiros tenham acesso ao que acontece de fato na implementação das principais iniciativas estratégicas. Ao ter acesso a múltiplas fontes de dados sobre a empresa, os conselheiros poderão formar uma visão mais embasada das barreiras à execução das estratégias. Dada a influência que a arquitetura de informações à disposição do CA exerce no seu aprendizado sobre a empresa, e a escassez de tempo do conselheiro, é importante assegurar que o CA seja municiado com informações de alta relevância, evitando-se a proliferação de relatórios com informações irrelevantes.

Infere-se, portanto, que a implantação de processos estruturados de acesso a informações contribuirá para que o CA avalie melhor as reais condições em que a empresa opera por meio do aumento dos seus conhecimentos sobre o negócio.

\subsection{3.}

\section{Influência do conhecimento do negócio}

Confirmou-se empiricamente que o Conhecimento do Negócio influencia de forma direta e positiva a Dinâmica de Trabalho do CA e, de forma indireta, a Eficácia na Monitoração da IE. Este resultado é consistente com a proposição teórica de que os conhecimentos específicos do negócio e da indústria são importantes para que os CAs desempenhem suas tarefas de monitoração (Nonaka, 1994; Forbes \& Milliken, 1999), alinhando-se também com a percepção dos conselheiros de administração entrevistados.

Assim, infere-se que os CAs que disponham de um maior conhecimento organizacional estarão mais bem preparados para intervir nas questões estratégicas de maior complexidade. Ao serem capazes de identificar e questionar as barreiras organizacionais e ambientais à implementação das iniciativas estratégicas, os conselheiros contribuirão para uma dinâmica de trabalho mais eficiente no CA. Ressalta-se, no entanto, que o efeito do Conhecimento do Negócio sobre a Dinâmica de Trabalho do CA, com coeficiente de 0,31 (Figura 10), é menor que o da Liderança do Presidente do CA $(=0,45)$. Uma possível explicação para esse achado é a visão de que o PCA contribui para o aprendizado organizacional do 
CA ao ativar o estoque de conhecimentos disponível, estimulando o seu efetivo uso (Forbes \& Milliken, 1999).

\subsection{4. \\ Influência da dinâmica de trabalho do CA}

Os resultados demonstraram que a Dinâmica de Trabalho do CA é um antecedente direto da Eficácia na Monitoração da IE. Confirmando os achados preliminares das entrevistas de profundidade com conselheiros, verificou-se que as formas como os CAs efetivamente trabalham em equipe e interagem com a equipe executiva influenciam significativamente o seu desempenho na monitoração estratégica. Com auxílio do Modelo final confirmou-se aqui, no contexto especifico da tarefa de monitoração da IE, o achado genérico de que a cultura decisória do CA influencia o seu desempenho (Gabrielsson \& Huse, 2004a).

Verificou-se também que os efeitos da liderança do PCA, do acesso a informações e do estoque de conhecimentos específicos sobre a monitoração estratégica são mediados pela dinâmica interna do CA. Evidenciou-se, assim, a existência de uma lógica sistêmica de desempenho organizacional no CA, pela qual a eficácia na tarefa de monitoração estratégica depende de uma sequiência de acesso, articulação, compartilhamento e aplicação de conhecimentos relevantes (Nonaka, 1994; Grant, 1996; Kale \& Singh, 2007). Conclui-se, portanto, que dadas as diversas restrições de informações, de conhecimentos e de interação entre conselheiros, a produção em equipe eleva a qualidade da participação do CA no processo de monitoração das estratégias empresariais.

\subsection{5.}

\section{Influência da atenção à monitoração da IE}

Em linha com as predições do modelo conceitual, verificou-se que desempenho do CA na monitoração estratégica depende diretamente do grau de atenção dedicado à tarefa. Conforme discutido na análise do referencial teórico, diversas tarefas e atribuições disputam a atenção dos CAs e a monitoração da IE nem sempre é percebida como a mais importante. Os resultados empíricos sugerem que a adoção de políticas internas e normas que incluam a monitoração 
da IE na pauta do CA contribuirá para aumentar o desempenho do CA nessa tarefa. Quanto aos fatores antecedentes, confirmou-se que o PCA tem um papel importante em orientar e disciplinar os trabalhos do CA para assegurar uma atenção regular à monitoração do rumo estratégico.

Uma comparação dos parâmetros padronizados dos dois antecedentes diretos da Eficácia na Monitoração da IE, ilustrados na Figura 10, permite outra inferência relevante. O parâmetro padronizado da ligação entre a Atenção à Monitoração da IE e a Eficácia na Monitoração da IE $(\mathrm{AT} \rightarrow \mathrm{MO}=0,55)$ é maior que aquele entre a Dinâmica de Trabalho do CA e a Eficácia na Monitoração da IE (DI $\rightarrow \mathrm{MO}=0,32$ ). Isto significa que o aumento de AT em uma unidade aumentará MO em 0,48 unidades, ao passo que o aumento de DI em uma unidade aumentará MO em 0,32 unidades. Essa diferença sugere que a atenção à tarefa pode ser mais eficaz que a dinâmica de trabalho para melhorar o desempenho do CA na monitoração da IE. Este achado reforça a importância da adoção de medidas que elevem a atenção do CA ao processo de monitoração estratégica. 


\section{7 \\ Conclusões}

Este capítulo, que conclui o trabalho, inicia-se com um resumo do estudo, em que são revistos as etapas seguidas e os resultados alcançados (seção 7.1).

Em seguida, na seção 7.2, são discutidas as contribuições e implicações para a pesquisa acadêmica, do ponto de vista conceitual e metodológico. Posteriormente, são discutidas as implicações dos resultados para a prática gerencial e são formuladas recomendações para conselheiros, acionistas e reguladores (seção 7.3).

Na seção 7.4 são discutidas as limitações do estudo. Por fim, são sugeridas novas linhas de pesquisa futura (seção 7.5).

\section{1. Resumo do estudo e resultados}

Este estudo analisou de que forma fatores não estruturais antecedentes podem influenciar a eficácia de um CA na tarefa de monitoração da IE. A revisão da literatura pertinente revelou a inexistência de modelos específicos que auxiliem na melhoria do desempenho dos CAs nas suas tarefas de monitoração estratégica. Com base em modelos gerais de eficácia de CAs disponíveis na literatura, desenvolveu-se um modelo preliminar específico, no qual se propôs que a eficácia de um CA naquela tarefa é influenciada por fatores comportamentais, contextuais e normativos.

Por meio de uma pesquisa de campo com conselheiros de administração experientes, foram obtidos subsídios para a proposição um modelo conceitual simplificado. Nesse modelo, sugeriu-se que a Eficácia de um CA na Monitoração da IE é influenciada, de diferentes formas possíveis: (i) pela Liderança do Presidente do CA; (ii) pelo Acesso a Informações; (iii) pelo Conhecimento do Negócio; (iv) pela Dinâmica de Trabalho do CA; e (v) pela Atenção à Monitoração da IE. 
Para testar as hipóteses de relações entre esses fatores, foi elaborado um instrumento baseado em seis escalas de medição dos construtos da pesquisa. Conduziu-se uma survey com uma amostra de 217 questionários válidos, respondidos por conselheiros de administração de empresas brasileiras. As hipóteses foram testadas por meio da modelagem de equações estruturais. Quatro modelos estruturais concorrentes foram especificados e testados, apresentando índices de ajuste aceitáveis. O Modelo final da pesquisa foi o que: (i) melhor se ajustou aos dados; e (ii) apresentou significância estatística para todas as relações hipotéticas.

À diferença dos demais, o Modelo final evidenciou uma lógica de mediação entre os construtos antecedentes pesquisados. Verificou-se que a Dinâmica de Trabalho do CA e a Atenção à Monitoração da IE possuem efeitos diretos, positivos e significantes sobre a Eficácia na Monitoração da IE, ao passo que os efeitos do Acesso a Informações, do Conhecimento do Negócio e da Liderança do Presidente do CA, também positivos e significantes, são mediados pela Dinâmica de Trabalho do CA. De modo particularmente relevante, evidenciou-se a importância da Liderança do PCA como antecedente indireto da Eficácia da Monitoração da IE, uma vez que influencia simultaneamente o Acesso a Informações, a Dinâmica de Trabalho do CA e a Atenção à Monitoração da IE.

\section{2. \\ Implicações para a pesquisa acadêmica}

Este estudo trouxe contribuições para o desenvolvimento da pesquisa nos campos da GC, eficácia de CAs e gestão estratégica, descritas a seguir.

\subsection{1.}

\section{Contribuições teóricas}

Pode-se destacar, dentre os produtos da pesquisa, cinco contribuições teóricas. Primeiramente, ao fornecer evidência empírica inovadora sobre a existência de relações mediadas entre as variáveis pesquisadas, no contexto específico da monitoração da IE no CA, este estudo contribui para um melhor entendimento de como o potencial de criação de valor dos CAs pode ser ativado. Isso é relevante, pois, embora alguns estudos recentes sobre os determinantes do 
desempenho dos CAs tenham reconhecido o impacto de fatores não estruturais, poucos deles evidenciaram a importância relativa e a natureza do relacionamento entre essas variáveis. A lógica de mediação verificada no Modelo final deste estudo poderá ser útil para a formulação de novas proposições sobre determinantes do desempenho de CAs em outras tarefas de controle e serviço.

Em segundo lugar, a tarefa de monitoração estratégica do CA foi reconceituada com a perspectiva da Teoria de Produção em Equipe - TPE. Essa nova abordagem teórica mostrou-se bem sucedida em caracterizar o desempenho do CA na tarefa de monitoração da IE como o resultado de antecedentes não estruturais que viabilizam a sua produção em equipe. O uso da TPE permitiu a identificação de novos fatores de previsão, de difícil aproximação pelo emprego exclusivo da teoria de agência.

O construto Eficácia na Monitoração da IE foi definido operacionalmente de forma inovadora, com base em perspectivas teóricas complementares de agência, processo estratégico e produção em equipe. Essa definição operacional poderá ser útil para embasar futuras pesquisas.

Explorou-se aqui a influência de um novo e importante previsor do controle estratégico no CA, que é a atenção dedicada à tarefa. Dada a diversidade de tarefas que um CA deve desempenhar, pode ser útil incorporar a influência da atenção dedicada a elas nos modelos gerais existentes de eficácia de CAs.

Finalmente, o modelo conceitual preliminar desenvolvido na seção 2.3 é, em si mesmo, um produto de pesquisa que poderá embasar novas proposições e testes empíricos sobre as relações não investigadas neste estudo. Esse modelo, por mapear de modo sistemático o universo de relações entre as variáveis que, a partir da atuação dos CAs, podem influenciar a IE, constitui um referencial que poderá ser explorado por outros pesquisadores.

\subsection{2.}

\section{Contribuições metodológicas}

Possivelmente a maior crítica em relação à pesquisa em CAs refere-se à distância do seu real funcionamento, com o argumento de que a maioria dos estudos em GC emprega dados secundários e trata o trabalho do CA como uma 'caixa preta'. 
Para endereçar essa lacuna, este estudo procurou responder a uma recomendação recorrente na pesquisa recente em CAs, que é de utilizar o conselheiro como fonte primária de dados. O método de pesquisa empregado combinou entrevistas de profundidade com conselheiros experientes e uma survey com conselheiros de empresas brasileiras. Essa abordagem integrada permitiu a captura de informações detalhadas e válidas sobre a natureza do envolvimento dos CAs no asseguramento da IE.

Há reconhecidas dificuldades metodológicas e empíricas para ganhar acesso aos membros da elite empresarial, como é o caso dos conselheiros de administração. A seqüência de procedimentos aqui empregados para a distribuição e seguimento da survey com conselheiros contribuiu para a obtenção de uma amostra potencialmente representativa. Outro fator de sucesso foi o apoio institucional de organizações como o IBGC e a empresa de consultoria Booz \& Company. O fato de essas organizações serem identificadas com o tema da GC contribuiu para que os respondentes se motivassem a responder ao questionário. Além disso, pôde-se obter acesso a dados cadastrais de conselheiros de administração brasileiros, o que facilitou a distribuição dos questionários.

A escolha de empresas brasileiras como contexto empírico desta pesquisa endereça uma crítica recorrente aos estudos em GC, que é o estudo extensivo de empresas norte-americanas. Espera-se, com isso, contribuir para o conhecimento no campo da governança estratégica no contexto de economias emergentes e em particular no contexto brasileiro, no qual há poucos estudos empíricos.

As escalas de medição dos construtos específicos da pesquisa, até então indisponíveis na literatura, foram validadas e poderão ser empregadas em futuros estudos.

\section{3.}

\section{Implicações gerenciais}

Há diversas implicações e recomendações, oriundas deste estudo, potencialmente úteis para a melhoria das práticas de GC e de gestão estratégica. As recomendações aqui contidas unem-se a um crescente conjunto de estudos que apontam para a necessidade de uma maior profissionalização dos CAs. Mais 
especificamente, elas indicam linhas de ação que poderão contribuir para o desenvolvimento da capacitação de monitoração estratégica nos CAs.

Este estudo sugere que os CAs precisam ter recursos e capacitações específicos de liderança, informações, conhecimentos de negócio, processos de trabalho e relacionamento interpessoal que lhes permitam ter uma atuação mais independente e eficaz sobre os riscos estratégicos das empresas. O modelo aqui desenvolvido poderá ser usado por empresas, investidores e reguladores como uma base para delinear com mais clareza o potencial papel dos CAs nas suas responsabilidades de monitoração estratégica.

Os resultados contribuem para compreender o papel do presidente do CA de uma forma mais ampla, no âmbito do desempenho do CA e da gestão estratégica. A contribuição desse PCA revelou-se crítica e multifacetada, como facilitador do acesso a informações, da dinâmica de trabalho e da atenção do CA ao rumo da IE. Como demonstrado, PCAs que apresentem esses comportamentos e competências contribuem mais significativamente para o desempenho do CA nas tarefas de monitoração estratégica. Adicionalmente, o PCA deve ser capaz de assegurar a monitoração regular da IE no CA de forma harmônica e construtiva com o CEO, de modo a evitar conflitos. Logo, os resultados sugerem que ter um PCA com tais características de liderança é uma ação de alto potencial de impacto para a melhoria da capacidade de gestão estratégica das empresas. Recomenda-se, portanto, que os processos de recrutamento e avaliação do PCA incorporem esses atributos.

A importância do acesso a informações indica a necessidade de aumentar o tempo e as formas de interação do conselheiro com a empresa. Os conselheiros devem alocar tempo significativo em adição às reuniões formais do CA para interagir com a empresa e obter informações relevantes sobre o estado de implementação das principais iniciativas estratégicas. Com esse fim, devem ser criados canais formais e informais de acesso do conselheiro à equipe executiva. A necessidade de uma maior alocação de tempo às atividades formais e informais de obtenção de informações sugere que os conselheiros deveriam dedicar mais que um dia por mês à empresa. Essas recomendações alinham-se à crescente percepção de que o número máximo de CAs em que um conselheiro pode participar deve ser limitado. Em relação ao comitê de estratégia, sugere-se que tenha a atribuição específica de subsidiar o CA com análises do progresso da 
implementação dos projetos estratégicos. Conforme indicado por alguns dos conselheiros entrevistados, recomenda-se que o CA defina formalmente, em conjunto com a equipe executiva, as prioridades de IE da empresa e seus requerimentos específicos de informação para poder monitorar as iniciativas estratégicas priorizadas.

A importância do conhecimento do negócio sugere que os membros do CA precisam ser dotados de experiência relevante. A experiência na indústria permitirá que os conselheiros identifiquem mais claramente o contexto externo que afeta a IE e as possíveis respostas estratégicas. No âmbito interno, ao compreenderem o modelo de negócio e a cadeia de valor das empresas, os conselheiros estarão mais aptos a avaliar as barreiras organizacionais à implementação das estratégias. Logo, a exemplo de algumas empresas citadas nas entrevistas de profundidade com conselheiros, recomenda-se a implantação de programas de indução estratégica de novos conselheiros e de treinamento nas operações da empresa, como forma de expandir o conhecimento da realidade do campo da IE e de travar contato com os executivos responsáveis pela IE. Ao serem capazes de articular os diferentes elementos da agenda estratégica da empresa, os conselheiros poderão avaliar até que ponto as novas propostas estratégicas são coerentes e devem ser acatadas. Assim, recomenda-se que CAs cuja intervenção no processo de formulação estratégica seja baixa participem regularmente de sessões de discussão e entendimento da agenda estratégica da empresa.

Conforme os resultados indicaram, o aumento do estoque de conhecimento de negócio no CA também melhorará sua dinâmica interna de trabalho, ao propiciar discussões mais aprofundadas das questões de IE. Portanto, os processos de recrutamento e de avaliação de conselheiros deverão levar em consideração a sua contribuição para o estoque de conhecimento do negócio do CA. Sugere-se também que a proporção de conselheiros com experiência e conhecimentos relevantes do negócio seja monitorada. Ao atuar no sentido de que um número relevante de conselheiros tenha um bom nível de conhecimento do negócio, os acionistas e agentes reguladores contribuirão para melhorar o gerenciamento do risco estratégico das empresas.

Quanto à dinâmica de trabalho do CA, os resultados indicam a acionistas, agentes reguladores e conselheiros que a qualidade da Governança Corporativa 
depende não só de forma, mas também de substância. Ao revelar comportamentos e processos de trabalho que contribuem para o desempenho do CA na tarefa de monitoração da IE, este estudo ressalta a importância de aspectos não estruturais que são de difícil especificação em códigos de boas práticas de governança. Como recomendação prática, sugere-se aqui que os processos de avaliação de desempenho dos CAs incluam indicadores da sua dinâmica interna de trabalho, da contribuição individual dos conselheiros para a qualidade das interações com outros conselheiros e com o CEO, e para os processos de análise e tomada de decisão no CA.

Este estudo ressaltou a importância de que as tarefas de controle estratégico sejam priorizadas, dado que diversas tarefas e responsabilidades competem pela atenção do CA. Conforme relatado por um dos entrevistados, a mediação de conflitos horizontais entre acionistas, a discussão de partes relacionadas e o cumprimento de responsabilidades estatutárias e legais são temas que consomem a maior parte da atenção de diversos CAs. A ênfase nessas tarefas pode tornar estreita a perspectiva estratégica dos CAs, reduzindo as atividades de gestão de riscos a uma dimensão defensiva, não estratégica e de baixo potencial de criação de valor. Sendo assim, recomenda-se que os CAs incorporem em suas agendas de trabalho instâncias regulares e processos sistemáticos de monitoração dos pilares das estratégias das empresas.

Finalmente, o modelo e os instrumentos de medição aqui desenvolvidos poderão ser usados por conselheiros, acionistas e consultores interessados em avaliar de forma sistemática o desempenho dos CAs na monitoração estratégica e em seus antecedentes.

\section{4. \\ Limitações do estudo}

Os resultados do estudo devem ser considerados à luz de algumas limitações importantes.

As relações aqui propostas precisam ser verificadas em outros contextos antes que sejam generalizáveis. É possível que as relações observadas não sejam válidas para CAs de empresas não brasileiras. Logo, deve-se ter cautela antes de proceder a generalizações para empresas de outras economias, emergentes ou 
desenvolvidas, uma vez que as características específicas do contexto brasileiro podem ter afetado os resultados. Portanto, recomenda-se que pesquisas futuras testem a validade deste modelo em países com diferentes ambientes de governança corporativa e de proteção legal.

No desenvolvimento do modelo conceitual, pressupôs-se que a eficácia de um CA na monitoração da IE afeta a implementação das estratégias empresariais. Essa premissa, não testada aqui por uma decisão de delimitação do estudo, pode não ser confirmada empiricamente. Sugere-se que estudos futuros enderecem esta limitação.

As relações entre os construtos não estruturais incluídos no modelo final foram capazes de explicar $54 \%$ da variância da Eficácia na Monitoração da IE. Esse resultado confirma o poder explicativo dos antecedentes não estruturais estudados e suporta a delimitação de variáveis adotada na pesquisa por razões de relevância e parcimônia. No entanto, com base em diversos estudos da linha mais tradicional da pesquisa em GC, pode-se supor que alguns fatores estruturais também influenciem a eficácia dos CAs na tarefa de monitoração estratégica. Logo, novos trabalhos poderão verificar se tais fatores estruturais terão contribuição incremental significativa no desempenho dos CAs nessa tarefa. Também será interessante comparar o poder explicativo dos fatores estruturais e não estruturais, de modo a analisar sua importância relativa.

\section{5.}

\section{Sugestões para estudos futuros}

A fundamentação teórica e os resultados deste estudo propiciam várias oportunidades de pesquisas futuras. Conforme discutido na seção anterior, novos estudos serão importantes para suplantar as limitações identificadas. Sugerem-se aqui algumas oportunidades adicionais de pesquisa.

Uma consideração importante em estudos de determinantes de GC de empresas brasileiras é o seu elevado grau de concentração de propriedade (Leal \& Carvalhal da Silva, 2005). Na amostra trabalhada, o percentual médio de ações com direito a voto em poder do maior acionista foi de $49,1 \%$, o que corrobora essa percepção. Estudos recentes demonstraram que empresas com propriedade concentrada podem ser menos propensas a adotar práticas avançadas de GC 
(Anand, Milne \& Purda, 2006; Silveira et al., 2009). A concentração de propriedade acarreta conflitos principal-principal (Dharwadkar, George \& Brandes, 2000) e pode produzir efeitos potencialmente relevantes para a monitoração estratégica no CA que não foram mensurados neste estudo. Por exemplo, CAs dominados por um grupo de controle podem privilegiar a implementação de estratégias sub-ótimas que, em seu benefício, expropriam valor dos acionistas não controladores. Além disso, do ponto de vista da sua dinâmica de trabalho, os CAs predominantemente ocupados por convidados do controlador podem negligenciar a discussão de pontos e contrapontos relevantes. Logo, sugere-se investigar os efeitos que a concentração de propriedade pode ter nas relações entre os fatores não estruturais aqui estudados e o desempenho do CA na monitoração estratégica.

Em empresas de controle definido, o tipo de controle também pode ser uma contingência relevante. Por exemplo, a empresa familiar constitui a forma predominante de organização da atividade econômica no Brasil (Esperança, Sousa, Soares \& Pereira, 2011). No entanto, estudos anteriores sugerem que a qualidade da GC em empresas de controle familiar pode ser negativamente influenciada por fatores como concentração de poder nas mãos das famílias controladoras, centralização de decisões estratégicas, paternalismo entre membros das famílias e falta de confiança nos administradores (Schulze, Lubatkin \& Dino, 2003). Nesse contexto, a influência dos fatores antecedentes aqui pesquisados pode variar significativamente, assim como a própria eficácia do CA em monitorar a IE. Portanto, novas pesquisas que estudem esse fenômeno no contexto específico da empresa familiar poderão ser úteis.

Outra questão a ser analisada em futuros estudos é o impacto do controle governamental sobre a qualidade da governança estratégica, uma vez que empresas controladas por governos podem apresentar indefinição estratégica (Carneiro, Silva \& Cavalcanti, 2003) ou interferência política nas decisões estratégicas (Musacchio \& Lazzarini, 2012).

Adicionalmente, estudos de CAs de empresas controladas por fundos de private equity, que se caracterizam por um padrão ativo de governança (Acharya, Kehoe \& Reyner, 2009), poderão revelar novos elementos de dinâmica interna e métodos de trabalho relevantes para o seu desempenho na monitoração estratégica. 
Por fim, a influência dos fatores antecedentes da Atenção à Monitoração da IE, propostos no modelo conceitual preliminar, não foi testada devido à delimitação de variáveis adotada na pesquisa. Devido à importância do construto, evidenciada nos resultados da modelagem estrutural, sugere-se que futuras pesquisas analisem empiricamente a validade desses antecedentes.

Em conclusão, este estudo apresentou uma abordagem nova e potencialmente proveitosa para a compreensão dos fatores não estruturais antecedentes da eficácia dos CAs na monitoração da IE. Sua contribuição é relevante porque há pouco conhecimento acumulado na área, apesar das crescentes responsabilidades dos CAs para com o sucesso estratégico das organizações. Até onde foi possível investigar, não há estudos anteriores que tenham analisado os fatores antecedentes de eficácia de CAs na monitoração da IE. O modelo aqui desenvolvido revelou a natureza das relações entre os fatores estudados e permitirá a aplicação de mecanismos concretos para melhorar o desempenho do CA na tarefa de monitoração estratégica. Ao analisar em profundidade o real funcionamento dos CAs, espera-se que este estudo amplie a base de conhecimento e promova novos esforços de pesquisa neste importante tema. 


\section{Referências bibliográficas}

ACHARYA, V. V.; KEHOE, C.; REYNER, M. Private Equity vs. PLC Boards in the U.K.: A Comparison of Practices and Effectiveness. Journal of Applied Corporate Finance, v. 21, n. 1, p. 45-56, 2009.

ALCHIAN, A. A.; DEMSETZ, H. Production, information costs, and economic organization. The American Economic Review, v. 62, n. 5, p. 777-795, 1972.

ALDRIGHI, D.; POSTALI, F. Business Groups in Brazil. In: COLPAN, A. M.; HIKINO, T.; LINCOLN, J. R. (Ed.). The Oxford Handbook of Business Groups. New York: Oxford University Press, 2010. Cap.13. p. 353-386.

ALLEN, M.; RENNER, C.; ENGLISH, D. Evaluating the corporate board. Strategic Finance (USA), v. 85, n. 7, p. 37-42, 2004.

ANAND, A. I.; MILNE, F.; PURDA, L. Voluntary Adoption of Corporate Governance Mechanisms. American Law and Economics Association Papers, v. 39, p. 1-47, 2006.

ANDERSON, J. C.; GERBING, D. W. Structural equation modeling in practice: A review and recommended two-step approach. Psychological Bulletin, v. 103, n. 3, p. 411-423, 1988.

ANDREWS, K. R. Corporate strategy as a vital function of the board. Harvard Business Review, v. 59, n. 6, p. 174-184, 1981.

ARGYRIS, C. Strategy implementation: An experience in learning. Organizational Dynamics, v. 18, n. 2, p. 5-15, 1989.

BAGOZZI, R. P.; PHILLIPS, L. Representing and Testing Organizational Theories: A Holistic Construal. Administrative Science Quarterly, v. 17, p. 459489, 1982.

BARNEY, J. Firm resources and sustained competitive advantage. Journal of Management, v. 17, n. 1, p. 99-120, 1991.

BARNEY, J.; WRIGHT, M.; KETCHEN JR, D. J. The resource-based view of the firm: Ten years after 1991. Journal of Management, v. 27, n. 6, p. 625-641, 2001.

BARTON, D.; WONG, S. C. Y. Improving board performance in emerging markets. McKinsey Quarterly, n. 1, p. 74-83, 2006.

BERLE, A.; MEANS, G. The modern corporation and private property. New York: MacMillan Publishing Company, 1932. 
BHAGAT, S.; BLACK, B. The Uncertain Relationship Between Board Composition and Firm Performance. Business Lawyer, v. 54, p. 921-963, 1999.

BLAIR, M. M.; STOUT, L. A. A Team Production Theory of Corporate Law. Virginia Law Review, v. 85, n. 2, p. 248-328, 1999.

Director Accountability and the Mediating Role of the Corporate Board. Washington University Law Quarterly, v. 79, n. 2, p. 403, 2001.

BOEKER, W. Strategic Change: The Effects of Founding and History. The Academy of Management Journal, v. 32, n. 3, p. 489-515, 1989.

BOURGEOIS, L. J.; BRODWIN, D. R. Strategic implementation: Five approaches to an elusive phenomenon. Strategic Management Journal, v. 5, n. 3, p. 241-264, 1984.

BRAUER, M.; SCHMIDT, S. Defining the strategic role of boards and measuring boards' effectiveness in strategy implementation. Corporate Governance: International Journal of Business in Society, v. 8, p. 649-660, 2008.

BROWN, C. C. Putting the corporate board to work. New York: Macmillan, 1976.

BUCK, T.; FILATOTCHEV, I.; WRIGHT, M. Agents, Stakeholders and Corporate Governance in Russian Firms. Journal of Management Studies, v. 35, n. 1, p. 81-104, 1998.

CARNEIRO, J. M. T.; SILVA, J. F.; CAVALCANTI, M. A. D. F. Impactos da privatização sobre as estratégias competitivas de empresas de petróleo: um estudo de casos. RAE Eletrônica, v. 2, 2003. Disponível em: <http://www.scielo.br/scielo.php?script=sci_arttext\&pid=S1676$56482003000200003 \&$ nrm=iso>.

CARVALHAL DA SILVA, A. L. Governança corporativa e sucesso empresarial: Melhores práticas para aumentar o valor da firma. São Paulo: Saraiva, 2006.

CHARAN, R. Boards that deliver: advancing corporate governance from compliance to competitive advantage. San Francisco: Jossey-Bass, 2005.

CLAESSENS, S. Corporate Governance and Development. Washington: The World Bank, 2003.

COMISSÃO DE VALORES MOBILIÁRIOS. Recomendações da CVM sobre governança corporativa. Rio de Janeiro: Comissão de Valores Mobiliários, 2002. Disponível em: <www.cvm.gov.br/port/public/publ/cartilha/cartilha.doc〉.

CONVERSE, J. M.; PRESSER, S. Survey Questions: Handcrafting the Standardized Questionnaire. Thousand Oaks: Sage Publications, 1986. (Sage University Paper series on Quantitative Applications in the Social Sciences, 007$01)$. 
COULSON-THOMAS, C. What the personnel director can bring to the boardroom table. Personnel Management, v. 23, n. 10, p. 36-39, 1991.

CYERT, R. M.; MARCH, J. G. A behavioral theory of the firm. New Jersey: Prentice-Hall Inc., 1992.

DAILY, C. M.; DALTON, D. R.; CANNELLA, A. A. Corporate governance: Decades of dialogue and data. The Academy of Management Review, v. 28, n. 3, p. 371-382, 2003.

DALTON, D. R.; DALTON, C. M. Integration of Micro and Macro Studies in Governance Research: CEO Duality, Board Composition, and Financial Performance. Journal of Management, June 11, 20102010.

DAVIES, A. A Strategic Approach to Corporate Governance. Hampshire: Gower, 1999.

DAY, G. S.; WENSLEY, R. Marketing theory with a strategic orientation. The Journal of Marketing, v. 47, n. 4, p. 79-89, 1983.

DEMB, A.; NEUBAUER, F. The corporate board: confronting the paradoxes. Oxford University Press, USA, 1992.

DEMB, A.; NEUBAUER, F. F. How can the board add value? European Management Journal, v. 8, n. 2, p. 156-160, 1990.

DHARWADKAR, R.; GEORGE, G.; BRANDES, P. Privatization in Emerging Economies: An Agency Theory Perspective. The Academy of Management Review, v. 25, n. 3, p. 650-669, 2000.

DONALDSON, G. A new tool for boards: the strategic audit. Harvard Business Review, v. 73, n. 4, p. 99-107, 1995.

DONALDSON, L.; DAVIS, J. Stewardship theory or agency theory: CEO governance and shareholder returns. Australian Journal of Management, v. 16, n. 1, p. 49, 1991.

DREW, S.; KAYE, R. Engaging Boards in Corporate Direction-Setting Strategic Scorecards. European Management Journal, v. 25, n. 5, p. 359-369, 2007.

DULEWICZ, V.; MACMILLAN, K.; HERBERT, P. Appraising and Developing the Effectiveness of Boards and Their Directors. Journal of General Management, v. 20, n. 3, p. 1-19, Spring95 1995.

EASTERBROOK, F. H.; FISCHEL, D. R. The Economic Structure of Corporate Law. Cambridge: Harvard University Press, 1991.

EELLS, R. The Meaning of Modern Business. New York: Columbia University Press, 1960.

EMERY, F.; TRIST, E. The Causal Texture of Organizational Environments. Human Relations, v. 18, p. 21-32, 1965. 
ESPERANÇA, J. P.; SOUSA, A.; SOARES, E.; PEREIRA, I. Corporate Governance no Espaço Lusófono. Alfragide: Texto, 2011.

FAMA, E.; JENSEN, M. Separation of ownership and control. The Journal of Law and Economics, v. 26, n. 2, p. 301, 1983.

FILATOTCHEV, I.; WRIGHT, M.; UHLENBRUCK, K.; TIHANYI, L.; HOSKISSON, R. E. Governance, organizational capabilities, and restructuring in transition economies. Journal of World Business, v. 38, n. 4, p. 331-347, 2003.

FINANCIAL REPORTING COUNCIL. The Combined Code on Corporate Governance. London: Financial Reporting Council, 2008.

FINKELSTEIN, S.; HAMBRICK, D. Strategic Leadership. St. Paul: West Publishing Company, 1996.

FLOYD, S. W.; WOOLDRIDGE, B. Managing strategic consensus: the foundation of effective implementation. Academy of Management Executive, v. 6, n. 4, p. 27-39, 1992.

FORBES, D. P.; MILLIKEN, F. J. Cognition and Corporate Governance: Understanding Boards of Directors as Strategic Decision-Making Groups. The Academy of Management Review, v. 24, n. 3, p. 489-505, 1999.

FREELAND, C. Future of Capitalism Debate - Part 1. Financial Times, 2009. Disponível em: <http://www.ft.com/intl/cms/s/0/3ca10aec-1ed2-11de-b24400144feabdc0.html\#axzz2HfcVIiht>.

FREEMAN, R. E. Strategic Management: A Stakeholder Approach. Boston: Pitman, 1984.

FRIEDMAN, M. The Social Responsibility of Business is to Increase its Profits. The New York Times Magazine1970. p. 122-126.

GABRIELSSON, J.; HUSE, M. Context, behavior, and evolution: Challenges in research on boards and governance. International Studies of Management and Organization, v. 34, n. 2, p. 11-36, 2004a.

Context, Behavior, and Evolution: Challenges in Research on Boards and Governance. International Studies of Management \& Organization, p. 11-36, $2004 b$.

GABRIELSSON, J.; HUSE, M.; MINICHILLI, A. Understanding the leadership role of the board chairperson through a team production approach. International Journal of Leadership Studies, v. 3, n. 1, p. 21-39, 2007.

GNAN, L.; ZATTONI, A. Board Task Performance in Small Firms: The Role of Personal Incentives and Board Porcesses. In: HUSE, M. (Ed.). The Value Creating Board: Corporate Governance and Organizational Behaviour. New York: Routledge, 2009. p. 452-470. 
GOLDEN, B.; ZAJAC, E. When will boards influence strategy? Inclination $\mathrm{x}$ power $=$ strategic change. Strategic Management Journal, v. 22, n. 12, p. 10871111, 2001.

GRANT, R. Toward a Knowledge-Based Theory of the Firm. Strategic Management Journal, v. 17, p. 109-122, 1996.

GRUNDEI, J.; TALAULICAR, T. Company Law and Corporate Governance of Start-ups in Germany: Legal Stipulations, Managerial Requirements, and Modification Strategies. Journal of Management and Governance, v. 6, n. 1, p. 1-27, 2002/03/01 2002.

GUTH, W. D.; MACMILlAN, I. C. Strategy Implementation Versus Middle Management Self-Interest. Strategic Management Journal, v. 7, n. 4, p. 313327, 1986.

HAIR, J. F.; BLACK, W. C.; BABIN, B. J.; ANDERSON, R. E. Multivariate data analysis. Upper Saddle River, NJ: Pearson, 2010.

HENDRY, K.; KIEL, G. C. The Role of the Board in Firm Strategy: integrating agency and organisational control perspectives. Corporate Governance: An International Review, v. 12, n. 4, p. 500-520, 2004.

HENDRY, K. P.; KIEL, G. C.; NICHOLSON, G. How Boards Strategise: A Strategy as Practice View. Long Range Planning, v. In Press, Corrected Proof, 2009.

HITT, M. A.; IRELAND, R. D.; HOSKISSON, R. E. Strategic Management: Competitiveness and Globalization. Mason: South-Western, 2009.

HOSKISSON, R. E.; HITT, M. A.; WAN, W. P.; YIU, D. Theory and research in strategic management: Swings of a pendulum. Journal of Management, v. 25, n. 3, p. 417-456, June 1, 19991999.

HREBINIAK, L. Obstacles to effective strategy implementation. Organizational Dynamics, v. 35, n. 1, p. 12-31, 2006.

HREBINIAK, L. G.; JOYCE, W. F. Implementing strategy. New York: Macmillan, 1984.

HU, L. T.; BENTLER, P. M. Cutoff criteria for fit indexes in covariance structure analysis: Conventional criteria versus new alternatives. Structural Equation Modeling: A Multidisciplinary Journal, v. 6, n. 1, p. 1-55, 1999.

HUSE, M. Relational norms as a supplement to neo-classical understanding of directorates: An empirical study of boards of directors. Journal of SocioEconomics, v. 22, n. 3, p. 219-240, 1993.

Accountability and creating accountability: A framework for exploring behavioural perspectives of corporate governance. British Journal of Management, v. 16, n. S1, p. S65-S79, 2005. 
Boards, governance and value creation: The human side of corporate governance. Cambridge Univ Pr, 2007.

The Value Creating Board and Behavioural Perspectives. In: HUSE, M. (Ed.). The Value Creating Board: Corporate Governance and Organizational Behaviour. London: Routledge, 2009a. p. 3-9.

The Value Creating Board: Corporate Governance and Organizational Behaviour. London: Routledge, 2009b.

HUSE, M.; HOSKISSON, R.; ZATTONI, A.; VIGANÒ, R. New perspectives on board research: changing the research agenda. Journal of Management and Governance, v. 15, n. 1, p. 5-28, 2011.

HUSE, M.; MINICHILLI, A.; SCHØNING, M. Corporate Boards as Assets for Operating in the New Europe: The Value of Process-Oriented Boardroom Dynamics. Organizational Dynamics, v. 34, n. 3, p. 285-297, 2005.

HUSE, M.; RINDOVA, V. Stakeholders' Expectations of Board Roles: The Case of Subsidiary Boards. Journal of Management and Governance, v. 5, n. 2, p. 153-178, 2001/06/01 2001.

INSTITUTO BRASILEIRO DE GOVERNANÇA CORPORATIVA. Código das Melhores Práticas de Governança Corporativa. São Paulo: Instituto Brasileiro de Governança Corporativa, 2009.

Panorama da Governança Corporativa no Brasil. São Paulo: Instituto Brasileiro de Governança Corporativa, 2010. Disponível em: <http://www.ibgc.org.br/CentroConhecimento.aspx>.

JEHN, K. A. A Multimethod Examination of the Benefits and Detriments of Intragroup Conflict. Administrative Science Quarterly, v. 40, n. 2, p. 256-282, 1995.

JENSEN, M.; MECKLING, W. Theory of the firm: Managerial behavior, agency costs and ownership structure. Journal of financial economics, v. 3, n. 4, p. 305360, 1976.

JENSEN, M. C. Agency Cost of Free Cash Flow, Corporate Finance, and Takeovers. American Economic Review, v. 76, n. 2, 1986.

The modern industrial revolution, exit, and the failure of internal control systems. Journal of Finance, v. 48, n. 3, p. 831-880, 1993.

JICK, T. D. Mixing qualitative and quantitative methods: Triangulation in action. Administrative Science Quarterly, v. 24, n. 4, p. 602-611, 1979.

JOHN, K.; SENBET, L. W. Corporate governance and board effectiveness. Journal of Banking \& Finance, v. 22, n. 4, p. 371-403, 1998. 
JOHNSON, J. L.; DAILY, C. M.; ELLSTRAND, A. E. Boards of Directors: A Review and Research Agenda. Journal of Management, v. 22, n. 3, p. 409-438, June 1, 19961996.

JUDGE, W.; ZEITHAML, C. Institutional and strategic choice perspectives on board involvement in the strategic decision process. Academy of Management Journal, p. 766-794, 1992.

KAHNEMAN, D.; TVERSKY, A. Prospect Theory: An Analysis of Decision under Risk. Econometrica, v. 47, n. 2, p. 263-291, 1979.

KAKABADSE, A.; KAKABADSE, N. The geopolitics of governance: The impact of contrasting philosophies. Hampshire: Palgrave, 2001.

KALE, P.; SINGH, H. Building firm capabilities through learning: the role of the alliance learning process in alliance capability and firm-level alliance success. Strategic Management Journal, v. 28, n. 10, p. 981-1000, 2007.

KAPLAN, R.; NORTON, D. The balanced scorecard: Measures that drive performance. Harvard Business Review, v. 70, n. 1, p. 71-79, 1992.

KLAPPER, L. F.; LOVE, I. Corporate governance, investor protection, and performance in emerging markets. Journal of Corporate Finance, v. 10, n. 5, p. 703-728, 2004.

KOCOUREK, P.; VAN LEE, R.; KELLY, C.; NEWFROCK, J. Too Much SOX Can Kill You. Strategy+ Business, n. November, p. 1-5, 2004.

LEAL, R. P. C.; CARVALHAL DA SILVA, A. L. Corporate governance index, firm valuation and performance in Brazil. Revista Brasileira de Finanças, v. 3, n. 1, p. 1-18, 2005.

LEBLANC, R. Assessing Board Leadership. Corporate Governance: An International Review, v. 13, n. 5, p. 654-666, 2005.

LEBLANC, R.; SCHWARTZ, M. S. The black box of board process: Gaining access to a difficult subject. Corporate Governance: An International Review, v. 15, n. 5, p. 843-851, 2007.

LI, Y.; GUOHUI, S.; EPPLER, M. Making Strategy Work: A Literature Review on the Factors influencing Strategy Implementation. ICA Working Paper 2/2008, p.1-46, 2008. Disponível em: <http://doc.rero.ch/lm.php?url=1000,42,6,20080314094536-BU/wpca0802.pdf >.

Acesso em: 12 de Março de 2010.

LORSCH, J.; MACIVER, E. Pawns or Potentates: The Reality of America's Corporate Boards. Boston, MA: Harvard Business School Press, 1989.

MAASSEN, G. An International Comparison of Corporate Governance Models. Amsterdam: Spencer Stuart, 1999. 
MACAVOY, P. W.; MILlSTEIN, I. M. The Recurrent Crisis in Corporate Governance. Basinstoke and New York: Palgrave, 2003.

MACE, M. Directors: Myth and reality. Boston: Harvard University Press, 1971.

MACEDO-SOARES, T. D. L. V. A.; SCHUBSKY, A. M. G. Contribution of expatriates in the management of subsidiaries to the corporate governance of international firms: the case of Vale. Brazilian Administration Review, v. 7, p. 98-114, 2010.

MAHONEY, J. T. A resource-based theory of sustainable rents. Journal of Management, v. 27, n. 6, p. 651-660, 2001.

MCDONALD, M. L.; WESTPHAL, J. D. A little help here? Board control, CEO identification with the corporate elite, and strategic help provided to CEOs at other firms. Academy of Management Journal, v. 53, n. 2, p. 343-370, 2010.

MCGRATH, R. G.; MACMILLAN, I. C.; VENKATARAMAN, S. Defining and Developing Competence: A Strategic Process Paradigm. Strategic Management Journal, v. 16, n. 4, p. 251-275, 1995.

MCKINSEY \& COMPANY. What directors know about their companies: A McKinsey Survey. McKinsey Quarterly, web exclusive, 2006. Disponível em: <www.mckinseyquarterly.com/links/22434>. Acesso em: 29 de Março de 2010.

MELO, M. A. C. A Pesquisa-ação e o Processo de Planejamento: Uma Perspectiva de Aprendizagem. In: V Enegep, Florianópolis. 1985. p.1-6.

Inovações e modernização tecnológica e organizacional nas MPME: o domínio interorganizacional. In: Proposição de Políticas para a Promoção de Sistemas Produtivos Locais de Micro, Pequenas e Médias Empresas, Angra dos Reis. Rede de Sistemas Produtivos e Inovativos Locais - UFRJ, 2002. p.1-22.

MINTZBERG, H. Patterns in Strategy Formation. Management Science, v. 24, n. 9, p. 934-948, 1978.

MUSACCHIO, A.; LAZZARINI, S. G. Leviathan in Business: Varieties of State Capitalism and their Implications for Economic Performance. Harvard Business School Working Paper, n. 12-108, 2012. Disponível em: <http://www.hbs.edu/faculty/Publication\%20Files/12-108.pdf>. Acesso em: 25 de Janeiro de 2012.

NADLER, D. What's the board's role in strategy development?: Engaging the board in corporate strategy. Strategy \& Leadership, v. 32, n. 5, p. 25-33, 2004.

NICHOLSON, G. J.; KIEL, G. C. A Framework for Diagnosing Board Effectiveness. Corporate Governance, v. 12, n. 4, p. 442-460, 2004.

NOBLE, C. H. The Eclectic Roots of Strategy Implementation Research. Journal of Business Research, v. 45, n. 2, p. 119-134, 1999. 
NONAKA, I. A Dynamic Theory of Organizational Knowledge Creation. Organization Science, v. 5, n. 1, p. 14-37, 1994.

NUnNally, J.; BERnSteIn, I. Psychometric Theory. 3. ed. New York, 1994.

OCASIO, W. Towards an Attention-based View of the Firm. Strategic Management Journal, v. 18, n. summer special issue, p. 187-206, 1997.

OLSSON, U. H.; FOSS, T.; TROYE, S. V.; HOWELL, R. D. The Performance of ML, GLS, and WLS Estimation in Structural Equation Modeling Under Conditions of Misspecification and Nonnormality. Structural Equation Modeling: A Multidisciplinary Journal, v. 7, n. 4, p. 557-595, 2000/10/01 2000.

ORGANISATION FOR ECONOMIC COOPERATION AND DEVELOPMENT. OECD Principles of Corporate Governance. Paris: OECD Publications Services, 2004.

OWEN, N. The Failure of HIH Insurance: Vol. I. A Corporate Collapse and Its Lessons. HIH Royal Commission. Canberra. 2003

PARK, J. Reengineering boards of directors. Business Horizons, v. 38, n. 2, p. 63-69, 1995.

PEARCE, J. A. The Relationship of Internal Versus External Orientations to Financial Measures of Strategic Performance. Strategic Management Journal, v. 4, n. 4, p. 297-306, 1983.

PENROSE, E. T. The theory of the growth of the firm. New York: Wiley, 1959.

PETROVIC, J. Unlocking the role of a board director: a review of the literature. Management Decision, v. 46, n. 9, p. 1373-1392, 2008.

PETTIGREW, A.; MCNULTY, T. Power and Influence in and Around the Boardroom. Human Relations, v. 48, n. 8, p. 845-873, August 1, 19951995.

PETTIGREW, A. M. On Studying Managerial Elites. Strategic Management Journal, v. 13, p. 163-182, 1992.

PFEFFER, J.; SALANCIK, G. R. The External Control of Organizations: A Resource Dependence Perspective. Stanford: Stanford University Press, 2003.

PODSAKOFF, P.; MACKENZIE, S.; LEE, J.; PODSAKOFF, N. Common Method Biases in Behavioral Research: A Critical Review of the Literature and Recommended Remedies. Journal of Applied Psychology, v. 88, n. 5, p. 879903, 2003.

PUGLIESE, A.; BEZEMER, P.; ZATTONI, A.; HUSE, M.; VAN DEN BOSCH, F.; VOLBERDA, H. Boards of Directors' Contribution to Strategy: A Literature Review and Research Agenda. Corporate Governance: An International Review, v. 17, n. 3, p. 292-306, 2009. 
REMENYI, D.; WILLIAMS, B.; MONEY, A.; SWARTZ, E. Doing research in business and management: an introduction to process and method. London: Sage Publications, 1998.

SADTLER, D. R. Brief case: The role of today's board in corporate strategy. Long Range Planning, v. 26, n. 4, p. 112-113, 1993.

SCHMIDT, S.; BRAUER, M. Strategic Governance: how to assess board effectiveness in guiding strategy execution. Corporate Governance, v. 14, n. 1, p. 13-22, 2006.

SCHREYÖGG, G.; KLIESCH EBERL, M. How dynamic can organizational capabilities be? Towards a dual process model of capability dynamization. Strategic Management Journal, v. 28, n. 9, p. 913-933, 2007.

SCHULZE, W. S.; LUBATKIN, M. H.; DINO, R. M. Toward a Theory of Agency and Altruism in Family Firms. Journal of Business Venturing, v. 18, n. 4, p. 473-490, 2003.

SELlEVOlL, T.; HUSE, M.; HANSEN, C. The Value Creating Board: Results from the "Follow-Up Surveys" 2005/2006 in Norwegian firms. Norwegian School of Management BI. Oslo. 2007. (Research Report 2/2007)

SELSKY, J.; GOES, J.; BABÜROGLU, O. Contrasting perspectives of strategy making: Applications in "hyper" environments. Organization Studies, v. 28, n. 1, p. 71-94, 2007.

SHLEIFER, A.; VISHNY, R. W. A Survey of Corporate Governance. The Journal of Finance, v. LII, n. 2, p. 737-783, 1997.

SICILIANO, J. Governance and strategy implementation: expanding the board's involvement. Business Horizons, v. 45, n. 6, p. 33-38, 2002.

SILVEIRA, A. M.; LEAL, R. P. C.; BARROS, L. A. B. C.; CARVALHAL DA SILVA, A. L. Evolution and Determinants of Firm-Level Corporate Governance Quality in Brazil. Revista de Administração da Universidade de São Paulo, v. 44, p. 173-189, 2009.

SISON, L. V.; KLEINER, B. H. Differences between company officers and company executives. Management Research News, v. 24, n. 3/4, p. 157-161, 2001 .

SNOW, C.; HAMBRICK, D. Measuring organizational strategies: Some theoretical and methodological problems. Academy of Management Review, v. 5, n. 4, p. 527-538, 1980.

SPECTOR, P. E. Summated Rating Scale Construction: An Introduction Newbury Park: Sage, 1992. (Sage University Paper series on Quantitative Applications in the Social Sciences, series no. 07-064).

STEINBERG, R.; BROMILOW, C. The director's role in strategy development. Directors and Boards, v. 25, n. 1, p. 48-51, 2000. 
STILES, P. The Impact of the Board on Strategy: An Empirical Examination. Journal of Management Studies, v. 38, n. 5, p. 627-650, 2001.

STILES, P.; TAYLOR, B. Benchmarking corporate governance: The impact of the Cadbury Code. Long Range Planning, v. 26, n. 5, p. 61-71, 1993.

The Strategic Role of the Board. Corporate Governance: An International Review, v. 4, n. 1, p. 3-10, 1996.

Boards at work: How directors view their roles and responsibilities. New York: Oxford University Press, 2001.

TACHEVA, S.; HUSE, M. Women directors and board task performance: Mediating and moderating effects of board working style. In: EURAM Meeting. 2006. p.17-20. Disponível em: <http://www.boeckler.de/pdf/v_2006_03_30_huse2_f5.pdf>.

TEECE, D. J. Explicating dynamic capabilities: the nature and microfoundations of (sustainable) enterprise performance. Strategic Management Journal, v. 28, p. 1319-1350, 2007.

THE ECONOMIST INTELLIGENCE UNIT. Strategy execution: Achieving operational excellence. 2004. Disponível em: $<$ http://www.eiu.com/site_info.asp?info_name=eiu_Celerant_Achieving_Operatio nal_Efficiency>.

TUGGLE, C. S.; SIRMON, D. G.; REUTZEL, C. R.; BIERMAN, L. Commanding board of director attention: investigating how organizational performance and CEO duality affect board members' attention to monitoring. Strategic Management Journal, v. 31, n. 9, p. 946-968, 2010.

VAFEAS, N. Board Meeting Frequency and Firm Performance. Journal of Financial Economics, v. 53, n. 1, p. 113-142, 1999.

WAGEMAN, R. Interdependence and Group Effectiveness. Administrative Science Quarterly, v. 40, n. 1, p. 145-180, 1995.

WALKER JR, O. C.; RUEKERT, R. W. Marketing's Role in the Implementation of Business Strategies: A Critical Review and Conceptual Framework. Journal of Marketing, v. 51, p. 15-33, 1987.

WESTPHAL, J. D.; BEDNAR, M. K. Pluralistic Ignorance in Corporate Boards and Firms' Strategic Persistence in Response to Low Firm Performance. Administrative Science Quarterly, v. 50, n. 2, p. 262-298, 2005.

YOUNG, M. N.; PENG, M. W.; AHLSTROM, D.; BRUTON, G. D.; JIANG, Y. Corporate Governance in Emerging Economies: A Review of the PrincipalPrincipal Perspective. Journal of Management Studies, v. 45, n. 1, p. 196-220, 2008.

ZAHRA, S. A. Increasing the board's involvement in strategy. Long Range Planning, v. 23, n. 6, p. 109-117, 1990. 
ZAHRA, S. A.; PEARCE, J. A. Boards of directors and corporate financial performance: A review and integrative model. Journal of Management, v. 15, $\mathrm{n}$. 2, p. 291, 1989.

Determinants of board directors' strategic involvement. European Management Journal, v. 8, n. 2, p. 164-173, 1990.

ZAJAC, E. J.; WESTPHAL, J. D. The Costs and Benefits of Managerial Incentives and Monitoring in Large U.S. Corporations: When is More not Better? Strategic Management Journal, v. 15, n. S1, p. 121-142, 1994.

ZHANG, P. Power and trust in board-CEO relationships. Journal of Management \& Governance, p. 1-21, 2011/10/01 2011. 


\section{Apêndice - questionário utilizado na pesquisa}

Página 1 de 4

PORTUGUÊS

\section{CONSELHOS DE ADMINISTRAÇÃO E EXECUÇÃO ESTRATÉGICA}

Prezado/a Conselheiro/a de Administração,

Os Conselhos de Administração têm o importante papel de zelar pelo sucesso estratégico das empresas. Esta pesquisa, conduzida pela PUC-Rio com apoio do Instituto Brasileiro de Governança Corporativa (IBGC) e da Booz \& Company, busca aprimorar $o$ entendimento sobre fatores que contribuem para uma efetiva atuação dos Conselhos na monitoração da execução estratégica. 0 preenchimento deste pequeno questionário requer cerca de 5 a 10 minutos. Suas respostas são confidenciais e serão analisadas apenas em agregado.

Ao preencher o questionário completo, enviaremos-lhe uma cópia exclusiva do relatório da pesquisa. A sua colaboração será importante para atingirmos um painel representativo da governança corporativa no Brasil.

Instruções
- Preencha o questionário somente se o Sr./Sra. atua ou já atuou como Conselheiro(a) de
Administração de alguma empresa (qualquer empresa)
- Escolha o Conselho de Administração mais atuante em que o Sr./Sra. tenha trabalhado como
Conselheiro/a de Administração (preferencialmente de empresa sediada no Brasil)
- Responda todas as questões com base no Conselho de Administração escolhido
- Devolva o questionário preenchido no stand do IBGC

\section{Sobre a empresa escolhida:}

País onde está registrada:

Principal ramo de atividade: $\square$ indústria

A empresa é considerada de alta tecnologia?

Há quantos anos foi fundada? $\square 0$ a 10

Qual a receita anual? ( $\mathrm{R} \$$ milhões/ano)

$\square$ outro (qual país?

$\square$ comércio $\square$ bancos

$\square \operatorname{sim}$

$\square 10$ a 20

$\square$ 0 a 100

$\square$ não

Qual o grau de diversificação dos negócios da empresa?

$\square 100 \mathrm{a} 1 \mathrm{bi}$

guros $\square$ serviços

Qual o grau de atuação da empresa em mercados internacionais?

O controle do capital votante da empresa é:

$\square$ familiar

A empresa é listada em alguma bolsa de valores?

$\square \operatorname{sim}$

$\square$ baixo

$\square 30$ a 40

$\square 1 \mathrm{a} 10 \mathrm{bi}$

$\square>40$

Há participação de fundo de private equity/capital de risco no capital da empresa?

$\square$ médio $\square$ alto

Qual o percentual aproximado de ações com direito a

voto em poder do maior acionista/quotista da empresa? $\%$

Sobre o Conselho de Administração escolhido:

Os cargos de Presidente do Conselho e Presidente executivo da empresa são ocupados pela mesma pessoa?

baixo

$\square$ médio

$\square$ alto

$\square$ governamental

$\square$ não

investidor profissional definido

0 Conselho é formado por quantos membros? (não incluir suplentes e Conselho Fiscal)

Quantos são mulheres? mulheres

Quantas reuniões o Conselho de Administração realiza anualmente? reuniões/ano 
Página 2 de 4

Responda às questões a seguir considerando o Conselho de Administração escolhido:

\begin{tabular}{ccc} 
& não & \\
$\begin{array}{cc}\text { discordo } \\
\text { muito }\end{array}$ & $\begin{array}{c}\text { nem } \\
\text { neordo }\end{array}$ & concordo \\
discordo & muito \\
\hline
\end{tabular}

Quanto ao acesso a informações, nossos conselheiros:

Obtêm as informações para as discussões do Conselho de Administração com suficiente antecedência.

Têm acesso a informações suficientes para monitorar a execução estratégica da empresa.

Interagem com a empresa além das reuniões do Conselho de Administração para obter informações.

Têm acesso a informações não-financeiras relevantes para a tomada de decisão.

Obtêm informações de diversas fontes, não se restringindo aos relatórios fornecidos pela diretoria executiva.

São apoiados por comitês ou comissões do Conselho para obterem as informações de que precisam (se não houver comitês, deixe em branco)

Têm acesso aos funcionários da empresa para obter as informações de que precisam.

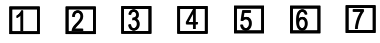

$\begin{array}{lllllll}1 & 2 & 3 & 4 & 5 & 6 & 7\end{array}$

$\begin{array}{llllllll}1 & 2 & 3 & 4 & 5 & 6 & 7\end{array}$

$\begin{array}{lllllll}1 & 2 & 3 & 4 & 5 & 6 & 7\end{array}$

$\begin{array}{lllllll}1 & 2 & 3 & 4 & 5 & 6 & 7\end{array}$

$\begin{array}{lllllll}1 & 2 & 3 & 4 & 5 & 6 & 7\end{array}$

$\begin{array}{lllllll}1 & 2 & 3 & 4 & 5 & 6 & 7\end{array}$

Algum outro elemento relevante?

Quanto ao conhecimento do negócio, coletivamente o Conselho:

Conhece muito bem as operações da empresa.

$\begin{array}{llllllll}1 & 2 & 3 & 4 & 5 & 6 & 7\end{array}$

Conhece muito bem as competências e capacitações internas da empresa.

$\begin{array}{llllllll}1 & 2 & 2 & 3 & 4 & 5 & 6 & 7\end{array}$

Conhece muito bem os principais setores em que a empresa opera.

$\begin{array}{llllllll}1 & 2 & 3 & 4 & 5 & 6 & 7\end{array}$

Conhece muito bem o ambiente competitivo onde a empresa opera (concorrentes, fornecedores, clientes, regulação).

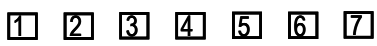

Conhece muito bem as prioridades estratégicas da empresa.

$\begin{array}{llllllll}1 & 2 & 3 & 4 & 5 & 6 & 7\end{array}$

Participa de atividades de treinamento e aprendizagem sobre

$\begin{array}{lllllll}11 & 2 & 3 & 4 & 5 & 6 & 7\end{array}$ os negócios da empresa.

Tem um papel ativo na definição da estratégia da empresa.

$\begin{array}{lllllll}1 & 2 & 3 & 4 & 5 & 6 & 7\end{array}$

Algum outro elemento relevante? 
Página 3 de 4

\begin{tabular}{ccc} 
& não & \\
discordo & concordo & \\
muito & nem & concordo \\
discordo & muito \\
\hline
\end{tabular}

Quanto à dinâmica de trabalho do Conselho, nossos conselheiros:

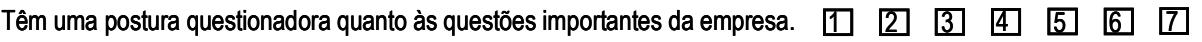

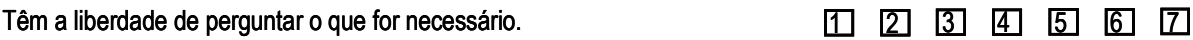

Dizem o que pensam de forma aberta. $\quad$\begin{tabular}{lllllll}
\hline & 2 & 3 & 4 & 5 & 6 & 6
\end{tabular}

Freqüentemente discordam quanto a questões importantes da empresa. $\left.\quad \begin{array}{llllll}1 & 2 & 3 & 4 & 5 & 6\end{array}\right]$

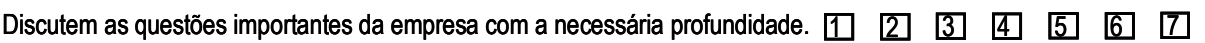

Contribuem decisivamente para a discussão das questões $\quad$\begin{tabular}{lllllll}
\hline & 2 & 3 & 4 & 5 & 6 & 4
\end{tabular} importantes da empresa.

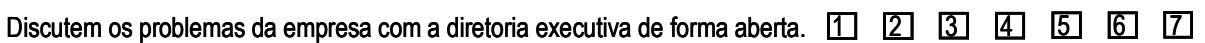

Algum outro elemento relevante?

O Presidente (ou líder) do Conselho de Administração é excelente em:

Direcionar a pauta do Conselho para as questões de alta importância estratégica da empresa.

1) 25 $3545 \quad 6 \quad 7$

Viabilizar um fluxo de informações relevantes para o Conselho.

$\begin{array}{llllllll}1 & 2 & 3 & 4 & 5 & 6 & 7\end{array}$

Estimular a atitude questionadora do Conselho.

$\begin{array}{llllllll}1 & 2 & 3 & 4 & 5 & 6 & 7\end{array}$

Garantir a contribuição de cada um dos conselheiros.

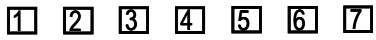

Assegurar que as questões estratégicas são discutidas no Conselho com a profundidade necessária.

$\begin{array}{lllllll}1 & 2 & 3 & 4 & 5 & 6 & 7\end{array}$

Promover discussões conclusivas no Conselho.

$\begin{array}{llllllll}1 & 2 & 3 & 4 & 5 & 6 & 7\end{array}$

Priorizar as iniciativas estratégicas que devem ser monitoradas pelo Conselho.

Algum outro elemento relevante?

$3 / 4$

CONTINUA 
Página 4 de 4

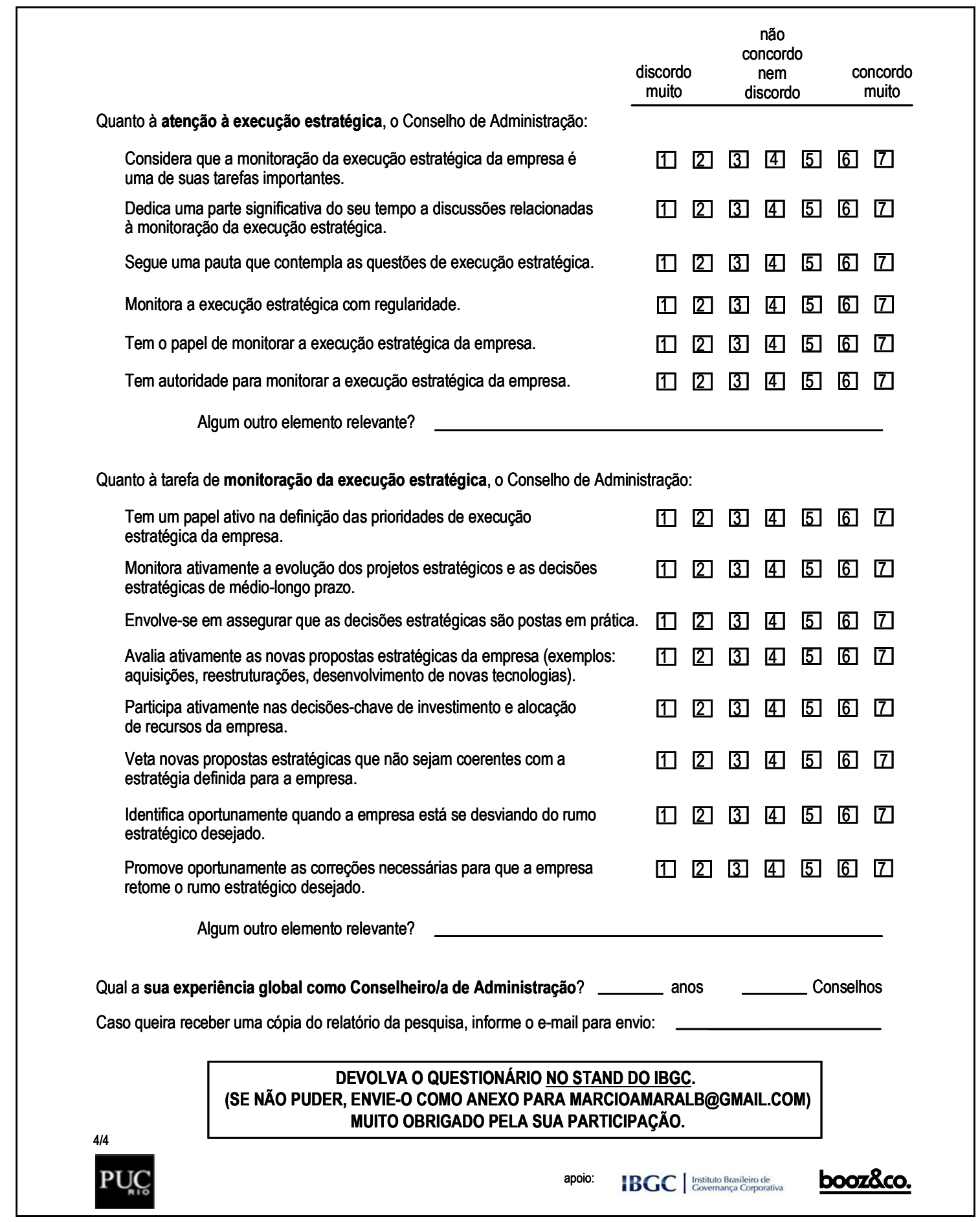

